\title{
Comparison of the Fatigue Characteristics of Recycled Asphalt Pavements
}

Lara Smith

Follow this and additional works at: https://researchrepository.wvu.edu/etd

\section{Recommended Citation}

Smith, Lara, "Comparison of the Fatigue Characteristics of Recycled Asphalt Pavements" (2015). Graduate Theses, Dissertations, and Problem Reports. 6668.

https://researchrepository.wvu.edu/etd/6668

This Thesis is protected by copyright and/or related rights. It has been brought to you by the The Research Repository @ WVU with permission from the rights-holder(s). You are free to use this Thesis in any way that is permitted by the copyright and related rights legislation that applies to your use. For other uses you must obtain permission from the rights-holder(s) directly, unless additional rights are indicated by a Creative Commons license in the record and/ or on the work itself. This Thesis has been accepted for inclusion in WVU Graduate Theses, Dissertations, and Problem Reports collection by an authorized administrator of The Research Repository @ WVU. For more information, please contact researchrepository@mail.wvu.edu. 


\title{
Comparison of the Fatigue Characteristics of Recycled Asphalt Pavements
}

\author{
Lara Smith
}

Thesis submitted to the Benjamin Statler College of Engineering and Mineral Resources at West Virginia University

in partial fulfillment of the requirements for the degree of

Master of Science in

Civil Engineering

John P. Zaniewski, Ph.D., P.E., Chair

Avinash Unnikrishnan, Ph. D.

Yoojung Yoon, Ph. D.

Department of Civil and Environmental Engineering

Morgantown, West Virginia

2015

Keywords: Recycled Asphalt Pavement (RAP), Fatigue, S-VECD, AMPT, Dynamic Modulus

Copyright 2015 Lara Smith 


\title{
ABSTRACT \\ Comparison of the Fatigue Characteristics of Recycled Asphalt Pavements
}

\author{
Lara Smith
}

When the service life of asphalt pavement has expired, it can be reclaimed and reused as a percentage of new pavement. This recycled asphalt pavement (RAP) usually is exposed to years of environmental conditioning and oxidation, which stiffens the asphalt binder. As the binder stiffens, certain engineering properties change, such as dynamic modulus, and the pavement begins to experience distresses.

The asphalt mixture performance tester (AMPT) is a new performance testing machine that applies load cycles within a cell that also acts as an environmental conditioning chamber. This research focused on the using the AMPT to determine dynamic modulus and fatigue characteristics of mix designs with three RAP levels and two binder grades. Asphalt Pavement Hierarchical Analysis Toolbox - Fatigue Program was the analysis software utilized that generated the three fatigue coefficients in the traditional fatigue equation. Kenpave, developed by Yang Huang, was used to develop strain-modulus curves so that the mix designs could be compared at a designated loading frequency and the respective dynamic modulus and strain level. 


\section{Table of Contents}

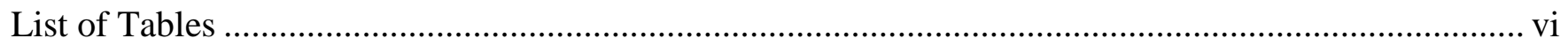

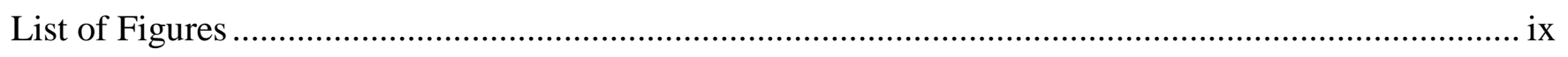

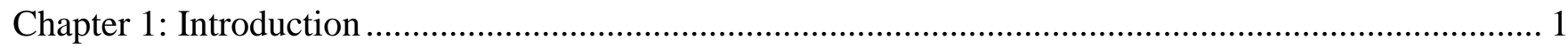

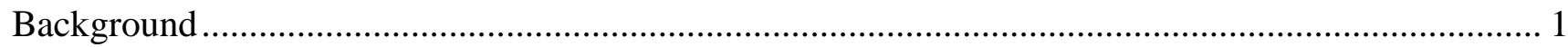

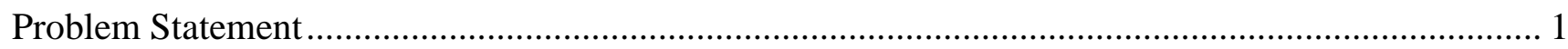

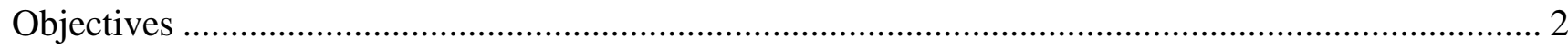

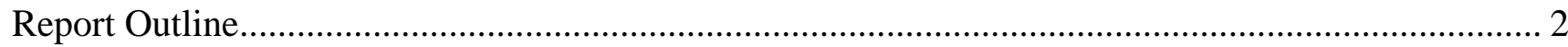

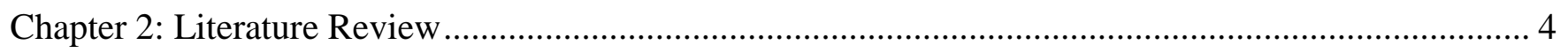

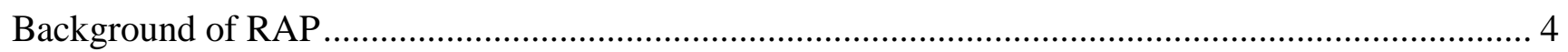

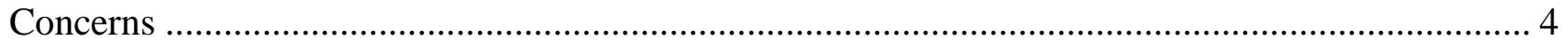

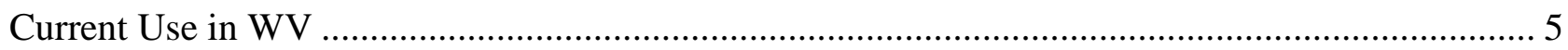

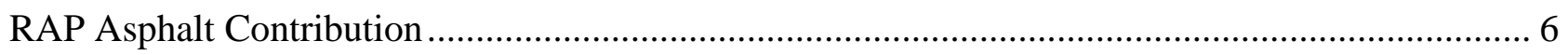

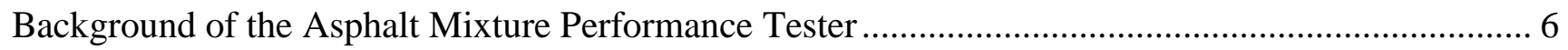

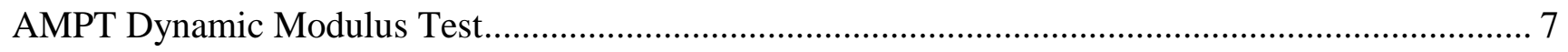

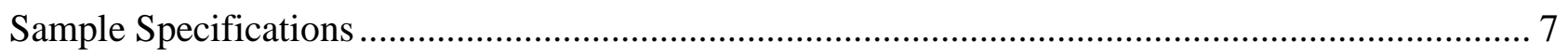

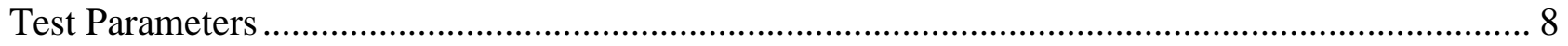

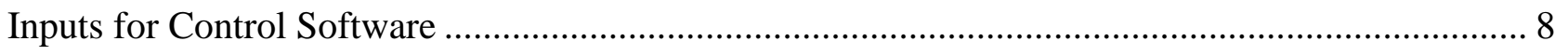

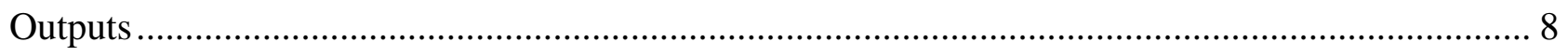

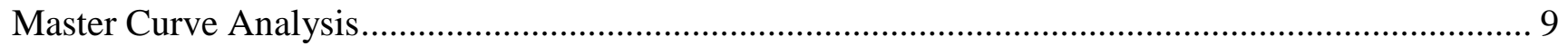

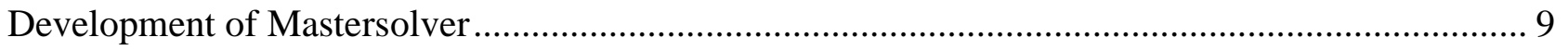

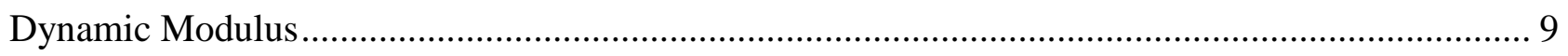

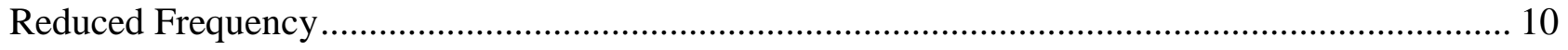

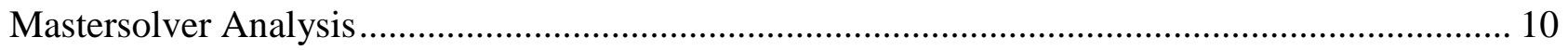

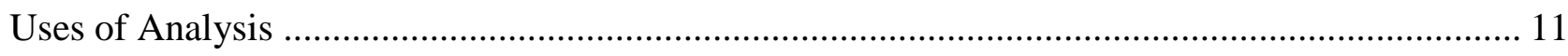

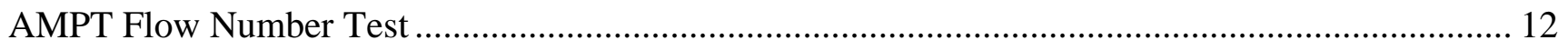

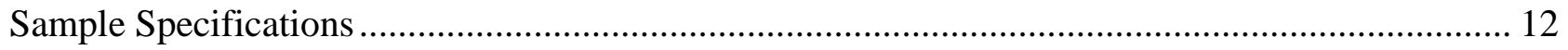

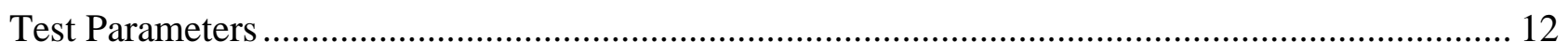

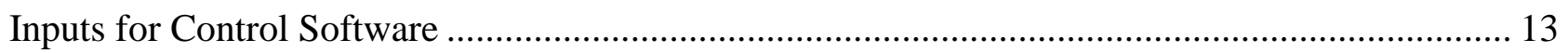

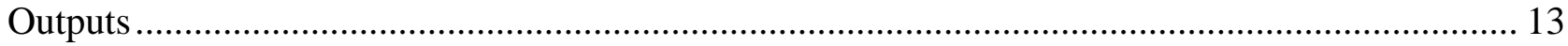

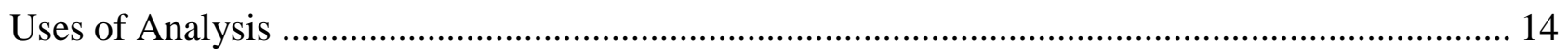




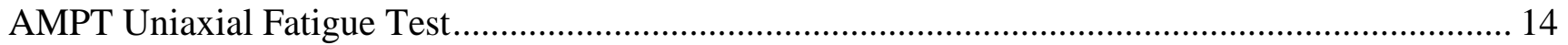

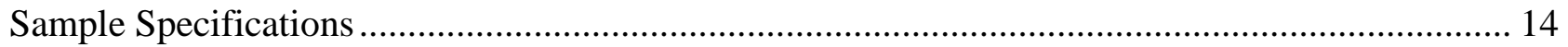

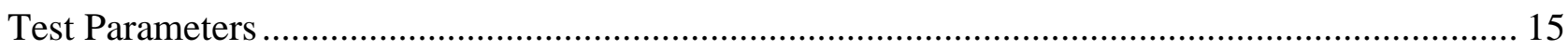

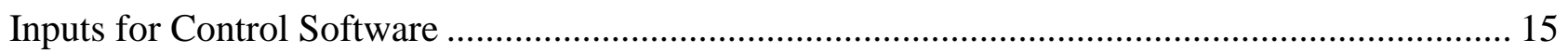

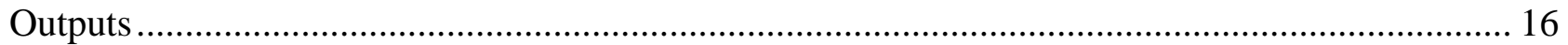

Asphalt Pavement Hierarchical Analysis Toolbox - Fatigue Program ……………………................. 17

Development of Simplified Viscoelastic Continuum Damage Model................................................ 17

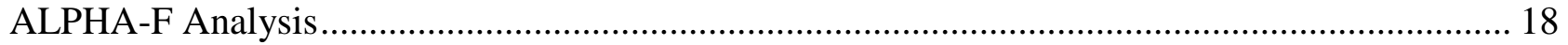

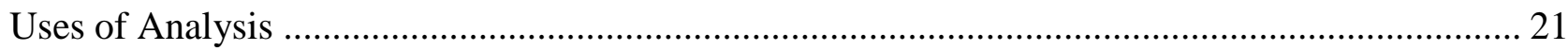

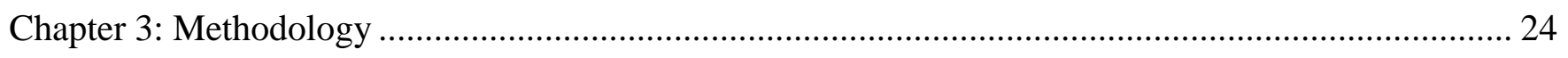

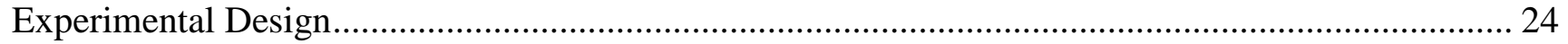

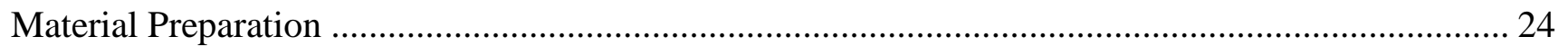

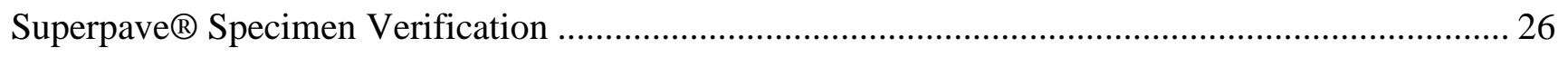

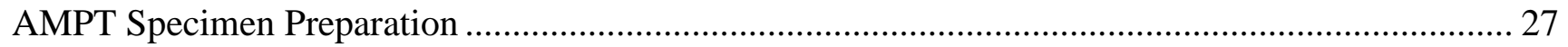

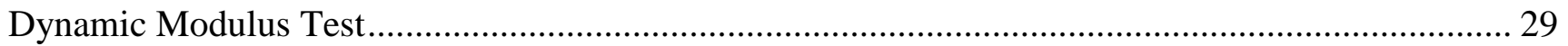

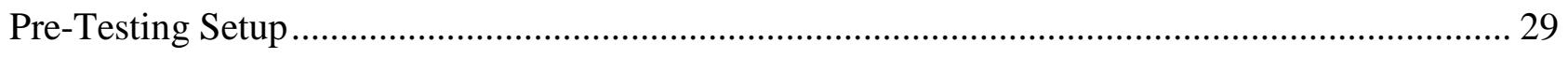

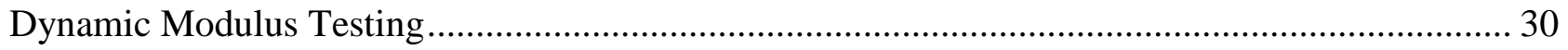

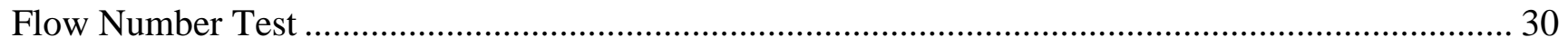

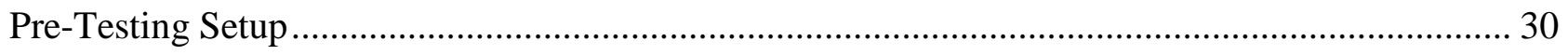

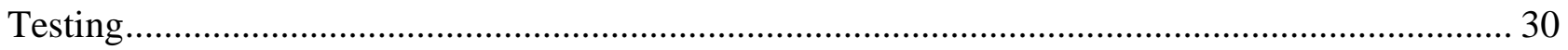

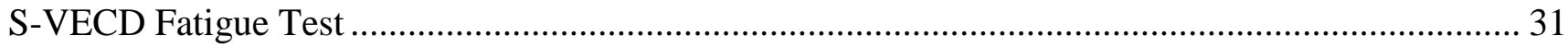

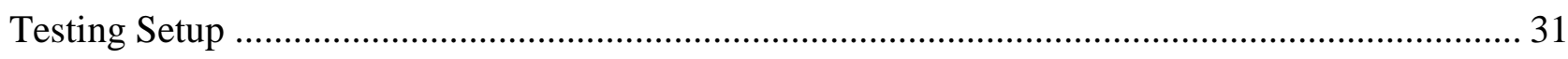

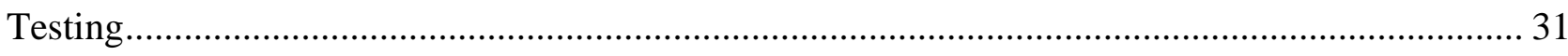

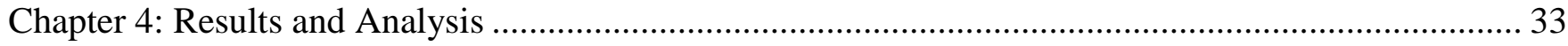

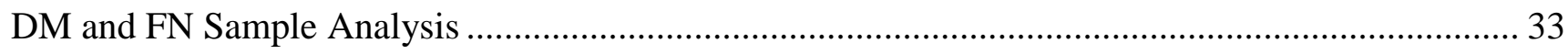

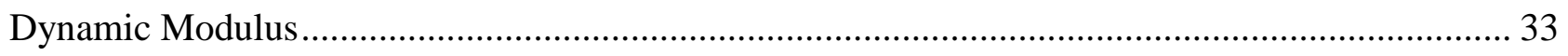

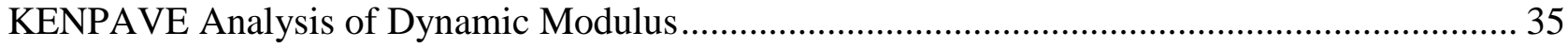

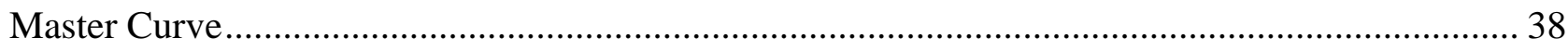

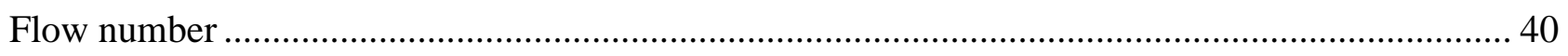

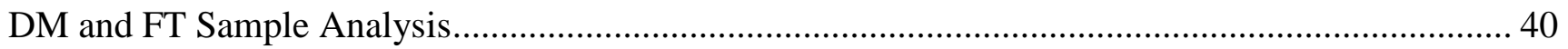

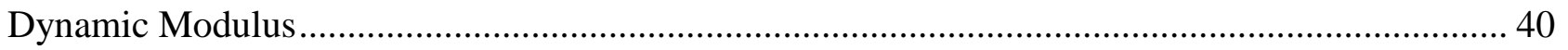




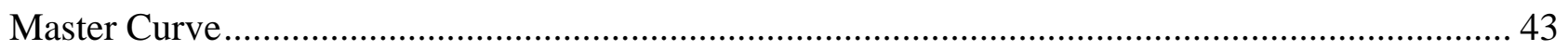

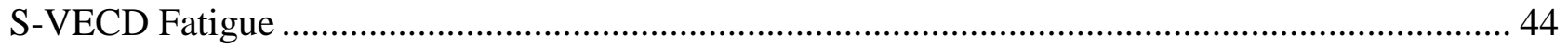

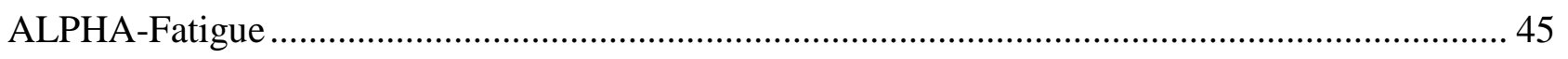

Kenpave Analysis of Dynamic Modulus ............................................................................ 51

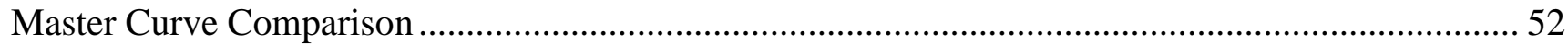

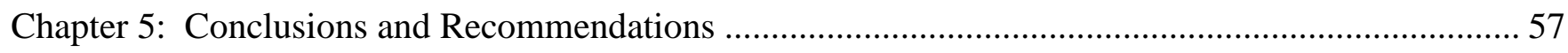

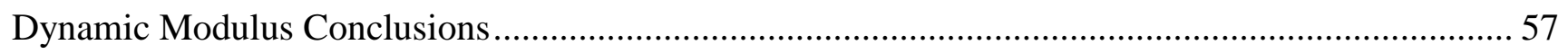

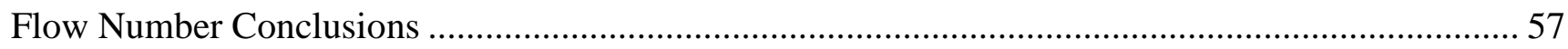

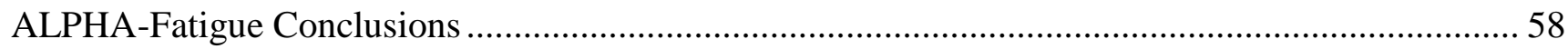

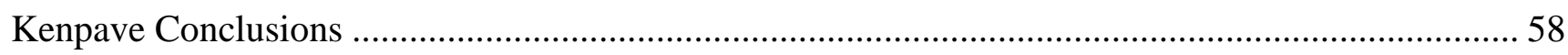

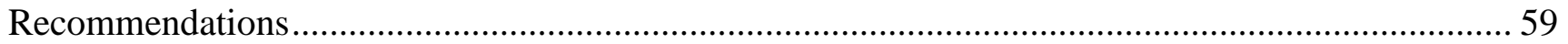

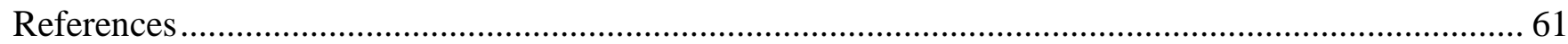

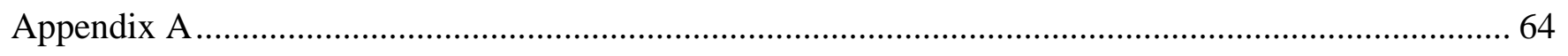

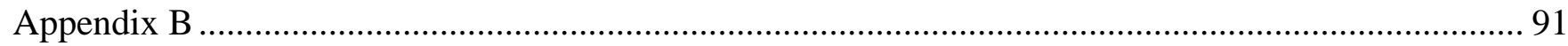

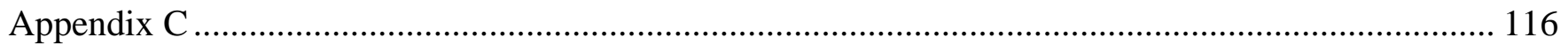




\section{List of Tables}

Table 1 - Test Specimen Dimensional Tolerances6 ……….......................................................... 7

Table 2 - Recommended Testing Temperatures and Loading Frequencies10 ....................................... 8

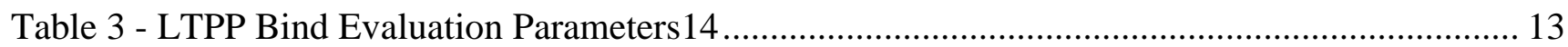

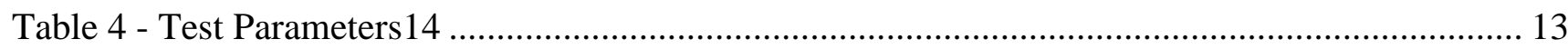

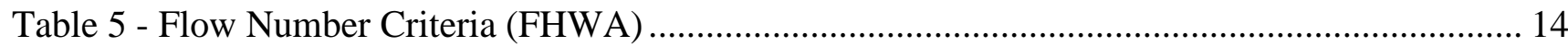

Table 6 - Test Specimen Dimensional Tolerances1 …………………………………………….... 15

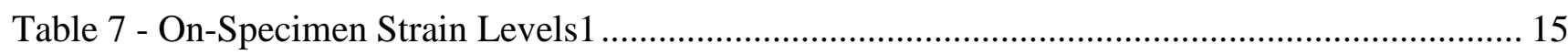

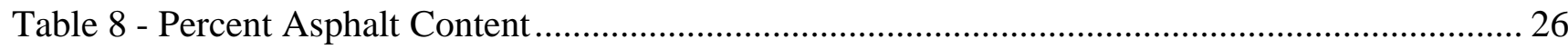

Table 9 - Gmm, Gmb and VTM of Verification Samples ……………………………………..... 27

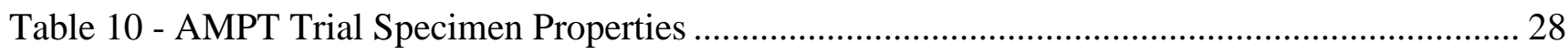

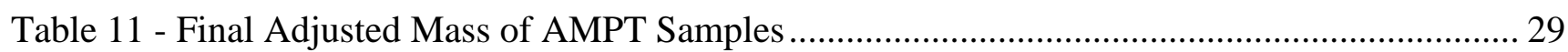

Table 12 - On-Specimen Strain Levels for the Second and Third Specimens ..................................... 32

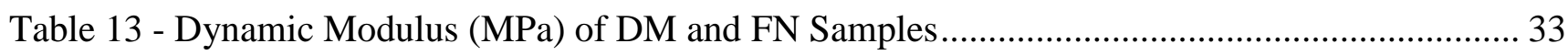

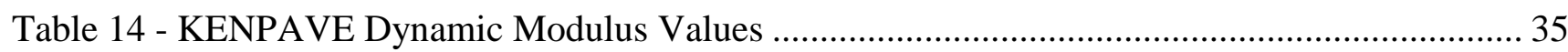

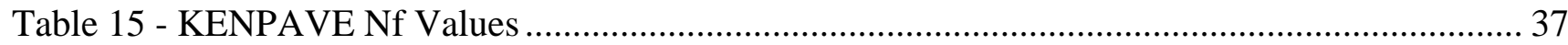

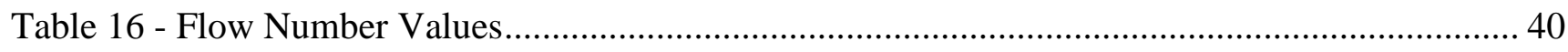

Table 17 - Dynamic Modulus (MPa) of DM and FT Samples .............................................................. 41

Table 18 - Fingerprint Dynamic Modulus and Fatigue Test Data ........................................................... 45

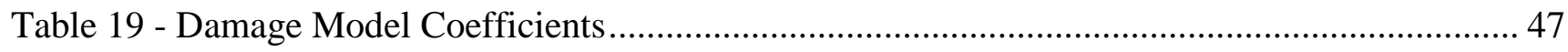

Table 20 - Shift Factor Coefficients and Mastercurve Function Coefficients ......................................50

Table 21 - Traditional Strain Fatigue Relationship Coefficients ............................................................5 50

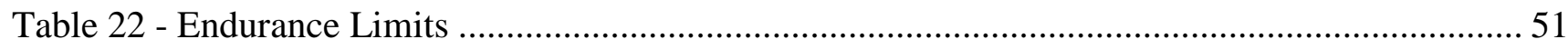

Table 23 - Kenpave Analysis of DM and FT Samples …………................................................... 51

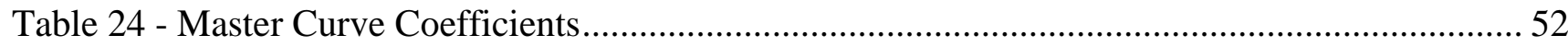

Table 25 - 0\% RAP Replicate 1 Flow Number Data ........................................................................... 91

Table 26 - 0\% RAP Replicate 2 Flow Number Data ......................................................................... 92

Table 27 - 15\% RAP Replicate 1 Flow Number Data …………………………………….................. 93

Table 28 - 15\% RAP Replicate 2 Flow Number Data .......................................................................... 94

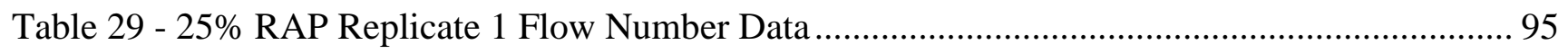


Table 30 - 25\% RAP Replicate 2 Flow Number Data .............................................................. 96

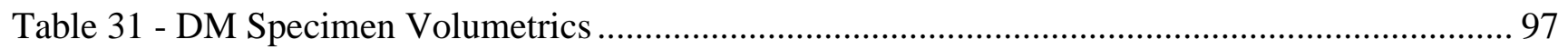

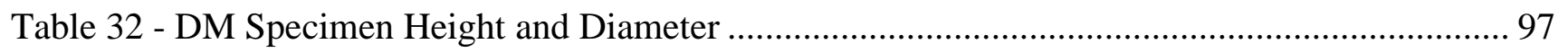

Table 33 - PG 70-22 0\% RAP Replicate $1-4^{\circ} \mathrm{C}$ DM Test Data .................................................... 98

Table 34 - PG 70-22 0\% RAP Replicate $1-20^{\circ} \mathrm{C}$ DM Test Data ................................................. 98

Table 35 - PG 70-22 0\% RAP Replicate $1-40^{\circ} \mathrm{C}$ DM Test Data ................................................. 99

Table 36 - PG 70-22 0\% RAP Replicate 2 - $4^{\circ} \mathrm{C}$ DM Test Data .................................................... 99

Table 37 - PG 70-22 0\% RAP Replicate 2 - 20 C DM Test Data ................................................ 100

Table 38 - PG 70-22 0\% RAP Replicate 2 - 40 C DM Test Data ................................................ 100

Table 39 - PG 70-22 0\% RAP Replicate $3-4^{\circ} \mathrm{C}$ DM Test Data ................................................. 101

Table 40 - PG 70-22 0\% RAP Replicate 3 - 20 C DM Test Data ............................................... 101

Table 41 - PG 70-22 0\% RAP Replicate 3 - 40 ${ }^{\circ} \mathrm{C}$ DM Test Data................................................. 102

Table 42 PG 70-22 15\% RAP Replicate $1-4^{\circ} \mathrm{C}$ DM Test Data .................................................. 102

Table 43 - PG 70-22 15\% RAP Replicate 1 - 20 C DM Test Data ............................................. 103

Table 44 - PG 70-22 15\% RAP Replicate 1 - 40 ${ }^{\circ} \mathrm{C}$ DM Test Data ............................................. 103

Table 45 - PG 70-22 15\% RAP Replicate 2 - $4^{\circ} \mathrm{C}$ DM Test Data ................................................. 104

Table 46 - PG 70-22 15\% RAP Replicate 2 - 20 C DM Test Data .............................................. 104

Table 47 - PG 70-22 15\% RAP Replicate 2 - 40 C DM Test Data .............................................. 105

Table 48 - PG 70-22 15\% RAP Replicate $3-4^{\circ} \mathrm{C}$ DM Test Data ................................................ 105

Table 49 - PG 70-22 15\% RAP Replicate 3 - 20 C DM Test Data .............................................. 106

Table 50 - PG 70-22 15\% RAP Replicate 3 - 40 C DM Test Data ............................................. 106

Table 51 - PG 70-22 25\% RAP Replicate 1- $4^{\circ} \mathrm{C}$ DM Test Data ................................................. 107

Table 52 - PG 70-22 25\% RAP Replicate 1-20² C DM Test Data ............................................... 107

Table 53 - PG 70-22 25\% RAP Replicate $1-40^{\circ} \mathrm{C}$ DM Test Data ............................................... 108

Table 54 - PG 70-22 25\% RAP Replicate 2- $4^{\circ} \mathrm{C}$ DM Test Data ................................................. 108

Table 55 - PG 70-22 25\% RAP Replicate 2-20 CM Test Data ............................................... 109

Table 56 - PG 70-22 25\% RAP Replicate 2- 40 ${ }^{\circ} \mathrm{C}$ DM Test Data ................................................ 109

Table 57 - PG 70-22 25\% RAP Replicate $3-4^{\circ} \mathrm{C}$ DM Test Data .............................................. 110

Table 58 - PG 70-22 25\% RAP Replicate 3 - 20 C DM Test Data .............................................. 110

Table 59 - PG 70-22 25\% RAP Replicate $3-40^{\circ} \mathrm{C}$ DM Test Data ............................................ 111

Table 60 - PG 64-22 25\% RAP Replicate $1-4^{\circ} \mathrm{C}$ DM Test Data ................................................ 111 
Table 61 - PG 64-22 25\% RAP Replicate 1-20C DM Test Data ................................................ 112

Table 62 - PG 64-22 25\% RAP Replicate $1-40^{\circ} \mathrm{C}$ DM Test Data ............................................... 112

Table 63 - PG 64-22 25\% RAP Replicate $2-4^{\circ} \mathrm{C}$ DM Test Data ................................................ 113

Table 64 - PG 64-22 25\% RAP Replicate 2 - 20 C DM Test Data .............................................. 113

Table 65 - PG 64-22 25\% RAP Replicate $2-40^{\circ} \mathrm{C}$ DM Test Data ............................................... 114

Table 66 - PG 64-22 25\% RAP Replicate $3-4^{\circ} \mathrm{C}$ DM Test Data ................................................ 114

Table 67 - PG 64-22 25\% RAP Replicate 3 - 20 C DM Test Data ............................................. 115

Table 68 - PG 64-22 25\% RAP Replicate 3 - 40 C DM Test Data ............................................. 115

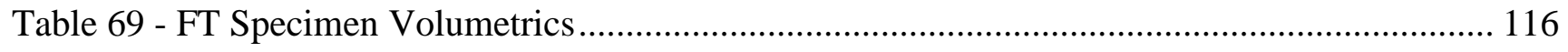

Table 70 - FT Specimen Height and Diameter .................................................................. 117 


\section{List of Figures}

Figure 1 - ALPHA-F Phase Angle and Failure Cycle (With Sudden Drop in Phase Angle)..... 19

Figure 2 - ALPHA-F Phase Angle Phase Angle and Failure Cycle (Without Sudden Drop in Phase

Angle) 20

Figure 3 - Best Fit Selection Dialogue Box 20

Figure 4 - Various Fatigue Equations20. 23

Figure 5 - Average Dynamic Modulus at $4^{\circ} \mathrm{C}$ of DM and FN Samples ......................................... 34

Figure 6 - Average Dynamic Modulus at $20^{\circ} \mathrm{C}$ of DM and FN Samples ........................................ 34

Figure 7 - Average Dynamic Modulus at $40^{\circ} \mathrm{C}$ of DM and FN Samples ........................................ 35

Figure 8 - Pavement Structure Cross Section ......................................................................... 36

Figure 9 - Conventional Pavement - Strain Based Fatigue........................................................... 36

Figure 10 - Full Depth Pavement - Strain Based Fatigue ....................................................... 37

Figure 11 - Dynamic Modulus Master Curve for PG 70 -22 with 0\% RAP................................... 38

Figure 12 - Dynamic Modulus Master Curve for PG 70-22 with 15\% RAP.................................... 39

Figure 13 - Dynamic Modulus Master Curve for PG 70-22 with 25\% RAP.................................... 39

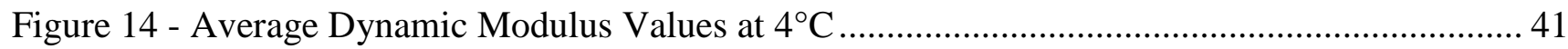

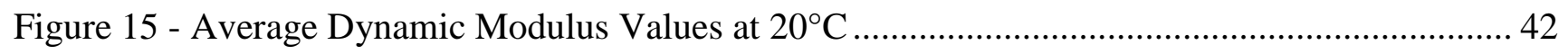

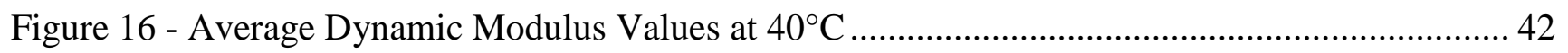

Figure 17 - Dynamic Modulus Master Curve for PG 70-22 with 0\% RAP ...................................... 43

Figure 18 - Dynamic Modulus Master Curve for PG 70-22 with 15\% RAP.................................. 43

Figure 19 - Dynamic Modulus Master Curve for PG 70-22 with 25\% RAP................................... 44

Figure 20 - Dynamic Modulus Master Curve for PG 64-22 with 25\% RAP................................... 44

Figure 21 - ALPHA-F Phase Angle and Failure Cycle Dialogue Box ........................................... 46

Figure 22 - ALPHA-F Phase Angle and Failure Cycle Dialogue Box ........................................... 46

Figure 23 - \% RAP vs. Damage Coefficient"a"...................................................................... 47

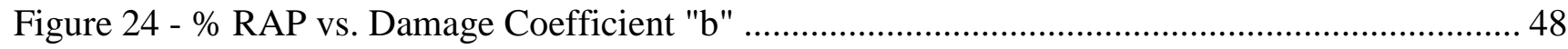

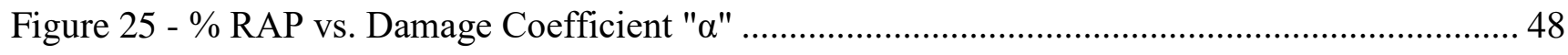

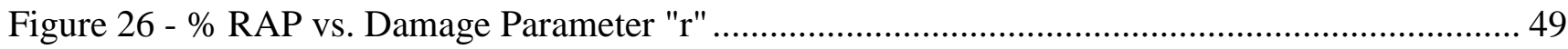

Figure 27 - \%RAP vs. Damage Parameter "s"......................................................................... 49

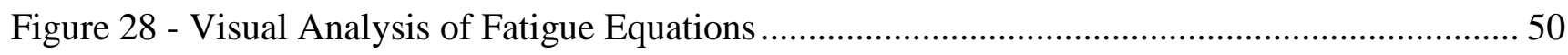


Figure 29 - Comparison of 0\% RAP Between DM and FN and DM and FT ................................. 53

Figure 30 - Comparison of 15\% RAP Between DM and FN and DM and FT ............................... 53

Figure 31 - Comparison of 25\% RAP Between DM and FN and DM and FT .............................. 54

Figure 32 - DM and FN Master Curve Comparison by \% RAP .................................................... 55

Figure 33- DM and FT Master Curve Comparison by \% RAP ..................................................... 56

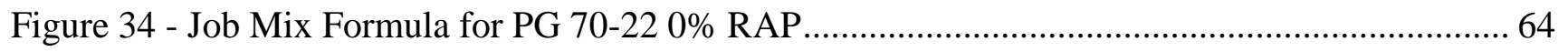

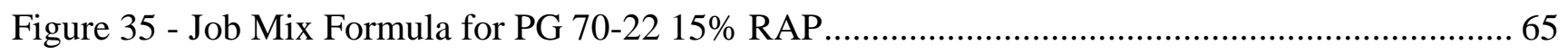

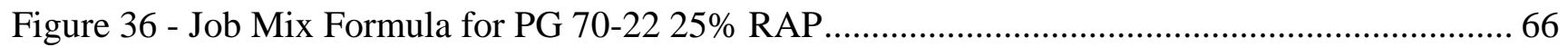

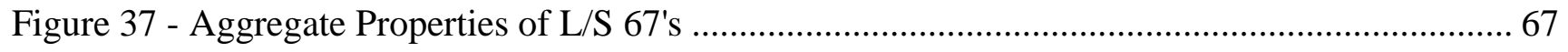

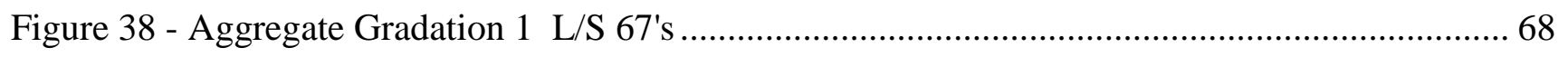

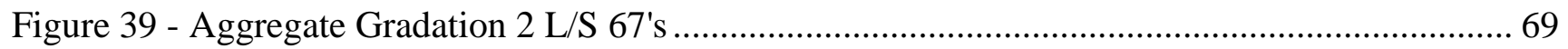

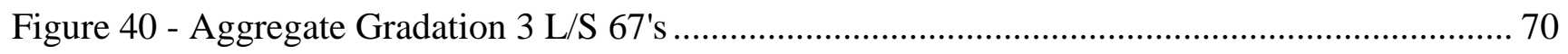

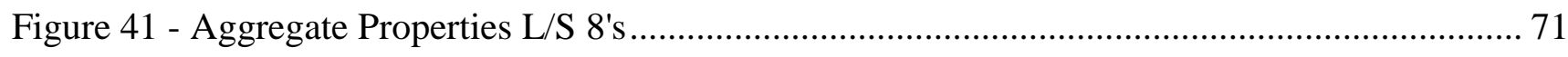

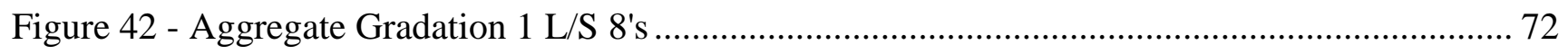

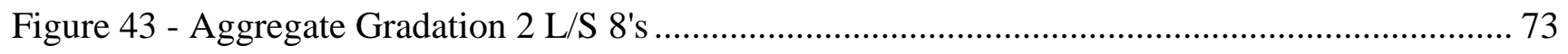

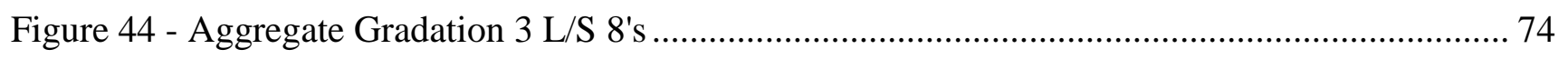

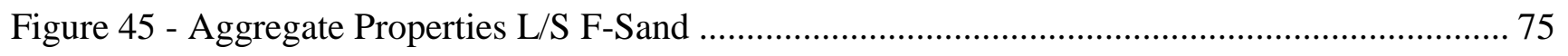

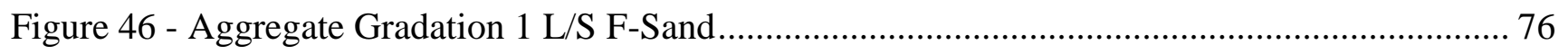

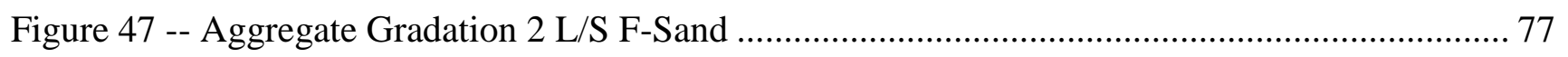

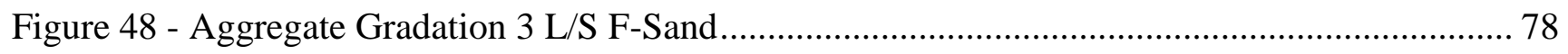

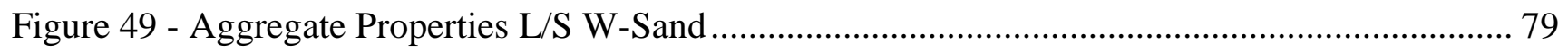

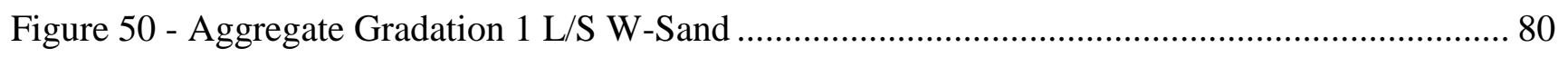

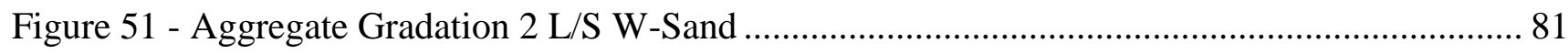

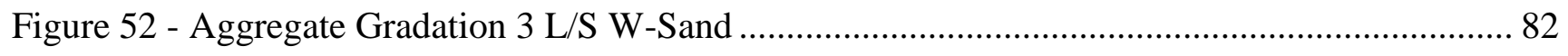

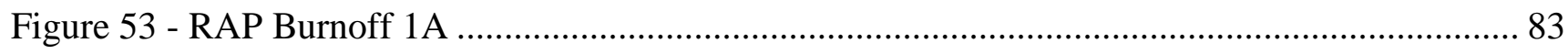

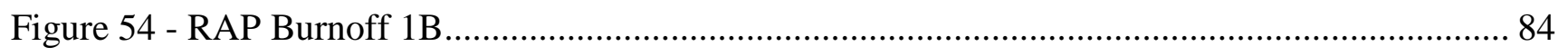

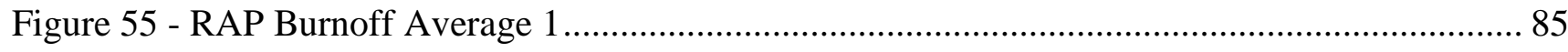

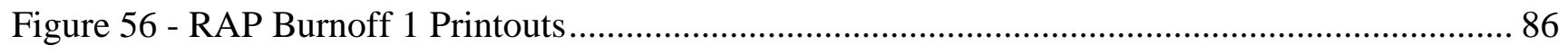

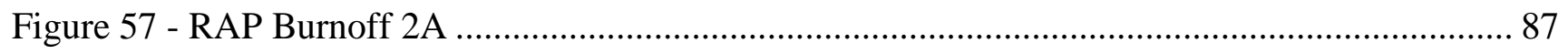

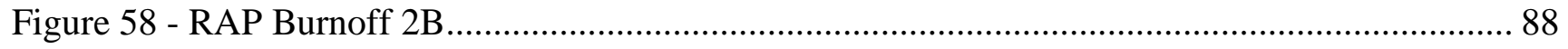

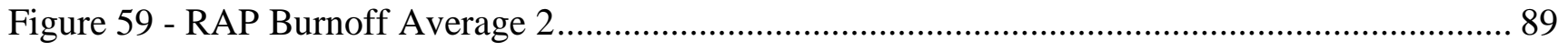




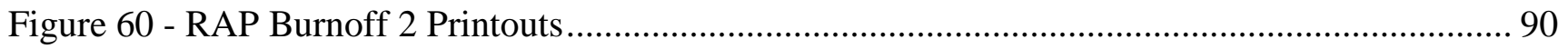

Figure 61 - PG 70-22 With 0\% RAP Fatigue Report Page 1 ..................................................... 118

Figure 62 - PG 70-22 With 0\% RAP Fatigue Report Page 2 ..................................................... 119

Figure 63 - PG 70-22 With 0\% RAP Fatigue Report Page 3 ..................................................... 120

Figure 64 - PG 70-22 With 15\% RAP Fatigue Report Page 1 ................................................... 121

Figure 65 - PG 70-22 With 15\% RAP Fatigue Report Page 2 ................................................... 122

Figure 66 - PG 70-22 With 15\% RAP Fatigue Report Page 3 .................................................. 123

Figure 67 - PG 70-22 With 25\% RAP Fatigue Report Page 1 .................................................... 124

Figure 68 - PG 70-22 With 25\% RAP Fatigue Report Page 2 ................................................ 125

Figure 69 - PG 70-22 With 25\% RAP Fatigue Report Page 3 ................................................. 126

Figure 70 - PG 64-22 With 25\% RAP Fatigue Report Page 1 ................................................... 127

Figure 71 - PG 64-22 With 25\% RAP Fatigue Report Page 2 ................................................... 128

Figure 72 - PG 64-22 With 25\% RAP Fatigue Report Page 3 .................................................. 129 


\section{Chapter 1: Introduction}

\section{Background}

As recycling asphalt pavement becomes a more common practice, it is essential to ensure that the performance of the material meets current standards. After asphalt concrete has been exposed to several years of environmental conditions and repeated loads, it experiences distresses. Fatigue and rutting are two major distresses which should be evaluated in asphalt concrete pavements. Recycled asphalt pavement (RAP) may experience distresses at a different rate and magnitude than virgin asphalt pavement due to the aging of the recycled binder. In order for RAP to be a feasible option, it must be able to endure as many, if not more, loading cycles as a virgin mixture. Having a higher number of cycles to failure can increase the service life and reduce the financial cost of repairs and replacements.

The Asphalt Mixture Performance Tester (AMPT) is a dynamic testing machine that encloses an asphalt specimen in an environmental conditioning chamber that can also apply confining pressure for triaxial testing. Dynamic modulus, flow number, and flow time are three main tests that the machine is used for which can be used to predict the rutting potential of the pavement. However, a new uniaxial fatigue test was standardized in 2014 which allows damage characteristics to be evaluated using Simplified Continuum Damage Uniaxial Fatigue (SCDUF) or Simplified Viscoelastic Continuum Damage (S-VECD) models ${ }^{1}$. This test requires three specimens to be tested at three micro strain levels after performing a fingerprint dynamic modulus test on each. Exported data from the AMPT can be analyzed using the ALPHA Fatigue software developed by Drs. Richard Kim and Shane Underwood.

\section{Problem Statement}

This research was performed to compare four mix designs using the Uniaxial Fatigue Test (UTS 032) and Dynamic Modulus Test (UTS 006), and three mix designs using the Flow Number Test (UTS 
005). In total, 54 AMPT specimens were produced; 36 tested using the uniaxial fatigue test, 12 tested using the dynamic modulus test, and 6 tested using both the dynamic modulus and flow number tests. Results from the AMPT were analyzed with the Asphalt Pavement Hierarchical Analysis Toolbox Fatigue Program (ALPHA-F) and the MasterSolver developed by Dr. Ramon Bonaquist.

Superpave job mix formulas for three RAP levels and two binder grades were provided by West Virginia Paving. Virgin aggregate, RAP, and binder were obtained from West Virginia Paving's asphalt plant in Beaver, West Virginia.

\section{Objectives}

The first objective of this experiment was to provide a comparison of fatigue characteristics between mix designs using PG 70 - 22 with 0\%, 15\%, and 25\% RAP, analyzed using the ALPHA-F software. The second objective was to provide a comparison of fatigue characteristics between two binders PG 70 - 22 and PG $64-22$ with 25\% RAP, analyzed using the ALPHA-F software. Finally, the third objective was to provide a comparison of the flow number and fatigue characteristics between mix designs using PG $70-22$ with $0 \%, 15 \%$, and $25 \%$ RAP.

Achieving these objectives is important, because if the addition of RAP proves to be detrimental to the pavement's fatigue performance it will need to be reevaluated as a usable material. In contrast, if it proves to be beneficial to the performance, RAP should be considered in more applications.

\section{Report Outline}

This report is split into five chapters with the first chapter being the introduction. The second chapter provides a literature review of RAP, the AMPT, Dynamic Modulus, Flow Number, and the Uniaxial Fatigue Test. Chapter three describes the experimental design and methodology. Chapter four presents a summary of the raw data, as well as the analysis using the MasterSolver and ALPHA-F 
software. The fifth chapter summarizes the findings and provides recommendations for future research. Lastly, the appendix provides supplemental tables and figures. 


\section{Chapter 2: Literature Review}

\section{Background of RAP}

Recycling not only is beneficial environmentally, it can also be more cost effective than using virgin material. RAP is asphalt pavement that has been milled, or ripped up, from a roadway. Since RAP is taken from the roadway, it can contain the original pavement as well as any repairs or maintenance treatments ${ }^{2}$. RAP stockpiles are subject to segregation similar to aggregate stockpiles; making them susceptible to variations in gradation. In addition, RAP stockpiles may also be made up of several roadways with assorted gradations, asphalt contents, and binder grades ${ }^{2}$.

Previous studies have shown that in Hveem and Marshall Mix designs, the performance of RAP mixes can surpass virgin mixes ${ }^{2}$. From those studies, it can be predicted that Superpave mix designs with high RAP will also outperform virgin mixtures. An appendix to AASHTO M 323 provides the Superpave mix design process for mixes with RAP. This appendix is based on the National Cooperative Highway Research Program (NCHRP) Report 452². The AASHTO specification allows up to 15 percent RAP without modifying the binder, use of a lower temperature grade binder if the RAP content is between 15 and 25 percent, and the use of a viscosity blending procedure if the RAP content is more than 25 percent. The WVDOH has largely incorporated AASHTO M 323 into their material procedure for designing Superpave mixes, including the provision for designing mixes with RAP.

\section{Concerns}

To accommodate RAP in new mixes, some things need to be considered. First, one must determine what the RAP contributes to the mix in terms of aggregates and asphalt content. Stockpiles may contain different roadway segments, which vary in aggregate gradation, asphalt content, et cetera. Stockpile sampling and testing must be performed for binder content and gradation. To do this, samples 
should be taken from at least 10 random places and at a minimum depth of $150 \mathrm{~mm}$ from the surface of the stockpile ${ }^{2}$. Superpave mix designs also have strict regulations on source and consensus properties, which the RAP will need to meet in order to be used.

There have been concerns over the issue of RAP acting like black rock. This means that the asphalt in the RAP does not blend at all with the virgin binder. NCHRP performed studies on this in Project D9 - 12, and concluded that low RAP pavements act as if total blending has occurred, and high RAP pavements act as if partial blending has occurred. Assuming total blending occurs, asphalt content can be determined by using an ignition furnace or extraction via chemical solvent.

When the pavement is removed from the roadway, it can vary in size from very fine to large chunks greater than five inches. A characteristic of RAP is that it contains a greater number of fines than larger chunks ${ }^{7}$. Removing the RAP material smaller than the number 30 sieve can improve the gradation by reducing the amount of dust in the material ${ }^{7}$. Another method for is to split the material on the number 4 sieve and determine asphalt contents and gradations for each.

\section{Current Use in WV}

AASHTO M 323 requires reducing the binder grade when the amount of RAP between 15 and 25 percent. In 2014, the West Virginia Department of Transportation (WVDOT) issued a memo allowing increased the allowable RAP content to 25\% in Marshall Base 1 and 2 and Superpave 19.0, 25, and $37.5 \mathrm{~mm} \mathrm{mixes}^{3}$ without the requirement to modify the binder grade. All mix designs are still subject to meeting the guidelines set in MP 401.02.24, with the exception of Section 5, Line 5.4; the requirement that a softer binder grade for mix designs using greater than $15 \% \mathrm{RAP}^{3}$. 


\section{RAP Asphalt Contribution}

RAP must undergo some testing prior to use, such as asphalt content. Asphalt content can be determined by following the method in American Society for Testing and Materials (ASTM) designation D6307: Standard Test Method for Asphalt Content of Hot-Mix Asphalt by Ignition Method. The fine fraction of the RAP, passing the $4.75 \mathrm{~mm}$ sieve, generally has a higher asphalt content than the coarse fraction. The asphalt contents of both fractions can be determined by splitting the RAP on the $4.75 \mathrm{~mm}$ sieve and running a burn-off for both, then performing a weighted average. The binder contained in the RAP can also contribute to the mix as a stiffer binder than the original performance grade used, but recent research has shown the effect is not significant in mixtures containing less than $25 \% \mathrm{RAP}^{4}$.

\section{Background of the Asphalt Mixture Performance Tester}

The Asphalt Mixture Performance Tester (AMPT) is a machine designed to test engineering properties of hot-mix asphalt specimens by applying dynamic loading within a temperature controlled triaxial cell. It was developed through National Cooperative Highway Research Program (NCHRP) as a simple performance tester for the hot-mix asphalt mix design ${ }^{5}$. The AMPT can be used for tests such as Dynamic Modulus, Uniaxial Fatigue, Flow Number, and Overlay Testing.

The loading is applied using a hydraulic servomechanism that can be controlled using a computer equipped with Universal Testing Software (UTS) designed for the AMPT. The bottom plate in the cell is mounted on the actuator, the movable fixture, while the top plate is fixed. For tests requiring direct tension, specimens are glued to end platens and then bolted to both the top and bottom plates.

As well as dynamic loading, the AMPT also can condition the asphalt specimens to a desired temperature prior to and during testing. This is achieved using heated or cooled air circulated through 
the cell and controlled using the temperature controller. Samples can be conditioned using stand-alone chambers as well, to facilitate sequential testing of multiple samples.

\section{AMPT Dynamic Modulus Test}

For this test and related analysis, referenced AASHTO documents are:

- PP 60 - 14, Standard Practice for Preparation of Cylindrical Performance Test

Specimens Using the Superpave Gyratory Compactor (SGC),

- $\quad$ TP 79 - 13, Standard Method of Test for Determining the Dynamic Modulus and Flow Number for Asphalt Mixture Performance Tester (AMPT), and

- PP 61 - 13, Standard Practice for Developing Dynamic Modulus Master Curves for Asphalt Mixtures using the Asphalt Mixture Performance Tester (AMPT).

- TP 107-14, Standard Method of Test for Determining the Damage Characteristic Curve of Asphalt Mixtures from Direct Tension Cyclic Fatigue Tests

\section{Sample Specifications}

For the AMPT, cylindrical performance test specimens must be acquired from Superpave Gyratory Compactor (SGC) specimens that have a diameter of $150 \mathrm{~mm}$ and a minimum height of $160 \mathrm{~mm}^{6}$. Cored and sawn samples must meet the tolerance specified by AASHTO PP $60-14$, shown in Table 1.

Table 1 - Test Specimen Dimensional Tolerances ${ }^{6}$

\begin{tabular}{|l|c|}
\hline \multicolumn{1}{|c|}{ Item } & Specification \\
\hline Average diameter & 98 to $104 \mathrm{~mm}$ \\
\hline Standard deviation of diameter & $\leq 0.5 \mathrm{~mm}$ \\
\hline Height & 147.5 to $152.5 \mathrm{~mm}$ \\
\hline End flatness & $\leq 0.5 \mathrm{~mm}$ \\
\hline End perpendicularity & $\leq 1.0 \mathrm{~mm}$ \\
\hline
\end{tabular}




\section{Test Parameters}

Since the AMPT can test at various temperatures and loading frequencies, recommended settings are based on the performance grade, shown in Table 2.

Table 2 - Recommended Testing Temperatures and Loading Frequencies ${ }^{10}$

\begin{tabular}{|c|l|c|l|c|c|}
\hline \multicolumn{2}{|c|}{ PG 58 - XX and softer } & \multicolumn{1}{c|}{ PG 64 - XX and PG 70 - XX } & \multicolumn{2}{c|}{ PG 76 - XX and stiffer } \\
\hline $\begin{array}{c}\text { Temperature } \\
{ }^{\circ} \mathrm{C}\end{array}$ & $\begin{array}{l}\text { Loading } \\
\text { Frequencies, } \mathrm{Hz}\end{array}$ & $\begin{array}{c}\text { Temperature } \\
{ }^{\circ} \mathrm{C}\end{array}$ & $\begin{array}{c}\text { Loading } \\
\text { Frequencies, } \mathrm{Hz}\end{array}$ & $\begin{array}{c}\text { Temperature } \\
{ }^{\circ} \mathrm{C}\end{array}$ & $\begin{array}{c}\text { Loading } \\
\text { Frequencies, Hz }\end{array}$ \\
\hline 4 & $10,1,0.1$ & 4 & $10,1,0.1$ & 4 & $10,1,0.1$ \\
\hline 20 & $10,1,0.1$ & 20 & $10,1,0.1$ & 20 & $10,1,0.1$ \\
\hline 35 & $10,1,0.1$, and & 40 & $10,1,0.1$, and & 45 & $10,1,0.1$, and \\
& 0.01 & & 0.01 & & 0.01 \\
\hline
\end{tabular}

\section{Inputs for Control Software}

Information required for the UTS006 (Dynamic Modulus Test) includes ${ }^{10}$ :

- diameter measured at the top, middle, and bottom of the sample

- height measured at four points $90^{\circ}$ from each other

- $\quad$ sample identity

- test temperature

- test frequency

\section{Outputs}

The Dynamic Modulus Test reports the following in a summary .csv file for the three test temperatures:

- dynamic modulus

- phase angle

- average temperature

- average confining pressure 
- average micro strain

- load drift

- load standard error

- average deformation standard error

- deformation uniformity

- phase uniformity

\section{Master Curve Analysis}

\section{Development of MasterSolver}

In April of 2009, NCHRP released an excel workbook, with Ramon Bonaquist being the principal investigator, that allowed users of the AMPT to generate dynamic modulus master curves. This workbook, known as MasterSolver, utilizes a modified version of the Mechanistic-Empirical Design Guide (MEPDG) master curve equation, the Arrhenius equation, and the Hirsch model ${ }^{8}$.

\section{Dynamic Modulus}

Historically, the stiffness of the asphalt mixture has been described by the dynamic modulus determined by compressive testing. The modified equation that the MasterSolver utilizes to generate the dynamic modulus master curve is as follows:

$$
\log \left|E^{*}\right|=\log (\text { Min })+\frac{\log (\text { Max })-\log (\text { Min })}{1+e^{\beta+\gamma \log \left(\omega_{r}\right)}}
$$

Where:

$\left|E^{*}\right|=$ dynamic modulus

$\omega_{r}=$ reduced frequency, $\mathrm{Hz}$

Max = limiting maximum modulus, $k s i$

Min = limiting minimum modulus, $k s i$ 
$\beta$, and $\gamma=$ fitting parameters

\section{Reduced Frequency}

In order to incorporate dynamic modulus data tested at various temperatures and frequencies to a master curve, it must be fitted to a reduced frequency curve. The reduced frequency can be determined using Equation 2, known as the Arrhenius equation.

$$
\log \omega_{r}=\log \omega+\frac{\Delta E_{a}}{19.14714}\left(\frac{1}{T}-\frac{1}{T_{r}}\right)
$$

Where:

$\omega_{r}=$ reduced frequency at the reference temperature

$\omega=$ loading frequency at the test temperature

$T_{r}=$ reference temperature ${ }^{\circ} \mathrm{K}$

$T=$ test temperature,${ }^{\circ} \mathrm{K}$

$\Delta E_{a}=$ activation energy (treated as a fitting parameter) $\mathrm{J} / \mathrm{mol}$

\section{MasterSolver Analysis}

The MasterSolver workbook requires users to extract certain data points from the .csv files the AMPT produces as well as determine other information that is not utilized within the UTS006 (Dynamic Modulus Test) software such as voids in the mineral aggregate (VMA). The required inputs and are summarized in the list below ${ }^{8}$.

\section{Inputs}

- voids in the mineral aggregate (VMA)

- voids filled with asphalt (VFA) 
- test temperature

- loading frequency

- modulus

- phase angle

Once the data has been entered, the Excel add-on known as Solver can be used to minimize the sum of squares (error squared) between the predicted and actual log of the average modulus ${ }^{8}$. This allows the data to be "fit" to the reduced frequency explained previously. The outputs from the analysis are summarized in the list below ${ }^{8}$.

\section{Outputs}

- average modulus

- modulus covariance

- average phase angle

- phase angle standard deviation

- $\quad$ fitted modulus

- goodness of fit $\left(\mathrm{R}^{2}\right)$

- $\beta$ (parameter)

- $\gamma$ (parameter)

- $\mathrm{E}^{*}$ versus reduced frequency master curve

- phase angle versus reduced frequency master curve

\section{Uses of Analysis}

The master curves generated from the MasterSolver analysis can be used for various applications. The curves predict how the asphalt's dynamic modulus and phase angle will behave at 
various test temperatures and loading frequencies. This allows mix designs to be compared across those parameters.

\section{AMPT Flow Number Test}

For this test and related analysis, referenced AASHTO documents are:

- PP 60 - 14: the Standard Practice for Preparation of Cylindrical Performance Test Specimens Using the Superpave Gyratory Compactor (SGC)

- TP 79 - 13: Standard Method of Test for Determining the Dynamic Modulus and Flow Number for Asphalt Mixture Performance Tester (AMPT).

\section{Sample Specifications}

For the AMPT, cylindrical performance test specimens must be acquired from Superpave Gyratory Compactor (SGC) specimens that have a diameter of $150 \mathrm{~mm}$ and a minimum height of 160 $\mathrm{mm}^{6}$. Cored and sawn samples must meet the tolerance specified by AASHTO PP $60-14$, shown in Table 1.

\section{Test Parameters}

The testing temperature for the flow number test is the high adjusted PG temperature that can be determined using the (Long Term Pavement Performance) LTPP Bind program (http://www.fhwa.dot.gov/research/tfhrc/programs/infrastructure/pavements/ltpp/dwnload.cfm). This program is based on project location and the respective climate. The evaluation parameters for using the LTPP Bind are presented in Table 3. 
Table 3 - LTPP Bind Evaluation Parameters ${ }^{14}$

\begin{tabular}{|c|c|c|}
\hline \multicolumn{2}{|c|}{ Evaluation Parameter } & HMA and WMA \\
\hline \multicolumn{2}{|c|}{ Desired Reliability, \% } & 50 \\
\hline \multicolumn{2}{|c|}{ Target Rut Depth, mm } & 12.5 \\
\hline \multicolumn{2}{|c|}{ Adjustment for Traffic Loading and Speed } & 0.0 \\
\hline \multirow[t]{2}{*}{ Depth of Layer, mm } & Surface Layers & 20 \\
\hline & Intermediated and Base Layers & Depth at the top of surface of the layer \\
\hline
\end{tabular}

The testing parameters for the flow number test are presented in Table 4.

Table 4 - Test Parameters ${ }^{14}$

\begin{tabular}{|c|c|}
\hline Test Parameter & Value \\
\hline Test Temperature & Determined from LTPP Bind \\
\hline Repeated Axial Stress & $600 \mathrm{kPa}$ \\
\hline Contact Stress & $30 \mathrm{kPa}$ \\
\hline Confining Stress & $0 \mathrm{kPa}$ \\
\hline
\end{tabular}

\section{Inputs for Control Software}

Information required for the AMPT's control software UTS005 (Flow Number Test) includes ${ }^{15}$ :

- diameter measured at the top, middle, and bottom of the sample

- height measured at four points $90^{\circ}$ from each other

- sample identity

- test temperature

- axial stress

- contact stress

- termination micro strain

- termination cycles

\section{Outputs}

The Flow Number Test reports the following in a summary .csv file for each specimen: 
- deviator stress

- micro strain

- confining stress

- load standard error

- temperature

- contact stress

- flow number

\section{Uses of Analysis}

The reported flow number is essentially the number of test cycles that correspond to the minimum point in the "Rate of Change in Axial Strain versus the Number of Loading Cycles" curve ${ }^{19}$. The test is destructive due to a loading pulse of 0.1 seconds and a rest time of 0.9 seconds. This test is important in determining rutting resistance of the mixture. The Table 5 shows the requirements for different design ESALs.

Table 5 - Flow Number Criteria (FHWA)

\begin{tabular}{|c|c|}
\hline Design Traffic, Million ESAL & Flow Number \\
\hline$<3$ & N/A \\
\hline 3 to 10 & 50 \\
\hline 10 to 30 & 190 \\
\hline$>30$ & 740 \\
\hline
\end{tabular}

\section{AMPT Uniaxial Fatigue Test}

\section{Sample Specifications}

For the AMPT, cylindrical performance test specimens must be compacted using the Superpave Gyratory Compactor (SGC) to a diameter of $150 \mathrm{~mm}$ and a minimum height of $180 \mathrm{~mm}^{1}$. The 
compacted samples are cored and sawn samples and must meet the tolerance specified by AASHTO TP $107-14$, shown in Table 6.

Table 6 - Test Specimen Dimensional Tolerances ${ }^{1}$

\begin{tabular}{|l|c|}
\hline \multicolumn{1}{|c|}{ Item } & Specification \\
\hline Average diameter & 100 to $104 \mathrm{~mm}$ \\
\hline Standard deviation of diameter & $\leq 0.5 \mathrm{~mm}$ \\
\hline Height & 127.5 to $132.5 \mathrm{~mm}$ \\
\hline End flatness & $\leq 0.5 \mathrm{~mm}$ \\
\hline End perpendicularity & $\leq 1.0 \mathrm{~mm}$ \\
\hline
\end{tabular}

\section{Test Parameters}

AASHTO's PP 107-14 designates that the test temperature for fatigue testing shall be the average of the high and low temperatures minus three based on the $98 \%$ reliability climactic PG determined by LTPPBind ${ }^{1}$. TP 107-14 recommends performing the test on the first sample at a strain level of 300 micro strain and the second and third strain levels are based on the performance of the first specimen per Table 7 .

Table 7 - On-Specimen Strain Levels ${ }^{1}$

\begin{tabular}{|c|c|c|}
\hline Case & $\boldsymbol{\varepsilon}_{\mathrm{OS} 2}$ & $\boldsymbol{\varepsilon}_{\mathrm{OS} 3}$ \\
\hline $500<\mathrm{N}_{\mathrm{f} 1}<1,000$ & $\varepsilon_{\mathrm{OS} 1}-100$ & $\varepsilon_{\mathrm{OS} 1}-150$ \\
\hline $1,000<\mathrm{N}_{\mathrm{f} 1}<5,000$ & $\varepsilon_{\mathrm{OS} 1}-50$ & $\varepsilon_{\mathrm{OS} 1}-100$ \\
\hline $5,000<\mathrm{N}_{\mathrm{f} 1}<20,000$ & $\varepsilon_{\mathrm{OS} 1}+50$ & $\varepsilon_{\mathrm{OS} 1}-50$ \\
\hline $20,000<\mathrm{N}_{\mathrm{f} 1}<100,000$ & $\varepsilon_{\mathrm{OS} 1}+100$ & $\varepsilon_{\mathrm{OS} 1}+50$ \\
\hline $100,000<\mathrm{N}_{\mathrm{f} 1}<5,000$ & $\varepsilon_{\mathrm{OS} 1}+150$ & $\varepsilon_{\mathrm{OS} 1}+100$ \\
\hline
\end{tabular}

\section{Inputs for Control Software}

Information required for the UTS032 (S-VECD Fatigue Test) includes ${ }^{1}$ :

- test temperature

- gauge length 
- diameter measured at the top, middle, and bottom of the sample

- $\quad$ height measured at four points $90^{\circ}$ from each other

- $\quad$ sample identity

- $\quad$ target peak-to-peak axial micro strain

\section{Outputs}

The UTS032 (S-VECD Fatigue Test) software reports the following in .csv files from the final five cycles of the dynamic modulus fingerprint test, initial five cycles of the S-VECD test, and the final five cycles of the S-VECD test:

- time

- axial stress

- actuator strain

- $\quad$ axial micro strain (for each LVDT)

- temperature

- $\operatorname{load}$

- actuator displacement

- displacement (for each LVDT)

The UTS032 (S-VECD Fatigue Test) software reports the following analyzed data in a .csv file from the S-VECD test:

- dynamic modulus

- cycle count

- phase angle

- $\quad$ peak-to-peak stress 
- peak-to-peak average axial micro strain

- peak-to-peak actuator micro strain

- temperature

- machine compliance factor

- load standard error

- minimum and maximum actuator strain

- minimum and maximum strain (for each LVDT)

- peak-to-peak load

- minimum and maximum load

- peak-to-peak actuator displacement

- peak-to-peak displacement (for each LVDT)

- minimum and maximum actuator displacement

- minimum and maximum displacement (for each LVDT)

\section{Asphalt Pavement Hierarchical Analysis Toolbox - Fatigue Program}

\section{Development of Simplified Viscoelastic Continuum Damage Model}

Continuum damage theory (CDT) has been used to predict damage within materials since the 1960 's ${ }^{12}$. Damage can be tested by applying a load with a constant rate of strain or by cyclic loading. For asphalt, the loading level to cause failure is higher than what most testing apparatuses can apply ${ }^{12}$. The cyclic loading can be applied by a controlled stress test, push-pull test, pull-pull test, or controlled strain test. Simplified viscoelastic continuum damage (S-VECD) is a recent development that can be used for predicting fatigue in asphalt pavements ${ }^{12}$. 
S-VECD produces a damage characteristic curve that relates the damage parameter $(\mathrm{S})$ to the pseudo-secant modulus (C). To generate this curve, the damage caused by the first loading cycle is included, but the few cycles after are excluded ${ }^{13}$. It has also been found that push-pull can be used as long as the tensile strain does not fall below 25 and does not exceed 37.5 micro strains ${ }^{13}$. Software has been developed to allow users to analyze S-VECD data more easily than with other iterative methods.

\section{ALPHA-F Analysis}

ALPHA-F was developed by Drs. Richard Kim and Shane Underwood to facilitate data analysis of fatigue testing using the AMPT. This software produces a model prediction report which can be used to compare characteristics of asphalt mixtures.

\section{Analysis steps}

Upon launching the ALPHA-F program the user is ask for a series on inputs, including the location of the data files for use during the analysis, including:

UTS006 (Dynamic Modulus Test) summary .csv files of three test temperatures (for three $\left|\mathrm{E}^{*}\right|$ samples)

- VFA

- VMA

- UTS032 (S-VECD Fatigue Test) initial five cycles .csv files (for at least three Fatigue samples)

- UTS032 (S-VECD Fatigue Test) final five cycles .csv files (for at least three Fatigue samples)

ALPHA-F computes the phase angle versus cycle number and displays the results on a plot as shown on Figure xx. The user is allowed to adjust the point used for the fatigue analysis, but the 
recommendation is to select the point where there is a sudden drop in the phase angle as shown on Figure 1. However, the figure included with the ALPHA-F user guide does not display this behavior as shown on Figure 2; no guidance is given for the selection of the failure cycle when there is no sudden drop in the phase angle. The "OK" button is selected and the program computes the damage models.

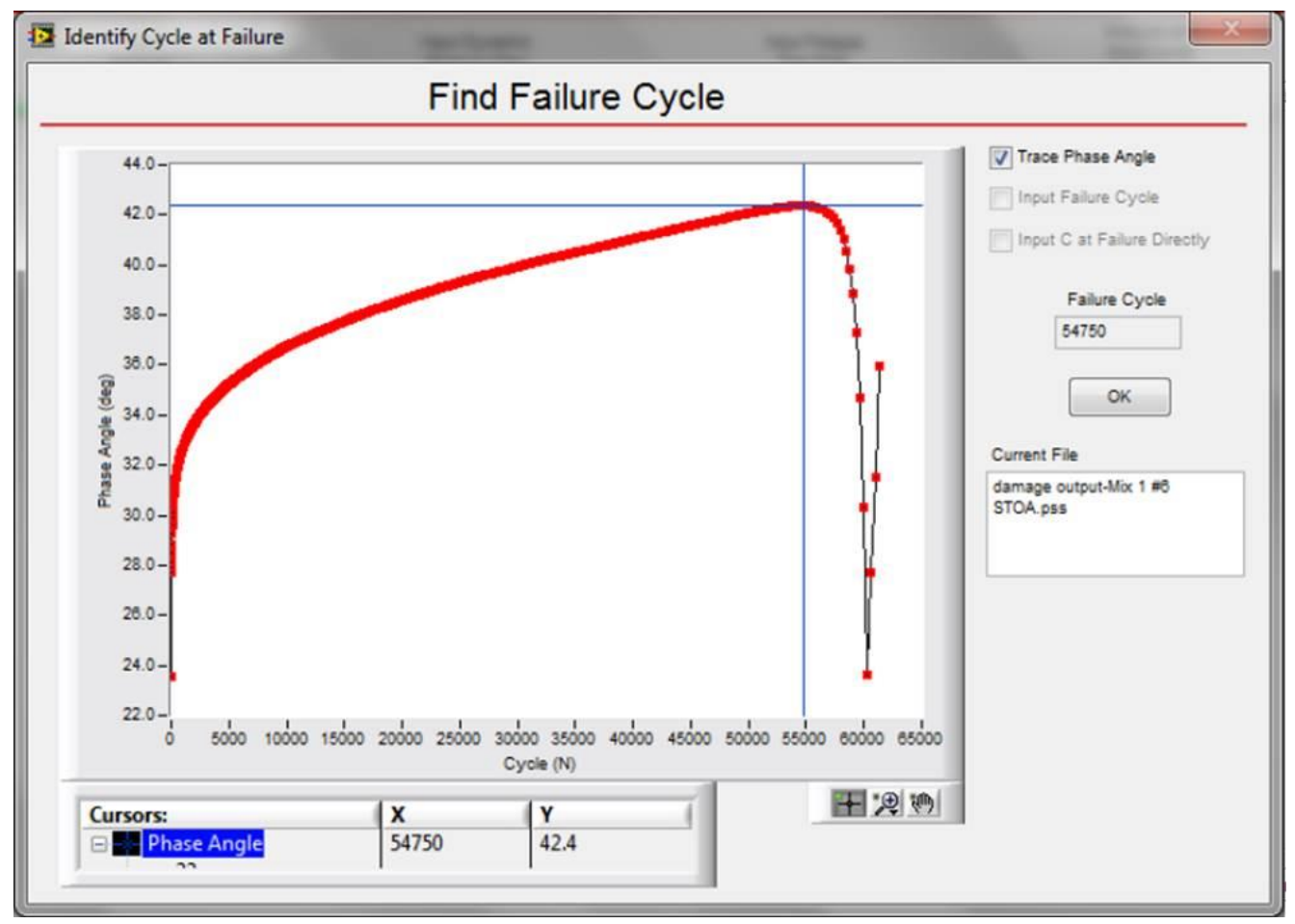

Figure 1 - ALPHA-F Phase Angle and Failure Cycle (With Sudden Drop in Phase Angle) 


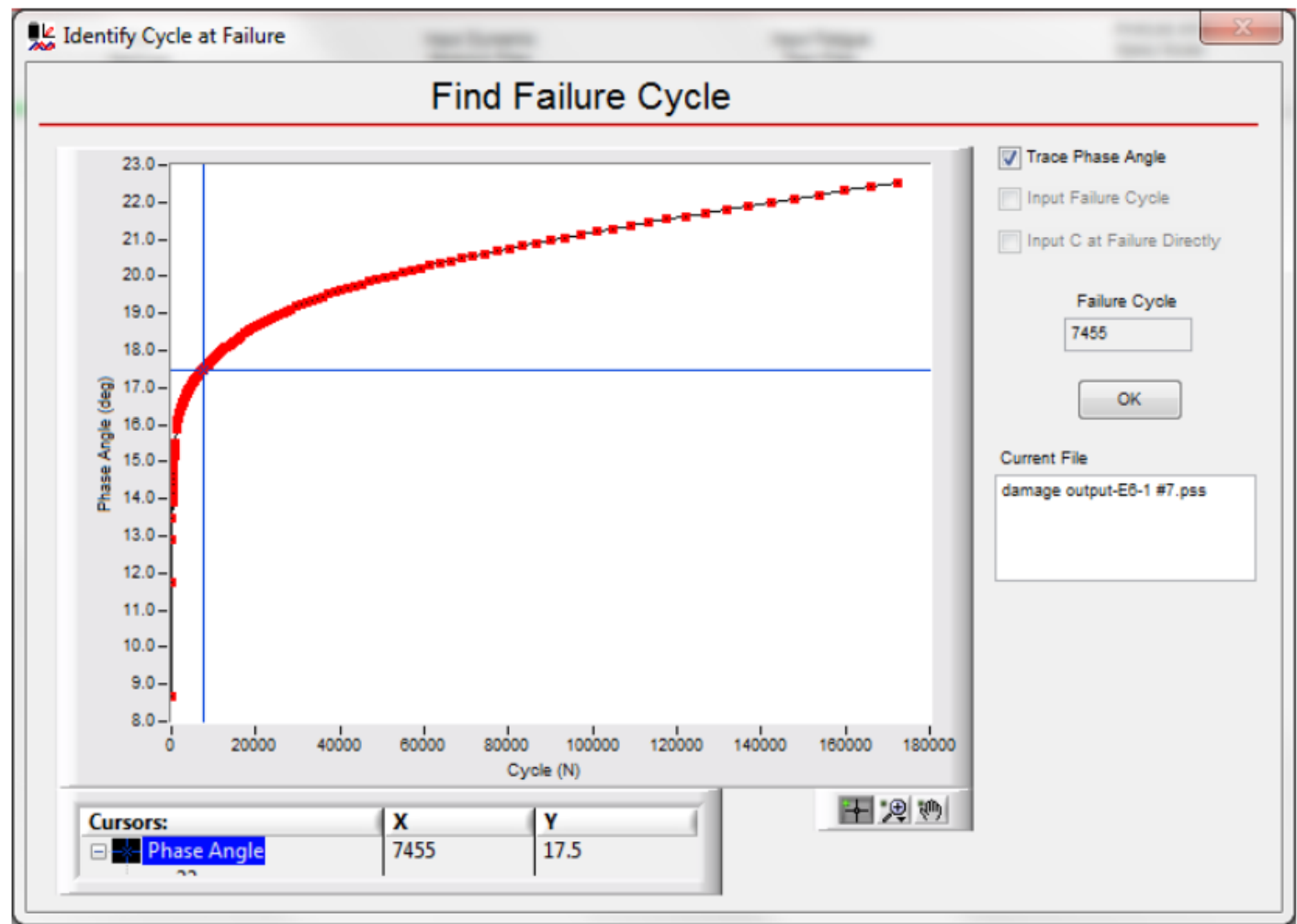

Figure 2 - ALPHA-F Phase Angle Phase Angle and Failure Cycle (Without Sudden Drop in Phase Angle)

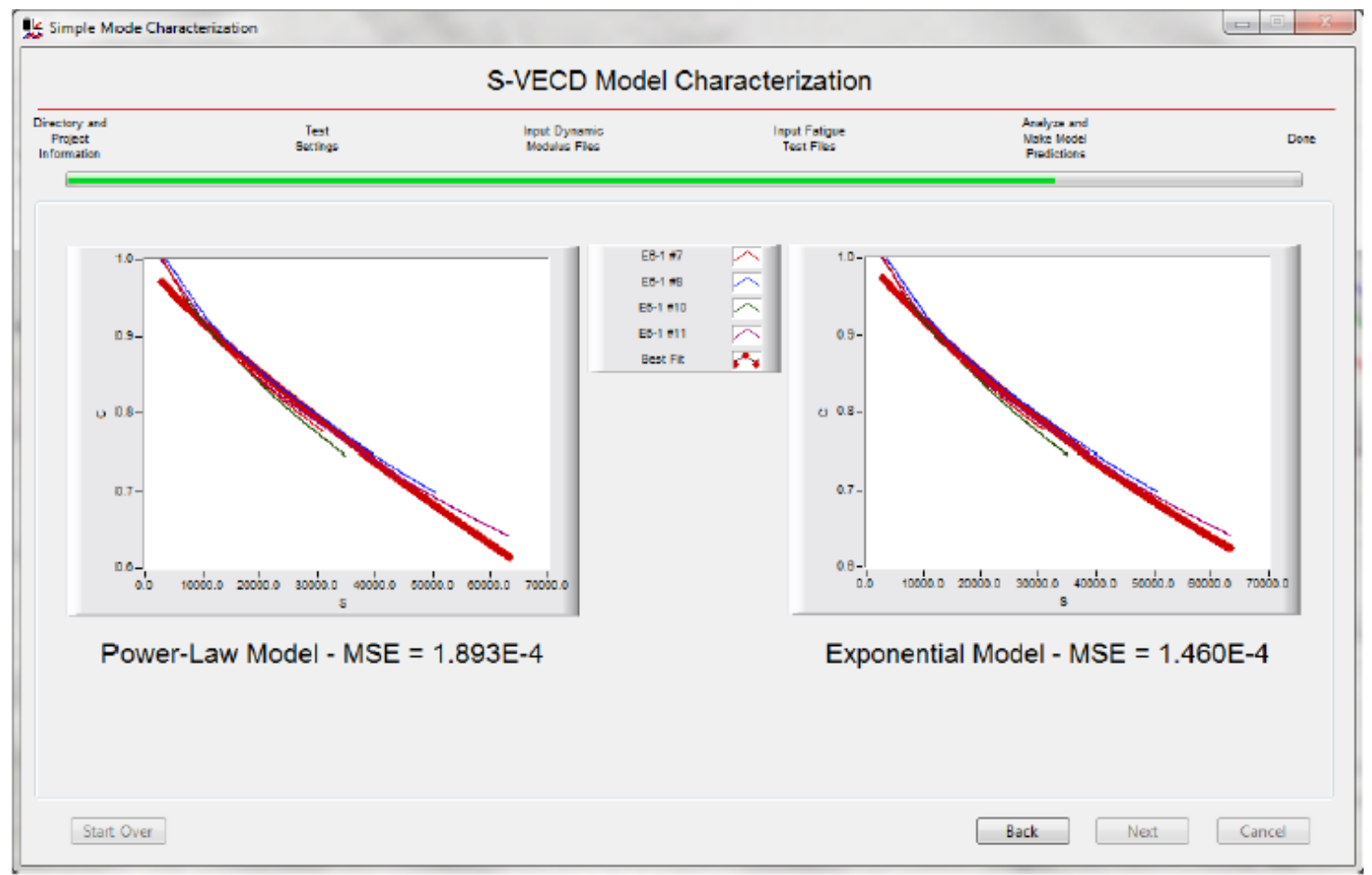

Figure 3 - Best Fit Selection Dialogue Box 
ALPHA-F does a best fit analysis of the damage using both a power-law model and an exponential model as shown on Figure 3. The user can select either of the models but the recommendation is to use the model with the lowest mean square error, MSE. After selecting the damage model the program completes the analysis and displays a summary screen as shown in Figure 3 and an output file of the analysis is created, including:

- $\mathrm{K}_{1}, \mathrm{~K}_{2}$, and $\mathrm{K}_{3}$ for traditional strain fatigue relationship

- endurance limit at $5,10,15,20$, and $25^{\circ} \mathrm{C}$

- damage model coefficients: a, b, y, z, $\alpha$

- parameter $\mathrm{r}$ and $\mathrm{s}$ in failure criterion

- shift factor coefficients: $\mathrm{T}_{\mathrm{r}}$ and $\mathrm{E}_{\mathrm{a}}$

- master curve parameters: $\kappa, \beta, \delta$, and $\gamma$

\section{Uses of Analysis}

The main use of fatigue analysis is to predict the k-values using the traditional strain fatigue relationship as defined by Equation 3.

$$
N_{f}=K_{1}\left(\frac{1}{\varepsilon_{t}}\right)^{K_{2}}\left(\left|E^{*}\right|\right)^{K_{3}}
$$

Where:

$K_{1}, K_{2}$, and $K_{3}=$ constants

$\varepsilon_{t}=$ strain

$\left|E^{*}\right|=$ dynamic modulus 
The K-values are constants that can be determined from damage models produced by performing regression analyses on laboratory fatigue test data to correlate to field performance. The formulas used in the damage models of ALPHA-F are defined in Equations 4, 5, and 6.

$$
\begin{aligned}
& C=e^{a S^{b}} \\
& C=1-y S^{z} \\
& N_{f}=r\left(G^{r}\right)^{S}
\end{aligned}
$$

Where:

$C=$ psuedo modulus

$r, S=$ damage parameters

$G^{r}=$ rate of average released pseudo strain

$y, z=$ fitting coefficients for the power model

$a, b=$ fitting coefficients for the exponential model

The Asphalt Institute used 0.0796, 3.291, and 0.854 and Shell used 0.0685, 2.363, and 5.671 for $\mathrm{K}_{1}, \mathrm{~K}_{2}$, and $\mathrm{K}_{3}$, respectively ${ }^{16}$. Rauhut, as cited by Hass et. al (1994) showed there is a large difference in the fatigue curves produced by different researchers, Figure 4. 


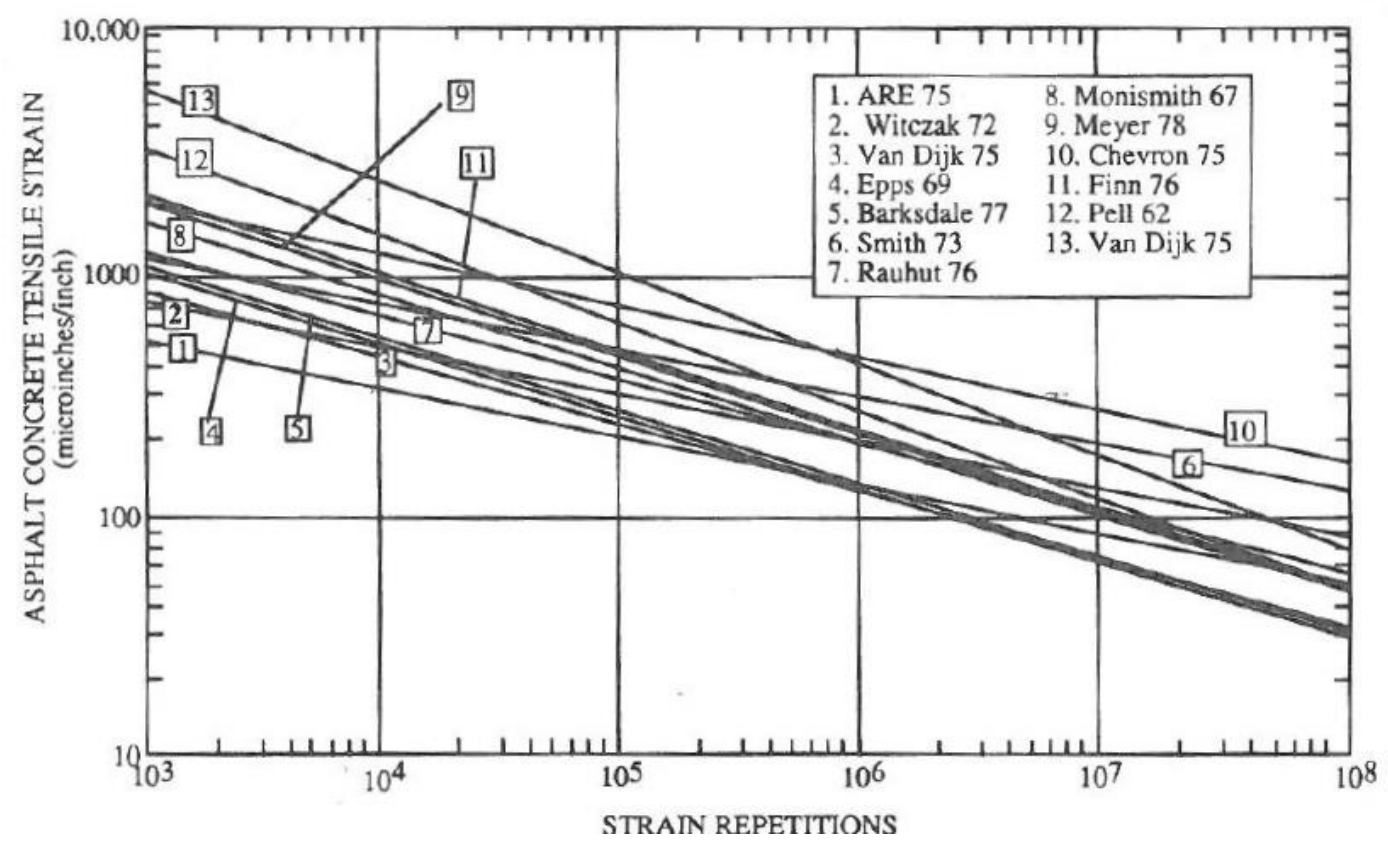

Figure 4 - Various Fatigue Equations ${ }^{20}$

When evaluating a material for fatigue properties, an endurance limit may exist. Strains less than the endurance limit do not damage the fatigue properties of the material so in effect an infinite number of load applications can be applied to the pavement without causing fatigue damage. This concept is used for perpetual pavement design. The Texas Department of Transportation uses a strain limit of $<70 \mu$-strain in their perpetual pavement design manual ${ }^{20}$. 


\section{Chapter 3: Methodology}

\section{Experimental Design}

The first factor of this experiment is RAP content, which has three levels: $0 \%, 15 \%$, and $25 \%$. The second factor of this experiment is binder grade, which has two levels: PG 70-22 and PG 64-22. Objective one was accomplished by preparing twenty seven samples with PG 70-22 with 0\%, 15\%, and $25 \%$ RAP contents and testing for dynamic modulus and fatigue characteristics. Objective two was accomplished by preparing nine additional samples with PG 64-22 and 25\% RAP content and testing for dynamic modulus and fatigue characteristics. Objective three was accomplished by preparing six samples with PG 70-22 and 0\%, 15\%, and 25\% RAP contents and testing for dynamic modulus and flow number.

For simplicity, the samples prepared to achieve objectives one and two are hereinafter referred to as DM and FT samples and the samples prepared to achieve objective three are hereinafter referred to as DM and FN samples. It shall be noted that the DM and FN samples were prepared and tested over a year before the DM and FT samples.

\section{Material Preparation}

For this experiment all aggregate samples were obtained from West Virginia Paving's plant in Beaver, WV. Limestone stockpiles used were 67's, 8's, F-Sand, and W-Sand. Processed RAP was also obtained from this location. Aggregate material properties are presented in Appendix A, following the job mix formulas. Upon arrival at West Virginia University’s Asphalt Technology Lab, the virgin aggregate went through the following steps

1. Initial drying at $110^{\circ} \mathrm{C}$ for 6 hours

2. Initial sieving for 9 minutes 
3. Separated by sieve size

4. Washing using drum washer

5. Final drying at $110^{\circ} \mathrm{C}$ for 10 hours

6. Final sieving until no additional aggregate passed

7. Stored in sealed plastic buckets

The gradation for each stockpile as documented in the West Virginia Paving mix design submission was used to compute a weigh-out table of the amount of aggregate needed for each stockpile and for each sieve. The aggregates for each mix were weighed out and stored in sealed plastic bags until mixing.

Upon arrival at West Virginia University's Asphalt Technology Lab, RAP underwent the following steps:

1. Initial drying at $100^{\circ} \mathrm{C}$ for 4 hours

2. Split on the \#4 $(4.75 \mathrm{~mm})$ sieve and separated

3. Stored in sealed plastic buckets

The RAP was separated on the \#4 sieve to determine proportions of "coarse" and "fine" material. These proportions were kept consistent between mixes to promote uniformity between specimens. The asphalt content of the fine and coarse RAP were determined using an NCAT oven and assuming a correction factor of zero.

Asphalt binder was delivered in gallon cans, so it was necessary to split the binder, at a temperature of $100^{\circ} \mathrm{C}$, into quart cans. The amount of asphalt in each can was targeted to be slightly 
more than what was needed for each specimen. This method prevented excessive heating and cooling of the asphalt. Unused asphalt binder from mixing was discarded to maintain consistency between mixes.

\section{Superpave ${ }^{\circledR}$ Specimen Verification}

Mix designs were initially verified in the spring of 2014, for the dynamic modulus and flow number tests. All of the job mix formulas were able to produce Superpave bulk and Rice samples that met the specification. Due to the delay in testing, new material was used for the fatigue testing. In order to verify that the mix designs used could still meet an air void content (VTM) of $4.0 \%$, Superpave® bulk and Rice samples were remade in accordance with AASHTO T $312-12$ and T $209-12$. It was found that not all of the mix designs could meet the standard specification, so the asphalt contents $\left(\mathrm{P}_{\mathrm{b}}\right)$ were altered for PG 70 - 22 with 15\% RAP and 25\% RAP, and PG $64-22$ with $25 \%$ RAP. Table 8 lists the asphalt contents used in all mix designs that achieved an air void content of $4.0 \pm 0.5 \%$.

Table 8 - Percent Asphalt Content

\begin{tabular}{|c|c|c|}
\hline Binder Grade & \% RAP & P $_{\mathbf{b}}$ \\
\hline \multicolumn{2}{|c|}{ DM and FT } \\
\hline PG 64-22 & 25 & $4.9 \%$ \\
\hline \multirow{4}{*}{ PG 70-22 } & 0 & $4.9 \%$ \\
\cline { 2 - 3 } & 15 & $4.6 \%$ \\
\cline { 2 - 3 } & 25 & $4.9 \%$ \\
\hline \multicolumn{3}{|c|}{ DM and FN } \\
\hline \multirow{3}{*}{ PG 70-22 } & 0 & $4.9 \%$ \\
\cline { 2 - 3 } & 15 & $5.1 \%$ \\
\cline { 2 - 3 } & 25 & $4.7 \%$ \\
\hline
\end{tabular}

With the altered asphalt contents, the theoretical maximum $\left(\mathrm{G}_{\mathrm{mm}}\right)$ and bulk $\left(\mathrm{G}_{\mathrm{mb}}\right)$ specific gravities were determined and used to calculate air void content (VTM). The results are summarized Table 9. 
Table $9-G_{m m}, G_{m b}$ and VTM of Verification Samples

\begin{tabular}{|c|c|c|c|c|}
\hline Binder Grad & \% RAP & $\mathbf{G}_{\mathbf{m b}}$ & $\mathbf{G}_{\mathbf{m m}}$ & VTM, \% \\
\hline \multicolumn{5}{|c|}{ DM and FT } \\
\hline PG 64-22 & 25 & 2.433 & 2.522 & 3.5 \\
\hline \multirow{3}{*}{ PG 70-22 } & 0 & 2.434 & 2.527 & 3.7 \\
\cline { 2 - 5 } & 15 & 2.436 & 2.535 & 3.9 \\
\cline { 2 - 5 } & 25 & 2.420 & 2.526 & 4.1 \\
\hline \multicolumn{5}{|c|}{ DM and FN } \\
\hline \multirow{3}{*}{ PG 70-22 } & 0 & 2.416 & 2.515 & 3.9 \\
\cline { 2 - 5 } & 15 & 2.422 & 2.512 & 3.6 \\
\cline { 2 - 5 } & 25 & 2.427 & 2.538 & 4.4 \\
\hline
\end{tabular}

\section{AMPT Specimen Preparation}

Using the theoretical maximum specific gravities from the verification samples, the mass required to produce a specimen with a target height was calculated. Knowing that this equation does not fully represent the relationship between whole sample and cored specimen air void contents, it was assumed that multiple iterations would be required to achieve target VTM. Equation 7, given in AASHTO PP 60 - 14, was the first step in calculating target sample mass and is restated below for convenience.

$$
\text { Mass }=\left[\frac{100-\left(V_{a t}+F\right)}{100}\right] * G_{m m} * 176.7147 * H
$$

Where:

$\mathrm{V}_{\mathrm{at}}=$ target air void content

$\mathrm{F}=$ air void adjustment factor (1.0 for fine graded and 1.5 for coarse graded mixtures)

$\mathrm{G}_{\mathrm{mm}}=$ theoretical maximum specific gravity of the mix

$\mathrm{H}=$ sample height, $\mathrm{cm}$

Using $\mathrm{V}_{\mathrm{at}}=7.0 \%, \mathrm{~F}=1.5, \mathrm{H}=18 \mathrm{~cm}$, and respective $\mathrm{G}_{\mathrm{mm}}$ values, the preliminary desired masses of the samples were calculated. After cooling overnight, the samples were then cored to a 
diameter of $100 \mathrm{~mm}$ and approximately $15 \mathrm{~mm}$ sawed off each end. The cored specimens were dried and tested for bulk specific gravity in accordance with T 331 - 13 and the air void results are listed in Table 10.

Table 10 - AMPT Trial Specimen Properties

\begin{tabular}{|c|c|c|c|c|c|}
\hline Binder Grade & \% RAP & $\mathbf{G}_{\mathbf{m m}}$ & Mass, $\mathbf{g}$ & $\mathbf{G}_{\mathbf{m b}}$ & VTM, \% \\
\hline \multicolumn{7}{|c|}{ DM and FT } \\
\hline PG 64-22 & 25 & 2.527 & 7354.8 & 2.428 & 3.9 \\
\hline \multirow{3}{*}{ PG 70-22 } & 0 & 2.535 & 7378.1 & 2.445 & 3.6 \\
\cline { 2 - 6 } & 15 & 2.526 & 7351.9 & 2.446 & 3.2 \\
\cline { 2 - 6 } & 25 & 2.522 & 7340.2 & 2.409 & 4.5 \\
\hline \multicolumn{6}{|c|}{ DM and FN } \\
\hline PG 70-22 & 0 & 2.515 & 7320 & 2.423 & 3.7 \\
\cline { 2 - 6 } & 15 & 2.512 & 7311 & 2.433 & 3.1 \\
\cline { 2 - 6 } & 25 & 2.538 & 7387 & 2.402 & 5.4 \\
\hline
\end{tabular}

The mass and air voids (VTM) of the samples is used to compute an adjusted mass per Equation $8^{6}$. Since the mass of the trial samples was less than the 7 percent target, the mass for the test samples was reduced.

$$
\operatorname{Mass}_{a d j}=\left(\frac{100-V_{a t}}{100-V_{a m}}\right) * \text { Mass }
$$

Where:

Mass $_{\text {adj }}=$ adjusted mass

$V_{a t}=$ target air void content

$V_{a m}=$ measured air void content

Mass $=$ mass used for trial specimen

The cored specimens were evaluated in the same manner as previously stated and the final masses determined to be used for AMPT sample fabrication are stated in the Table 11. 
Table 11 - Final Adjusted Mass of AMPT Samples

\begin{tabular}{|c|c|c|c|c|c|}
\hline Binder Grade & \% RAP & $\mathbf{G}_{\mathbf{m m}}$ & Final Adjusted Mass, $\mathbf{g}$ & $\mathbf{G}_{\mathbf{m b}}$ & VTM (\%) \\
\hline \multicolumn{7}{|c|}{ DM and FT } \\
\hline PG 64-22 & 25 & 2.527 & 7080.0 & 2.350 & 6.8 \\
\hline \multirow{3}{*}{ PG 70-22 } & 0 & 2.535 & 7085.0 & 2.349 & 7.0 \\
\cline { 2 - 7 } & 15 & 2.526 & 7100.0 & 2.363 & 6.8 \\
\cline { 2 - 7 } & 25 & 2.522 & 7090.0 & 2.359 & 6.6 \\
\hline \multicolumn{7}{|c|}{ DM and FN } \\
\hline \multirow{3}{*}{ PG 70-22 } & 0 & 2.515 & 7085.0 & 2.330 & 7.3 \\
\cline { 2 - 7 } & 15 & 2.512 & 7100.0 & 2.342 & 6.8 \\
\cline { 2 - 7 } & 25 & 2.538 & 7090.0 & 2.349 & 7.4 \\
\hline
\end{tabular}

Samples were made with the final adjusted masses in Table 11. All samples were compacted to a height of $180 \mathrm{~mm}$ and the dynamic modulus and flow number samples had $15 \mathrm{~mm}$ removed from each end, while the fatigue samples had $25 \mathrm{~mm}$ was removed from each end. As the samples were cut it was observed that near the completion of the cutting the weight of the waste piece caused it to fall away before the cut was complete. This resulted is some tearing away of the material on the sample side of the cut. The process for cutting the samples should be refined in future research. The samples were sawn and cored and the dimensional requirements of PP 60-13 (DM and FN samples) or TP 107-14 (DM and FT) were measured and the compliance of the samples to the requirements was verified.

\section{Dynamic Modulus Test}

\section{Pre-Testing Setup}

To perform the dynamic modulus test, AMPT specimens were produced in accordance with PP $61-13$ and TP $79-13$. Devcon 5-minute epoxy was used to attach the gauge points to the specimen and allowed to cure for at least one hour prior to being placed into the environmental conditioning unit. A dummy sample with an internal thermometer was also placed in the conditioning unit to verify that the specimens would be at the target test temperature after conditioning. 


\section{Dynamic Modulus Testing}

Once a specimen reached test temperature, it was placed into the AMPT testing chamber between two end platens separated by Teflon spacers and LVDT's were attached to the gauge points with the fixtures provided by InstroTek. The LVDT's were adjusted to zero displacement according to the "levels" tool within the software. The cell was lowered and the temperature was monitored also using the "levels" tool within the software until all testing specifications were met. During equalization, the required inputs were entered into the testing software to conserve time. Testing was initiated using the hydraulic manifold system and performed using the "start" function of the UTS006 software that automatically applies the load at the designated frequency. After the test was completed, the specimen was placed back in the environmental conditioning unit at the next test temperature. At the conclusion of all tests, gauge points were removed and soaked in acetone to remove the epoxy for future use.

\section{Flow Number Test}

\section{Pre-Testing Setup}

To perform the flow number test, AMPT specimens were produced in accordance with PP $61-$ 13 and TP 79 - 13. A dummy sample with an internal thermometer was placed in the conditioning unit with the specimens to be tested, to verify that the specimens would be at the target test temperature after conditioning.

\section{Testing}

Once a specimen reached test temperature, it was placed into the AMPT testing chamber between two end platens separated by greased latex friction reducing spacers. The cell was lowered and the temperature monitored using the "levels" tool within the software until the desired testing temperature was reached. During equalization, the inputs listed in Chapter 2 were entered into the 
testing software to conserve time. Testing was initiated using the hydraulic manifold system and performed using the "start" function of the UTS005 software that automatically applied the required loading and stopped the test when a failure criterion was reached.

\section{S-VECD Fatigue Test}

\section{Testing Setup}

To perform the S-VECD fatigue test, AMPT specimens were produced in accordance with PP 60-14 and TP 107-14. Devcon 5-minute epoxy was used to attach the gauge points to the specimen prior to end platen gluing. Devcon 10110 (steel putty) was used to attach the steel end platens required for tensile testing with the AMPT. Each specimen remained in the end platen gluing jig for a minimum of four hours to allow the steel putty to set. After the four hours, the specimen was able to be removed from the jig and allowed to cure for an additional twelve hours before being placed in the environmental conditioning unit. A dummy sample with an internal thermometer was also placed in the conditioning unit to verify that the specimens would be at the target test temperature after conditioning.

\section{Testing}

Once a specimen reached test temperature, it was placed into the AMPT testing chamber and the end platens were bolted to the bottom plate. To bolt the specimen to the top plate, the actuator was raised and a seating load of $0.09 \mathrm{kN}$ was applied. To improve consistency in testing, the bolts were tightened to 6.00 foot-pounds using a torque wrench. After tightening all bolts, the seating load was removed so the specimen was not experiencing any compressive or tensile loading. The LVDT's were attached to the gauge points and adjusted to slightly above the minimum displacement according to the "levels" tool within the software. This was done to allow the LVDT to displace a greater distance since the fatigue test elongates the specimen. The cell was lowered and the temperature was monitored using 
the "levels" tool within the software until all testing specifications were met. During equalization, the required inputs were entered into the testing software to conserve time.

Fatigue testing requires that successive specimens be tested at varying strain levels. Although TP 107-14 recommends a strain level of 300 micro strains for the first sample, the InstroTek technician that assisted with setting up the AMPT in the WVU Asphalt Technology Lab recommended using an initial strain of 150 micro strains. Based on this value and Table 6 the strain levels used during this research are presented in Table 11. The $\mathrm{N}_{\mathrm{f}}$ values found during the testing of the first sample of each of the factors and level combinations was always greater than 100,000 so only the last line of Table 12 applied to this research.

Table 12 - On-Specimen Strain Levels for the Second and Third Specimens

\begin{tabular}{|c|c|c|}
\hline Case & $\boldsymbol{\varepsilon}_{\text {OS2 }}$ & $\boldsymbol{\varepsilon}_{\text {OS3 }}$ \\
\hline $500<\mathrm{N}_{\mathrm{f}}<1,000$ & 50 & -- \\
\hline $1,000<\mathrm{N}_{\mathrm{f}}<5,000$ & 100 & 50 \\
\hline $5,000<\mathrm{N}_{\mathrm{f}}<20,000$ & 200 & 100 \\
\hline $20,000<\mathrm{N}_{\mathrm{f}}<100,000$ & 250 & 200 \\
\hline $100,000<\mathrm{N}_{\mathrm{f}}$ & 300 & 250 \\
\hline
\end{tabular}

After the test was complete, the gauge points were removed and soaked in acetone to remove the epoxy for future use. The specimen was then placed into an oven at $150^{\circ} \mathrm{C}$ for one hour to soften the steel putty for easier removal. End platens were cleaned with WD-40, then ethyl alcohol, and finally acetone to ensure no residue was left behind. 


\section{Chapter 4: Results and Analysis}

\section{DM and FN Sample Analysis}

\section{Dynamic Modulus}

All samples used for dynamic modulus testing met the standards set in PP 60-14 and were at an air void content of $7.0 \pm 0.5 \%$. Data from the dynamic modulus tests is presented in Appendix B and summarized in Table 13.

Table 13 - Dynamic Modulus (MPa) of DM and FN Samples

\begin{tabular}{|c|c|c|c|c|c|c|c|c|c|c|c|}
\cline { 2 - 12 } \multicolumn{2}{c|}{} & \multicolumn{9}{c|}{ Test Temp } \\
\cline { 2 - 13 } \multicolumn{2}{c|}{} & \multicolumn{3}{c|}{$4{ }^{\circ} \mathrm{C}$} & \multicolumn{3}{c|}{$20^{\circ} \mathrm{C}$} & \multicolumn{4}{c|}{$40^{\circ} \mathrm{C}$} \\
\hline \%RAP & Replicate & $10 \mathrm{~Hz}$ & $1.0 \mathrm{~Hz}$ & $0.1 \mathrm{~Hz}$ & $10 \mathrm{~Hz}$ & $1.0 \mathrm{~Hz}$ & $0.1 \mathrm{~Hz}$ & $10 \mathrm{~Hz}$ & $1.0 \mathrm{~Hz}$ & $0.1 \mathrm{~Hz}$ & $0.01 \mathrm{~Hz}$ \\
\hline \multirow{2}{*}{0} & 1 & 13,004 & 9,646 & 6,529 & 4,130 & 3,516 & 1,786 & 1,365 & 579 & 248 & 131 \\
\cline { 2 - 13 }$y$ & 2 & 14,610 & 10,756 & 7,081 & 6,109 & 3,330 & 1,648 & 1,282 & 545 & 248 & 152 \\
\hline \multirow{2}{*}{15} & 1 & 16,396 & 12,679 & 8,977 & 8,108 & 4,902 & 2,627 & 1,848 & 793 & 345 & 179 \\
\cline { 2 - 12 } & 2 & 14,713 & 11,073 & 7,715 & 12,969 & 7,922 & 4,371 & 2,275 & 1,027 & 462 & 234 \\
\hline \multirow{2}{*}{25} & 1 & 16,085 & 12,362 & 8,756 & 8,508 & 5,150 & 2,785 & 2,399 & 1,076 & 469 & 221 \\
\cline { 2 - 11 } & 2 & 15,513 & 12,266 & 8,639 & 9,205 & 5,743 & 3,199 & 2,572 & 1,151 & 496 & 241 \\
\hline
\end{tabular}


The average dynamic modulus for each combination of mix type, loading frequency, and temperature was determined and is presented in Figures 5, 6 and 7.

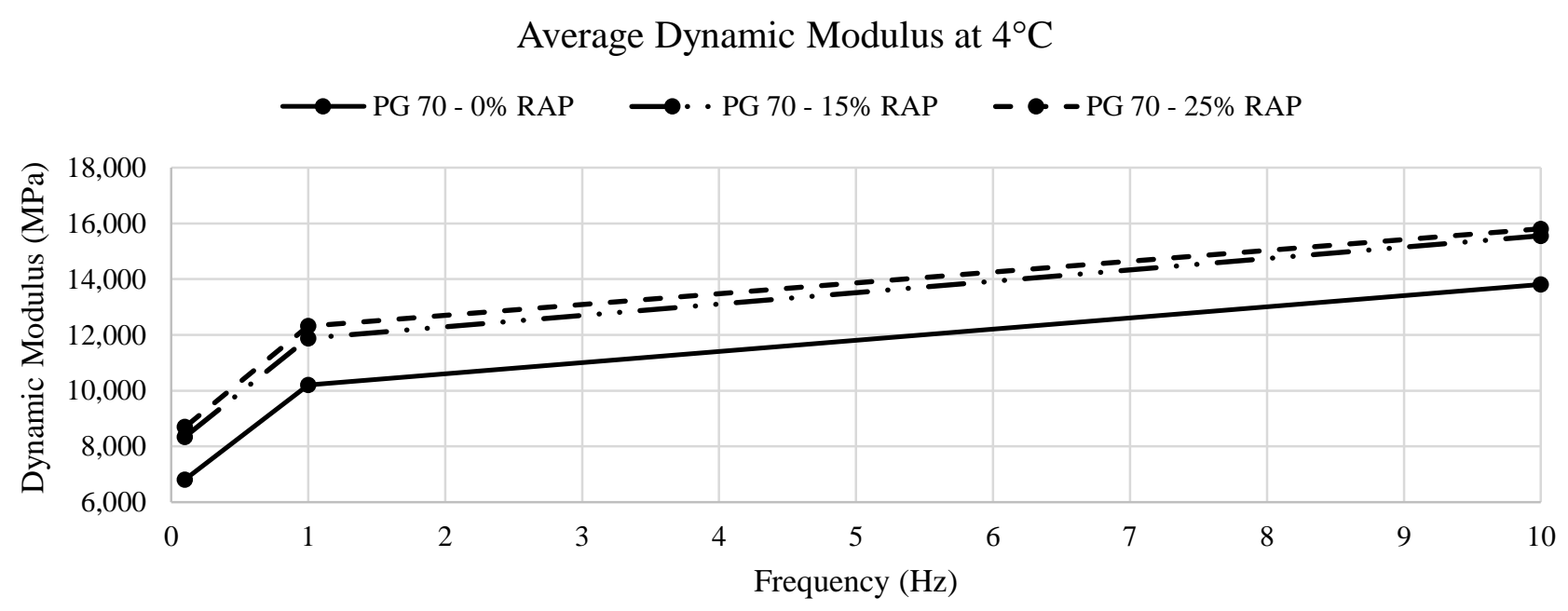

Figure 5 - Average Dynamic Modulus at $4^{\circ} \mathrm{C}$ of DM and FN Samples

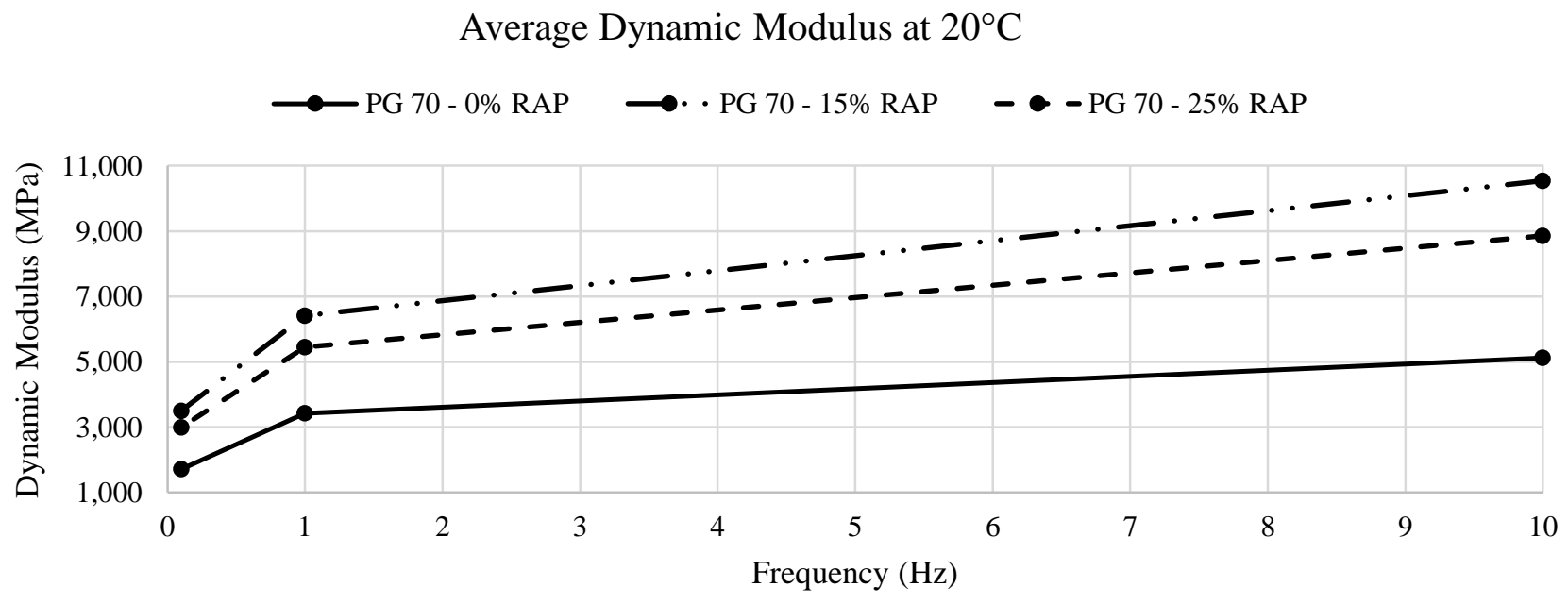

Figure 6 - Average Dynamic Modulus at $20^{\circ} \mathrm{C}$ of DM and FN Samples 


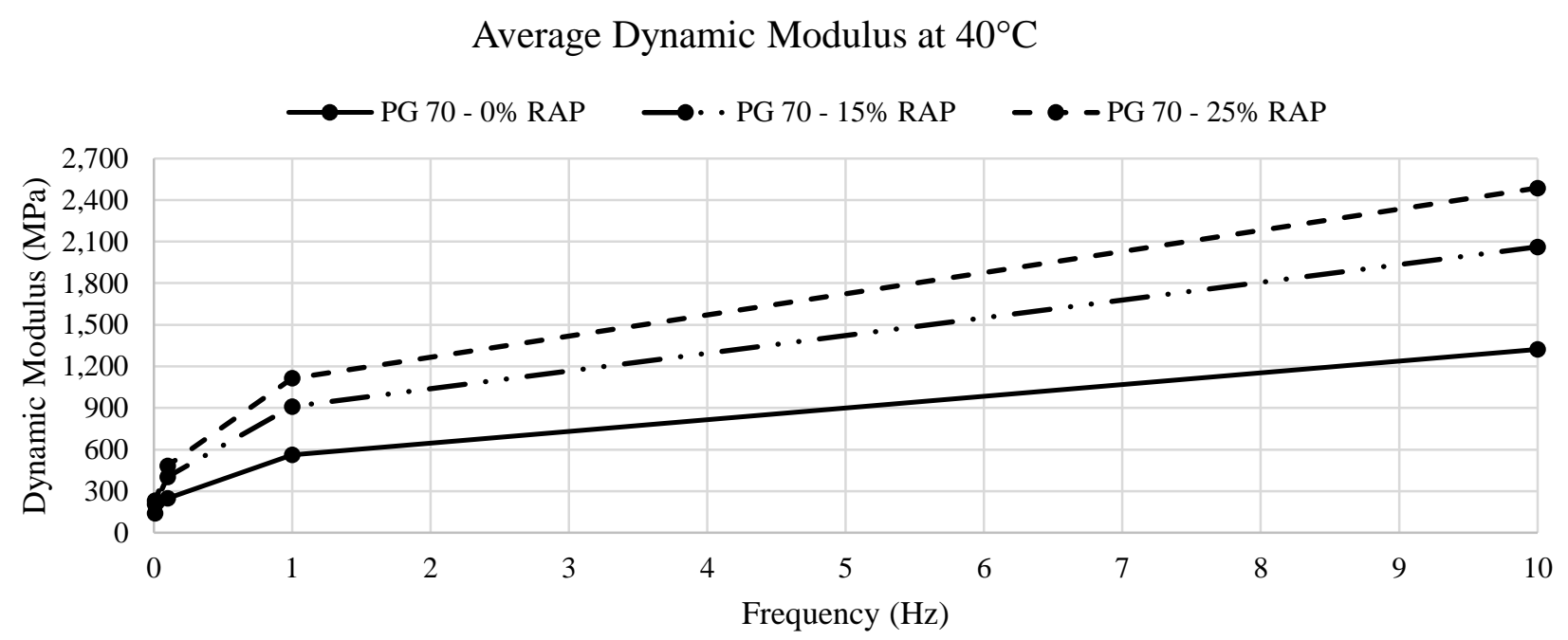

Figure 7 - Average Dynamic Modulus at $40^{\circ} \mathrm{C}$ of DM and FN Samples

\section{KENPAVE Analysis of Dynamic Modulus}

To analyze the dynamic modulus, the frequency was first determined using Equation 9.

$$
d=\frac{12 a}{s}
$$

Where:

$\boldsymbol{d}=$ duration $(\mathrm{sec})$

$\boldsymbol{a}=$ contact radius (in)

$\boldsymbol{s}=\operatorname{speed}(\mathrm{ft} / \mathrm{sec})$

For a 4500 load and $110 \mathrm{psi}$ tire pressure the contact radius is 3.61 in At $55 \mathrm{mph}$ the duration was calculated to be 0.54 seconds, yielding a frequency of $1.866 \mathrm{~Hz}$. Using the master curves, the dynamic moduli at $1.866 \mathrm{~Hz}$ and $20^{\circ}$ were determined and are presented in Table 14

Table 14 - KENPAVE Dynamic Modulus Values

\begin{tabular}{|c|c|c|c|}
\hline Binder Grade & \% RAP & Dynamic Modulus (psi) & Dynamic Modulus (MPa) \\
\hline \multirow{3}{*}{ PG 70-22 } & 0 & 550,000 & 3,792 \\
\cline { 2 - 4 } & 15 & 790,000 & 5,447 \\
\cline { 2 - 4 } & 25 & 800,000 & 5,516 \\
\hline
\end{tabular}


Using KENPAVE, fatigue and rutting modulus vs. strain graphs were created for a range of modulus for both a full-depth pavement and conventional pavement, Figure 8, and are shown in Figures 9 and 10.
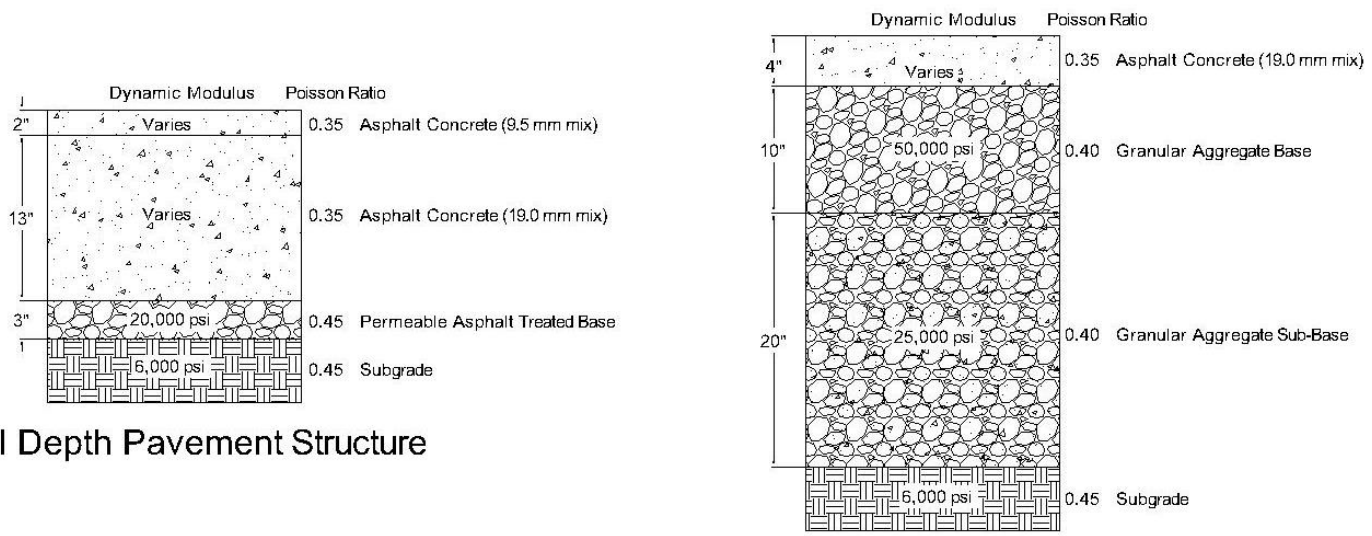

Conventional Pavement Structure

Figure 8 - Pavement Structure Cross Section

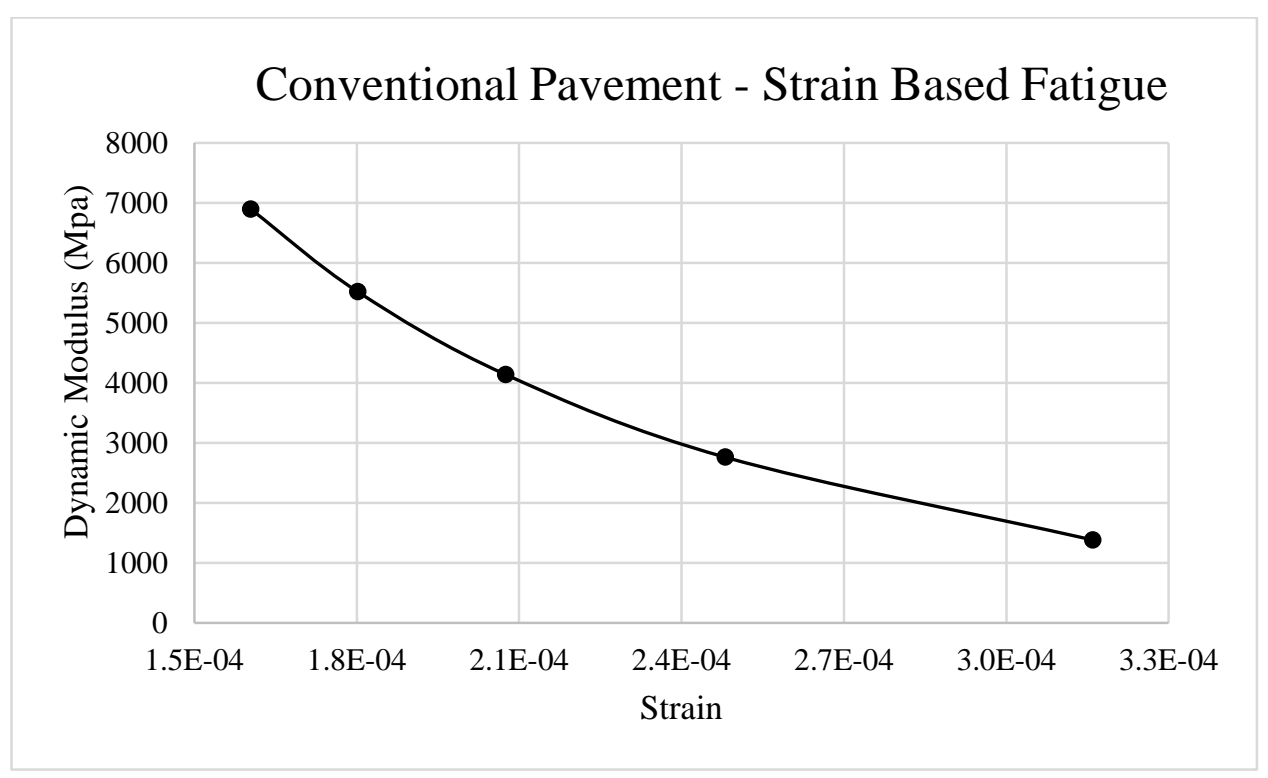

Figure 9 - Conventional Pavement - Strain Based Fatigue 


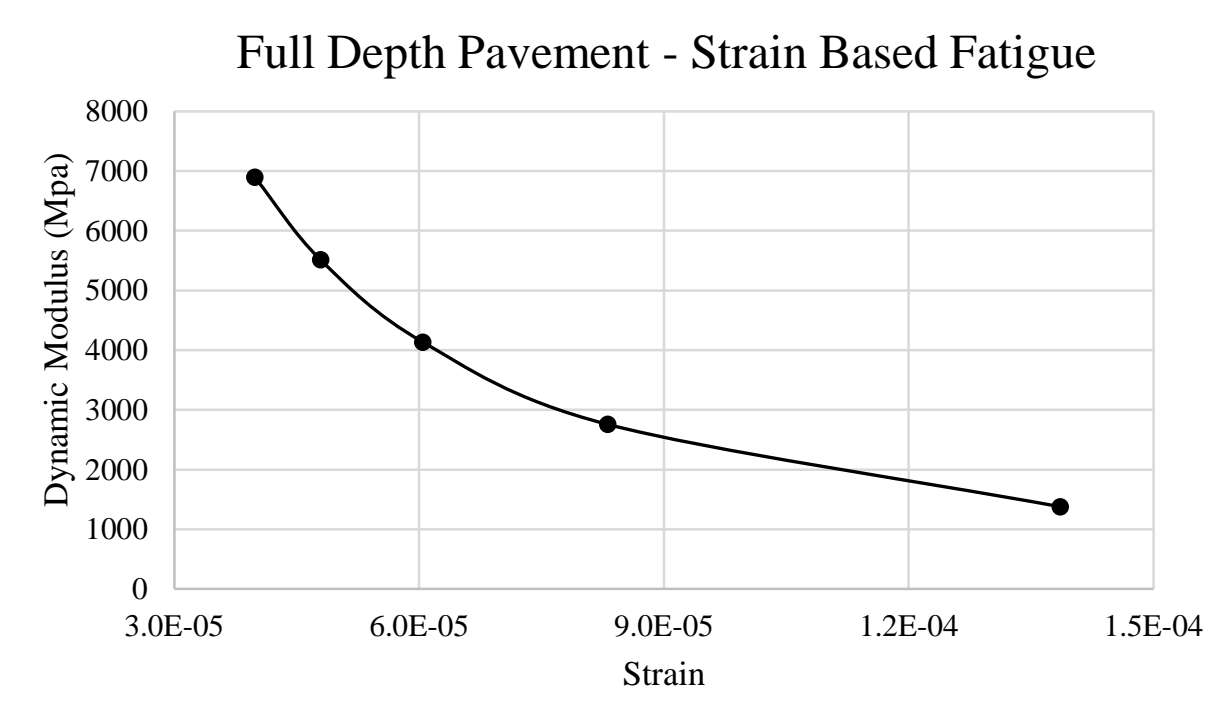

Figure 10 - Full Depth Pavement - Strain Based Fatigue

Using the strains corresponding to the various moduli, the $\mathrm{N}_{\mathrm{f}}$ values were calculated to compare the mix designs. The Asphalt Institutes values for $f_{1}, f_{2}$, and $f_{3}$ were used in Equation 3 to define Equation 10. The results of using this equation are presented in Table 15.

$$
N_{f}=0.0796\left(\frac{1}{\epsilon}\right)^{3.291}\left(\frac{1}{E}\right)^{0.854}
$$

where:

$\boldsymbol{N}_{\boldsymbol{f}}=$ number of passes until fatigue occurs

$\boldsymbol{\epsilon}=$ strain

$\boldsymbol{E}=\operatorname{modulus}(p s i)$

Table 15 - KENPAVE $N_{f}$ Values

\begin{tabular}{|c|c|c|c|c|c|c|}
\cline { 3 - 7 } \multicolumn{2}{c|}{} & \multicolumn{2}{c|}{ Full Depth } & \multicolumn{2}{c|}{ Conventional } \\
\hline \multirow{3}{*}{ Binder Grade } & \% RAP & Dynamic Modulus (psi) & $\boldsymbol{\varepsilon}$ & $\mathbf{N}_{\mathbf{f}}$ & $\boldsymbol{\varepsilon}$ & $\mathbf{N}_{\mathbf{f}}$ \\
\cline { 2 - 7 } & 0 & 550,000 & 0.00108 & $56,800,000$ & 0.00359 & $1,100,000$ \\
\cline { 2 - 7 } & 15 & 790,000 & 0.000796 & $115,500,000$ & 0.00298 & $1,500,000$ \\
\cline { 2 - 7 } & 25 & 800,000 & 0.000786 & $119,000,000$ & 0.00297 & $1,500,000$ \\
\hline
\end{tabular}


From Table 15, it can be seen that the full depth pavement has a higher predicted $\mathrm{N}_{\mathrm{f}}$ value in all mix types than the conventional pavement. It also can be seen that the two RAP containing mixtures had higher $\mathrm{N}_{\mathrm{f}}$ values than the virgin mixture. The strain values are $>70$ micro strains, which means that these pavements are not likely to be considered a perpetual design.

\section{Master Curve}

Using the MasterSolver workbook, the dynamic modulus master curves were generated for the three RAP contents. Note the data points on the graph are for the reduced frequency, not the test frequency.

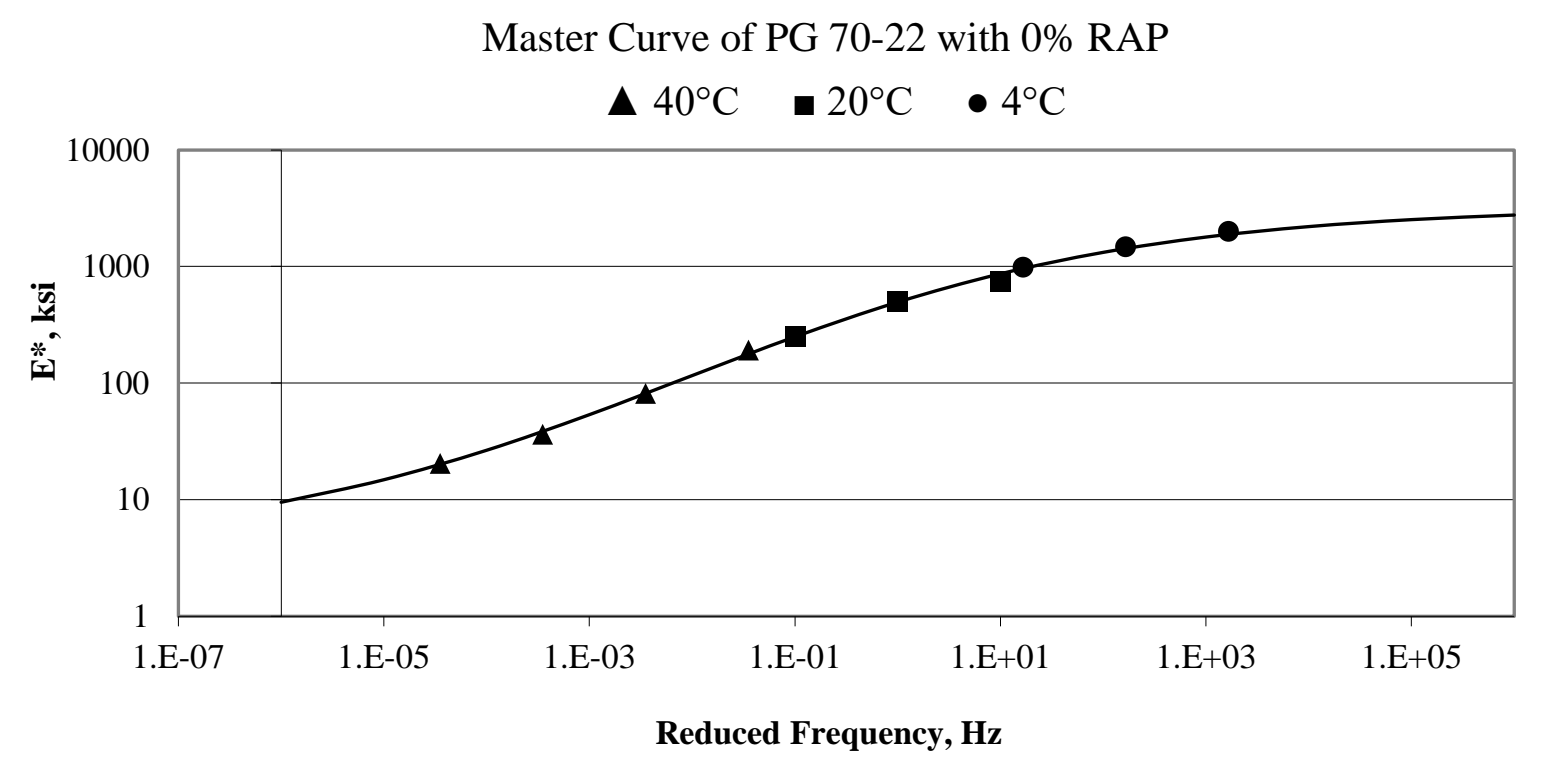

Figure 11 - Dynamic Modulus Master Curve for PG 70 -22 with 0\% RAP 


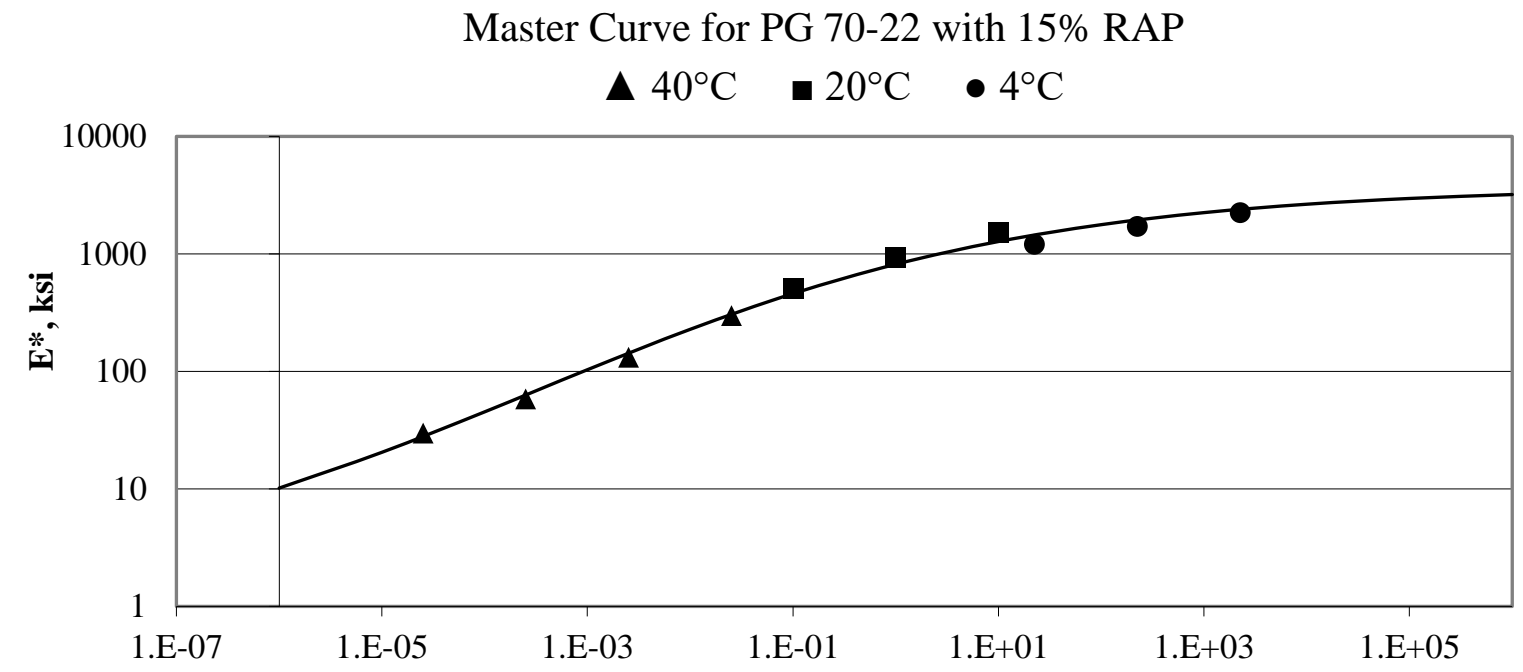

Reduced Frequency, $\mathrm{Hz}$

Figure 12 - Dynamic Modulus Master Curve for PG 70-22 with 15\% RAP

Master Curve for PG 70-22 with 25\% RAP
$\Delta 40^{\circ} \mathrm{C}-20^{\circ} \mathrm{C} \bullet 4^{\circ} \mathrm{C}$

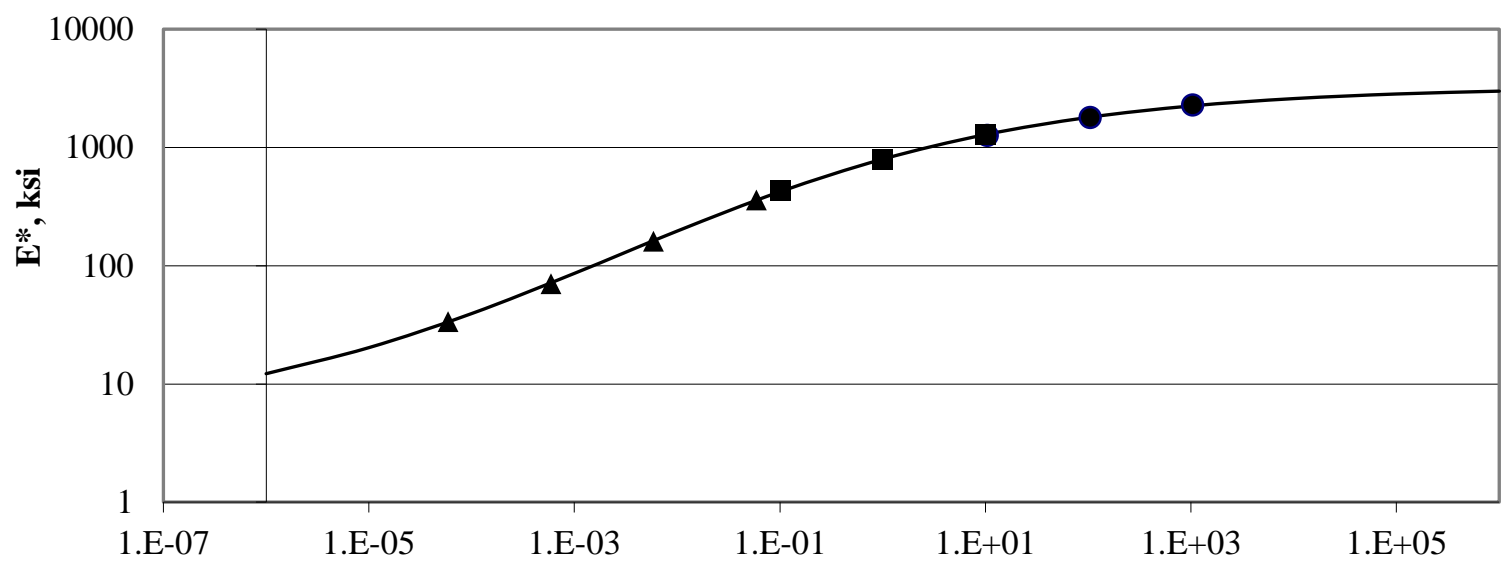

Reduced Frequency, $\mathrm{Hz}$

Figure 13 - Dynamic Modulus Master Curve for PG 70-22 with 25\% RAP 


\section{Flow number}

All samples used for flow number testing met the standards set in PP 60-14 and were at an air void content of $7.0 \pm 0.5 \%$. Data from the flow number test is presented in Appendix B and summarized in Table 16.

Table 16 - Flow Number Values

\begin{tabular}{|c|c|c|c|}
\hline Binder Grade & \% RAP & Replicate & Flow Number \\
\hline \multirow{4}{*}{ PG 70-22 } & \multirow{2}{*}{0} & 1 & 178 \\
\cline { 3 - 4 } & \multirow{2}{*}{15} & 2 & 167 \\
\cline { 3 - 4 } & \multirow{2}{*}{25} & 2 & 342 \\
\cline { 2 - 4 } & & 2 & 555 \\
\cline { 2 - 4 } & & 2 & 591 \\
\hline
\end{tabular}

From Table 16, it can be seen that as RAP content increased, flow number increased. This can be related to the contributed binder of the RAP acting as a stiffer binder and less susceptible to rutting than a softer binder.

\section{DM and FT Sample Analysis}

\section{Dynamic Modulus}

All samples used for dynamic modulus testing met the standards set in PP 60-14 and were at an air void content of $7.0 \pm 0.5 \%$. Data from the dynamic modulus test is presented in Appendix B and summarized in Table 17. 
Table 17 - Dynamic Modulus (MPa) of DM and FT Samples

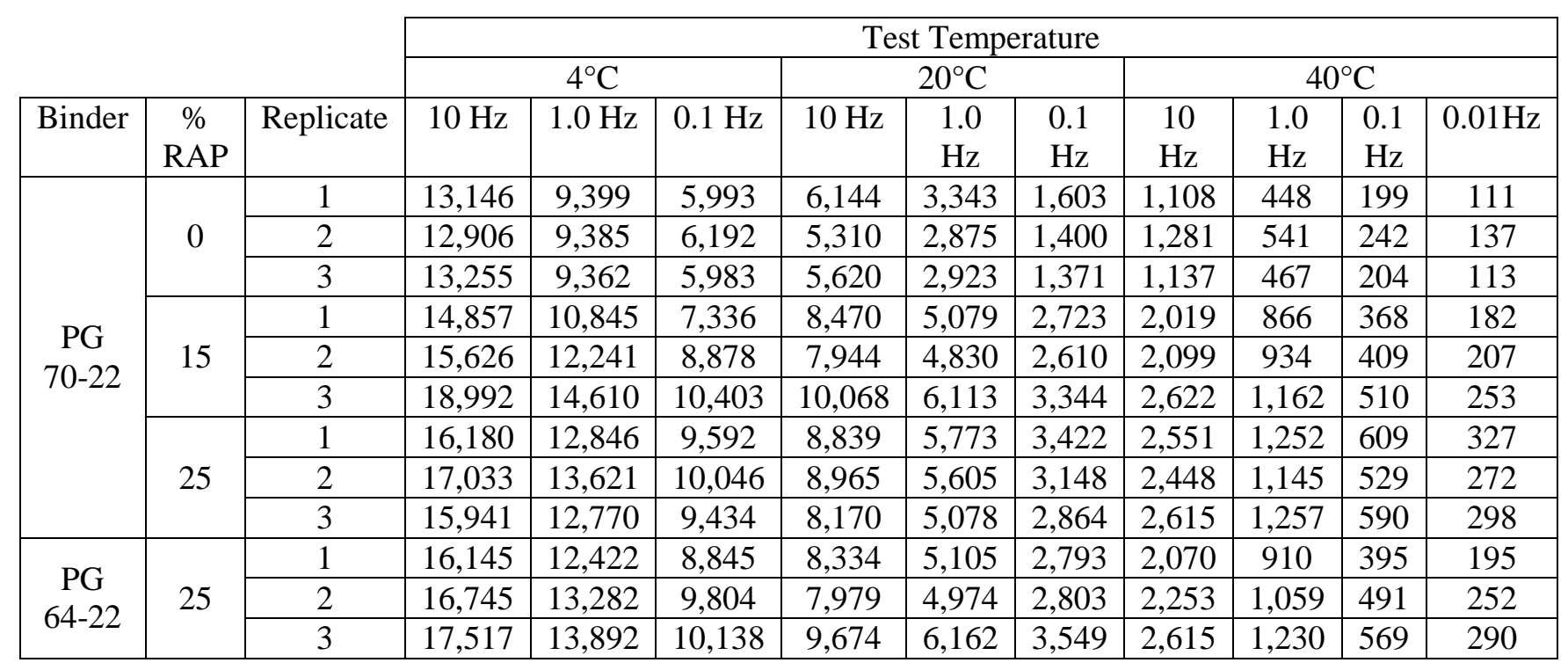

The average dynamic modulus for each combination of mix type, loading frequency, and temperature was calculated and is presented in Figures 14, 15 and 16.

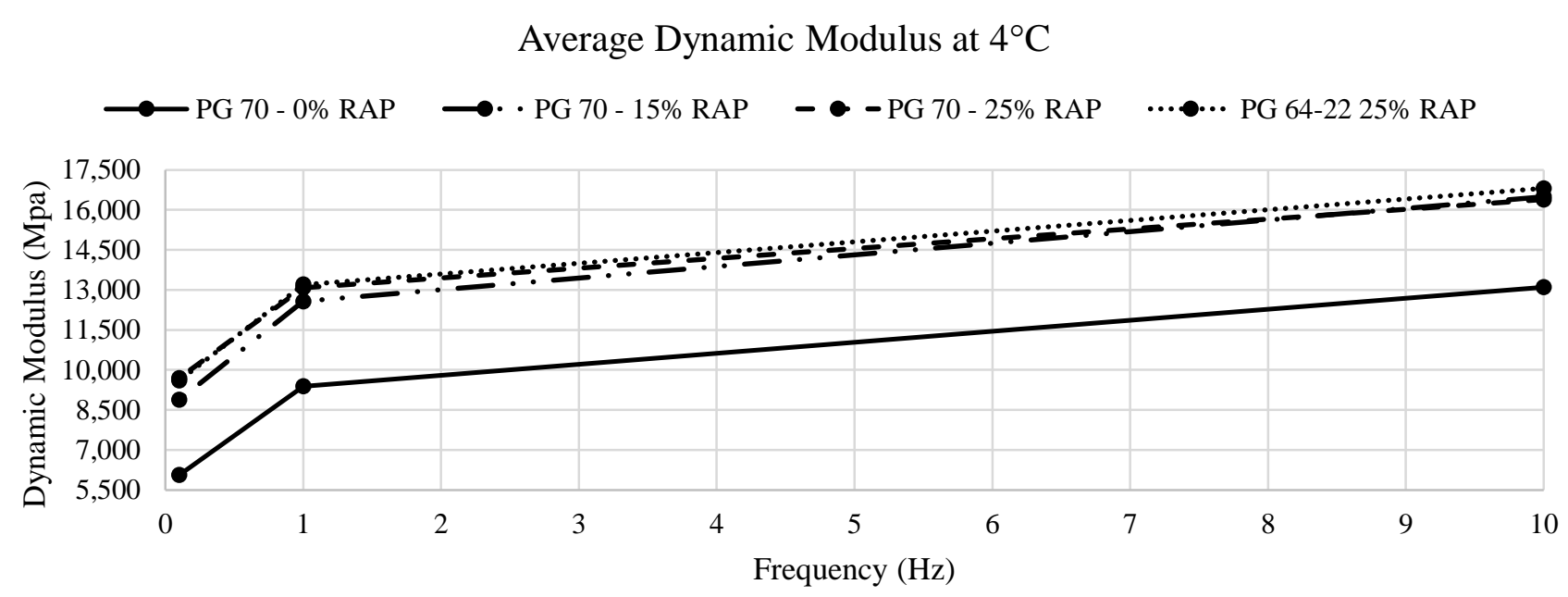

Figure 14 - Average Dynamic Modulus Values at $4{ }^{\circ} \mathrm{C}$ 
Average Dynamic Modulus at 20C

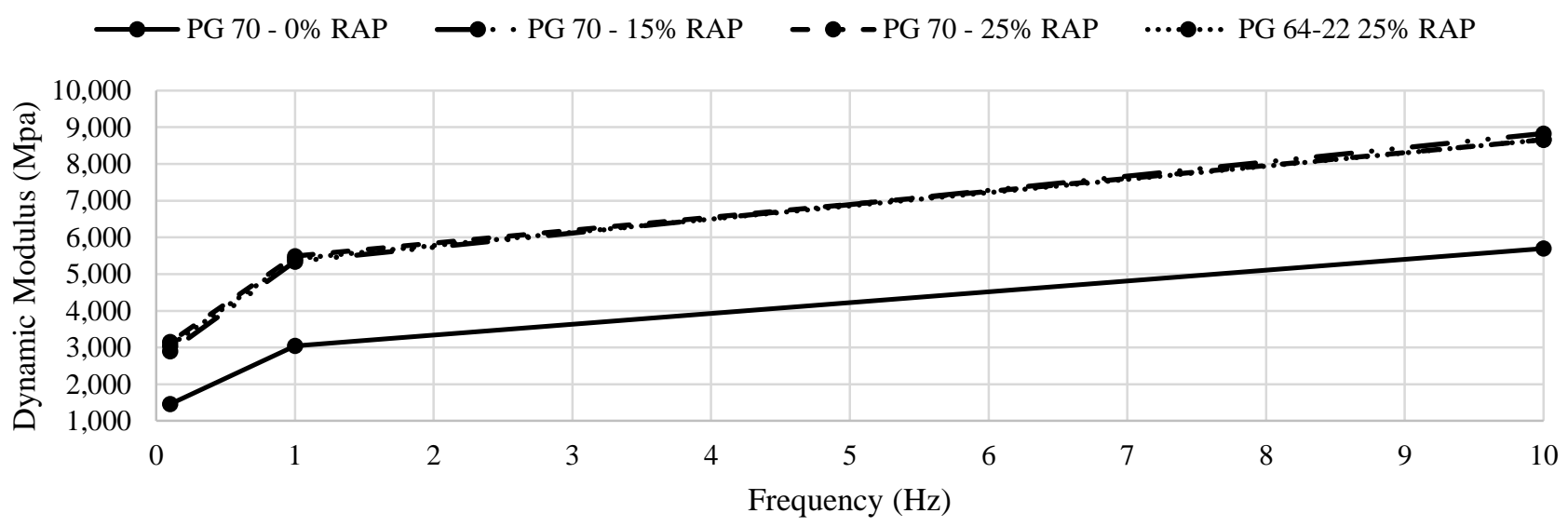

Figure 15 - Average Dynamic Modulus Values at $20^{\circ} \mathrm{C}$

Average Dynamic Modulus at 40C

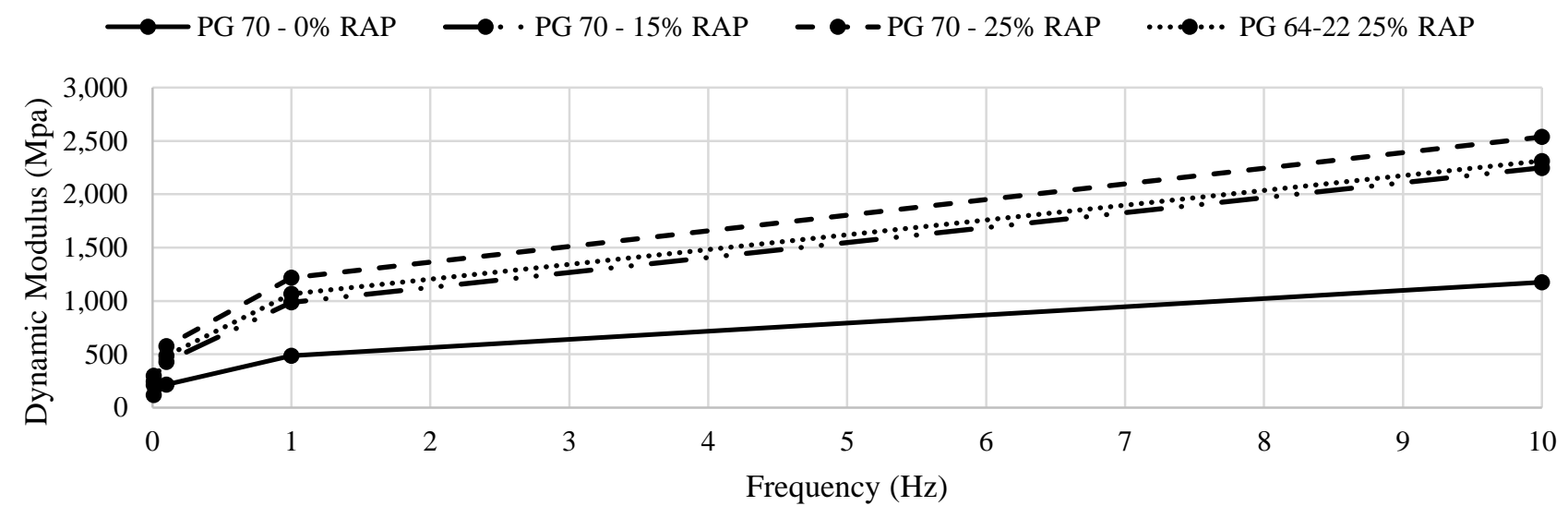

Figure 16 - Average Dynamic Modulus Values at $40^{\circ} \mathrm{C}$ 


\section{Master Curve}

Using the MasterSolver workbook, the following dynamic modulus master curves were generated.

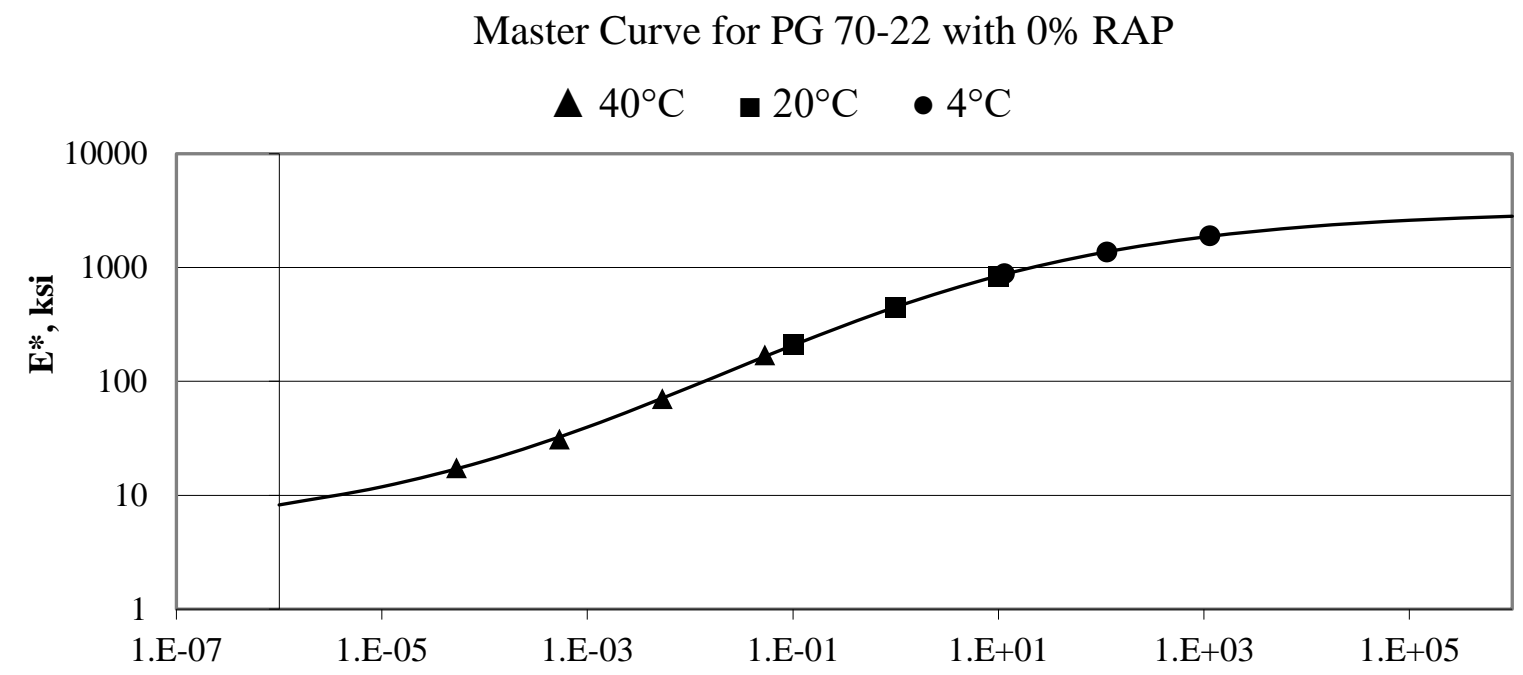

Reduced Frequency, $\mathrm{Hz}$

Figure 17 - Dynamic Modulus Master Curve for PG 70-22 with 0\% RAP

Master Curve for PG 70-22 with 15\% RAP

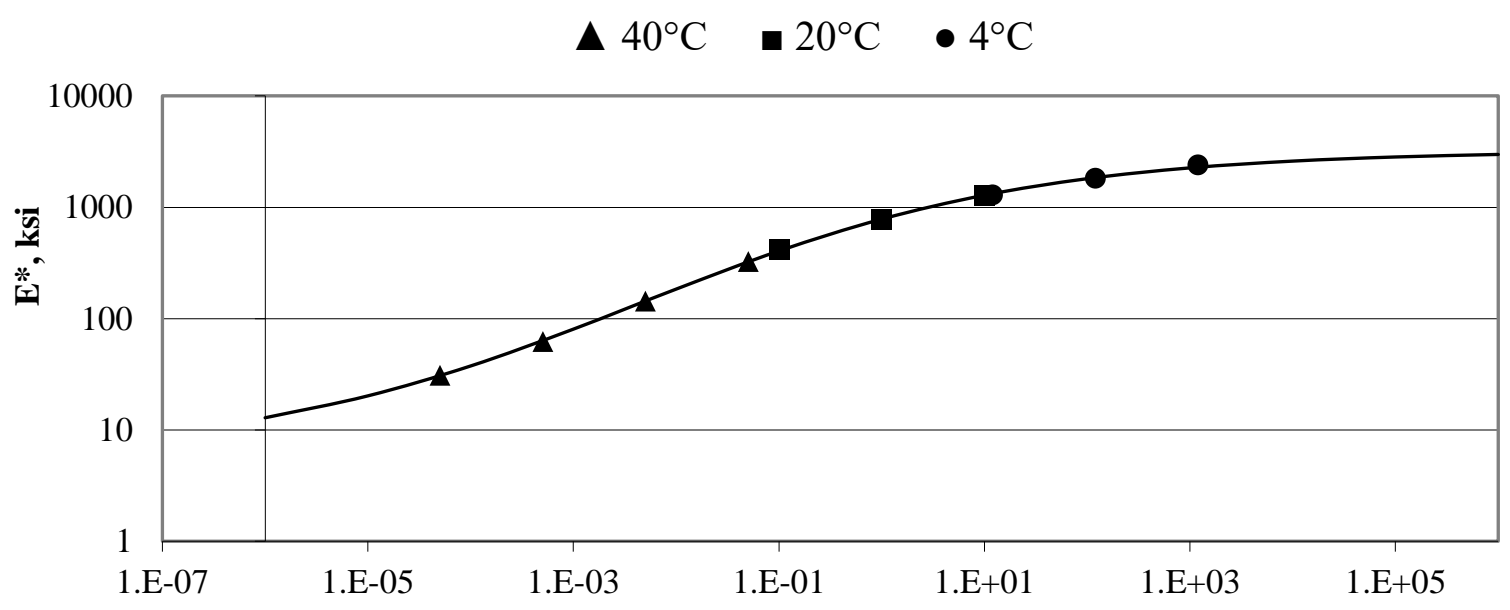

Reduced Frequency, $\mathrm{Hz}$

Figure 18 - Dynamic Modulus Master Curve for PG 70-22 with 15\% RAP 


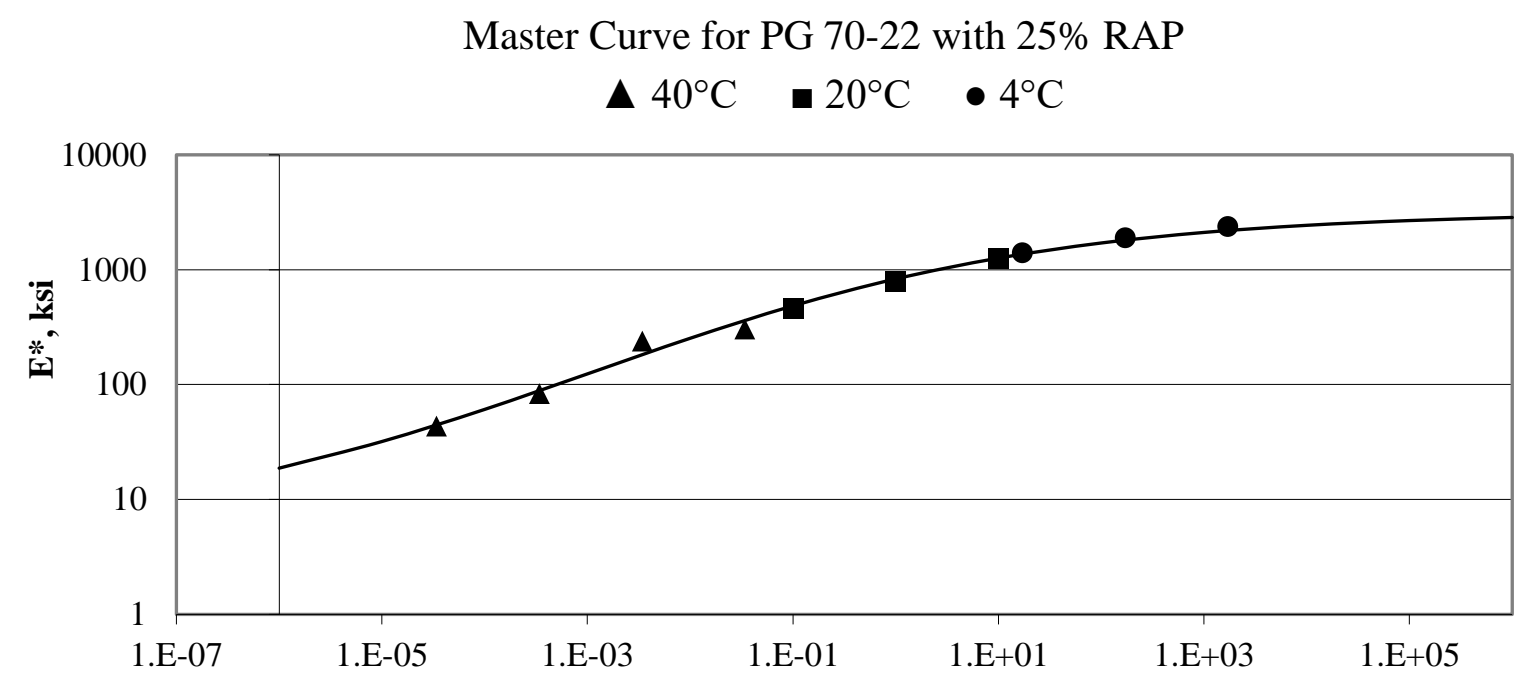

Reduced Frequency, $\mathrm{Hz}$

Figure 19 - Dynamic Modulus Master Curve for PG 70-22 with 25\% RAP

Master Curve for PG 64-22 with 25\% RAP

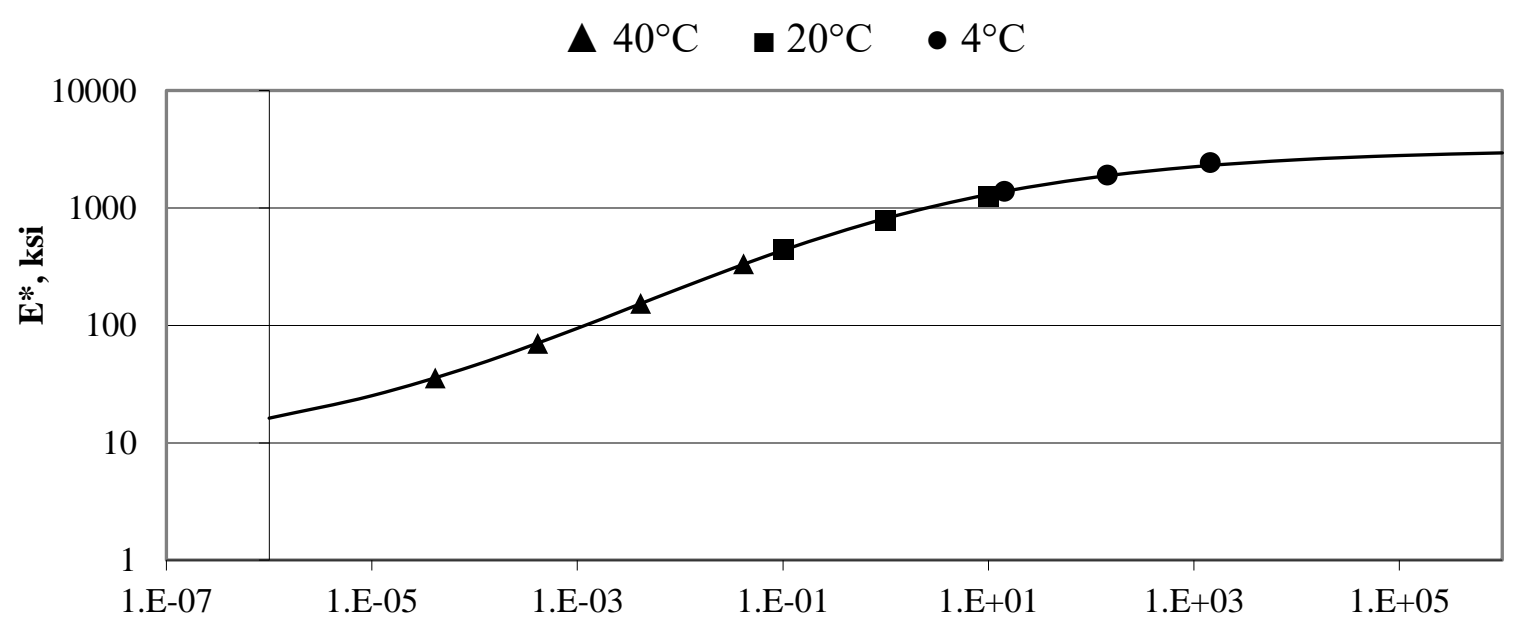

Reduced Frequency, $\mathrm{Hz}$

Figure 20 - Dynamic Modulus Master Curve for PG 64-22 with 25\% RAP

\section{S-VECD Fatigue}

The Dynamic Modulus Fingerprint Test is a required preliminary test prior to running the S-

VECD Fatigue Test. Due to mechanical complications, not all results were usable for analysis; tests that 
encountered errors were omitted from this chapter. The errorless results from this test are summarized in Table 18, while all fatigue test data is presented in Appendix B.

Table 18 - Fingerprint Dynamic Modulus and Fatigue Test Data

\begin{tabular}{|c|c|c|c|c|c|c|}
\hline Binder & \% RAP & Replicate & Micro strain & Initial E* (MPa) & Final E* (MPa) $^{*}$ & $\mathbf{N}_{\mathbf{f}}$ \\
\hline \multirow{17}{*}{ PG 70-22 } & \multirow{6}{*}{0} & $1 \mathrm{a}$ & 150 & 8,368 & 8,270 & $>100,000$ \\
\hline & & $1 \mathrm{c}$ & 250 & 1,0131 & 10,042 & 11,620 \\
\hline & & $2 b$ & 175 & 8,414 & 8,310 & $>100,000$ \\
\hline & & $2 c$ & 200 & 8,647 & 8,541 & $>100,000$ \\
\hline & & $3 a$ & 150 & 9,216 & 9,082 & $>100,000$ \\
\hline & & $3 b$ & 300 & 8,647 & 8,535 & 15,070 \\
\hline & \multirow{6}{*}{15} & $1 \mathrm{a}$ & 150 & 11,119 & 10,990 & $>100,000$ \\
\hline & & $1 \mathrm{~b}$ & 300 & 12,485 & 12,363 & 1,720 \\
\hline & & $1 \mathrm{c}$ & 250 & 11,695 & 11,569 & 21,430 \\
\hline & & $2 a$ & 150 & 10,560 & 10,460 & $>100,000$ \\
\hline & & $3 a$ & 150 & 11,776 & 11,648 & $>100,000$ \\
\hline & & $3 \mathrm{c}$ & 250 & 10,478 & 10,421 & 52,490 \\
\hline & \multirow{5}{*}{25} & $1 \mathrm{a}$ & 150 & 11,491 & 11,402 & $>100,000$ \\
\hline & & $2 a$ & 150 & 11,328 & 11,194 & $>100,000$ \\
\hline & & $2 b$ & 300 & 11,304 & 11,164 & 2,750 \\
\hline & & $3 a$ & 150 & 11,529 & 11,468 & $>100,000$ \\
\hline & & $3 b$ & 300 & 11,192 & 11,082 & 1,810 \\
\hline \multirow{6}{*}{ PG 64-22 } & \multirow{6}{*}{25} & $1 \mathrm{a}$ & 150 & 11,141 & 11,019 & $>100,000$ \\
\hline & & $1 b$ & 300 & 10,214 & 10,124 & 16,590 \\
\hline & & $1 \mathrm{c}$ & 250 & 9,974 & 9,894 & 11,060 \\
\hline & & $2 a$ & 150 & 11,251 & 11,117 & $>100,000$ \\
\hline & & $3 a$ & 150 & 11,263 & 11,156 & $>100,000$ \\
\hline & & $3 c$ & 250 & 11,507 & 11,406 & 3,190 \\
\hline
\end{tabular}

\section{ALPHA-Fatigue}

The ALPHA-F software produces a model report for a set of samples. For this analysis, each mix type makes up an entire set. Since the "Identify Failure Cycle" screen did not always show the sudden drop in phase angle, it was assumed that the failure cycle was at the highest point on the graph, as shown in Figures 21 and 22. 


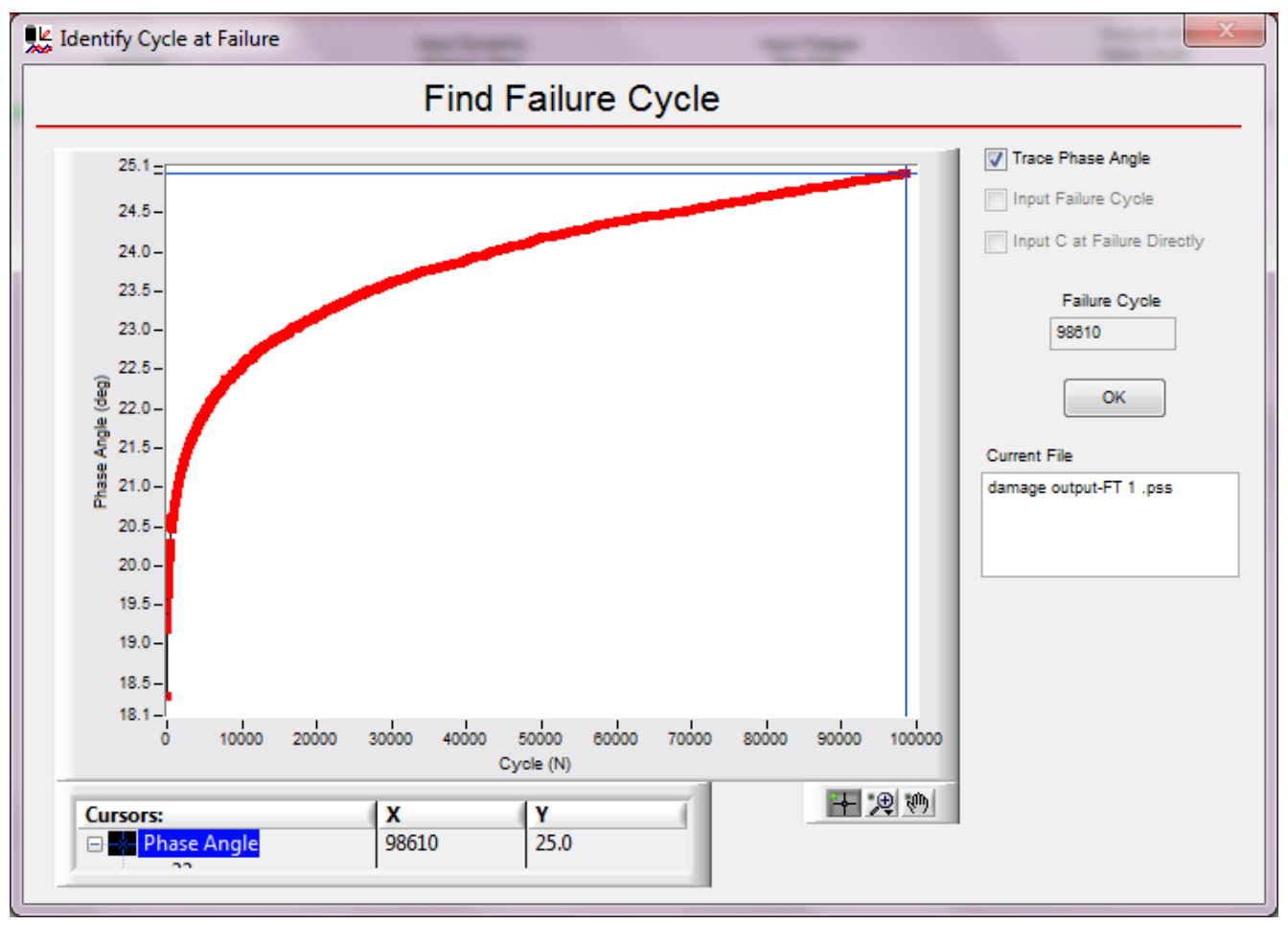

Figure 21 - ALPHA-F Phase Angle and Failure Cycle Dialogue Box

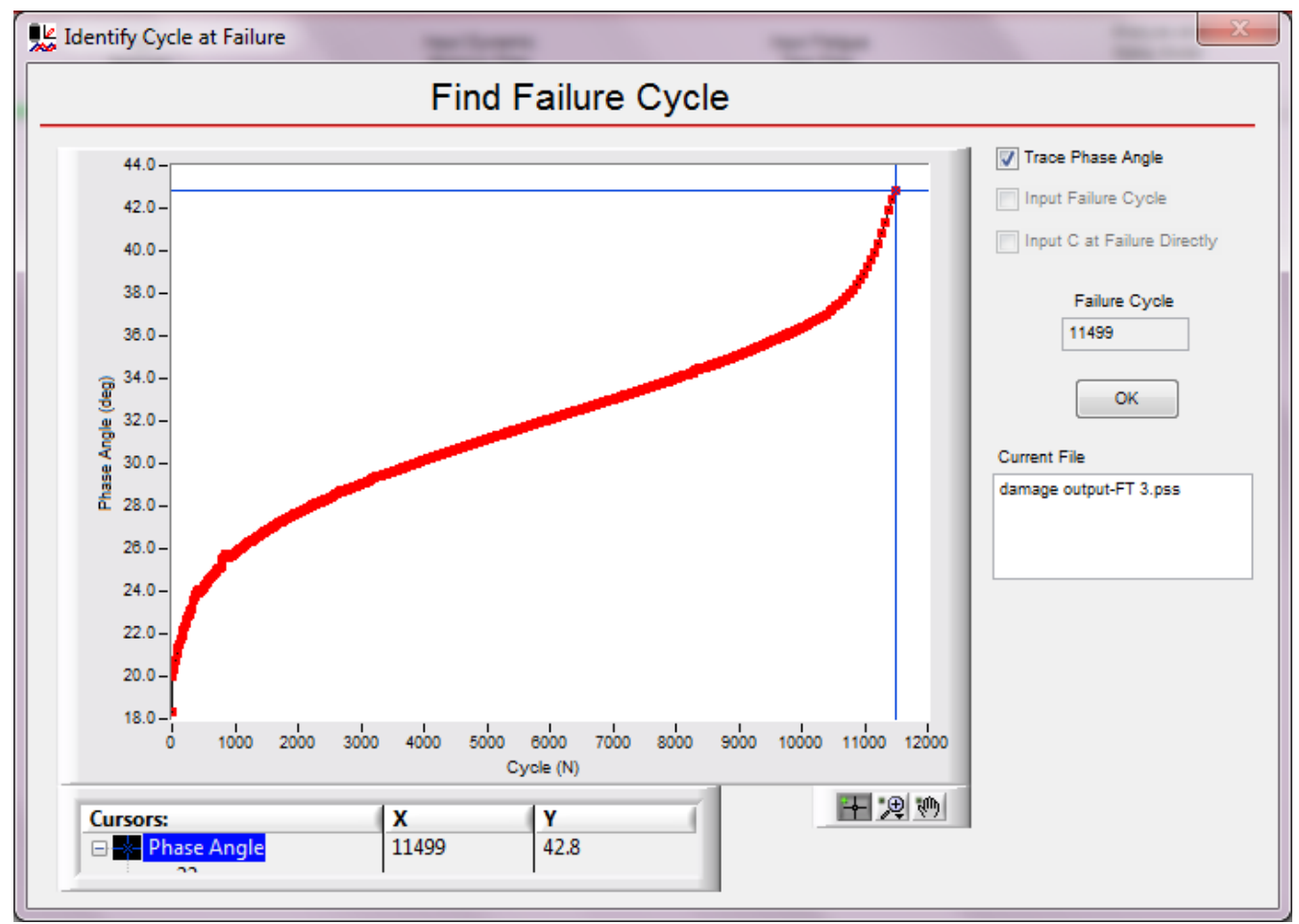

Figure 22 - ALPHA-F Phase Angle and Failure Cycle Dialogue Box 
The damage model coefficients, shift factor coefficients, master curve function coefficients, and K-values from Equations 3 - 6 in Chapter 2, are summarized in Tables 19, 20, and 21. To visually compare the damage coefficient and k-values across RAP levels, they are presented in Figures $23-27$, respectively.

Table 19 - Damage Model Coefficients

\begin{tabular}{|c|c|c|c|c|c|c|}
\hline Binder Grade & \% RAP & a & b & $\boldsymbol{\alpha}$ & $\mathbf{r}$ & S \\
\hline \multirow{3}{*}{ PG 70-22 } & 0 & $-4.83 \mathrm{E}-05$ & $8.78 \mathrm{E}-01$ & 3.716 & $1.09 \mathrm{E}+05$ & $-4.67 \mathrm{E}-01$ \\
\cline { 2 - 7 } & 15 & $-2.15 \mathrm{E}-05$ & $9.19 \mathrm{E}-01$ & 3.789 & $1.35 \mathrm{E}+05$ & $-5.41 \mathrm{E}-01$ \\
\cline { 2 - 7 } & 25 & $-1.96 \mathrm{E}-05$ & $9.21 \mathrm{E}-01$ & 4.084 & $1.26 \mathrm{E}+05$ & $-5.43 \mathrm{E}-01$ \\
\hline PG 64-22 & 25 & $-3.27 \mathrm{E}-05$ & $8.74 \mathrm{E}-01$ & 3.93 & $1.52 \mathrm{E}+05$ & $-5.22 \mathrm{E}-01$ \\
\hline
\end{tabular}

$\%$ RAP vs. Damage Coefficient "a"

$\longrightarrow$ PG 70-22 0\% RAP - PG 70-22 15\% RAP $\longrightarrow$ PG 70-22 25\% RAP $\longrightarrow$ PG 64-22 25\% RAP $\%$ RAP

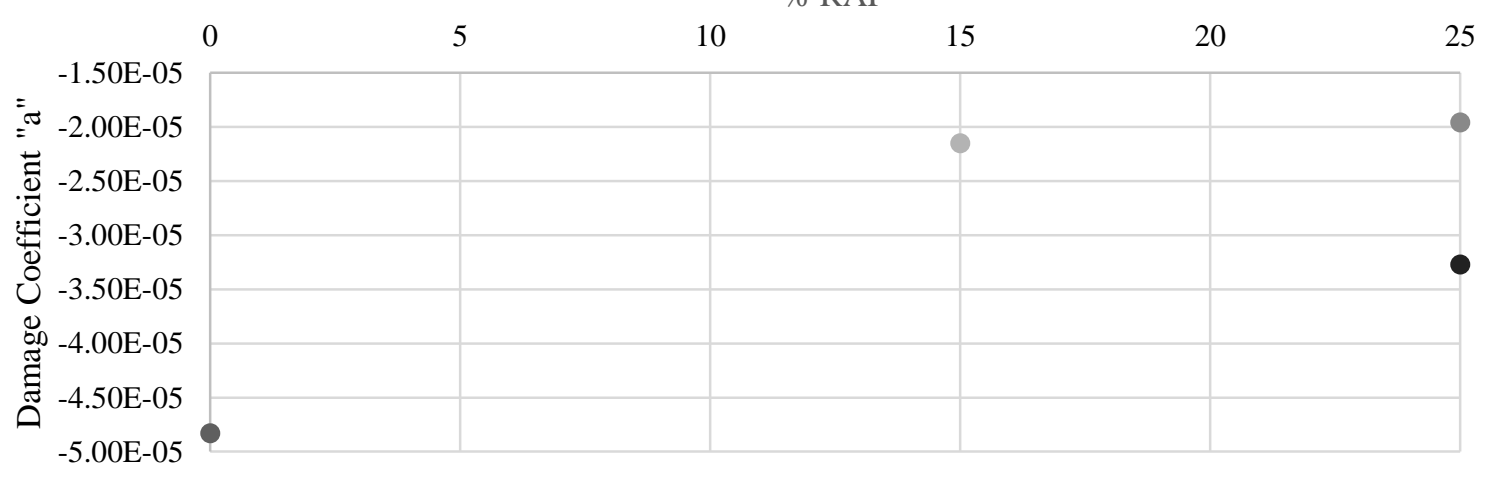

Figure 23 - \% RAP vs. Damage Coefficient " $a "$ 
\% RAP vs. Damage Coefficient "b"

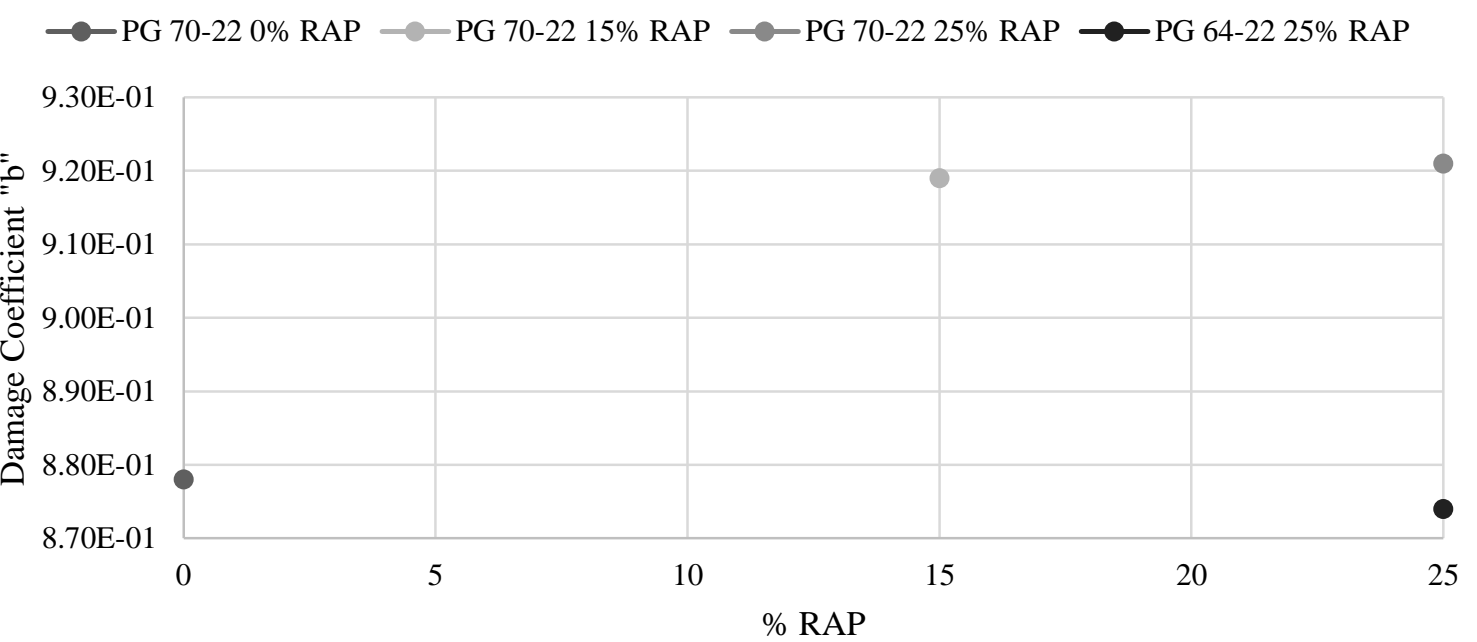

Figure 24 - \% RAP vs. Damage Coefficient "b"

$\%$ RAP vs. Damage Coefficient " $\alpha$ "

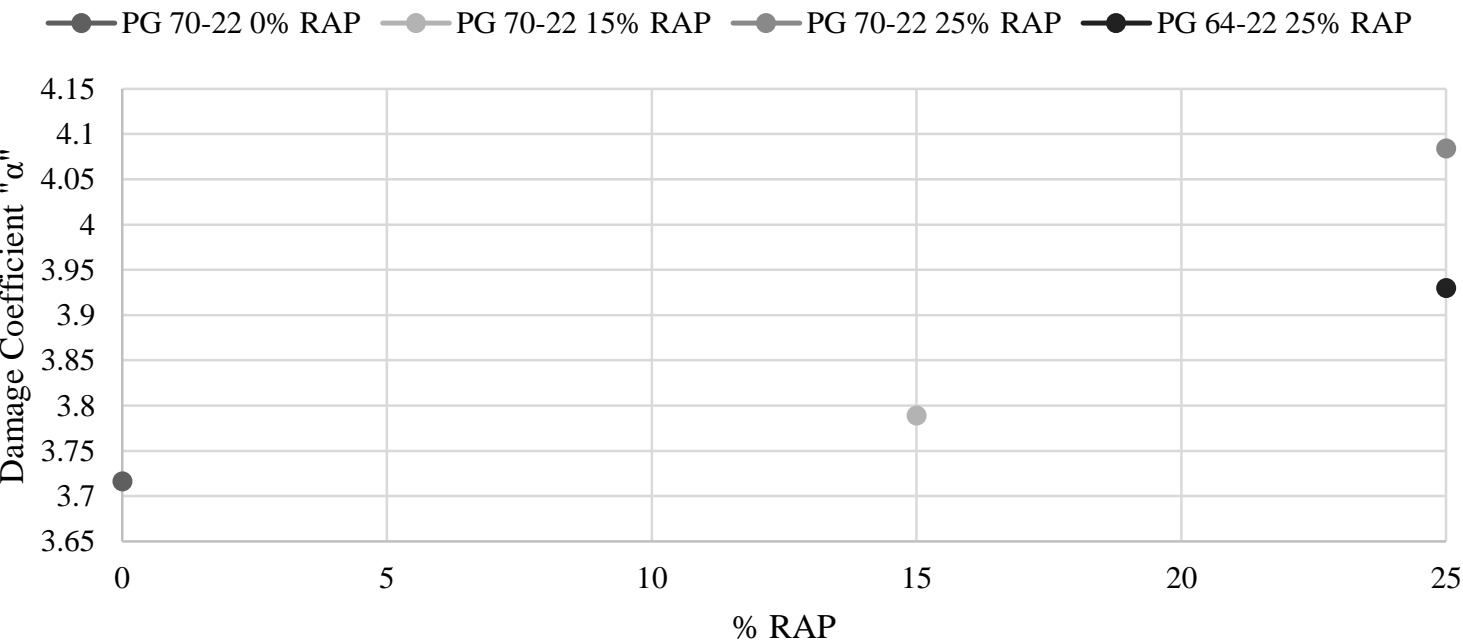

Figure 25 - \% RAP vs. Damage Coefficient " $\alpha$ " 
\% RAP vs. Damage Parameter "r"

$\longrightarrow$ PG 70-22 0\% RAP - PG 70-22 15\% RAP $\longrightarrow$ PG 70-22 25\% RAP $\longrightarrow$ PG 64-22 25\% RAP

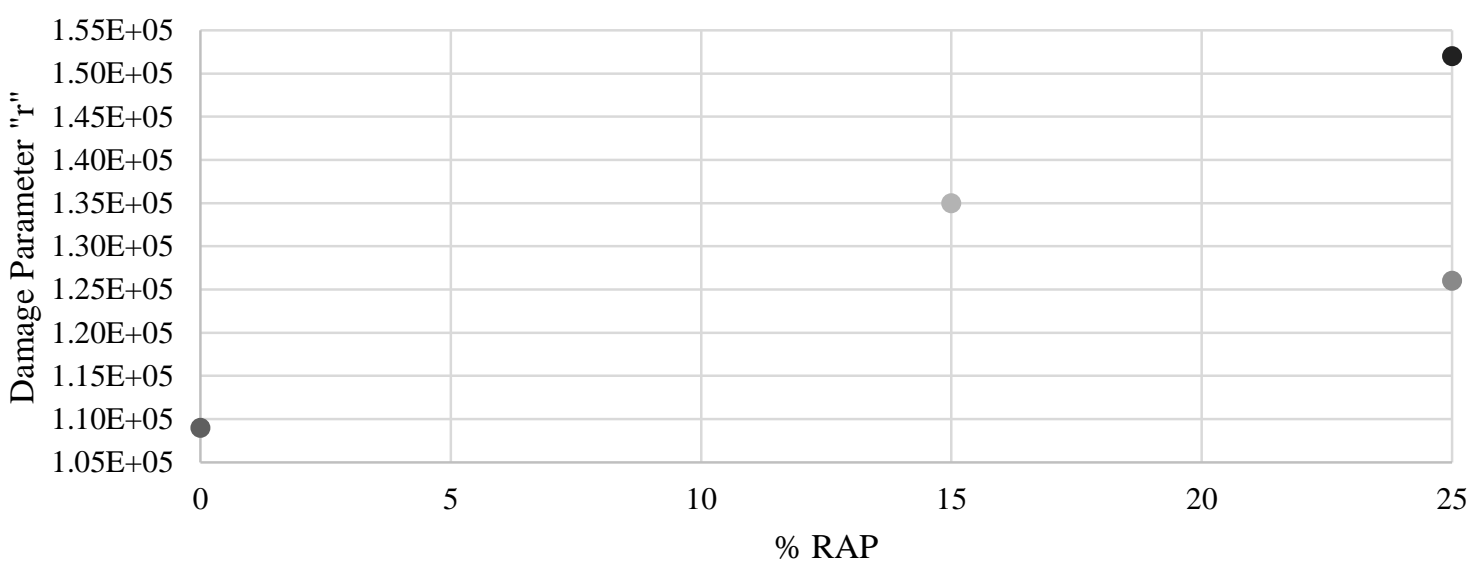

Figure 26 - \% RAP vs. Damage Parameter " $r$ "

$\%$ RAP vs. Damage Parameter "s"

$\longrightarrow$ PG 70-22 0\% RAP $-\mathrm{PG} 70-22$ 15\% RAP $-\mathrm{PG} 70-22$ 25\% RAP $\longrightarrow$ PG 64-22 25\% RAP

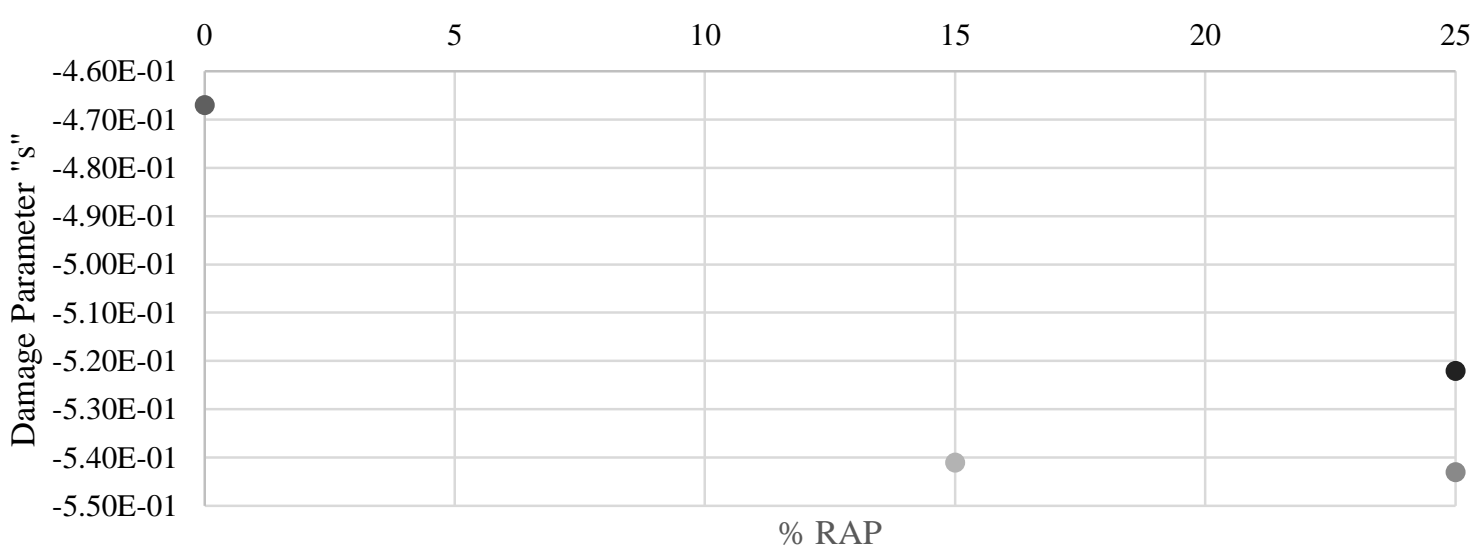

Figure 27 - \%RAP vs. Damage Parameter "s" 
Table 20 - Shift Factor Coefficients and Mastercurve Function Coefficients

\begin{tabular}{|c|c|c|c|c|c|c|c|}
\cline { 3 - 8 } \multicolumn{2}{c|}{} & \multicolumn{2}{c|}{ Shift Factor Coefficients } & \multicolumn{4}{c|}{ Mastercurve Function } \\
\hline Binder Grade & \% RAP & $\mathbf{T}_{\mathbf{r}}$ & $\mathbf{E}_{\mathbf{a}}$ & $\log ($ Min) & $\beta$ & $\log ($ Max) $-\log ($ Min $)$ & $\gamma$ \\
\hline \multirow{3}{*}{ PG 70-22 } & 0 & 21.1 & 199.84 & 1.48 & 2.86 & $-3.82 \mathrm{E}-01$ & $-5.16 \mathrm{E}-01$ \\
\cline { 2 - 8 } & 15 & 21.1 & 202.02 & 1.59 & 2.75 & $-7.58 \mathrm{E}-01$ & $-5.26 \mathrm{E}-01$ \\
\cline { 2 - 8 } & 25 & 21.1 & 205.68 & 1.79 & 2.55 & $-7.35 \mathrm{E}-01$ & $-5.10 \mathrm{E}-01$ \\
\hline PG 64-22 & 25 & 21.1 & 209.66 & 1.70 & 2.65 & $-7.58 \mathrm{E}-01$ & $-5.19 \mathrm{E}-01$ \\
\hline
\end{tabular}

Table 21 - Traditional Strain Fatigue Relationship Coefficients

\begin{tabular}{|c|c|c|c|c|c|c|c|}
\hline Binder Grade & \% RAP & $\mathbf{K}_{\mathbf{1}}$ (kpa) & $\mathbf{K}_{\mathbf{2}}(\mathbf{k p a})$ & $\mathbf{K}_{\mathbf{3}}(\mathbf{k p a})$ & $\mathbf{K}_{\mathbf{1}}$ (psi) & $\mathbf{K}_{\mathbf{2}}$ (psi) & $\mathbf{K}_{\mathbf{3}}$ (psi) \\
\hline \multirow{3}{*}{ PG 70-22 } & 0 & $2.58 \mathrm{E}+08$ & 2.434 & -1.894 & $6.65 \mathrm{E}+06$ & 2.434 & -1.894 \\
\cline { 2 - 8 } & 15 & $1.29 \mathrm{E}+07$ & 3.146 & -2.095 & $2.26 \mathrm{E}+05$ & 3.146 & -2.096 \\
\cline { 2 - 8 } & 25 & $9.42 \mathrm{E}+06$ & 3.213 & -2.124 & $1.56 \mathrm{E}+05$ & 3.213 & -2.124 \\
\hline PG 64-22 & 25 & $1.96 \mathrm{E}+07$ & 2.915 & -1.975 & $4.32 \mathrm{E}+05$ & 2.915 & -1.975 \\
\hline \multicolumn{2}{|c|}{ Asphalt Institute } & N/A & N/A & N/A & 0.0796 & 3.291 & -0.854 \\
\hline
\end{tabular}

The fatigue coefficients measured for the samples in this research are considerably different than the values used by the Asphalt Institute ${ }^{16}$. In order to verify that the fatigue equations behaved like the equations used in Figure 4, they were plotted in Figure 28 using consistent dynamic modulus and strain levels with the AI equation using units of psi.

\section{Visual Analysis of Fatigue Equations}

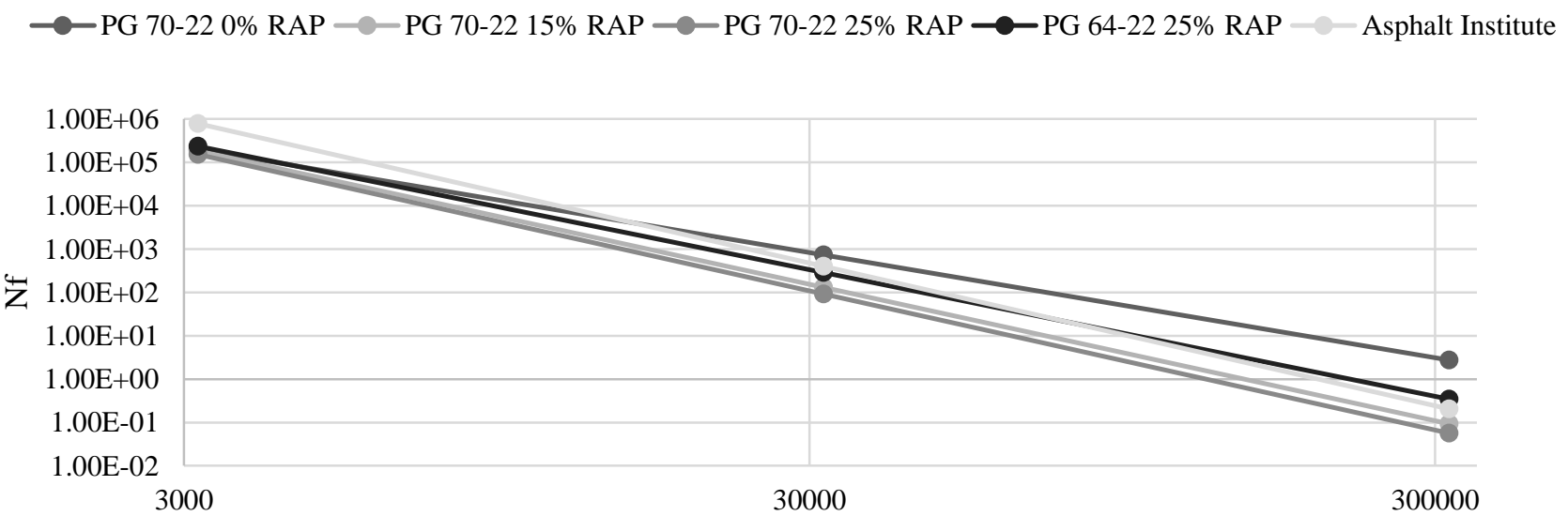

Micro strain

Figure 28 - Visual Analysis of Fatigue Equations 
The endurance limits reported by ALPHA-F are presented in Table 22. As RAP content increased, so did the endurance limit, for all reported temperatures. However, the softer binder grade performed worse than the stiffer binder grade with $0 \%$ RAP.

Table 22 - Endurance Limits

\begin{tabular}{|c|c|c|c|c|c|c|}
\hline \multirow{2}{*}{ Binder Grade } & \multirow{2}{*}{ \% Rap } & \multicolumn{6}{|c|}{ Endurance Limit (micro strain) } \\
\cline { 2 - 7 } & & $\mathbf{5}^{\circ} \mathbf{C}$ & $\mathbf{1 0}^{\circ} \mathbf{C}$ & $\mathbf{1 5}^{\circ} \mathbf{C}$ & $\mathbf{2 0}^{\circ} \mathbf{C}$ & $\mathbf{2 5}^{\circ} \mathbf{C}$ \\
\hline \multirow{3}{*}{ PG 70-22 } & 0 & 8 & 8 & 9 & 9 & 12 \\
\cline { 2 - 7 } & 15 & 11 & 11 & 12 & 13 & 16 \\
\cline { 2 - 7 } & 25 & 15 & 15 & 15 & 16 & 19 \\
\hline PG 64-22 & 25 & 6 & 5 & 5 & 5 & 6 \\
\hline
\end{tabular}

\section{Kenpave Analysis of Dynamic Modulus}

The DM and FT samples were analyzed using Kenpave in the same manner as the DM and FN samples, with the exception of using the k-values produced by ALPHA-F and the respective dynamic modulus and strain values. The results of this analysis are shown in Table 23.

Table 23 - Kenpave Analysis of DM and FT Samples

\begin{tabular}{|c|c|c|c|c|c|c|}
\cline { 3 - 7 } \multicolumn{4}{c|}{} & \multicolumn{2}{c|}{ Full Depth } & \multicolumn{2}{c|}{ Conventional } \\
\hline Binder Grade & \% RAP & Modulus (kpa) & $\boldsymbol{\varepsilon}$ & $\mathbf{N}_{\mathbf{f}}$ & $\boldsymbol{\varepsilon}$ & $\mathbf{N}_{\mathbf{f}}$ \\
\hline \multirow{3}{*}{ PG 70-22 } & 0 & $2,241,000$ & $1.05 \mathrm{E}-04$ & $1,170,000$ & $2.73 \mathrm{E}-04$ & 114,000 \\
\cline { 2 - 7 } & 15 & $6,378,000$ & $4.25 \mathrm{E}-05$ & $4,054,000$ & $1.69 \mathrm{E}-04$ & 53,000 \\
\cline { 2 - 7 } & 25 & $6,619,000$ & $4.10 \mathrm{E}-05$ & $3,827,000$ & $1.64 \mathrm{E}-04$ & 45,000 \\
\hline PG 64-22 & 25 & $6,550,000$ & $4.15 \mathrm{E}-05$ & $4,014,000$ & $1.65 \mathrm{E}-04$ & 72,000 \\
\hline
\end{tabular}

The same trend noted for the DM and FN samples, with respect to the full depth analysis having greater $\mathrm{N}_{\mathrm{f}}$ than conventional pavement, also appears to be true for the DM and FT samples. The strain levels are $>70$ micro strains, the TXDOT criteria for perpetual pavements ${ }^{21}$. 


\section{Master Curve Comparison}

The Equation 1 regression coefficients for the master curves are given in Table 24.

Table 24 - Master Curve Coefficients

\begin{tabular}{|l|l|l|l|c|c|}
\hline Binder & \% RAP & Max E & Min E & $\beta$ & $\gamma$ \\
\hline \multirow{3}{*}{ PG 70-22 } & 0 & 3187.3 & 4.3 & -0.86295 & -0.51545 \\
\cline { 2 - 6 } & 15 & 3223.0 & 5.7 & -1.24852 & -0.52620 \\
\cline { 2 - 6 } & 25 & 3198.1 & 5.0 & -1.33533 & -0.44922 \\
\hline PG 64-22 & 25 & 3185.7 & 7.2 & -1.24512 & -0.51845 \\
\hline
\end{tabular}

Despite previous research ${ }^{18}$ showing that the $\beta$ term is highly sensitive to binder differentiation, between PG 70-22 and PG 64-22 with 25\% RAP the difference is only 0.09021. However, the difference in the $\beta$ terms between $0 \%$ RAP and $25 \%$ RAP with PG 70-22, is 0.47238 . More research should be performed to determine if the addition of RAP has a correlation to the $\beta$ term. It should be noted that despite using the same equation as MasterSolver, ALPHA-F uses SI units, and therefore the master curve coefficients in Table 20 look very different from Table 24.

In order to determine if DM and FN and DM and FT specimens are significantly different, their respective master curves will be compared by plotting them on the same graph. The master curves will also be compared by the RAP content for both DM and FN samples and DM and FT samples. The results are shown below: 


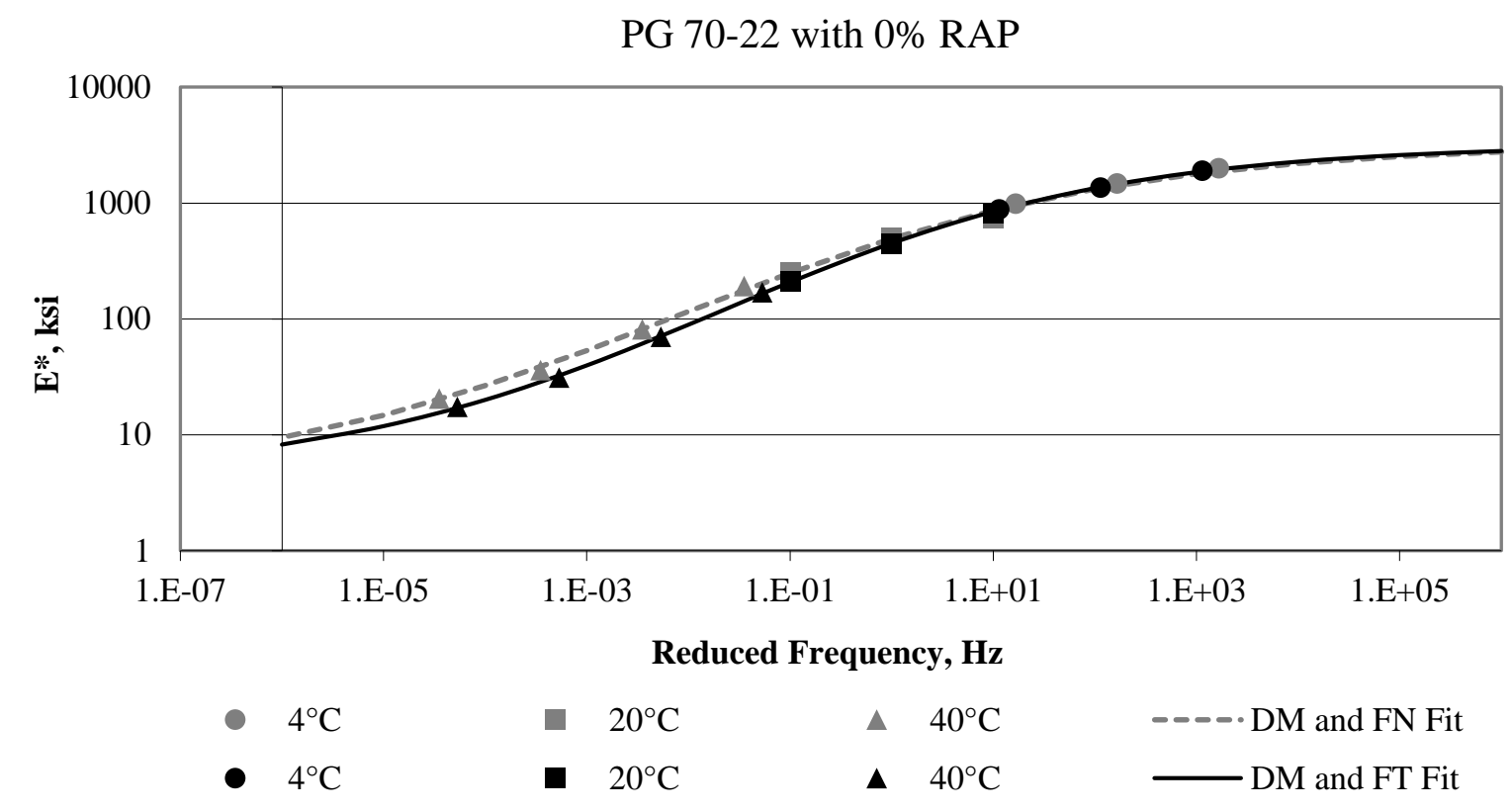

Figure 29 - Comparison of 0\% RAP Between DM and FN and DM and FT

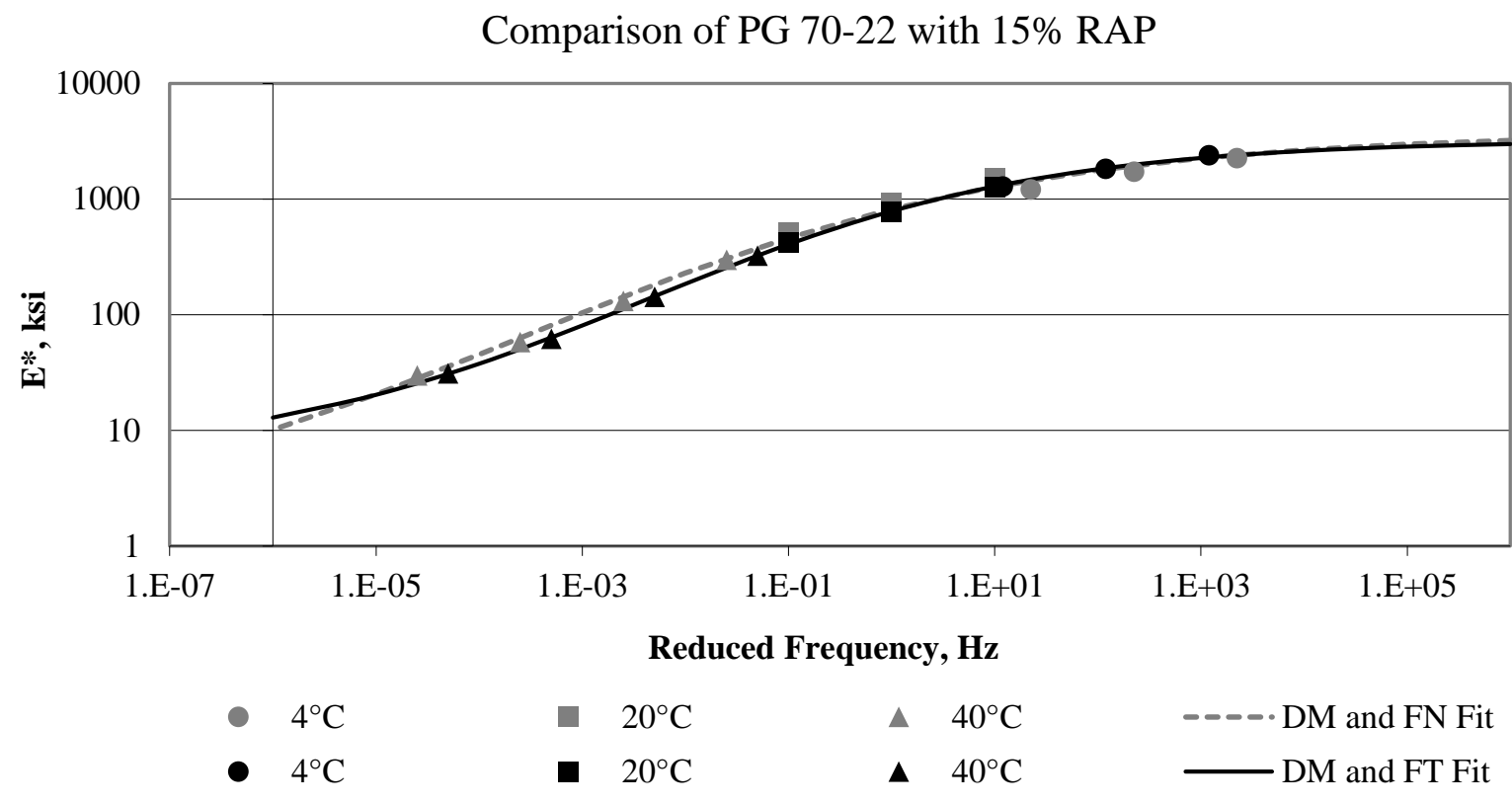

Figure 30 - Comparison of 15\% RAP Between DM and FN and DM and FT 


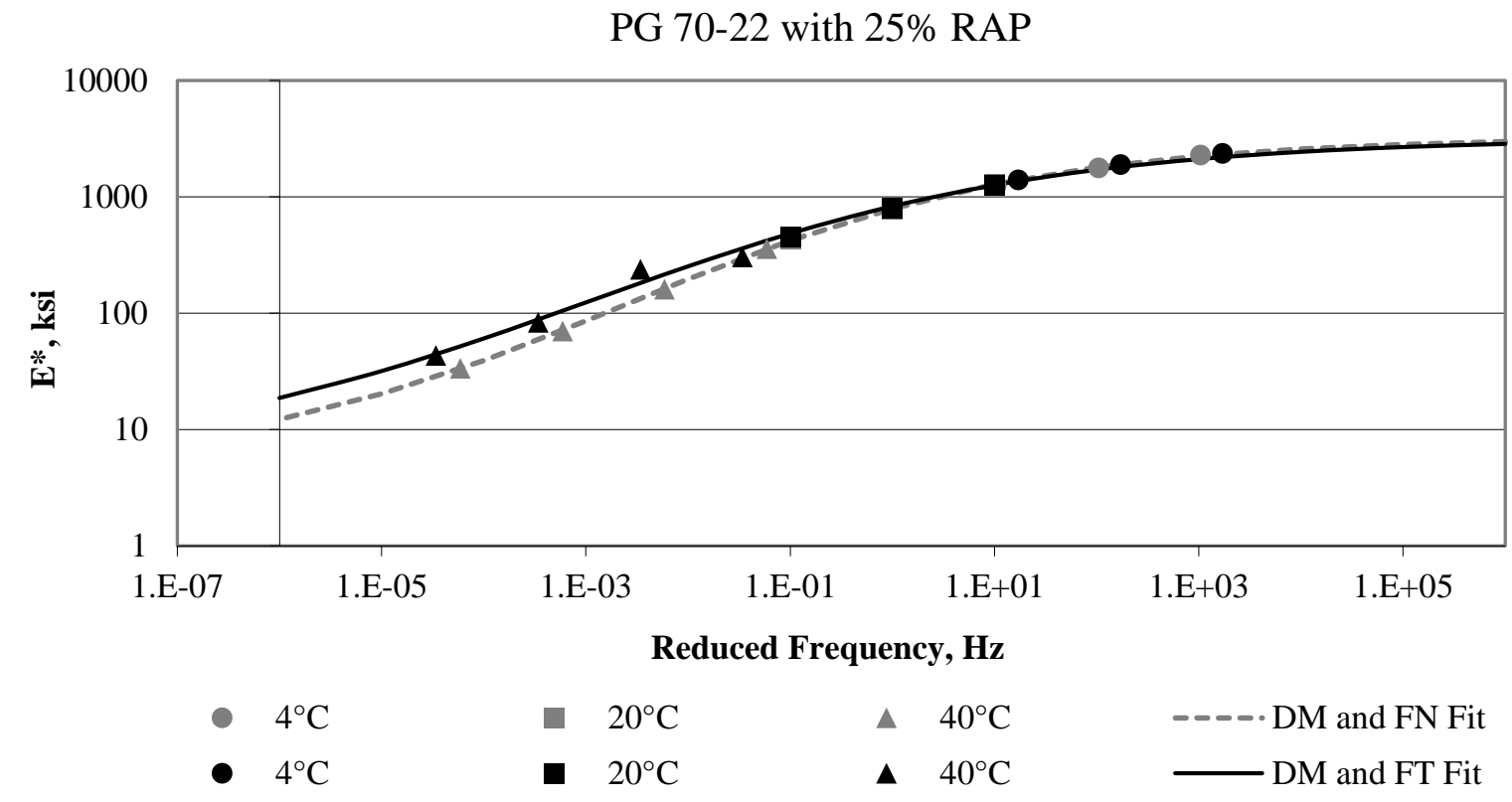

Figure 31 - Comparison of 25\% RAP Between DM and FN and DM and FT 
DM and FN Comparison

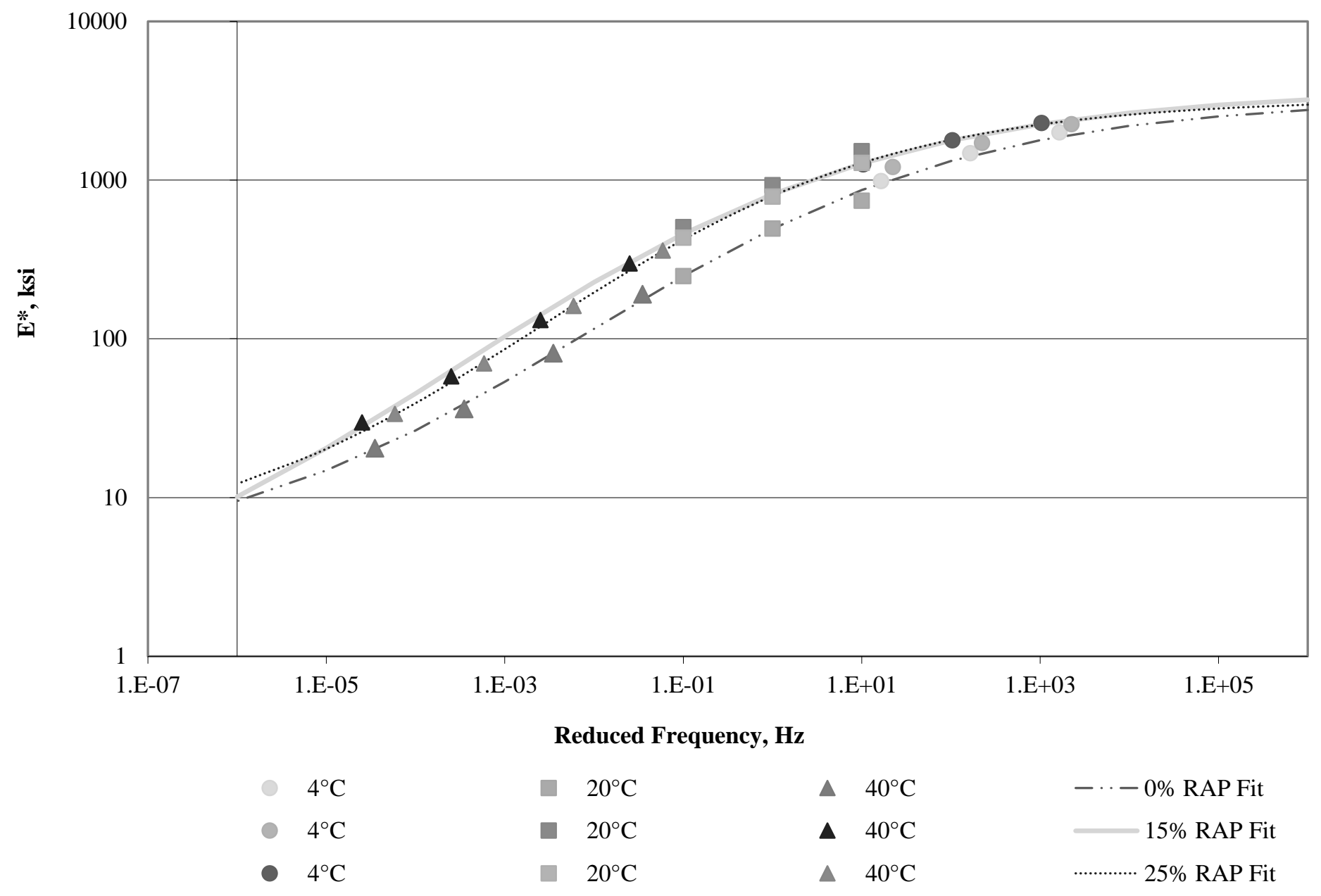

Figure 32 - DM and FN Master Curve Comparison by \% RAP 
DM and FT Comparison

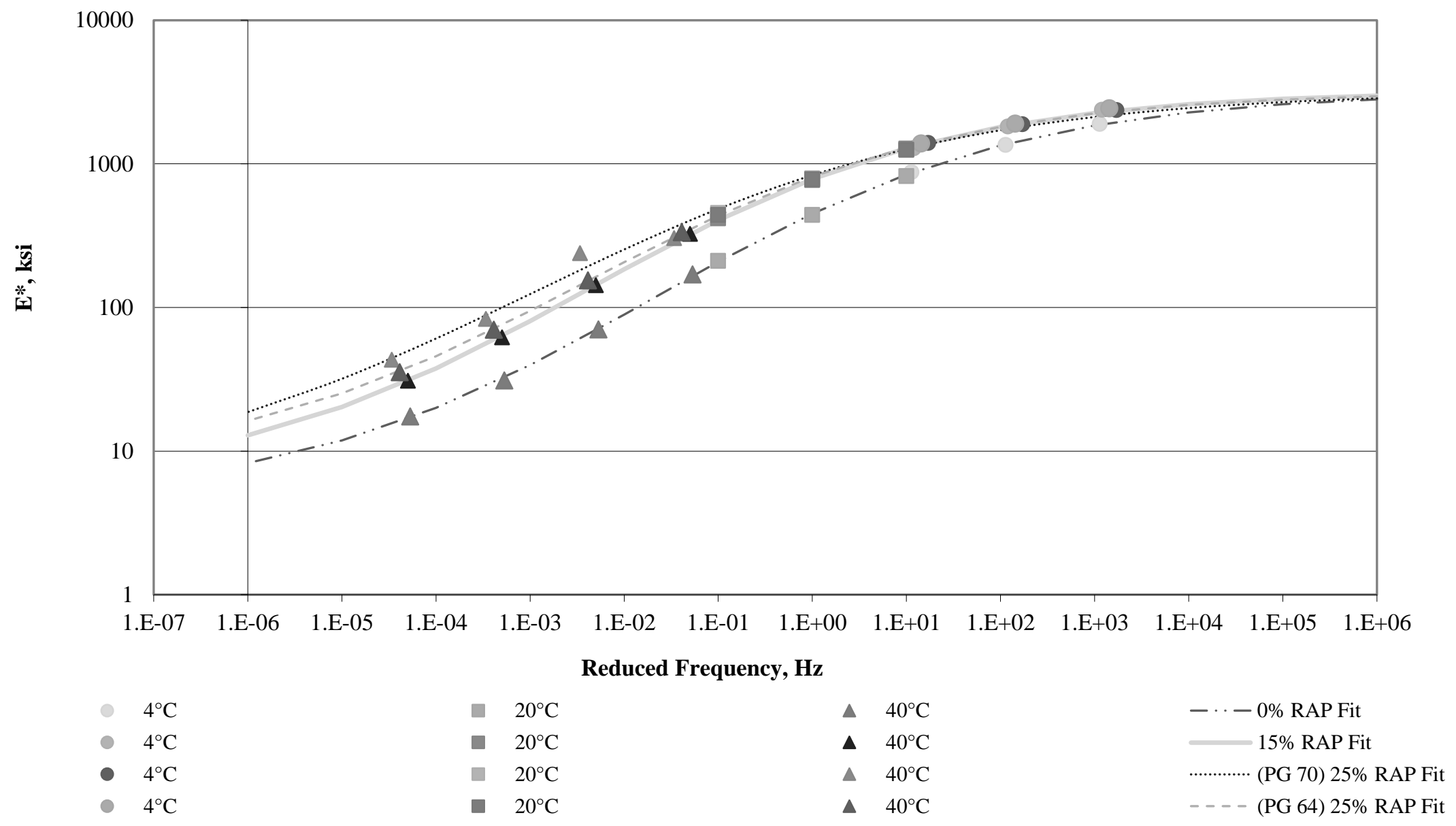

Figure 33- DM and FT Master Curve Comparison by \% RAP 


\section{Chapter 5: Conclusions and Recommendations}

\section{Dynamic Modulus Conclusions}

From the analyzed data presented in Chapter 4, it can be concluded that mixes with a $15 \%$ and $25 \%$ RAP content had a higher dynamic modulus value at the tested temperatures and frequencies than the virgin mix. The data shows when comparing RAP containing mixtures, the greater RAP content does not mean that the dynamic modulus will also be greater. For example, Figure 6 shows 15\% RAP has a higher dynamic modulus than 25\% RAP. More research is recommended to determine if RAP mixes react differently, compared to virgin mixtures, at other testing temperatures.

Showing RAP mixes have a higher dynamic modulus is important because dynamic modulus is generally described as the stiffness of the mix. If the mix is stiffer, then it may have a higher susceptibility to fatigue cracking, but lower susceptibility to permanent deformation. Further research is suggested to see if there is an optimum RAP content based on dynamic modulus values.

\section{Flow Number Conclusions}

From the analyzed data presented in Chapter 4, it can be concluded that mixes with $15 \%$ and $25 \%$ RAP content had a higher flow number than the virgin mix. In comparing the laboratory test results to the FHWA Criteria (Table 4), it was found that the virgin mix design did not meet the flow number required for the design traffic designated on the job mix formula sheet. However, both the $15 \%$ and $25 \%$ RAP mixes exceeded the minimum. Higher flow numbers mean that the mix is less susceptible to permanent deformation which was also reflected by the dynamic modulus analysis. 


\section{ALPHA-Fatigue Conclusions}

From the analyzed data presented in Chapter 4 , it can be concluded that the fatigue equations produced by ALHPA-F are reasonable. It was found that there is a large range of variation for these coefficients depending on the type of mix, asphalt content, and units used during testing and analysis.

The damage coefficients used in the ALPHA-F analysis were also compared across RAP levels. The absolute value of damage coefficients " $b$ " and " $\alpha$ " and damage parameters " $r$ " and "s", all increase with an increase in RAP, while the absolute value of damage coefficient "a" decreases. The absolute value of damage coefficient " $\alpha$ " and damage parameters " $r$ " and " $s$ ", all increase with a softer binder, while the absolute value of damage coefficients " $a$ " and "b" decrease with a softer binder. These coefficients are used in the modeling of the damage characteristic curve. If there is a relationship between the damage coefficients and RAP content, then there may also be a relationship in the damage characteristics and the K-values used in the traditional fatigue equation.

\section{Kenpave Conclusions}

According to the results of Kenpave analysis of the DM and FN samples, as RAP content increased, so did the number of cycles to failure in both full-depth and conventional pavement structures. This can be explained by the RAP mixtures experiencing lower strain since their dynamic modulus values were greater than the virgin mixture.

The Kenpave analysis of the DM and FT samples showed a greater number of cycles to failure for the RAP containing mixtures in the full-depth pavement structure. However, the 
virgin mix performed significantly better in a conventional pavement structure than the RAP containing mixtures.

In comparing the $\mathrm{N}_{\mathrm{f}}$ values based off of the $\mathrm{k}$-values determined by ALPHA-F and Asphalt Institute, it was seen that there is a significant difference between them. The DM and FN samples were only evaluated based on the dynamic modulus, while the DM and FT used both the dynamic modulus and damage characteristic equations. More research is recommended to evaluate if using Kenpave with ALPHA-F is a viable option.

\section{Recommendations}

There are several recommendations to the experimental design. The first recommendation is that more replicates be prepared to continue the dynamic modulus and flow number research performed in the spring of 2014 (DM and FN samples). This research only used two replicates due to time and material constraints. Second, not all 36 S-VECD Fatigue specimens were able to be analyzed using the ALPHA-F software. It is recommended to prepare additional specimens to replace the ones that experience errors during testing to achieve complete triplicates of each mix design. Third, in order to reduce the number of specimens lost, the cause of errors during testing should be eliminated. It is suspected that the errors encountered were from the LVDT jiggling out of the gauge fixtures after the fingerprint test. Further research is recommended to develop a way to keep the LVDTs from experiencing errors. Finally, $0 \%$ and 15\% RAP contents with PG 64-22 should also be tested using the same method as the 25\% RAP. These mix designs were not able to be prepared and tested due to time and material constraints.

Additional research topics were mentioned throughout this paper, in summary: 
- Determining if there is an optimum RAP content that produces a peak dynamic modulus

- AMPT sample preparation method that reduces edge breaking

- Determine if correlation exists between RAP content and $\beta$ term in master curve equation

- Determine if correlation exists between RAP content and damage coefficients and K-values

- Determine if ALPHA-F equations can be used with strains reported using Kenpave analysis 


\section{References}

1. AASHTO TP 107-14, 2014, "Standard Method of Test for: Determining the Damage Characteristic Curve of Asphalt Mixtures from Direct Tension Cyclic Fatigue Tests", AASHTO, Washington D.C.

2. "Recommended Use of Reclaimed Asphalt Pavement in the Superpave Mix Design Method: Technician's Manual." NCHRP Report 452 (2001). Print.

3. West Virginia Department of Transportation Division of Highways Special Provision. (2015). Asphalt Base, Wearing, And Patching and Leveling Courses.

4. "Improved Mix Design, Evaluation, and Materials Management Practices for Hot Mix Asphalt with High Reclaimed Asphalt Pavement Content." NCHRP Report 752 (2013). Print.

5. "Refining the Simple Performance Tester for Use in Routine Practice." NCHRP Report 614 (2008). Print.

6. AASHTO PP 60-14, 2014, "Standard Practice for: Preparation of Cylindrical Performance Test Specimens Using the Superpave Gyratory Compactor", AASHTO, Washington D.C.

7. Shannon, Cory Patrick. "Fractionation of recycled asphalt pavement materials: Improvement of volumetric design driteria for High-RAP content surface mixtures.” Master's thesis, University of Iowa, 2012. http:ir.uiowa.edu/etd/3380

8. Bonaquist R. (2011). MasterSolver: Version 2.2 [Software]. Available from http://apps.trb.org/cmsfeed/TRBNetProjectDisplay.asp?ProjectID=963

9. “Simple Performance Test for Superpave Mix Design" NCHRP Report 465 (2002). Print. 
10. AASHTO PP 61-13, 2013, "Standard Practice for: Developing Dynamic Modulus Master Curves for Asphalt Mixtures Using the Asphalt Mixture Performance Tester (AMPT)", AASHTO, Washington D.C.

11. Universal Testing Software (032 S-VECD Fatigue). Victoria, Australia: IPC Global.

12. ALPHA - F User Guide (2014). ALPHA-Fatigue. IPC Global, Raleigh, NC.

13. Underwood, S., Baek, C., \& Kim, Y. (2012). Simplified Viscoelastic Continuum Damage Model as Platform for Asphalt Concrete Fatigue Analysis. Transportation Research Record: Journal of the Transportation Research Board, 2296, 36-45. doi:10.3141/2296-04

14. AASHTO TP 79-13, 2013, "Standard Method of Test for: Determining the Dynamic Modulus and Flow Number for Hot Mix Asphalt (HMA) Using the Asphalt Mixture Performance Tester (AMPT)", AASHTO, Washington D.C.

15. Universal Testing Software (005 Flow Number). Victoria, Australia: IPC Global.

16. Huang textbook

17. "MP 401.02.24 Appendix C: Guide to Designing Hot-Mix Asphalt with Recycled Asphalt Pavement." West Virginia Division of Highways Hot-Mix Asphalt Technician Instruction Manual. Charleston, WV, 2014. Print.

18. Roberts, L., P. Romero, K. Vanfrank, and R. Ferrin. "Evaluation of Asphalt Mixture Performance Tester." Transportation Research Record: Journal of the Transportation Research Board 2296.-1 (2012): 69-76.

19. Roy, N., Veeraragavan, A., Jain, P. K., \& Krishnan, J. M. A Re-look at the Asphalt Mixture Performance Test Protocols and Computational Algorithms. Journal of Testing and Evaluation, 41. 
20. Haas, R., Hudson, W., \& Zaniewski, J. (1994). Modern Pavement Management (Original ed.). Malabar, Fla.: Krieger Pub.

21. Pavement Design Guide: Perpetual Pavement Design and Mechanistic Design Guidelines. (n.d.). Retrieved November 17, 2015, from http://onlinemanuals.txdot.gov/txdotmanuals/pdm/perpetual_pavement_design_and_mech anistic_design_guidelines.htm\#i1004019 


\section{Appendix A}

\section{Job Mix Formulas}

$\mathrm{T} 400$

04-10

WEST VIRGINIA DIVISION OF HIGHWAYS

JOB MIX FORMULA FOR HOT-MIX ASPHALT

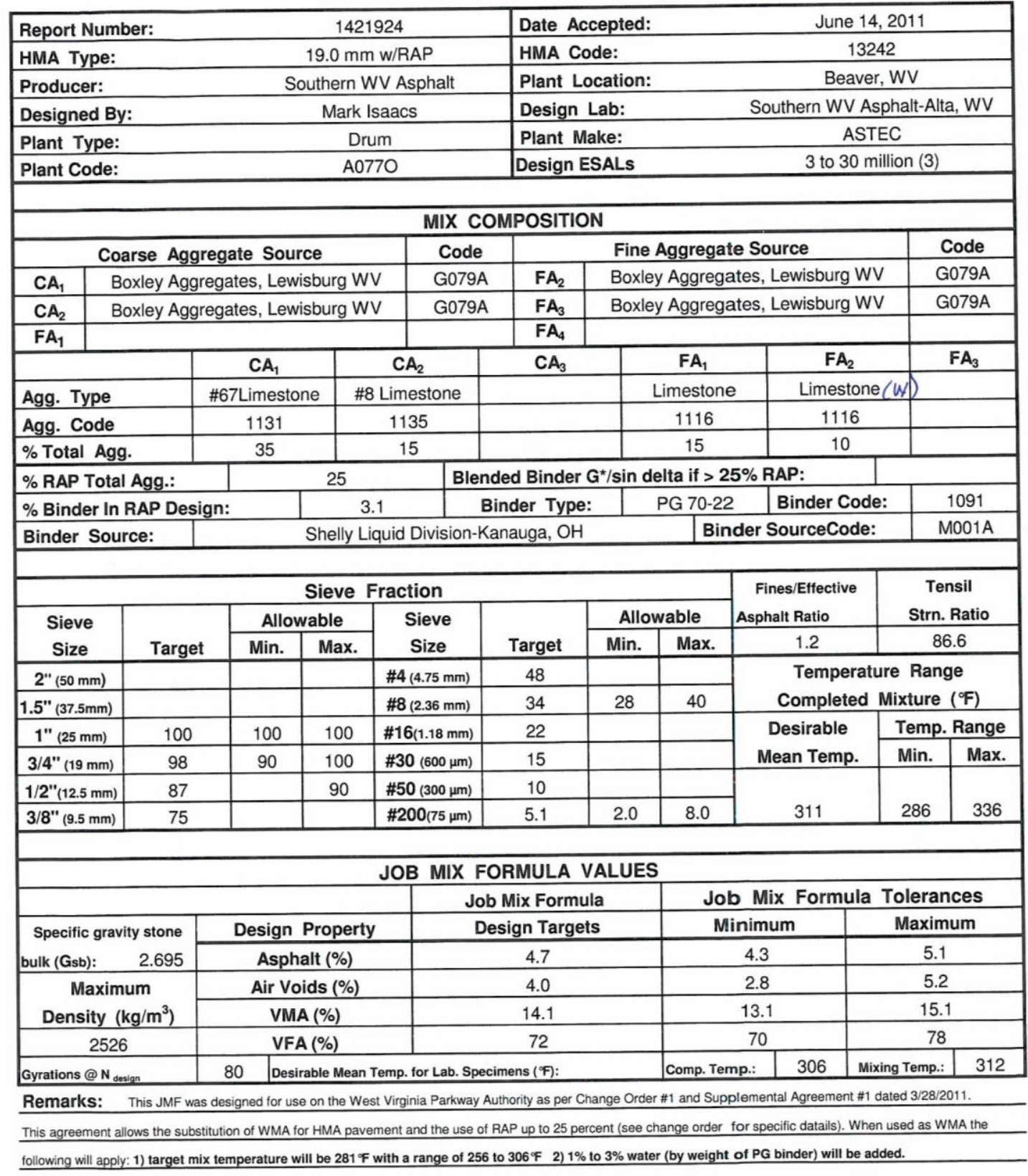

Figure 34 - Job Mix Formula for PG 70-22 0\% RAP 
T $400 \mathrm{SP}$

$03-00$

$$
\text { RAP - } 151 \mathrm{~b}
$$

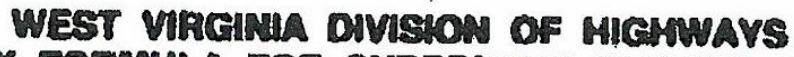
HOB MIX FORMULA FOF SUPERPAVE NOT-MM ASPMALT

\begin{tabular}{|c|c|c|c|}
\hline Repart number: & $13907 \times 9$ & Anfer horeynd: & April 5.2010 \\
\hline HAIA Type: & 19 mm uspiar : & Mina code: & 13242 \\
\hline Producer: & Soustren UV Asphan & Pund Locellon: & Beaver,we \\
\hline Doalgnead By: & 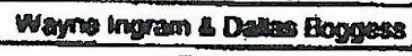 & Dondor Lob: & Southem wV Aephath, Ingleside, WV \\
\hline Plant Tres: & Drum & Fhen lintras: & Ashec \\
\hline Plant Code: & 10770 & Dainin Esalls: & 3 to $<30$ million (3) \\
\hline
\end{tabular}

\begin{tabular}{|c|c|c|c|c|c|c|c|c|c|c|}
\hline & & & & Milk & Dunit & $e_{1}$ & & & & \\
\hline $\operatorname{con}$ & ree anow & $\cos \mathrm{s}$ & ences & $\operatorname{cod}$ & & $n \in 4$ & 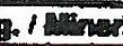 & 1 Filler Soune & & $\operatorname{Cods}$ \\
\hline CA $\sqrt{80 \times 1}$ & ley Agare: & gates, Le & vistoury & g. WV & FAM & Boxk & Aggrege: & 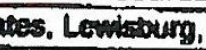 & Wv & COT9A \\
\hline CA & loy Agareg & gates, Le & sisbung & g.wM & Fas & Boxte & Y Agoreg? & alos, Lowisturg, & WV & CO79A \\
\hline \begin{tabular}{l|l}
$C_{6}$ &
\end{tabular} & & & & & Fab & & & & & \\
\hline & & Ch, & & . & $a_{3}$ & & $F A_{1}$ & $F A_{2}$ & & $F A_{2}$ \\
\hline Agg. Type & & 67 Limas & ine & 8 Limastone & & & Limestione & eNo & & ed \\
\hline Agg- Code & & 9131 & & 1135 & & & 1116 & & & \\
\hline$\%$ rowal $\mathrm{Ac}$ & & 35 & & 20 & & & (31) 3 & & & \\
\hline \%RAPTa & en Ars: & & (B4) & 15 & $\bmod \mathrm{Cm}$ & $\operatorname{ler} 6 \%$ & 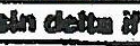 & $\rightarrow 20 \%$ RAP: & & \\
\hline \% vinder & n RAP D & Eign: & & $\begin{array}{lll}.2 & 18\end{array}$ & Wincter 5 & & Po: $70-22$ & I linder co & & $\$ 091$ \\
\hline Binder 5e & mex: I & & Dethy Lig & iquid Division, & Konauga. & & 100 & Sano Co & e: & MOO1A \\
\hline & & & Stom ! & Proation & & & & Flues / Ellect & & Tensojite \\
\hline Sieve & & Nher & neteres & sineve & & & areale & Amphat Ras & & Stro. Rasio \\
\hline Size & Terow & m. & then & Sine & Tereas & $m$ & Nane & 1.2 & & 88.1 \\
\hline $2^{n}(50 \mathrm{~mm})$ & & & & $448.75 \mathrm{nmm}$ & 45 & & & Tenpereta & ane & Angere \\
\hline $1.5^{\circ} 137.5 \mathrm{~mm}$ & & & & $00236 \mathrm{~mm}$ & 30 & 24 & 36 & Congletied & Minte & we $(7)$ \\
\hline $1 "(25 \mathrm{~mm})$ & 100 & 100 & 100 & $1611.98 \mathrm{~mm}$ & 20 & & & 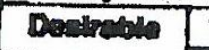 & Tem: & Q. Range \\
\hline $3 / 4^{\prime \prime}(19 \mathrm{~mm})$ & 96 & 90 & 100 & 130 (1000) & 14 & & & Mann Temp. & Nons。 & Max. \\
\hline $1 / 2^{\prime \prime} 112.5 \mathrm{~mm}$ & $\mathrm{BS}$ & & 90 & $5500000 \mathrm{ums}$ & 10 & & & & & \\
\hline $1 / 8^{\circ} 19.5 \mathrm{~mm}$ & 69 & & & Eeco (r5 mm & 5.2 & 20 & B.0 & 314 & 286 & 336 \\
\hline
\end{tabular}

\begin{tabular}{|c|c|c|c|c|}
\hline \multicolumn{5}{|c|}{ do 3 MIX FOFIULI VLLUSS } \\
\hline & \multirow{2}{*}{\multicolumn{2}{|c|}{ dob Min Fonnula Ternece }} & \multicolumn{2}{|c|}{ Job Cix Formela Tolarences } \\
\hline 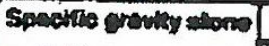 & & acouphed Tngat & Finimanom & Taxhoum \\
\hline Bum (Gom): 2.676 & Anphan (\%) & 5.7 & 4.7 & 5.5 \\
\hline Marionum & Air Volde (z) & 4.0 & 2.8 & 5.2 \\
\hline Density (krg/ming & $\min (x)$ & 14.4 & 13.4 & 15.4 \\
\hline 2523 & MFA(7) & 72 & 70 & 78 \\
\hline Gyretione $e^{\mathrm{N}}$ mover & & 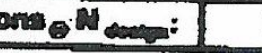 & Gyratar & \\
\hline
\end{tabular}

Design Gyration Lavel Chan fomulatied in accordance wim memoranolum dated 1/21/2010 Superpave Mix and 1394738 .

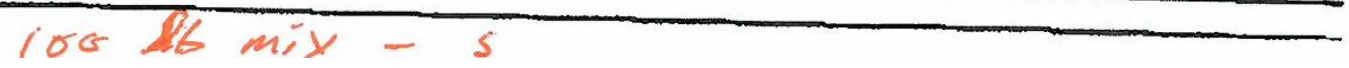


WEST VIRGINIA DIVISION OF HIGHWAYS JOB MIX FORMULA FOR SUPERPAVE HOT-MIX ASPHALT

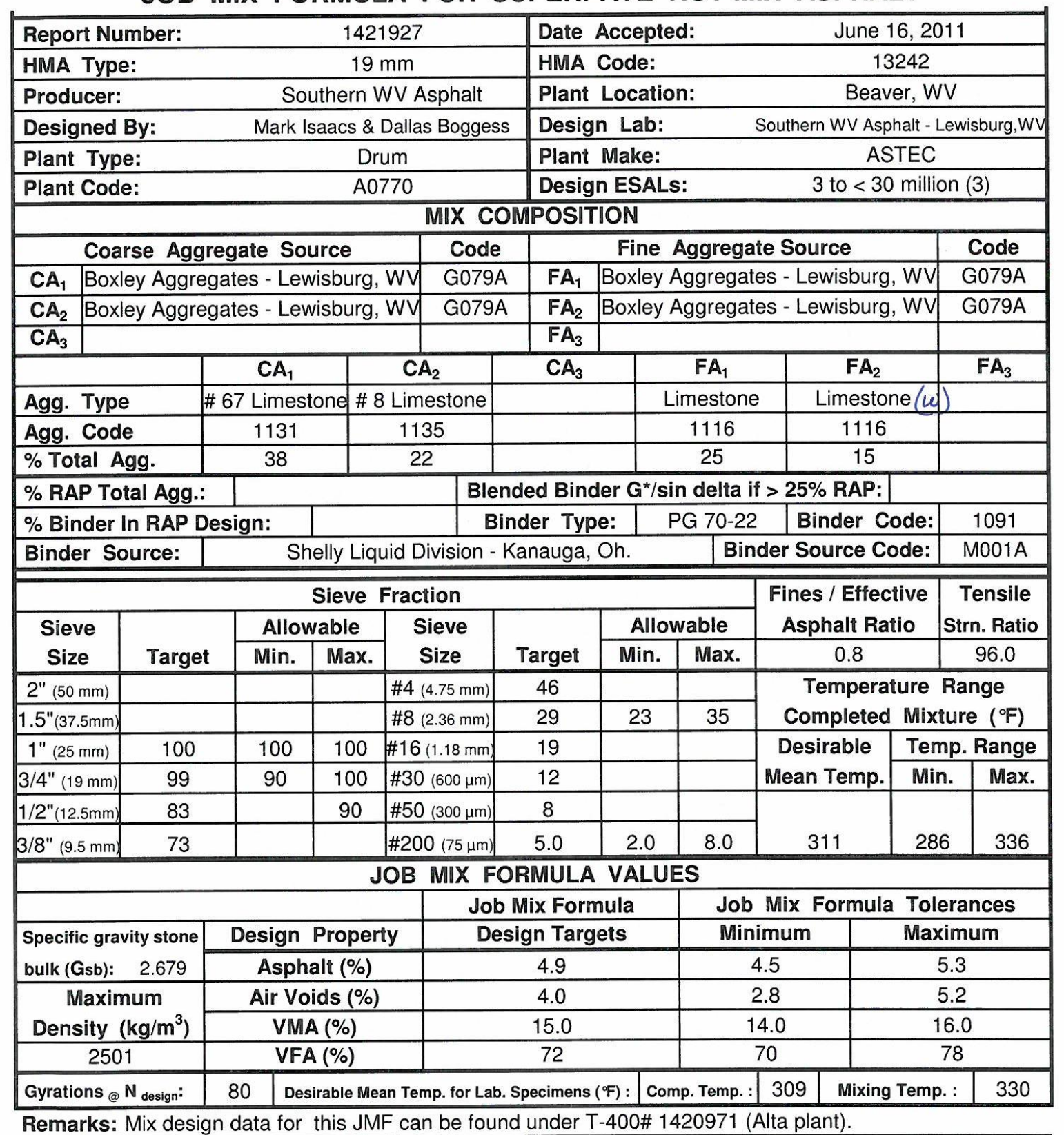




\section{Aggregate Properties}

Design Package

Attachment \#8

WEST VIRGINIA DIVISION OF HIGHWAYS

WORKSHEET FOR CALCULATING BULK SPECIFIC GRAVITY AND ABSORPTION OF COARSE AGGREGATE

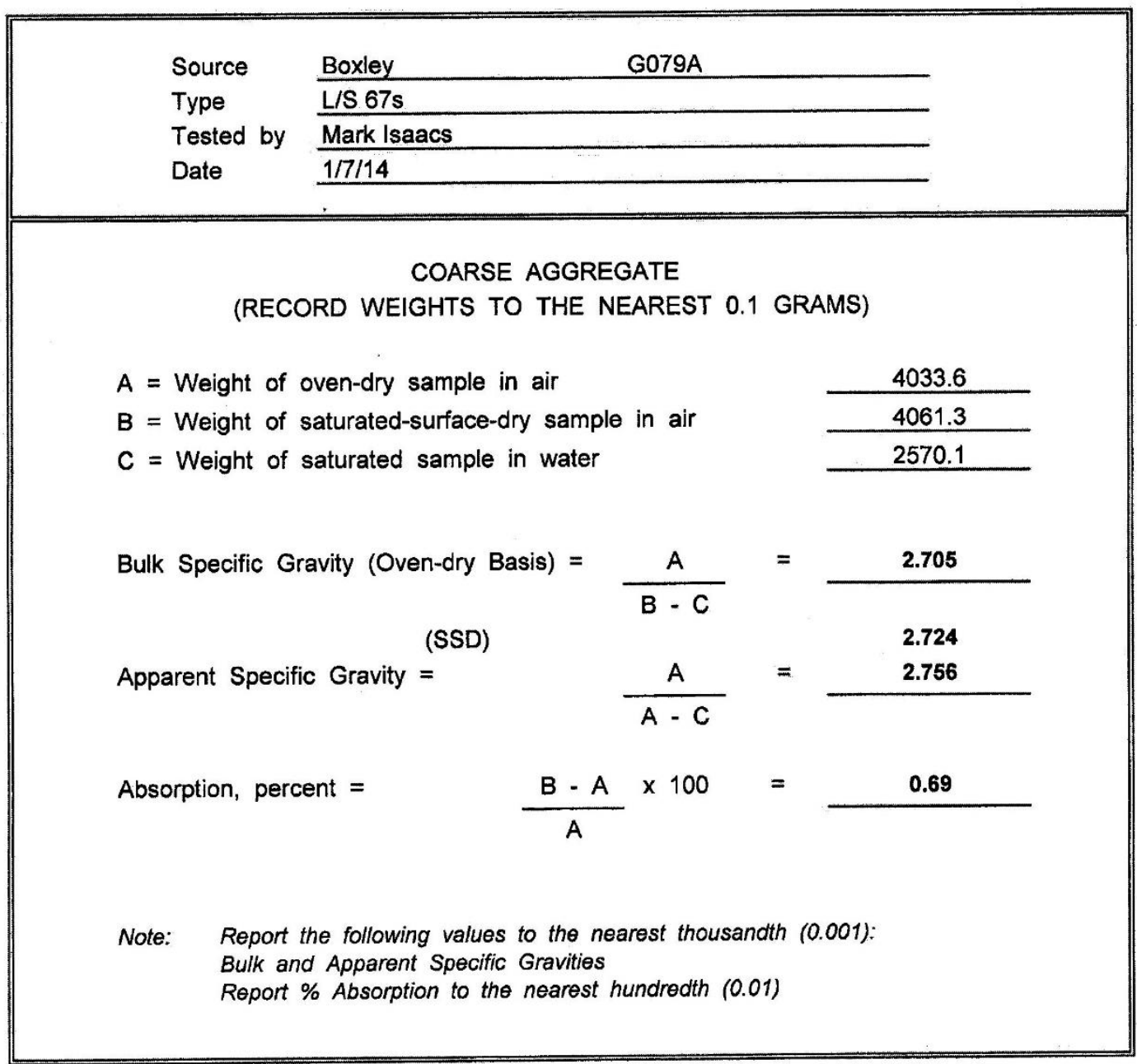

Figure 37 - Aggregate Properties of L/S 67's 


\title{
WEST VIRGINIA DIVISION OF HIGHWAYS
}

\author{
WASHED SIEVE ANALYSIS
}

(AASHTO T-11 AND T-27)

\begin{tabular}{|c|c|c|c|}
\hline Producer & Boxley & Aggregate Source & G079A \\
\hline Type of Mix & & Aggregate Type & L/S 67s \\
\hline Technician & Mark Isaacs & Date & $1 / 7 / 14$ \\
\hline
\end{tabular}

\begin{tabular}{|c|c|c|c|}
\hline $\begin{array}{c}\text { Sieve } \\
\text { Size } \\
\end{array}$ & $\begin{array}{l}\text { Weight } \\
\text { Retained }\end{array}$ & $\begin{array}{l}\text { Percent } \\
\text { Loss }\end{array}$ & $\begin{array}{l}\text { Percent } \\
\text { Passing }\end{array}$ \\
\hline $21 / 2 "(63 \mathrm{~mm})$ & & 0.0 & 100.0 \\
\hline 2" $(50 \mathrm{~mm})$ & 0.0 & 0.0 & 100.0 \\
\hline $11 / 2^{\prime \prime}(37.5 \mathrm{~mm})$ & 0.0 & 0.0 & 100.0 \\
\hline $1^{\prime \prime}(25 \mathrm{~mm})$ & 0.0 & 0.0 & 100.0 \\
\hline $3 / 4 "(19 \mathrm{~mm})$ & 188.6 & 7.3 & 92.7 \\
\hline $1 / 2 "(12.5 \mathrm{~mm})$ & 889.6 & 34.2 & 58.5 \\
\hline $3 / 8^{\prime \prime}(9.5 \mathrm{~mm})$ & 622.3 & 23.9 & 34.6 \\
\hline$\# 4(4.75 \mathrm{~mm})$ & 798.9 & 30.7 & 3.8 \\
\hline$\# 8(2.36 \mathrm{~mm})$ & 55.3 & 2.1 & 1.7 \\
\hline$\# 16(1.18 \mathrm{~mm})$ & 1.0 & 0.0 & 1.7 \\
\hline$\# 30$ (600um) & 1.6 & 0.1 & 1.6 \\
\hline$\# 50$ (300um) & 0.9 & 0.0 & 1.6 \\
\hline$\# 100$ (150um) & 1.9 & 0.1 & 1.5 \\
\hline$\# 200$ (75um) & 3.0 & 0.1 & 1.4 \\
\hline$-\# 200$ & 35.6 & 1.4 & \\
\hline Total & 2598.7 & & \\
\hline \multicolumn{3}{|c|}{$\begin{array}{l}\text { (A) Weight of original sample } \\
\text { (B) Weight after wash } \\
\text { (C) Loss of - \#200 after wash } \\
\text { (D) - \#200 from sieving (Pan Weight) } \\
\text { (T) Total passing \#200 (C + D) }\end{array}$} & \begin{tabular}{c|}
2599.6 \\
2566.3 \\
33.3 \\
2.3 \\
35.6 \\
\end{tabular} \\
\hline
\end{tabular}

Note: Report all values to the nearest tenth $(0.1)$ 


\section{WEST VIRGINIA DIVISION OF HIGHWAYS}

WASHED SIEVE ANALYSIS

(AASHTO T-11 AND T-27)

\begin{tabular}{|c|c|c|c|}
\hline \multirow{2}{*}{$\begin{array}{l}\text { Producer } \\
\text { Type of Mix }\end{array}$} & Boxley & \multirow{2}{*}{$\begin{array}{c}\text { Aggregate Source } \\
\text { Aggregate Type }\end{array}$} & \multirow{2}{*}{$\begin{array}{l}\text { G079A } \\
\text { L/S 67s }\end{array}$} \\
\hline & & & \\
\hline Technician & Mark Isaacs & Date & $1 / 7 / 14$ \\
\hline $\begin{array}{c}\text { Sieve } \\
\text { Size }\end{array}$ & $\begin{array}{l}\text { Weight } \\
\text { Retained }\end{array}$ & $\begin{array}{l}\text { Percent } \\
\text { Loss }\end{array}$ & $\begin{array}{l}\text { Percent } \\
\text { Passing }\end{array}$ \\
\hline $21 / 2 "(63 \mathrm{~mm})$ & & 0.0 & 100.0 \\
\hline $2^{\prime \prime}(50 \mathrm{~mm})$ & & 0.0 & 100.0 \\
\hline $11 / 2^{\prime \prime}(37.5 \mathrm{~mm})$ & 0.0 & 0.0 & 100.0 \\
\hline $1^{\prime \prime}(25 \mathrm{~mm})$ & 0.0 & 0.0 & 100.0 \\
\hline $3 / 4^{\prime \prime}(19 \mathrm{~mm})$ & 335.9 & 12.7 & 87.3 \\
\hline $1 / 2^{\prime \prime}(12.5 \mathrm{~mm})$ & 1023.6 & 38.5 & 48.8 \\
\hline $3 / 8 "(9.5 \mathrm{~mm})$ & 540.6 & 20.4 & 28.4 \\
\hline$\# 4(4.75 \mathrm{~mm})$ & 650.2 & 24.5 & 3.9 \\
\hline$\# 8(2.36 \mathrm{~mm})$ & 66.3 & 2.5 & 1.4 \\
\hline$\# 16(1.18 \mathrm{~mm})$ & 0.5 & 0.0 & 1.4 \\
\hline$\# 30$ (600um) & 0.6 & 0.0 & 1.4 \\
\hline$\# 50$ (300um) & 0.6 & 0.0 & 1.4 \\
\hline$\# 100$ (150um) & 3.2 & 0.1 & 1.2 \\
\hline$\# 200$ (75um) & 2.1 & 0.1 & 1.2 \\
\hline$-\# 200$ & 30.9 & 1.2 & \\
\hline Total & 2654.5 & & \\
\hline \multirow{5}{*}{\multicolumn{2}{|c|}{$\begin{array}{l}\text { (A) Weight of original sample } \\
\text { (B) Weight after wash } \\
\text { (C) Loss of - \#200 after wash } \\
\text { (D) - \#200 from sieving (Pan Weight) } \\
\text { (T) Total passing \#200 (C + D) }\end{array}$}} & & 2655.3 \\
\hline & & & 2626.3 \\
\hline & & & 29.0 \\
\hline & & & 1.9 \\
\hline & & & 30.9 \\
\hline
\end{tabular}

Note: Report all values to the nearest tenth (0.1)

\section{WEST VIRGINIA DIVISION OF HIGHWAYS}

WASHED SIEVE ANALYSIS

Figure 39 - Aggregate Gradation 2 L/S 67's 
(AASHTO T-11 AND T-27)

\begin{tabular}{|c|c|c|c|}
\hline Producer & Boxley & Aggregate Source & G079A \\
\hline Type of Mix & & Aggregate Type & L/S 67s \\
\hline Technician & Mark Isaacs & Date & $1 / 7 / 14$ \\
\hline
\end{tabular}

\begin{tabular}{|c|c|c|c|}
\hline $\begin{array}{l}\text { Sieve } \\
\text { Size }\end{array}$ & $\begin{array}{c}\text { Weight } \\
\text { Retained }\end{array}$ & $\begin{array}{l}\text { Percent } \\
\text { Loss }\end{array}$ & $\begin{array}{l}\text { Percent } \\
\text { Passing }\end{array}$ \\
\hline $21 / 2 "(63 \mathrm{~mm})$ & & 0.0 & 100.0 \\
\hline $2^{\prime \prime}(50 \mathrm{~mm})$ & & 0.0 & 100.0 \\
\hline $11 / 2^{\prime \prime}(37.5 \mathrm{~mm})$ & 0.0 & 0.0 & 100.0 \\
\hline $1^{\prime \prime}(25 \mathrm{~mm})$ & 0.0 & 0.0 & 100.0 \\
\hline $3 / 4^{\prime \prime}(19 \mathrm{~mm})$ & 251.6 & 9.8 & 90.2 \\
\hline $1 / 2^{\prime \prime}(12.5 \mathrm{~mm})$ & 812.3 & 31.7 & 58.5 \\
\hline $3 / 8^{11}(9.5 \mathrm{~mm})$ & 733.9 & 28.6 & 29.9 \\
\hline$\# 4(4.75 \mathrm{~mm})$ & 663.3 & 25.8 & 4.1 \\
\hline$\# 8(2.36 \mathrm{~mm})$ & 55.3 & 2.2 & 1.9 \\
\hline$\# 16(1.18 \mathrm{~mm})$ & 2.0 & 0.1 & 1.9 \\
\hline$\# 30$ (600um) & 0.4 & 0.0 & 1.8 \\
\hline$\# 50$ (300um) & 0.9 & 0.0 & 1.8 \\
\hline$\# 100$ (150um) & 1.2 & 0.0 & 1.8 \\
\hline$\# 200$ (75um) & 1.6 & 0.1 & 1.7 \\
\hline$-\# 200$ & 43.5 & 1.7 & \\
\hline Total & 2566.0 & & \\
\hline \multirow{5}{*}{\multicolumn{3}{|c|}{$\begin{array}{l}\text { (A) Weight of original sample } \\
\text { (B) Weight after wash } \\
\text { (C) Loss of - \#200 after wash } \\
\text { (D) - \#200 from sieving (Pan Weight) } \\
\text { (T) Total passing \#200 (C + D) }\end{array}$}} & 2566.3 \\
\hline & & & 2525.9 \\
\hline & & & 40.4 \\
\hline & & & 3.1 \\
\hline & & & 43.5 \\
\hline
\end{tabular}

Note: Report all values to the nearest tenth (0.1)

Figure 40 - Aggregate Gradation 3 L/S 67's 
Design Package

Attachment \#8

\section{WEST VIRGINIA DIVISION OF HIGHWAYS \\ WORKSHEET FOR CALCULATING BULK SPECIFIC GRAVITY AND ABSORPTION OF COARSE AGGREGATE}

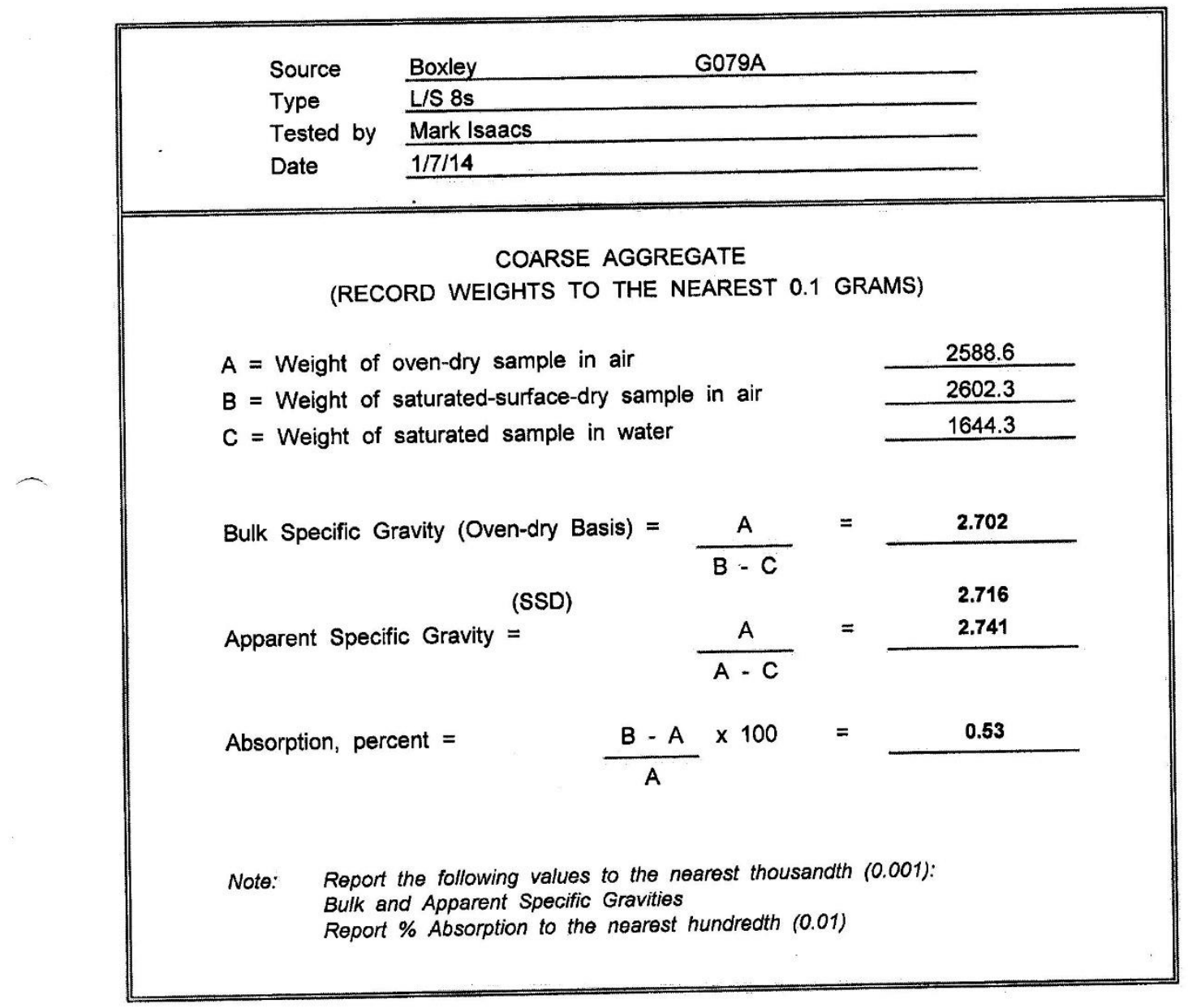

Figure 41 - Aggregate Properties L/S 8's 


\section{WEST VIRGINIA DIVISION OF HIGHWAYS}

\begin{tabular}{|c|c|c|c|}
\hline & $\begin{array}{l}\text { WASHE } \\
\text { (AASH }\end{array}$ & $\begin{array}{l}\text { VE ANALYSIS } \\
\text { (1 AND T-27) }\end{array}$ & \\
\hline Producer & Boxley & Aggregate Source & G079A \\
\hline Type of Mix & & Aggregate Type & L/S $8 \mathrm{~s}$ \\
\hline Technician & Mark Isaacs & Date. & $1 / 7 / 14$ \\
\hline $\begin{array}{c}\text { Sieve } \\
\text { Size } \\
\end{array}$ & $\begin{array}{c}\text { Weight } \\
\text { Retained }\end{array}$ & $\begin{array}{l}\text { Percent } \\
\text { Loss }\end{array}$ & $\begin{array}{l}\text { Percent } \\
\text { Passing } \\
\end{array}$ \\
\hline $21 / 2 "(63 \mathrm{~mm})$ & & 0.0 & 100.0 \\
\hline $2^{\prime \prime}(50 \mathrm{~mm})$ & 0.0 & 0.0 & 100.0 \\
\hline $11 / 2 "(37.5 \mathrm{~mm})$ & 0.0 & 0.0 & 100.0 \\
\hline $1 "(25 \mathrm{~mm})$ & 0.0 & 0.0 & 100.0 \\
\hline $3 / 4^{\prime \prime}(19 \mathrm{~mm})$ & 0.0 & 0.0 & 100.0 \\
\hline $1 / 2 "(12.5 \mathrm{~mm})$ & 0.0 & 0.0 & 100.0 \\
\hline $3 / 8 "(9.5 \mathrm{~mm})$ & 193.0 & 11.9 & 88.1 \\
\hline$\# 4(4.75 \mathrm{~mm})$ & 1244.9 & 76.7 & 11.3 \\
\hline$\# 8(2.36 \mathrm{~mm})$ & 133.2 & 8.2 & 3.1 \\
\hline$\# 16(1.18 \mathrm{~mm})$ & 15.9 & 1.0 & 2.1 \\
\hline$\# 30$ (600um) & 1.1 & 0.1 & 2.1 \\
\hline$\# 50$ (300um) & 0.9 & 0.1 & 2.0 \\
\hline$\# 100$ (150um) & 1.3 & 0.1 & 1.9 \\
\hline$\# 200$ (75um) & 1.9 & 0.1 & 1.8 \\
\hline$-\# 200$ & 29.3 & 1.8 & \\
\hline Total & 1621.5 & & \\
\hline $\begin{array}{l}\text { (A) Weight of orig } \\
\text { (B) Weight after } \mathrm{W} \\
\text { (C) Loss of - \#200 } \\
\text { (D) - \#200 from si } \\
\text { (T) Total passing }\end{array}$ & $\begin{array}{l}\text { I sample } \\
\text { h } \\
\text { ter wash } \\
\text { ng (Pan Weight) } \\
00 \text { (C + D) }\end{array}$ & & $\begin{array}{c}1622.3 \\
1594.9 \\
27.4 \\
1.9 \\
29.3 \\
\end{array}$ \\
\hline
\end{tabular}

Note: Report all values to the nearest tenth (0.1)

Figure 42 - Aggregate Gradation 1 L/S 8's 


\section{WEST VIRGINIA DIVISION OF HIGHWAYS}

WASHED SIEVE ANALYSIS

(AASHTO T-11 AND T-27)

\begin{tabular}{|c|c|c|c|}
\hline Producer & Boxley & Aggregate Source & G079A \\
\hline Type of Mix & & Aggregate Type & L/S $8 s$ \\
\hline Technician & Mark Isaacs & Date & $1 / 7 / 14$ \\
\hline
\end{tabular}

\begin{tabular}{|c|c|c|c|}
\hline $\begin{array}{c}\text { Sieve } \\
\text { Size }\end{array}$ & $\begin{array}{c}\text { Weight } \\
\text { Retained }\end{array}$ & $\begin{array}{c}\text { Percent } \\
\text { Loss }\end{array}$ & $\begin{array}{c}\text { Percent } \\
\text { Passing }\end{array}$ \\
\hline $21 / 2^{\prime \prime}(63 \mathrm{~mm})$ & & 0.0 & 100.0 \\
\hline $2^{\prime \prime}(50 \mathrm{~mm})$ & & 0.0 & 100.0 \\
\hline $11 / 2^{\prime \prime}(37.5 \mathrm{~mm})$ & 0.0 & 0.0 & 100.0 \\
\hline $1^{\prime \prime}(25 \mathrm{~mm})$ & 0.0 & 0.0 & 100.0 \\
\hline $3 / 4^{\prime \prime}(19 \mathrm{~mm})$ & 0.0 & 0.0 & 100.0 \\
\hline $1 / 2^{\prime \prime}(12.5 \mathrm{~mm})$ & 0.0 & 0.0 & 100.0 \\
\hline $3 / 8^{\prime \prime}(9.5 \mathrm{~mm})$ & 176.3 & 11.4 & 88.6 \\
\hline$\# 4(4.75 \mathrm{~mm})$ & 1188.6 & 77.0 & 11.6 \\
\hline$\# 8(2.36 \mathrm{~mm})$ & 144.2 & 9.3 & 2.3 \\
\hline$\# 16(1.18 \mathrm{~mm})$ & 11.9 & 0.8 & 1.5 \\
\hline$\# 30(600 \mathrm{um})$ & 0.5 & 0.0 & 1.5 \\
\hline$\# 50(300 \mathrm{um})$ & 0.6 & 0.0 & 1.4 \\
\hline$\# 100(150 \mathrm{um})$ & 1.0 & 0.1 & 1.4 \\
\hline$\# 200(75 \mathrm{um})$ & 1.1 & 0.1 & 1.3 \\
\hline -\#200 & 20.2 & 1.3 & \\
\hline Total & 1544.4 & & \\
\hline
\end{tabular}

(A) Weight of original sample

(B) Weight after wash

(C) Loss of - \#200 after wash

(D) - \#200 from sieving (Pan Weight)

(T) Total passing \#200 (C + D)

Note: Report all values to the nearest tenth (0.1)

\section{WEST VIRGINIA DIVISION OF HIGHWAYS}

WASHED SIEVE ANALYSIS 
(AASHTO T-11 AND T-27)

\begin{tabular}{|c|c|c|c|}
\hline \multirow{2}{*}{$\begin{array}{l}\text { Producer } \\
\text { Type of Mix }\end{array}$} & Boxley & \multirow{2}{*}{$\begin{array}{c}\text { Aggregate Source } \\
\text { Aggregate Type }\end{array}$} & \multirow{2}{*}{$\begin{array}{l}\text { G079A } \\
\text { L/S 8s }\end{array}$} \\
\hline & & & \\
\hline Technician & Mark Isaacs & Date & $1 / 7 / 14$ \\
\hline $\begin{array}{c}\text { Sieve } \\
\text { Size } \\
\end{array}$ & $\begin{array}{c}\text { Weight } \\
\text { Retained }\end{array}$ & $\begin{array}{l}\text { Percent } \\
\text { Loss }\end{array}$ & $\begin{array}{l}\text { Percent } \\
\text { Passing }\end{array}$ \\
\hline $21 / 2 "(63 \mathrm{~mm})$ & & 0.0 & 100.0 \\
\hline $2^{\prime \prime}(50 \mathrm{~mm})$ & & 0.0 & 100.0 \\
\hline $11 / 2^{\prime \prime}(37.5 \mathrm{~mm})$ & 0.0 & 0.0 & 100.0 \\
\hline $1^{\prime \prime}(25 \mathrm{~mm})$ & 0.0 & 0.0 & 100.0 \\
\hline $3 / 4^{\prime \prime}(19 \mathrm{~mm})$ & 0.0 & 0.0 & 100.0 \\
\hline $1 / 2^{\prime \prime}(12.5 \mathrm{~mm})$ & 0.0 & 0.0 & 100.0 \\
\hline $3 / 8^{\prime \prime}(9.5 \mathrm{~mm})$ & 196.3 & 12.4 & 87.5 \\
\hline$\# 4(4.75 \mathrm{~mm})$ & 1212.6 & 76.8 & 10.7 \\
\hline$\# 8(2.36 \mathrm{~mm})$ & 134.9 & 8.5 & 2.2 \\
\hline$\# 16(1.18 \mathrm{~mm})$ & 6.9 & 0.4 & 1.8 \\
\hline$\# 30$ (600um) & 1.6 & 0.1 & 1.7 \\
\hline$\# 50$ (300um) & 0.9 & 0.1 & 1.6 \\
\hline \#100 (150um) & 1.3 & 0.1 & 1.5 \\
\hline$\# 200$ (75um) & 2.1 & 0.1 & 1.4 \\
\hline$-\# 200$ & 22.0 & 1.4 & \\
\hline Total & 1578.6 & & \\
\hline A) Weight of origi & sample & & 1579.3 \\
\hline B) Weight after w & & & 1559.3 \\
\hline C) Loss of - \#200 & r wash & & 20.0 \\
\hline D) - \#200 from sie & (Pan Weight) & & 2.0 \\
\hline T) Total passing & $(C+D)$ & & 22.0 \\
\hline
\end{tabular}

Note: Report all values to the nearest tenth $(0.1)$

Figure 44 - Aggregate Gradation 3 L/S 8's 
WORKSHEET FOR CALCULATING BULK SPECIFIC GRAVITY AND ABSORPTION OF FINE AGGREGATE

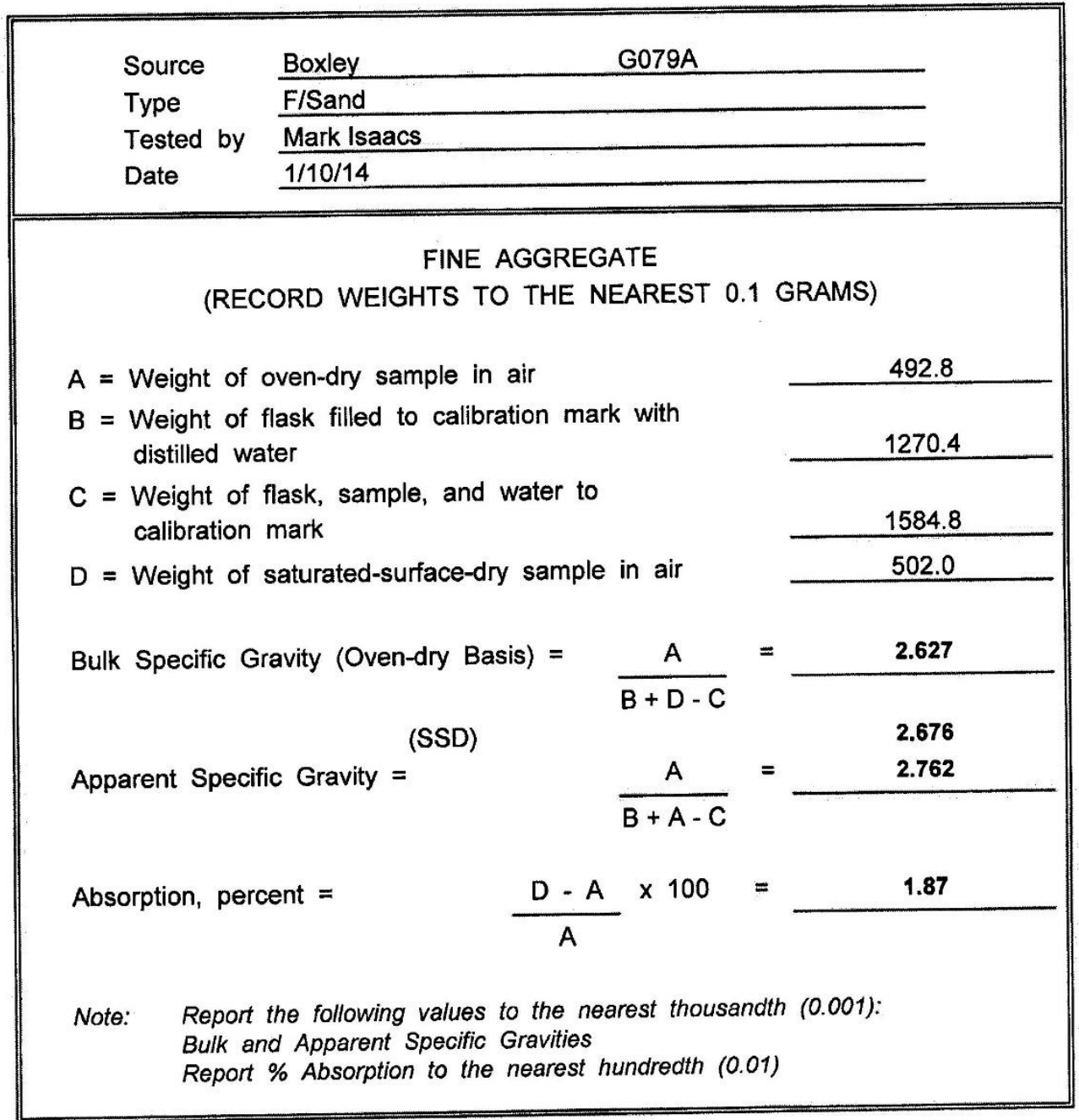




\section{WEST VIRGINIA DIVISION OF HIGHWAYS}

WASHED SIEVE ANALYSIS

(AASHTO T-11 AND T-27)

\begin{tabular}{|c|c|c|c|}
\hline Producer & Boxley & Aggregate Source & G079A \\
\hline Type of Mix & & Aggregate Type & F/Sand \\
\hline Technician & Mark Isaacs & Date & $1 / 10 / 14$ \\
\hline
\end{tabular}

\begin{tabular}{|c|c|c|c|}
\hline $\begin{array}{l}\text { Sieve } \\
\text { Size }\end{array}$ & $\begin{array}{c}\text { Weight } \\
\text { Retained }\end{array}$ & $\begin{array}{l}\text { Percent } \\
\text { Loss }\end{array}$ & $\begin{array}{l}\text { Percent } \\
\text { Passing }\end{array}$ \\
\hline $21 / 2^{\prime \prime}(63 \mathrm{~mm})$ & & 0.0 & 99.8 \\
\hline $2^{\prime \prime}(50 \mathrm{~mm})$ & & 0.0 & 99.8 \\
\hline $11 / 2 "(37.5 \mathrm{~mm})$ & 0.0 & 0.0 & 99.8 \\
\hline $1^{\prime \prime}(25 \mathrm{~mm})$ & 0.0 & 0.0 & 99.8 \\
\hline $3 / 4^{\prime \prime}(19 \mathrm{~mm})$ & 0.0 & 0.0 & 99.8 \\
\hline $1 / 2^{\prime \prime}(12.5 \mathrm{~mm})$ & 0.0 & 0.0 & 99.8 \\
\hline $3 / 8^{\prime \prime}(9.5 \mathrm{~mm})$ & 0.0 & 0.0 & 99.8 \\
\hline$\# 4$ (4.75mm) & 5.1 & 1.4 & 98.4 \\
\hline$\# 8(2.36 \mathrm{~mm})$ & 97.0 & 26.4 & 72.0 \\
\hline$\# 16(1.18 \mathrm{~mm})$ & 88.6 & 24.1 & 47.9 \\
\hline$\# 30$ (600um) & 45.9 & 12.5 & 35.4 \\
\hline$\# 50$ (300um) & 39.6 & 10.8 & 24.6 \\
\hline$\# 100$ (150um) & 30.2 & 8.2 & 16.4 \\
\hline$\# 200$ (75um) & 19.9 & 5.4 & 11.0 \\
\hline$-\# 200$ & 40.4 & 11.0 & \\
\hline Total & 366.7 & & \\
\hline \multicolumn{3}{|c|}{$\begin{array}{l}\text { (A) Weight of original sample } \\
\text { (B) Weight after wash } \\
\text { (C) Loss of - \#200 after wash } \\
\text { (D) - \#200 from sieving (Pan Weight) } \\
\text { (T) Total passing \#200 (C + D) }\end{array}$} & \begin{tabular}{c|}
$\frac{366.9}{329.6}$ \\
$\frac{37.3}{3.1}$ \\
40.4 \\
\end{tabular} \\
\hline
\end{tabular}

Note: Report all values to the nearest tenth (0.1)

Figure 46 - Aggregate Gradation 1 L/S F-Sand 


\section{WEST VIRGINIA DIVISION OF HIGHWAYS}

WASHED SIEVE ANALYSIS

(AASHTO T-11 AND T-27)

\begin{tabular}{|c|c|c|c|}
\hline Producer & Boxley & Aggregate Source & G079A \\
\hline Type of Mix & & Aggregate Type & F/Sand \\
\hline Technician & Mark Isaacs & Date & $1 / 10 / 14$ \\
\hline
\end{tabular}

\begin{tabular}{|c|c|c|c|}
\hline $\begin{array}{c}\text { Sieve } \\
\text { Size } \\
\end{array}$ & $\begin{array}{l}\text { Weight } \\
\text { Retained }\end{array}$ & $\begin{array}{l}\text { Percent } \\
\text { Loss }\end{array}$ & $\begin{array}{l}\text { Percent } \\
\text { Passing }\end{array}$ \\
\hline $21 / 2^{\prime \prime}(63 \mathrm{~mm})$ & & 0.0 & 99.9 \\
\hline $2^{\prime \prime}(50 \mathrm{~mm})$ & & 0.0 & 99.9 \\
\hline $11 / 2^{\prime \prime}(37.5 \mathrm{~mm})$ & 0.0 & 0.0 & 99.9 \\
\hline $1^{\prime \prime}(25 \mathrm{~mm})$ & 0.0 & 0.0 & 99.9 \\
\hline $3 / 4^{\prime \prime}(19 \mathrm{~mm})$ & 0.0 & 0.0 & 99.9 \\
\hline $1 / 2^{\prime \prime}(12.5 \mathrm{~mm})$ & 0.0 & 0.0 & 99.9 \\
\hline $3 / 8^{\prime \prime}(9.5 \mathrm{~mm})$ & 0.0 & 0.0 & 99.9 \\
\hline$\# 4(4.75 \mathrm{~mm})$ & 4.1 & 1.2 & 98.7 \\
\hline$\# 8(2.36 \mathrm{~mm})$ & 80.1 & 23.8 & 74.9 \\
\hline$\# 16(1.18 \mathrm{~mm})$ & 66.9 & 19.9 & 55.0 \\
\hline$\# 30$ (600um) & 57.6 & 17.1 & 37.9 \\
\hline$\# 50$ (300um) & 44.9 & 13.4 & 24.5 \\
\hline$\# 100$ (150um) & 31.9 & 9.5 & 15.0 \\
\hline$\# 200$ (75um) & 15.7 & 4.7 & 10.3 \\
\hline$-\# 200$ & 34.6 & 10.3 & \\
\hline Total & 335.8 & & \\
\hline \multicolumn{3}{|c|}{$\begin{array}{l}\text { (A) Weight of original sample } \\
\text { (B) Weight after wash } \\
\text { (C) Loss of - \#200 after wash } \\
\text { (D) - \#200 from sieving (Pan Weight) } \\
\text { (T) Total passing \#200 (C + D) }\end{array}$} & $\begin{array}{c}335.9 \\
302.9 \\
33.0 \\
1.6 \\
34.6 \\
\end{array}$ \\
\hline
\end{tabular}

Note: Report all values to the nearest tenth (0.1)

Figure 47 -- Aggregate Gradation 2 L/S F-Sand 


\section{WEST VIRGINIA DIVISION OF HIGHWAYS}

WASHED SIEVE ANALYSIS

(AASHTO T-11 AND T-27)

Producer

Boxley

Aggregate Source

G079A

Type of Mix

Technician

Mark Isaacs

Aggregate Type

F/Sand

Date $\quad 1 / 10 / 14$

\begin{tabular}{|c|c|c|c|}
\hline $\begin{array}{c}\text { Sieve } \\
\text { Size } \\
\end{array}$ & $\begin{array}{c}\text { Weight } \\
\text { Retained }\end{array}$ & $\begin{array}{l}\text { Percent } \\
\text { Loss }\end{array}$ & $\begin{array}{l}\text { Percent } \\
\text { Passing }\end{array}$ \\
\hline $21 / 2 "(63 \mathrm{~mm})$ & & 0.0 & 100.0 \\
\hline $2 "(50 \mathrm{~mm})$ & & 0.0 & 100.0 \\
\hline $11 / 2 "(37.5 \mathrm{~mm})$ & 0.0 & 0.0 & 100.0 \\
\hline 1" $(25 \mathrm{~mm})$ & 0.0 & 0.0 & 100.0 \\
\hline $3 / 4^{\prime \prime}(19 \mathrm{~mm})$ & 0.0 & 0.0 & 100.0 \\
\hline $1 / 2 "(12.5 \mathrm{~mm})$ & 0.0 & 0.0 & 100.0 \\
\hline $3 / 8^{\prime \prime}(9.5 \mathrm{~mm})$ & 0.0 & 0.0 & 100.0 \\
\hline$\# 4(4.75 \mathrm{~mm})$ & 1.9 & 0.6 & 99.4 \\
\hline$\# 8(2.36 \mathrm{~mm})$ & 83.9 & 24.4 & 75.0 \\
\hline$\# 16(1.18 \mathrm{~mm})$ & 66.8 & 19.4 & 55.6 \\
\hline$\# 30$ (600um) & 56.1 & 16.3 & 39.3 \\
\hline$\# 50$ (300um) & 44.9 & 13.0 & 26.3 \\
\hline$\# 100$ (150um) & 31.6 & 9.2 & 17.1 \\
\hline$\# 200$ (75um) & 18.9 & 5.5 & 11.6 \\
\hline$-\# 200$ & 39.8 & 11.6 & \\
\hline Total & 343.9 & & \\
\hline \multirow{5}{*}{\multicolumn{3}{|c|}{$\begin{array}{l}\text { (A) Weight of original sample } \\
\text { (B) Weight after wash } \\
\text { (C) Loss of - \#200 after wash } \\
\text { (D) - \#200 from sieving (Pan Weight) } \\
\text { (T) Total passing \#200 (C + D) }\end{array}$}} & 344.2 \\
\hline & & & 305.3 \\
\hline & & & 38.9 \\
\hline & & & 0.9 \\
\hline & & & 39.8 \\
\hline
\end{tabular}

Note: Report all values to the nearest tenth (0.1)

Figure 48 - Aggregate Gradation 3 L/S F-Sand 


\section{WORKSHEET FOR CALCULATING BULK SPECIFIC} GRAVITY AND ABSORPTION OF FINE AGGREGATE

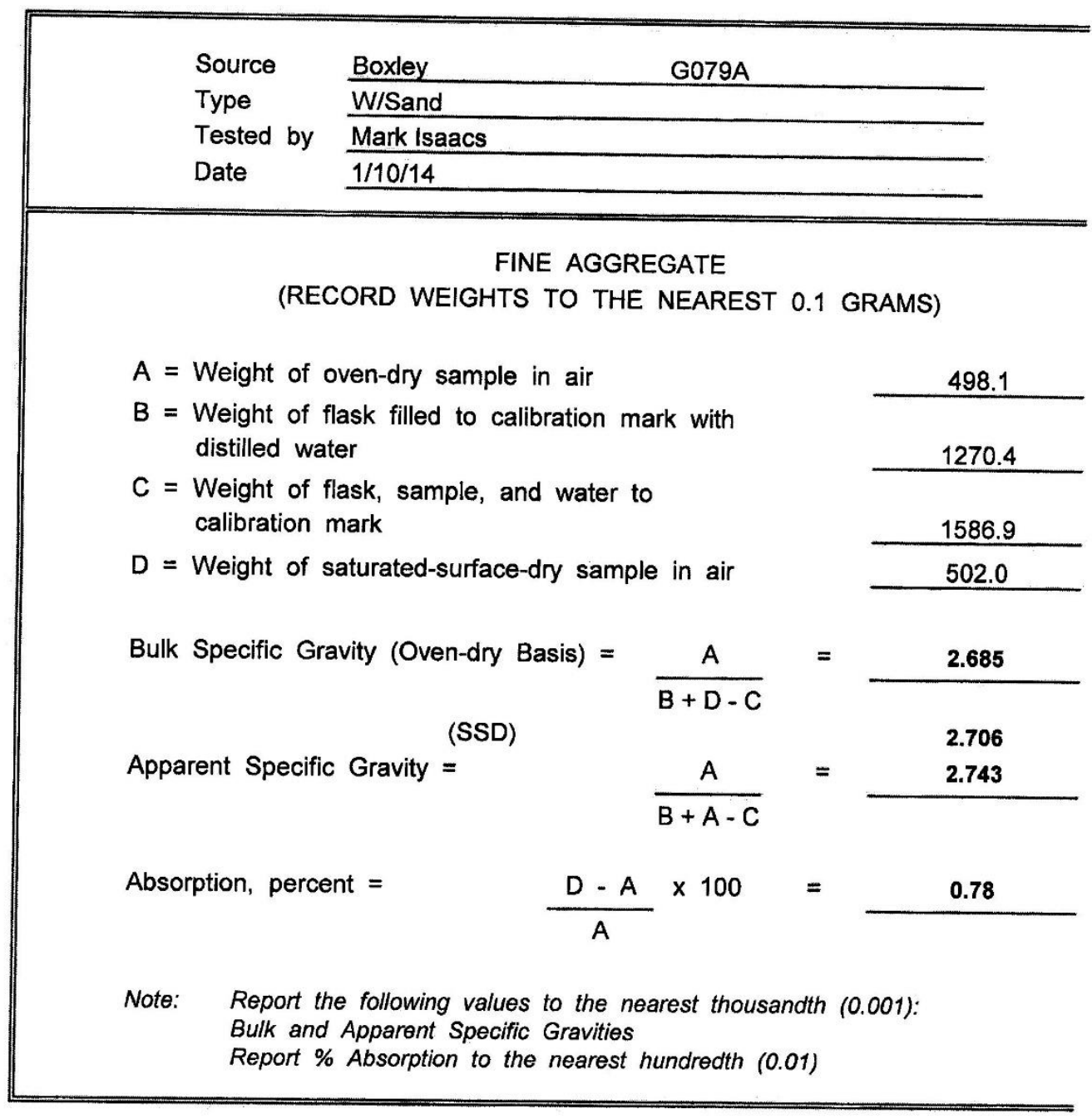




\title{
WEST VIRGINIA DIVISION OF HIGHWAYS
}

\author{
WASHED SIEVE ANALYSIS \\ (AASHTO T-11 AND T-27)
}

\begin{tabular}{|c|c|c|c|}
\hline Producer & Boxley & Aggregate Source & G079A \\
\hline Type of Mix & & Aggregate Type & W/Sand \\
\hline Technician & Mark Isaacs & Date & $1 / 10 / 14$ \\
\hline
\end{tabular}

\begin{tabular}{|c|c|c|c|}
\hline $\begin{array}{c}\text { Sieve } \\
\text { Size } \\
\end{array}$ & $\begin{array}{c}\text { Weight } \\
\text { Retained } \\
\end{array}$ & $\begin{array}{c}\text { Percent } \\
\text { Loss } \\
\end{array}$ & $\begin{array}{l}\text { Percent } \\
\text { Passing }\end{array}$ \\
\hline $21 / 2 "(63 \mathrm{~mm})$ & in & 0.0 & 99.9 \\
\hline $2^{\prime \prime}(50 \mathrm{~mm})$ & + & 0.0 & 99.9 \\
\hline $11 / 2^{\prime \prime}(37.5 \mathrm{~mm})$ & 0.0 & 0.0 & 99.9 \\
\hline $1^{\prime \prime}(25 \mathrm{~mm})$ & 0.0 & 0.0 & 99.9 \\
\hline $3 / 4^{\prime \prime}(19 \mathrm{~mm})$ & 0.0 & 0.0 & 99.9 \\
\hline $1 / 2 "(12.5 \mathrm{~mm})$ & 0.0 & 0.0 & 99.9 \\
\hline $3 / 8^{\prime \prime}(9.5 \mathrm{~mm})$ & 0.0 & 0.0 & 99.9 \\
\hline$\# 4(4.75 \mathrm{~mm})$ & 2.1 & 0.6 & 99.3 \\
\hline$\# 8(2.36 \mathrm{~mm})$ & 94.6 & 26.6 & 72.7 \\
\hline$\# 16(1.18 \mathrm{~mm})$ & 85.6 & 24.1 & 48.6 \\
\hline$\# 30$ (600um) & 65.1 & 18.3 & 30.3 \\
\hline$\# 50$ (300um) & 49.9 & 14.0 & 16.3 \\
\hline$\# 100$ (150um) & 33.2 & 9.3 & 7.0 \\
\hline$\# 200$ (75um) & 15.8 & 4.4 & 2.6 \\
\hline$-\# 200$ & 9.1 & 2.6 & \\
\hline Total & 355.4 & & \\
\hline \multirow{6}{*}{\multicolumn{3}{|c|}{$\begin{array}{l}\text { (A) Weight of original sample } \\
\text { (B) Weight after wash } \\
\text { (C) Loss of - \#200 after wash } \\
\text { (D) - \#200 from sieving (Pan Weight) } \\
\text { (T) Total passing \#200 (C + D) }\end{array}$}} & \\
\hline & & & 355.6 \\
\hline & & & 347.2 \\
\hline & & & 8.4 \\
\hline & & & 0.7 \\
\hline & & & 9.1 \\
\hline
\end{tabular}

Note: Report all values to the nearest tenth (0.1) 


\title{
WEST VIRGINIA DIVISION OF HIGHWAYS
}

\author{
WASHED SIEVE ANALYSIS \\ (AASHTO T-11 AND T-27)
}

\begin{tabular}{|c|c|c|c|}
\hline Producer & Boxley & Aggregate Source & G079A \\
\hline Type of Mix & & Aggregate Type & W/Sand \\
\hline Technician & Mark Isaacs & Date & $1 / 10 / 14$ \\
\hline
\end{tabular}

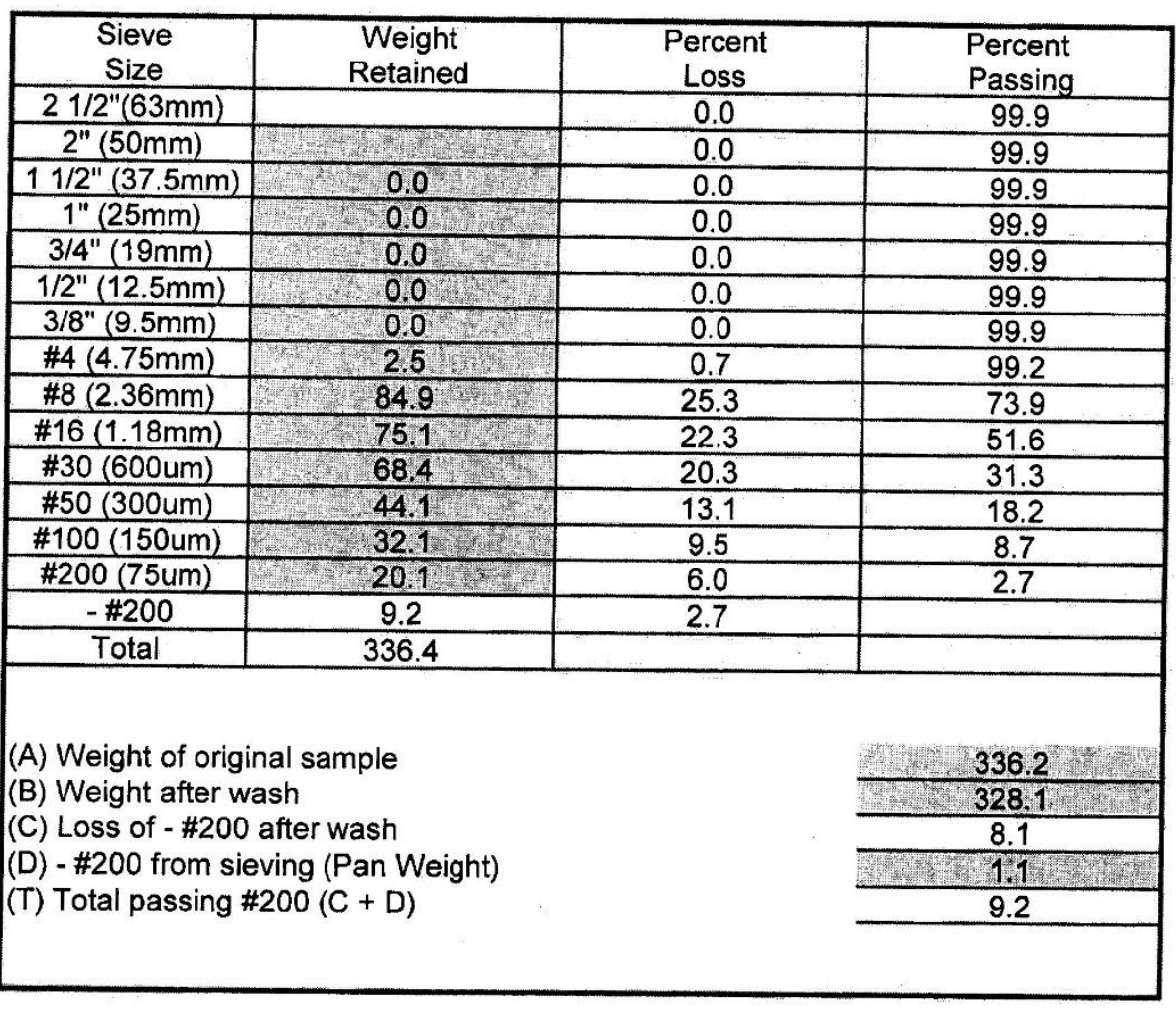

Note: Report all values to the nearest tenth (0.1)

\section{WEST VIRGINIA DIVISION OF HIGHWAYS}

WASHED SIEVE ANALYSIS 
(AASHTO T-11 AND T-27)

\begin{tabular}{|c|c|c|c|}
\hline Producer & Boxley & Aggregate Source & G079A \\
\hline Type of Mix & & Aggregate Type & W/Sand \\
\hline Technician & Mark Isaacs & Date & $1 / 10 / 14$ \\
\hline
\end{tabular}

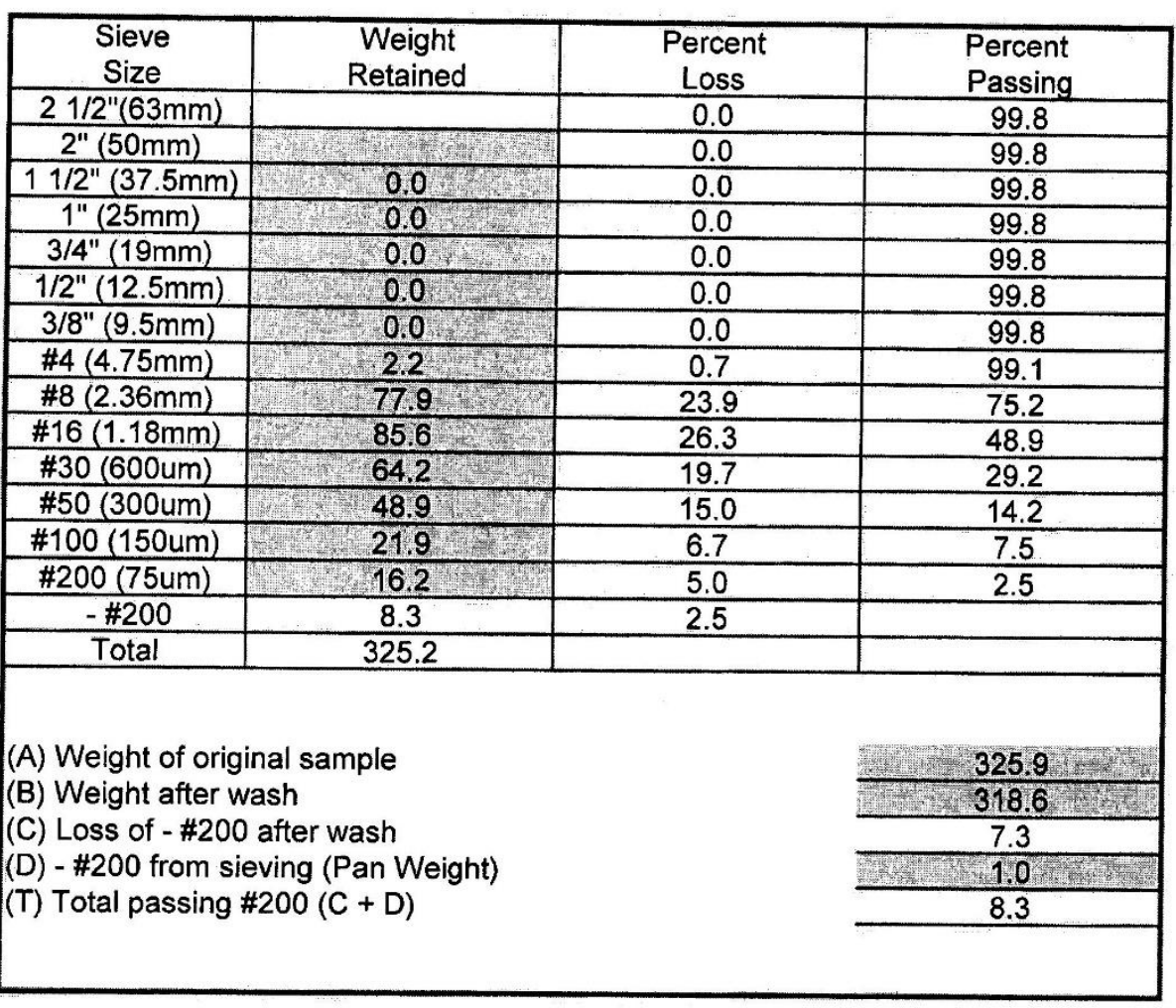

Note: Report all values to the nearest tenth (0.1)

Figure 52 - Aggregate Gradation 3 L/S W-Sand 
RAP Properties

T417

Rev. 01-01

\author{
Burnoff \#1 \\ West Virginia Division of Highways
}

Asphalt Content By Ignition Method (AASHTO T308, Test Method A) And

Mechanical Analysis Of Extracted Aggregate - AASHTO T30

Lab Number:

Material: Ret oi

Field Sample \#: $1 \mathrm{~A}$

Technician:

LhS T400\#:
Cal. Factor: Date: $3 / 24 / 15$

\begin{tabular}{|c|c|c|c|c|c|}
\hline \multicolumn{2}{|r|}{ Data Before Ignition } & Test Temp: $5388^{\circ} \mathrm{C}$ & \multicolumn{3}{|c|}{ Data After Ignition } \\
\hline & \multirow{3}{*}{$\begin{array}{l}\text { Weight of Basket }+ \text { Sample } \\
\text { Weight of Basket } \\
\text { Sample Weight }(A-B)\end{array}$} & $44 \Gamma \cdot 2$ & \multirow{3}{*}{\multicolumn{2}{|c|}{$\begin{array}{l}\text { (D) Weight of Basket + Aggregate } \\
\text { (E) Weight of Basket } \\
\text { (F) Aggregate Weight (D - E) }\end{array}$}} & \multirow{3}{*}{$\begin{array}{l}4369.5 \\
3408.8 \\
960.7\end{array}$} \\
\hline & & 3408.7 & & & \\
\hline & & 1008.5 & & & \\
\hline \multirow{2}{*}{\multicolumn{5}{|c|}{ (K) Percent Asphalt Check: $\quad\{[(\mathrm{C}-\mathrm{F}) / \mathrm{C}] \times 100-$ (Calibration Factor) $\}$}} & 4.74 \\
\hline \multicolumn{3}{|c|}{ Asphalt Content From Ignition Oven Printout Shall Be Used As Actual \% Asphalt } & & & $4+24$ \\
\hline \multicolumn{3}{|c|}{ Minus $75 \mu \mathrm{m}$ Material } & \multicolumn{3}{|c|}{ Washed Grading } \\
\hline \multirow{3}{*}{ (L) } & \multirow{3}{*}{$\begin{array}{l}\text { Weight In Pan After Gradation } \\
\text { Loss On Wash }(Q) \\
\text { Total - } 200(75 \mu \mathrm{m}) \text { Material }(L+Q)\end{array}$} & & \multirow{3}{*}{\multicolumn{2}{|c|}{$\begin{array}{l}\text { (N) Weight Before Wash } \\
\text { (O) Weight After Wash } \\
\text { (Q) Loss }(\mathrm{N}-\mathrm{O})\end{array}$}} & \\
\hline & & & & & \\
\hline & & & & & \\
\hline (S) & \multicolumn{4}{|c|}{ Total Aggregate In Sample For Gradation Calculations : } & \\
\hline
\end{tabular}

\begin{tabular}{|c|c|c|c|c|c|}
\hline \multicolumn{6}{|c|}{ Gradation Analysis } \\
\hline $\begin{array}{l}\text { Sieve } \\
\text { Size }\end{array}$ & $\begin{array}{c}\text { Weight } \\
\text { Retained }\end{array}$ & $\begin{array}{l}\text { Percent } \\
\text { Retained }\end{array}$ & $\begin{array}{l}\text { Percent } \\
\text { Passing }\end{array}$ & $\begin{array}{c}\text { Reported } \\
\text { Percent Passing }\end{array}$ & $\begin{array}{c}\text { Tolerance } \\
\text { Limits }\end{array}$ \\
\hline \multicolumn{6}{|l|}{2 in $(50 \mathrm{~mm})$} \\
\hline \multicolumn{6}{|l|}{$11 / 2 \mathrm{in}(37.5 \mathrm{~mm})$} \\
\hline \multicolumn{6}{|l|}{$1 \mathrm{in}(25 \mathrm{~mm})$} \\
\hline \multicolumn{6}{|l|}{$3 / 4$ in $(19 \mathrm{~mm})$} \\
\hline \multicolumn{6}{|l|}{$1 / 2$ in $(12.5 \mathrm{~mm})$} \\
\hline \multicolumn{6}{|l|}{$3 / 8 \mathrm{in}(9.5 \mathrm{~mm})$} \\
\hline \multicolumn{6}{|l|}{ No. $4(4.75 \mathrm{~mm})$} \\
\hline \multicolumn{6}{|l|}{ No. $8(2.36 \mathrm{~mm})$} \\
\hline \multicolumn{6}{|l|}{ No. $16(1.18) \mathrm{mm}$} \\
\hline \multicolumn{6}{|l|}{ No. $30(600 \mu \mathrm{m})$} \\
\hline \multicolumn{6}{|l|}{ No. $50(300 \mu \mathrm{m})$} \\
\hline \multicolumn{6}{|l|}{ No. $200(75 \mu \mathrm{m})$} \\
\hline \multicolumn{6}{|l|}{$-200(75 \mu \mathrm{m})(\mathrm{M})$} \\
\hline Total Wt. (W) & & & \multirow{2}{*}{\multicolumn{3}{|c|}{$\begin{array}{l}\text { The Summation Of The Retained Weights Of All } \\
\text { Of The Sieves Plus The Pan Weight Must Check } \\
\text { The Dry Weight After Wash }(O) \text { Within } 0.2 \% \text { Of } \\
\text { The Total Weight }(X) \text {. }\end{array}$}} \\
\hline $\begin{aligned} & 0.2 \% \text { Check: } \\
&= \text { Total Weight } \\
&\end{aligned}$ & $(X) \quad \begin{array}{l}W-Q \\
\end{array}$ & $\begin{array}{r}100(\mathrm{O}-\mathrm{X}) / 0 \\
\% \\
\end{array}$ & & & \\
\hline
\end{tabular}

Attach all asphalt content oven printouts to this report. 
T417

Rev. 01-01

West Virginia Division of Highways

Asphalt Content By Ignition Method (AASHTO T308, Test Method A) And Mechanical Analysis Of Extracted Aggregate - AASHTO T30

Lab Number:

Material: Pass.

Field Sample \#: 18

Technician: T400 \#: Cal. Factor: Date: 3/24/15

Data Before Ignition

Test Temp: 540

Data After Ignition

(A) Weight of Basket + Sample

(B) Weight of Basket

4296.5

3351.9

944.6

(D) Weight of Basket + Aggregate

(E) Weight of Basket

(F) Aggregate Weight (D - E)

4229.7

(C) Sample Weight (A - B)

$\{[(C-F) / C] \times 100$ - (Calibration Factor $)\}$ 3351.9

(K) Percent Asphalt Check: Asphalt Content From Ignition Oven Printout Shall Be Used As Actual \% Asphalt 877.8 Minus $75 \mu \mathrm{m}$ Material

(L) Weight In Pan After Gradation Loss On Wash (Q)

(M) Total - $200(75 \mu \mathrm{m})$ Material $(L+Q)$ Washed Grading

(S) Total Aggregate In Sample For Gradation Calculations :
(N) Weight Before Wash
(O) Weight After Wash
(Q) Loss $(\mathrm{N}-\mathrm{O})$ 4.07 7.00

\begin{tabular}{|c|c|c|c|c|c|}
\hline \multicolumn{6}{|c|}{ Gradation Analysis } \\
\hline $\begin{array}{l}\text { Sieve } \\
\text { Size }\end{array}$ & $\begin{array}{l}\text { Weight } \\
\text { Retained }\end{array}$ & $\begin{array}{l}\text { Percent } \\
\text { Retained }\end{array}$ & $\begin{array}{l}\text { Percent } \\
\text { Passing }\end{array}$ & $\begin{array}{c}\text { Reported } \\
\text { Percent Passing }\end{array}$ & $\begin{array}{c}\text { Tolerance } \\
\text { Limits }\end{array}$ \\
\hline \multicolumn{6}{|l|}{2 in $(50 \mathrm{~mm})$} \\
\hline \multicolumn{6}{|l|}{$11 / 2$ in $(37.5 \mathrm{~mm})$} \\
\hline \multicolumn{6}{|l|}{$1 \mathrm{in}(25 \mathrm{~mm})$} \\
\hline \multicolumn{6}{|l|}{$3 / 4$ in $(19 \mathrm{~mm})$} \\
\hline \multicolumn{6}{|l|}{$1 / 2$ in $(12.5 \mathrm{~mm})$} \\
\hline \multicolumn{6}{|l|}{$3 / 8 \mathrm{in}(9.5 \mathrm{~mm})$} \\
\hline \multicolumn{6}{|l|}{ No. $4(4.75 \mathrm{~mm})$} \\
\hline \multicolumn{6}{|l|}{ No. $8(2.36 \mathrm{~mm})$} \\
\hline \multicolumn{6}{|l|}{ No. $16(1.18) \mathrm{mm}$} \\
\hline \multicolumn{6}{|l|}{ No. $30(600 \mu \mathrm{m})$} \\
\hline \multicolumn{6}{|l|}{ No. $50(300 \mu \mathrm{m})$} \\
\hline \multicolumn{6}{|l|}{ No. $200(75 \mu \mathrm{m})$} \\
\hline \multicolumn{6}{|l|}{$-200(75 \mu \mathrm{m})(\mathrm{M})$} \\
\hline Total Wt. (W) & & & \multirow{2}{*}{\multicolumn{3}{|c|}{$\begin{array}{l}\text { The Summation Of The Retained Weights Of All } \\
\text { Of The Sieves Plus The Pan Weight Must Check } \\
\text { The Dry Weight After Wash (O) Within } 0.2 \% \text { Of } \\
\text { The Total Weight }(X) \text {. }\end{array}$}} \\
\hline $\begin{aligned} & 0.2 \% \text { Check: } \\
&= \text { Total Weight } \\
&\end{aligned}$ & $\begin{array}{r}W-Q \\
\end{array}$ & $\begin{array}{r}100(0-X) / 0 \\
\% \\
\end{array}$ & & & \\
\hline
\end{tabular}

Attach all asphalt content oven printouts to this report. 
T417

Rev. 01-01

West Virginia Division of Highways

Asphalt Content By Ignition Method (AASHTO T308, Test Method A) And Mechanical Analysis Of Extracted Aggregate - AASHTO T30

Lab Number: Material: Burnoff 1

Technician: LK.S T400 \#:

Field Sample \#:

\begin{tabular}{|c|c|c|c|c|c|}
\hline \multicolumn{2}{|r|}{ Data Before Ignition } & Test Temp: & \multicolumn{3}{|c|}{ Data After Ignition } \\
\hline & Weight of Basket + Sample & & \multirow{3}{*}{\multicolumn{2}{|c|}{$\begin{array}{l}\text { (D) Weight of Basket + Aggregate } \\
\text { (E) Weight of Basket } \\
\text { (F) Aggregate Weight (D-E) }\end{array}$}} & \\
\hline (B) & \multirow{2}{*}{$\begin{array}{l}\text { Weight of Basket } \\
\text { Sample Weight }(A-B)\end{array}$} & & & & \\
\hline (C) & & & & & \\
\hline (K) & \multicolumn{4}{|c|}{$[(C-F) / C] \times 100-($ Calibration Factor $)$} & \\
\hline \multicolumn{5}{|c|}{ Asphalt Content From Ignition Oven Printout Shall Be Used As Actual \% Asphalt } & \\
\hline \multicolumn{3}{|c|}{ Minus $75 \mu \mathrm{m}$ Material } & \multicolumn{3}{|c|}{ Washed Grading } \\
\hline \multirow[t]{3}{*}{ (L) } & \multirow{3}{*}{$\begin{array}{l}\text { Weight In Pan After Gradation } \\
\text { Loss On Wash }(Q) \\
\text { Total - } 200(75 \mu \mathrm{m}) \text { Material }(L+Q)\end{array}$} & 1.2 & \multirow{3}{*}{\multicolumn{2}{|c|}{$\begin{array}{l}\text { (N) Weight Before Wash } \\
\text { (O) Weight After Wash } \\
\text { (Q) Loss (N - O) }\end{array}$}} & 1748.2 \\
\hline & & 138.3 & & & 16099 \\
\hline & & 139.5 & & & 138.3 \\
\hline
\end{tabular}

\begin{tabular}{|c|c|c|c|c|c|}
\hline \multicolumn{6}{|c|}{ Gradation Analysis } \\
\hline $\begin{array}{l}\text { Sieve } \\
\text { Size }\end{array}$ & $\begin{array}{c}\text { Weight } \\
\text { Retained }\end{array}$ & $\begin{array}{l}\text { Percent } \\
\text { Retained }\end{array}$ & $\begin{array}{l}\text { Percent } \\
\text { Passing }\end{array}$ & $\begin{array}{c}\text { Reported } \\
\text { Percent Passing }\end{array}$ & $\begin{array}{l}\text { Tolerance } \\
\text { Limits }\end{array}$ \\
\hline 2 in $(50 \mathrm{~mm})$ & 0 & 0 & & & \\
\hline $11 / 2$ in $(37.5 \mathrm{~mm})$ & 0 & 0 & & & \\
\hline $1 \mathrm{in}(25 \mathrm{~mm})$ & 0 & 0 & & & \\
\hline $3 / 4 \mathrm{in}(19 \mathrm{~mm})$ & 0 & 0 & & & \\
\hline $1 / 2$ in $(12.5 \mathrm{~mm})$ & 0 & 0 & & & \\
\hline $3 / 8 \mathrm{in}(9.5 \mathrm{~mm})$ & 60.0 & 3.4 & & & \\
\hline No. $4(4.75 \mathrm{~mm})$ & 442.5 & 25.3 & & & \\
\hline No. $8(2.36 \mathrm{~mm})$ & 392.2 & 22.4 & & & \\
\hline No. $16(1.18) \mathrm{mm}$ & 300.8 & 17.2 & & & \\
\hline №. $30(600 \mu \mathrm{m})$ & 184.4 & 10.5 & & & \\
\hline No. $50(300 \mu \mathrm{m})$ & 124.5 & 7.1 & & & \\
\hline No. $200(75 \mu \mathrm{m})$ & $\begin{array}{l}20.4 \\
23.4\end{array}$ & $\begin{array}{l}4.6 \\
1.3\end{array}$ & & & \\
\hline$-200(75 \mu \mathrm{m})(\mathrm{M})$ & 139.5 & 8.0 & & & \\
\hline Total Wt. (W) & 1748.2 & & \multirow{3}{*}{\multicolumn{3}{|c|}{$\begin{array}{l}\text { The Summation Of The Retained Weights Of All } \\
\text { Of The Sieves Plus The Pan Weight Must Check } \\
\text { The Dry Weight After Wash }(O) \text { Within } 0.2 \% \text { Of } \\
\text { The Total Weight }(X) \text {. }\end{array}$}} \\
\hline $\begin{aligned} & 0.2 \% \text { Check: } \\
= & \text { Total Weight }\end{aligned}$ & $\begin{array}{r}W-Q \\
(X) 1609.9 \\
\end{array}$ & $\begin{array}{r}100(0-X) / 0 \\
\% \\
\end{array}$ & & & \\
\hline & & & & & \\
\hline
\end{tabular}

Attach all asphalt content oven printouts to this report. 


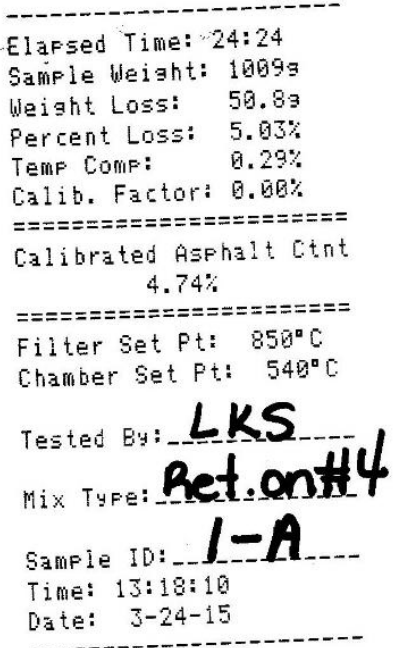

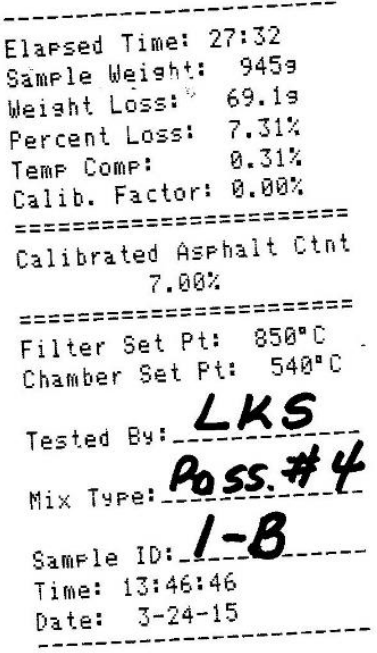

Figure 56 - RAP Burnoff 1 Printouts 
T417

Rev. 01-01

West Virginia Division of Highways

Asphalt Content By Ignition Method (AASHTO T308, Test Method A) And Mechanical Analysis Of Extracted Aggregate - AASHTO T30

Lab Number:

Material: Ret.on 4

Field Sample \#: $2 \mathrm{~A}$

Technician: T400 \#: Cal. Factor: Date: $3 / 25 / 15$

\begin{tabular}{l|l|l}
\hline Data Before Ignition & Test Temp: 540 & ${ }^{\circ} \mathrm{C}$
\end{tabular}

Data After Ignition

(A) Weight of Basket + Sample

(B) Weight of Basket 4495.8 3408.7 $108 \% .1$

(D) Weight of Basket + Aggregate

(E) Weight of Basket

(C) Sample Weight (A - B)

(F) Aggregate Weight (D - E)

(K) Percent Asphalt Check:

$\{[(\mathrm{C}-\mathrm{F}) / \mathrm{C}] \times 100$ - (Calibration Factor) $\}$

Asphalt Content From Ignition Oven Printout Shall Be Used As Actual \% Asphalt Minus $75 \mu \mathrm{m}$ Material

Washed Grading

(L) Weight In Pan After Gradation Loss On Wash (Q)

(M) Total - $200(75 \mu \mathrm{m})$ Material $(L+Q)$

(S) Total Aggregate In Sample For Gradation Calculations :

(N) Weight Before Wash

(O) Weight After Wash

(Q) Loss ( $\mathrm{N}-\mathrm{O})$

Gradation Analysis

\begin{tabular}{|c|c|c|c|c|c|}
\hline $\begin{array}{l}\text { Sieve } \\
\text { Size }\end{array}$ & $\begin{array}{c}\text { Weight } \\
\text { Retained }\end{array}$ & $\begin{array}{l}\text { Percent } \\
\text { Retained } \\
\end{array}$ & $\begin{array}{l}\text { Percent } \\
\text { Passing }\end{array}$ & $\begin{array}{c}\text { Reported } \\
\text { Percent Passing }\end{array}$ & $\begin{array}{c}\text { Tolerance } \\
\text { Limits } \\
\end{array}$ \\
\hline \multicolumn{6}{|l|}{2 in $(50 \mathrm{~mm})$} \\
\hline \multicolumn{6}{|l|}{$11 / 2$ in $(37.5 \mathrm{~mm})$} \\
\hline \multicolumn{6}{|l|}{1 in $(25 \mathrm{~mm})$} \\
\hline \multicolumn{6}{|l|}{$3 / 4 \mathrm{in}(19 \mathrm{~mm})$} \\
\hline \multicolumn{6}{|l|}{$1 / 2$ in $(12.5 \mathrm{~mm})$} \\
\hline \multicolumn{6}{|l|}{$3 / 8 \mathrm{in}(9.5 \mathrm{~mm})$} \\
\hline \multicolumn{6}{|l|}{ No. $4(4.75 \mathrm{~mm})$} \\
\hline \multicolumn{6}{|l|}{ No. $8(2.36 \mathrm{~mm})$} \\
\hline \multicolumn{6}{|l|}{ No. $16(1.18) \mathrm{mm}$} \\
\hline \multicolumn{6}{|l|}{ No. $30(600 \mu \mathrm{m})$} \\
\hline \multicolumn{6}{|l|}{ No. $50(300 \mu \mathrm{m})$} \\
\hline \multicolumn{6}{|l|}{ No. $200(75 \mu \mathrm{m})$} \\
\hline \multicolumn{6}{|l|}{$-200(75 \mu \mathrm{m})(\mathrm{M})$} \\
\hline Total Wt. (W) & & & \multirow{2}{*}{\multicolumn{3}{|c|}{$\begin{array}{l}\text { The Summation Of The Retained Weights Of All } \\
\text { Of The Sieves Plus The Pan Weight Must Check } \\
\text { The Dry Weight After Wash (O) Within } 0.2 \% \text { Of } \\
\text { The Total Weight }(X) \text {. }\end{array}$}} \\
\hline $\begin{aligned} & 0.2 \% \text { Check: } \\
= & \text { Total Weight }\end{aligned}$ & $\begin{array}{l}\text { W - Q } \\
\end{array}$ & $\begin{array}{r}100(\mathrm{O}-\mathrm{X}) / 0 \\
\% \\
\end{array}$ & & & \\
\hline
\end{tabular}

Attach all asphalt content oven printouts to this report. 
T417

Rev. 01-01

West Virginia Division of Highways

Asphalt Content By Ignition Method (AASHTO T308, Test Method A) And Mechanical Analysis Of Extracted Aggregate - AASHTO T30

Lab Number:

Material: $\mathrm{Pass} \# 4$ T400\#:

Field Sample \#: $2 B$

Technician:

$14 S$

\begin{tabular}{l|l|l|}
\hline Data Before Ignition & Test Temp:540 & ${ }^{\circ} \mathrm{C}$
\end{tabular} Cal. Factor: Date: $3 / 23 / 15$

(A) Weight of Basket + Sample

(B) Weight of Basket

$+403.9$

Data After Ignition

(C) Sample Weight (A - B) $33 \% 2.0$

(D) Weight of Basket + Aggregate

(E) Weight of Basket

1051.9

(F) Aggregate Weight (D - E)

(K) Percent Asphalt Check:

$\{[(C-F) / C] \times 100-($ Calibration Factor $)\}$

4329.0

3352.0

977.0

Asphalt Content From Ignition Oven Printout Shall Be Used As Actual \% Asphalt Minus $75 \mu \mathrm{m}$ Material

(L) Weight In Pan After Gradation Loss On Wash (Q)

(M) Total - $200(75 \mu \mathrm{m})$ Material $(\mathrm{L}+\mathrm{Q})$

(S) Total Aggregate In Sample For Gradation Calculations :

Washed Grading

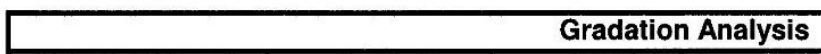

\begin{tabular}{|c|c|c|c|c|c|}
\hline \multicolumn{6}{|c|}{ Gradation Analysis } \\
\hline $\begin{array}{l}\text { Sieve } \\
\text { Size }\end{array}$ & $\begin{array}{c}\text { Weight } \\
\text { Retained }\end{array}$ & $\begin{array}{c}\text { Percent } \\
\text { Retained }\end{array}$ & $\begin{array}{l}\text { Percent } \\
\text { Passing }\end{array}$ & $\begin{array}{c}\text { Reported } \\
\text { Percent Passing }\end{array}$ & $\begin{array}{c}\text { Tolerance } \\
\text { Limits }\end{array}$ \\
\hline \multicolumn{6}{|l|}{2 in $(50 \mathrm{~mm})$} \\
\hline \multicolumn{6}{|l|}{$11 / 2$ in $(37.5 \mathrm{~mm})$} \\
\hline \multicolumn{6}{|l|}{1 in $(25 \mathrm{~mm})$} \\
\hline \multicolumn{6}{|l|}{$3 / 4$ in $(19 \mathrm{~mm})$} \\
\hline \multicolumn{6}{|l|}{$1 / 2$ in $(12.5 \mathrm{~mm})$} \\
\hline \multicolumn{6}{|l|}{$3 / 8$ in $(9.5 \mathrm{~mm})$} \\
\hline \multicolumn{6}{|l|}{ No. $4(4.75 \mathrm{~mm})$} \\
\hline \multicolumn{6}{|l|}{ No. $8(2.36 \mathrm{~mm})$} \\
\hline \multicolumn{6}{|l|}{ No. $16(1.18) \mathrm{mm}$} \\
\hline \multicolumn{6}{|l|}{ No. $30(600 \mu \mathrm{m})$} \\
\hline \multicolumn{6}{|l|}{ No. $50(300 \mu \mathrm{m})$} \\
\hline \multicolumn{6}{|l|}{ No. $200(75 \mu \mathrm{m})$} \\
\hline \multicolumn{6}{|l|}{$-200(75 \mu \mathrm{m})(\mathrm{M})$} \\
\hline Total Wt. (W) & & & \multirow{2}{*}{\multicolumn{3}{|c|}{$\begin{array}{l}\text { The Summation Of The Retained Weights Of All } \\
\text { Of The Sieves Plus The Pan Weight Must Check } \\
\text { The Dry Weight After Wash (O) Within } 0.2 \% \text { Of } \\
\text { The Total Weight }(X) \text {. }\end{array}$}} \\
\hline $\begin{aligned} & 0.2 \% \text { Check: } \\
&= \text { Total Weight } \\
&\end{aligned}$ & (X) $\begin{array}{r}W-Q \\
\end{array}$ & $\begin{array}{r}100(0-X) / 0 \\
\% \\
\end{array}$ & & & \\
\hline
\end{tabular}

Attach all asphalt content oven printouts to this report.
(N) Weight Before Wash
(O) Weight After Wash
(Q) Loss $(\mathrm{N}-\mathrm{O})$

(Line (F) Above)

Figure 58 - RAP Burnoff $2 B$ 
T417

Rev. 01-01

West Virginia Division of Highways

Asphalt Content By Ignition Method (AASHTO T308, Test Method A) And

Mechanical Analysis Of Extracted Aggregate - AASHTO T30

Lab Number:

Material: Burnoff 2

Technician: L.k.S. T400\#:

Technician: L.K.S. T400\#:

Field Sample \#:

Data Before Ignition

Test Temp:

${ }^{\circ} \mathrm{C}$

(A) Weight of Basket + Sample

(B) Weight of Basket

(C) Sample Weight (A - B)

(K) Percent Asphalt Check:

Asphalt Content From Ignition Oven Printout Shall Be Used As Actual \% Asphalt Minus $75 \mu \mathrm{m}$ Material

(L) Weight In Pan After Gradation Loss On Wash (Q)

(M) Total - $200(75 \mu \mathrm{m})$ Material $(\mathrm{L}+\mathrm{Q})$

(n)

Data After Ignition

(D) Weight of Basket + Aggregate

(E) Weight of Basket

(F) Aggregate Weight (D - E)

(S) Total Aggregate In Sample For Gradation Calculations

\begin{tabular}{|l|l|}
\hline (N) Weight Before Wash & 2013.3 \\
\cline { 2 - 2 } (O) Weight After Wash & 7755.6 \\
\cline { 2 - 2 } & 257.7 \\
\hline (Q) Loss (N - O) & (Line (F) Above) \\
\hline
\end{tabular}

\begin{tabular}{|c|c|c|c|c|c|}
\hline \multicolumn{6}{|c|}{ Gradation Analysis } \\
\hline $\begin{array}{c}\text { Sieve } \\
\text { Size }\end{array}$ & $\begin{array}{c}\text { Weight } \\
\text { Retained }\end{array}$ & $\begin{array}{l}\text { Percent } \\
\text { Retained }\end{array}$ & $\begin{array}{l}\text { Percent } \\
\text { Passing }\end{array}$ & $\begin{array}{c}\text { Reported } \\
\text { Percent Passing }\end{array}$ & $\begin{array}{c}\text { Tolerance } \\
\text { Limits } \\
\end{array}$ \\
\hline 2 in $(50 \mathrm{~mm})$ & 0 & 0 & & & \\
\hline $11 / 2$ in $(37.5 \mathrm{~mm})$ & 0 & 0 & & & \\
\hline $1 \mathrm{in}(25 \mathrm{~mm})$ & 0 & 0 & & & \\
\hline $3 / 4$ in $(19 \mathrm{~mm})$ & 0 & 0 & & & \\
\hline $1 / 2$ in $(12.5 \mathrm{~mm})$ & 0 & 0 & & & \\
\hline $3 / 8$ in $(9.5 \mathrm{~mm})$ & 70.9 & 3.5 & & & \\
\hline No. $4(4.75 \mathrm{~mm})$ & 494.4 & 24.5 & & & \\
\hline No. $8(2.36 \mathrm{~mm})$ & 426.5 & 21.2 & & & \\
\hline No. $16(1.18) \mathrm{mm}$ & 328.7 & 16.3 & & & \\
\hline No. $30(600 \mu \mathrm{m})$ & 197.3 & 98 & & & \\
\hline No. $50(300 \mu \mathrm{m})$ & 131.7 & 6.5 & & & \\
\hline No. $200(75 \mu \mathrm{m})$ & $\begin{array}{r}86.3 \\
19.8 \\
\end{array}$ & $\begin{array}{l}4.3 \\
10 \\
\end{array}$ & & & \\
\hline$-200(75 \mu \mathrm{m})(\mathrm{M})$ & 258.4 & 12.8 & & & \\
\hline Total Wt. (W) & 2014.0 & & \multirow{2}{*}{\multicolumn{3}{|c|}{$\begin{array}{l}\text { The Summation Of The Retained Weights Of All } \\
\text { Of The Sieves Plus The Pan Weight Must Check } \\
\text { The Dry Weight After Wash }(O) \text { Within } 0.2 \% \text { Of } \\
\text { The Total Weight }(X) \text {. }\end{array}$}} \\
\hline $\begin{array}{l}0.2 \% \text { Check: } \\
=\text { Total Weight }\end{array}$ & $(X) \quad W-Q$ & $\begin{array}{r}100(0-X) / 0 \\
\% \\
\end{array}$ & & & \\
\hline
\end{tabular}

Attach all asphalt content oven printouts to this report. 


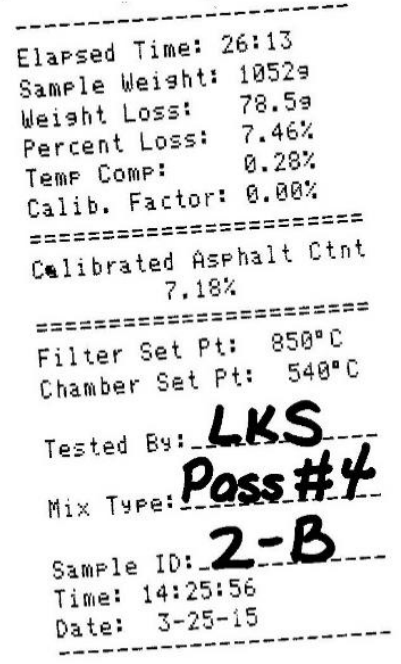

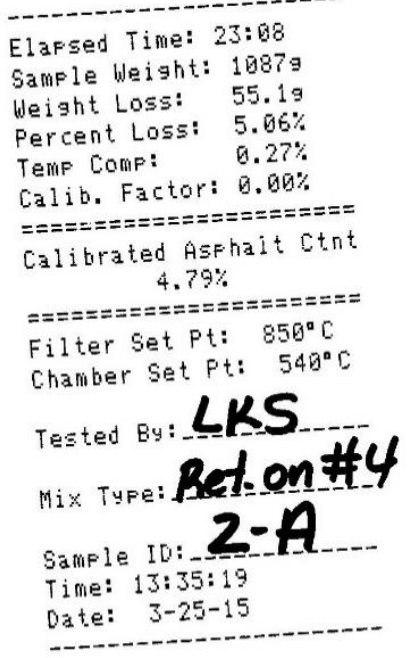

Figure 60 - RAP Burnoff 2 Printouts 


\section{Appendix B}

Flow Number Data (Spring 2014)

Table 25 - 0\% RAP Replicate 1 Flow Number Data

\begin{tabular}{|l|l|}
\hline \multicolumn{2}{|l|}{ PG 70-22 0\% RAP Replicate 1 } \\
\hline Specimen Avg Diameter (mm) & 100.32 \\
\hline Specimen Avg Height $(\mathrm{mm})$ & 148.685 \\
\hline Target Temperature $(\mathrm{degC})$ & 50 \\
\hline Target Confining Stress $(\mathrm{kPa})$ & 0 \\
\hline Target Contact Stress $(\mathrm{kPa})$ & 30 \\
\hline Target Deviator Stress $(\mathrm{kPa})$ & 600 \\
\hline Termination micro strain & 50000 \\
\hline Termination cycles & 10000 \\
\hline Sampling Interval (cycles) & 1 \\
\hline Flow number (cycles) & 178 \\
\hline Avg contact stress $(\mathrm{kPa})$ & 30 \\
\hline Max load Std Error $(\%)$ & 8.5 \\
\hline Average Temperature $(\mathrm{degC})$ & 50 \\
\hline Average Confining Stress $(\mathrm{kPa})$ & 0 \\
\hline Average Deviator Stress $(\mathrm{kPa})$ & 599.3 \\
\hline Micro strain at flow point & 31167 \\
\hline
\end{tabular}


Table 26 - 0\% RAP Replicate 2 Flow Number Data

\begin{tabular}{|l|r|}
\hline PG 70-22 0\% RAP Replicate 2 & \\
\hline Specimen Avg Diameter $(\mathrm{mm})$ & 100.397 \\
\hline Specimen Avg Height $(\mathrm{mm})$ & 148.765 \\
\hline Target Temperature $(\mathrm{degC})$ & 50 \\
\hline Target Confining Stress $(\mathrm{kPa})$ & 0 \\
\hline Target Contact Stress $(\mathrm{kPa})$ & 30 \\
\hline Target Deviator Stress $(\mathrm{kPa})$ & 600 \\
\hline Termination micro strain & 50000 \\
\hline Termination cycles & 10000 \\
\hline Sampling Interval (cycles) & 1 \\
\hline Flow number (cycles) & 167 \\
\hline Avg contact stress (kPa) & 30 \\
\hline Max load Std Error $(\%)$ & 7.6 \\
\hline Average Temperature $(\mathrm{degC})$ & 50 \\
\hline Average Confining Stress $(\mathrm{kPa})$ & 0 \\
\hline Average Deviator Stress $(\mathrm{kPa})$ & 599.3 \\
\hline Micro strain at flow point & 29006 \\
\hline
\end{tabular}


Table 27 - 15\% RAP Replicate 1 Flow Number Data

\begin{tabular}{|l|r|}
\hline PG 70-22 15\% RAP Replicate 1 & \\
\hline Specimen Avg Diameter $(\mathrm{mm})$ & 100.453 \\
\hline Specimen Avg Height $(\mathrm{mm})$ & 148.66 \\
\hline Target Temperature $(\mathrm{degC})$ & 50 \\
\hline Target Confining Stress $(\mathrm{kPa})$ & 0 \\
\hline Target Contact Stress $(\mathrm{kPa})$ & 30 \\
\hline Target Deviator Stress $(\mathrm{kPa})$ & 600 \\
\hline Termination micro strain & 50000 \\
\hline Termination cycles & 10000 \\
\hline Sampling Interval (cycles) & 1 \\
\hline Flow number (cycles) & 342 \\
\hline Avg contact stress $(\mathrm{kPa})$ & 30 \\
\hline Max load Std Error $(\%)$ & 9.8 \\
\hline Average Temperature $(\mathrm{degC})$ & 50 \\
\hline Average Confining Stress $(\mathrm{kPa})$ & 0 \\
\hline Average Deviator Stress $(\mathrm{kPa})$ & 599.3 \\
\hline Micro strain at flow point & 31359 \\
\hline
\end{tabular}


Table 28 - 15\% RAP Replicate 2 Flow Number Data

\begin{tabular}{|l|r|}
\hline PG 70-22 15\% RAP Replicate 2 & \\
\hline Specimen Avg Diameter $(\mathrm{mm})$ & 100.353 \\
\hline Specimen Avg Height $(\mathrm{mm})$ & 149.055 \\
\hline Target Temperature $(\mathrm{degC})$ & 50 \\
\hline Target Confining Stress $(\mathrm{kPa})$ & 0 \\
\hline Target Contact Stress $(\mathrm{kPa})$ & 30 \\
\hline Target Deviator Stress $(\mathrm{kPa})$ & 600 \\
\hline Termination micro strain & 50000 \\
\hline Termination cycles & 10000 \\
\hline Sampling Interval (cycles) & 1 \\
\hline Flow number (cycles) & 555 \\
\hline Avg contact stress $(\mathrm{kPa})$ & 30 \\
\hline Max load Std Error $(\%)$ & 7.8 \\
\hline Average Temperature $(\mathrm{degC})$ & 50 \\
\hline Average Confining Stress $(\mathrm{kPa})$ & 0 \\
\hline Average Deviator Stress $(\mathrm{kPa})$ & 599.4 \\
\hline Micro strain at flow point & 31114 \\
\hline
\end{tabular}


Table 29 - 25\% RAP Replicate 1 Flow Number Data

\begin{tabular}{|l|r|}
\hline PG 70-22 25\% RAP Replicate 1 & \\
\hline Specimen Avg Diameter $(\mathrm{mm})$ & 100.36 \\
\hline Specimen Avg Height $(\mathrm{mm})$ & 149.565 \\
\hline Target Temperature $(\mathrm{degC})$ & 50 \\
\hline Target Confining Stress $(\mathrm{kPa})$ & 0 \\
\hline Target Contact Stress $(\mathrm{kPa})$ & 30 \\
\hline Target Deviator Stress $(\mathrm{kPa})$ & 600 \\
\hline Termination micro strain & 50000 \\
\hline Termination cycles & 10000 \\
\hline Sampling Interval $(\mathrm{cycles})$ & 1 \\
\hline Flow number (cycles) & 591 \\
\hline Avg contact stress $(\mathrm{kPa})$ & 30 \\
\hline Max load Std Error $(\%)$ & 8.2 \\
\hline Average Temperature $(\mathrm{degC})$ & 50 \\
\hline Average Confining Stress $(\mathrm{kPa})$ & 0 \\
\hline Average Deviator Stress $(\mathrm{kPa})$ & 599.4 \\
\hline Micro strain at flow point & 31213 \\
\hline
\end{tabular}


Table 30 - 25\% RAP Replicate 2 Flow Number Data

\begin{tabular}{|l|r|}
\hline PG 70-22 25\% RAP Replicate 2 & \\
\hline Specimen Avg Diameter $(\mathrm{mm})$ & 100.38 \\
\hline Specimen Avg Height $(\mathrm{mm})$ & 148.815 \\
\hline Target Temperature $(\mathrm{degC})$ & 50 \\
\hline Target Confining Stress $(\mathrm{kPa})$ & 0 \\
\hline Target Contact Stress $(\mathrm{kPa})$ & 30 \\
\hline Target Deviator Stress $(\mathrm{kPa})$ & 600 \\
\hline Termination micro strain & 50000 \\
\hline Termination cycles & 10000 \\
\hline Sampling Interval $(\mathrm{cycles})$ & 1 \\
\hline Flow number $($ cycles) & 611 \\
\hline Avg contact stress $(\mathrm{kPa})$ & 30 \\
\hline Max load Std Error $(\%)$ & 7.4 \\
\hline Average Temperature $(\mathrm{degC})$ & 50 \\
\hline Average Confining Stress $(\mathrm{kPa})$ & 0 \\
\hline Average Deviator Stress $(\mathrm{kPa})$ & 599.4 \\
\hline Micro strain at flow point & 26702 \\
\hline
\end{tabular}


Dynamic Modulus Sample Properties (Summer 2015)

Table 31 - DM Specimen Volumetrics

\begin{tabular}{|c|c|c|c|c|c|c|c|c|c|}
\hline Binder & $\% \mathbf{R A P}$ & Replicate & $\mathbf{P b}$ & Gmm & Gmb & Gsb & VTM & VMA & VFA \\
\hline \multirow{9}{*}{ PG 70-22 } & \multirow{3}{*}{0} & 1 & $4.9 \%$ & 2.527 & 2.35 & 2.679 & $7.0 \%$ & $16.6 \%$ & $57.8 \%$ \\
\hline & & 2 & $4.9 \%$ & 2.527 & 2.336 & 2.679 & $7.5 \%$ & $17.1 \%$ & $56.1 \%$ \\
\hline & & 3 & $4.9 \%$ & 2.527 & 2.349 & 2.679 & $7.1 \%$ & $16.6 \%$ & $57.3 \%$ \\
\hline & \multirow{3}{*}{15} & 1 & $4.6 \%$ & 2.535 & 2.346 & 2.676 & $7.5 \%$ & $16.4 \%$ & $54.2 \%$ \\
\hline & & 2 & $4.6 \%$ & 2.535 & 2.36 & 2.676 & $6.9 \%$ & $15.9 \%$ & $56.5 \%$ \\
\hline & & 3 & $4.6 \%$ & 2.535 & 2.368 & 2.676 & $6.6 \%$ & $15.6 \%$ & $57.6 \%$ \\
\hline & \multirow{3}{*}{25} & 1 & $4.9 \%$ & 2.526 & 2.345 & 2.695 & $7.1 \%$ & $17.3 \%$ & $58.8 \%$ \\
\hline & & 2 & $4.9 \%$ & 2.526 & 2.363 & 2.695 & $6.5 \%$ & $16.6 \%$ & $60.9 \%$ \\
\hline & & 3 & $4.9 \%$ & 2.526 & 2.361 & 2.695 & $6.7 \%$ & $16.7 \%$ & $59.8 \%$ \\
\hline \multirow{3}{*}{ PG 64-22 } & \multirow{3}{*}{25} & 1 & $4.9 \%$ & 2.522 & 2.34 & 2.695 & $7.2 \%$ & $17.4 \%$ & $58.7 \%$ \\
\hline & & 2 & $4.9 \%$ & 2.522 & 2.354 & 2.695 & $6.7 \%$ & $16.9 \%$ & $60.4 \%$ \\
\hline & & 3 & $4.9 \%$ & 2.522 & 2.351 & 2.695 & $6.8 \%$ & $17.0 \%$ & $60.1 \%$ \\
\hline
\end{tabular}

Table 32 - DM Specimen Height and Diameter

\begin{tabular}{|c|c|c|c|c|}
\hline Binder & \% RAP & Replicate & Average Height (mm) & Average Diameter (mm) \\
\hline \multirow{3}{*}{0} & 1 & 150.74 & 100.48 \\
\cline { 3 - 5 } & \multirow{3}{*}{ PG 70-22 } & 2 & 151.66 & 100.26 \\
\cline { 3 - 5 } & \multirow{3}{*}{15} & 1 & 151.67 & 100.35 \\
\cline { 3 - 5 } & & 2 & 151.11 & 100.45 \\
\cline { 3 - 5 } & \multirow{3}{*}{25} & 3 & 151.53 & 100.42 \\
\cline { 3 - 5 } & \multirow{3}{*}{25} & 2 & 151.19 & 100.44 \\
\cline { 3 - 5 } & & 3 & 150.92 & 100.44 \\
\cline { 3 - 5 } & \multirow{3}{*}{25} & 1 & 150.03 & 100.39 \\
\cline { 3 - 5 } & & 2 & 152.02 & 100.37 \\
\hline \multirow{3}{*}{ PG 64-22 } & 3 & 151.26 & 100.37 \\
\cline { 3 - 5 } & & 3 & 150.13 & 100.41 \\
\hline
\end{tabular}




\section{Dynamic Modulus Data (Summer 2014)}

Table 33 - PG 70-22 0\% RAP Replicate $1-4{ }^{\circ} \mathrm{C}$ DM Test Data

\begin{tabular}{|c|c|c|c|}
\hline PG 70-22 0\% RAP Replicate $1-4^{\circ} \mathrm{C}$ & $10 \mathrm{~Hz}$ & $1 \mathrm{~Hz}$ & $0.1 \mathrm{~Hz}$ \\
\hline Dynamic modulus (MPa) & 13146 & 9399 & 5993 \\
\hline Phase angle (Degrees) & 11.99 & 16.34 & 21.88 \\
\hline Average temperature $\left({ }^{\circ} \mathrm{C}\right)$ & 3.9 & 3.9 & 3.9 \\
\hline Average confining pressure $(\mathrm{kPa})$ & 0.9 & 0.9 & 0.9 \\
\hline Average micro strain & 99 & 98 & 101 \\
\hline Load drift (\%) & 0.2 & 0 & 0 \\
\hline Load standard error $(\%)$ & 0.8 & 0.4 & 0.4 \\
\hline Average deformation drift $(\%)$ & -59.9 & -103.1 & -178.1 \\
\hline Average deformation standard error $(\%)$ & 2.9 & 2.7 & 3 \\
\hline Deformation uniformity $(\%)$ & 15.1 & 12.6 & 11.4 \\
\hline Phase uniformity $\left({ }^{\circ}\right)$ & 0.5 & 0.7 & 0.9 \\
\hline
\end{tabular}

Table 34 - PG 70-22 0\% RAP Replicate $1-20^{\circ} \mathrm{C}$ DM Test Data

\begin{tabular}{|c|c|c|c|}
\hline PG 70-22 0\% RAP Replicate $1-20^{\circ} \mathrm{C}$ & $10 \mathrm{~Hz}$ & $1 \mathrm{~Hz}$ & $0.1 \mathrm{~Hz}$ \\
\hline Dynamic modulus (MPa) & 6144 & 3343 & 1603 \\
\hline Phase angle (Degrees) & 23.37 & 29.19 & 32.99 \\
\hline Average temperature $\left({ }^{\circ} \mathrm{C}\right)$ & 20.3 & 20.3 & 19.9 \\
\hline Average confining pressure (kPa) & 0.6 & 0.6 & 0.4 \\
\hline Average micro strain & 97 & 94 & 96 \\
\hline Load drift (\%) & 0.1 & 0 & 0 \\
\hline Load standard error $(\%)$ & 1.3 & 0.4 & 0.5 \\
\hline Average deformation drift $(\%)$ & -240.1 & -291.7 & -299.4 \\
\hline Average deformation standard error $\%)$ & 5.5 & 4.1 & 3.9 \\
\hline Deformation uniformity $(\%)$ & 12.3 & 12.2 & 12.9 \\
\hline Phase uniformity (Degrees) & 1.1 & 1.1 & 1.3 \\
\hline
\end{tabular}


Table 35 - PG 70-22 0\% RAP Replicate $1-40^{\circ} \mathrm{C}$ DM Test Data

\begin{tabular}{|c|c|c|c|c|}
\hline PG 70-22 0\% RAP Replicate $1-40^{\circ} \mathrm{C}$ & $10 \mathrm{~Hz}$ & $1 \mathrm{~Hz}$ & $0.1 \mathrm{~Hz}$ & $0.01 \mathrm{~Hz}$ \\
\hline Dynamic modulus (MPa) & 1108 & 447.9 & 198.8 & 111.3 \\
\hline Phase angle (Degrees) & 37.07 & 33.64 & 28.11 & 22.11 \\
\hline Average temperature $\left({ }^{\circ} \mathrm{C}\right)$ & 40.1 & 40.2 & 40.2 & 40.1 \\
\hline Average confining pressure $(\mathrm{kPa})$ & 0 & 0 & 0 & 0 \\
\hline Average micro strain & 91 & 94 & 95 & 103 \\
\hline Load drift (\%) & 0.5 & 0.1 & -0.1 & -0.1 \\
\hline Load standard error (\%) & 4 & 1.4 & 2.8 & 1.5 \\
\hline Average deformation drift $(\%)$ & -402.7 & -176.9 & 79.2 & 3260.6 \\
\hline Average deformation standard error $(\%)$ & 9 & 4.4 & 5.2 & 100.5 \\
\hline Deformation uniformity $(\%)$ & 12.7 & 13.6 & 14.5 & 15.7 \\
\hline Phase uniformity (Degrees) & 1.5 & 1.6 & 0.6 & 1.1 \\
\hline
\end{tabular}

Table 36 - PG 70-22 0\% RAP Replicate $2-4^{\circ} \mathrm{C}$ DM Test Data

\begin{tabular}{|c|c|c|c|}
\hline PG 70-22 0\% RAP Replicate $2-4^{\circ} \mathrm{C}$ & $10 \mathrm{~Hz}$ & $1 \mathrm{~Hz}$ & $0.1 \mathrm{~Hz}$ \\
\hline Dynamic modulus (MPa) & 12906 & 9385 & 6192 \\
\hline Phase angle (Degrees) & 11.24 & 15.11 & 20.21 \\
\hline Average temperature $\left({ }^{\circ} \mathrm{C}\right)$ & 4.1 & 4.1 & 3.9 \\
\hline Average confining pressure $(\mathrm{kPa})$ & 0.7 & 0.7 & 0.7 \\
\hline Average micro strain & 98 & 99 & 101 \\
\hline Load drift (\%) & 0 & 0 & 0 \\
\hline Load standard error $(\%)$ & 0.9 & 0.4 & 0.4 \\
\hline Average deformation drift $(\%)$ & -50.2 & -85.7 & -148.7 \\
\hline Average deformation standard error $(\%)$ & 1.6 & 1.5 & 2 \\
\hline Deformation uniformity (\%) & 7.7 & 7.7 & 8.1 \\
\hline Phase uniformity (Degrees) & 0.2 & 0.5 & 1 \\
\hline
\end{tabular}


Table 37 - PG 70-22 0\% RAP Replicate $2-20^{\circ} \mathrm{C}$ DM Test Data

\begin{tabular}{|c|c|c|c|}
\hline PG 70-22 0\% RAP Replicate $2-20^{\circ} \mathrm{C}$ & $10 \mathrm{~Hz}$ & $1 \mathrm{~Hz}$ & $0.1 \mathrm{~Hz}$ \\
\hline Dynamic modulus (MPa) & 5310 & 2875 & 1400 \\
\hline Phase angle (Degrees) & 23.71 & 28.9 & 32.07 \\
\hline Average temperature $\left({ }^{\circ} \mathrm{C}\right)$ & 19.8 & 19.8 & 20.1 \\
\hline Average confining pressure $(\mathrm{kPa})$ & 0.1 & 0.1 & 0.2 \\
\hline Average micro strain & 97 & 94 & 95 \\
\hline Load drift (\%) & 0 & 0.1 & 0 \\
\hline Load standard error (\%) & 1.3 & 0.4 & 0.5 \\
\hline Average deformation drift (\%) & -217 & -265.5 & -281.5 \\
\hline Average deformation standard error $(\%)$ & 4.5 & 3.8 & 4 \\
\hline Deformation uniformity (\%) & 11.3 & 11.3 & 13.5 \\
\hline Phase uniformity (Degrees) & 0.7 & 1.1 & 1.3 \\
\hline
\end{tabular}

Table 38 - PG 70-22 0\% RAP Replicate $2-40^{\circ} \mathrm{C}$ DM Test Data

\begin{tabular}{|c|c|c|c|c|}
\hline PG 70-22 0\% RAP Replicate $2-40^{\circ} \mathrm{C}$ & $10 \mathrm{~Hz}$ & $1 \mathrm{~Hz}$ & $0.1 \mathrm{~Hz}$ & $0.01 \mathrm{~Hz}$ \\
\hline Dynamic modulus (MPa) & 1281 & 540.9 & 241.8 & 137.3 \\
\hline Phase angle (Degrees) & 35.69 & 33.42 & 28.23 & 23.97 \\
\hline Average temperature $\left({ }^{\circ} \mathrm{C}\right)$ & 40.1 & 40.2 & 40.1 & 40.2 \\
\hline Average confining pressure $(\mathrm{kPa})$ & 0 & 0 & 0 & 0 \\
\hline Average micro strain & 90 & 92 & 95 & 102 \\
\hline Load drift (\%) & 0.2 & 0 & -0.1 & 0.4 \\
\hline Load standard error (\%) & 3.7 & 1 & 1.9 & 1.7 \\
\hline Average deformation drift (\%) & -406 & -244.2 & -102 & 43.6 \\
\hline Average deformation standard error $(\%)$ & 8.5 & 4.5 & 4.8 & 6.1 \\
\hline Deformation uniformity (\%) & 17.7 & 18 & 21.4 & 23.6 \\
\hline Phase uniformity (Degrees) & 1.8 & 1.7 & 1.1 & 1.1 \\
\hline
\end{tabular}


Table 39 - PG 70-22 0\% RAP Replicate $3-4^{\circ} \mathrm{C}$ DM Test Data

\begin{tabular}{|c|c|c|c|}
\hline PG 70-22 0\% RAP Replicate $3-4^{\circ} \mathrm{C}$ & $10 \mathrm{~Hz}$ & $1 \mathrm{~Hz}$ & $0.1 \mathrm{~Hz}$ \\
\hline Dynamic modulus (MPa) & 13255 & 9362 & 5983 \\
\hline Phase angle (Degrees) & 12.39 & 16.96 & 22.5 \\
\hline Average temperature $\left({ }^{\circ} \mathrm{C}\right)$ & 4.1 & 4.1 & 3.9 \\
\hline Average confining pressure $(\mathrm{kPa})$ & 0.7 & 0.7 & 0.7 \\
\hline Average micro strain & 99 & 98 & 99 \\
\hline Load drift (\%) & 0 & 0 & 0 \\
\hline Load standard error (\%) & 0.9 & 0.4 & 0.4 \\
\hline Average deformation drift (\%) & -66 & -113.2 & -190.4 \\
\hline Average deformation standard error $(\%)$ & 2 & 2 & 2.9 \\
\hline Deformation uniformity (\%) & 25.4 & 23.1 & 19.9 \\
\hline Phase uniformity (Degrees) & 0.2 & 0.6 & 0.9 \\
\hline
\end{tabular}

Table 40 - PG 70-22 0\% RAP Replicate 3 - $20^{\circ} \mathrm{C}$ DM Test Data

\begin{tabular}{|c|c|c|c|}
\hline PG 70-22 0\% RAP Replicate 3 $-20^{\circ} \mathrm{C}$ & $10 \mathrm{~Hz}$ & $1 \mathrm{~Hz}$ & $0.1 \mathrm{~Hz}$ \\
\hline Dynamic modulus (MPa) & 5620 & 2923 & 1371 \\
\hline Phase angle (Degrees) & 25.62 & 31.02 & 33.79 \\
\hline Average temperature $\left({ }^{\circ} \mathrm{C}\right)$ & 19.9 & 19.8 & 20 \\
\hline Average confining pressure (kPa) & 0.3 & 0.3 & 0.4 \\
\hline Average micro strain & 98 & 94 & 95 \\
\hline Load drift (\%) & 0.2 & 0 & 0 \\
\hline Load standard error (\%) & 1.3 & 0.4 & 0.4 \\
\hline Average deformation drift (\%) & -274.8 & -321.5 & -330.6 \\
\hline Average deformation standard error $(\%)$ & 5.2 & 4.4 & 4.3 \\
\hline Deformation uniformity (\%) & 6.6 & 7.7 & 8.4 \\
\hline Phase uniformity (Degrees) & 0.3 & 0.6 & 0.7 \\
\hline
\end{tabular}


Table 41 - PG 70-22 0\% RAP Replicate $3-40^{\circ} \mathrm{C}$ DM Test Data

\begin{tabular}{|c|c|c|c|c|}
\hline PG 70-22 0\% RAP Replicate 3 $-40^{\circ} \mathrm{C}$ & $10 \mathrm{~Hz}$ & $1 \mathrm{~Hz}$ & $0.1 \mathrm{~Hz}$ & $0.01 \mathrm{~Hz}$ \\
\hline Dynamic modulus (MPa) & 1137 & 466.5 & 204.4 & 113 \\
\hline Phase angle (Degrees) & 36.43 & 33.19 & 27.74 & 22.37 \\
\hline Average temperature $\left({ }^{\circ} \mathrm{C}\right)$ & 40.3 & 40.3 & 40.3 & 40.1 \\
\hline Average confining pressure $(\mathrm{kPa})$ & 0 & 0 & 0 & 0 \\
\hline Average micro strain & 89 & 93 & 96 & 104 \\
\hline Load drift (\%) & 0.5 & 0 & 0.1 & 0.1 \\
\hline Load standard error (\%) & 4.3 & 0.8 & 1.2 & 1 \\
\hline Average deformation drift (\%) & -421.7 & -249.8 & -102.4 & 18.2 \\
\hline Average deformation standard error $(\%)$ & 8.8 & 4.7 & 5.2 & 7.1 \\
\hline Deformation uniformity (\%) & 4.5 & 3.9 & 3.5 & 4.3 \\
\hline Phase uniformity (Degrees) & 0.9 & 1 & 0.4 & 0.2 \\
\hline
\end{tabular}

Table 42 PG 70-22 15\% RAP Replicate $1-4^{\circ} \mathrm{C}$ DM Test Data

\begin{tabular}{|c|c|c|c|}
\hline PG 70-22 15\% RAP Replicate $1-4^{\circ} \mathrm{C}$ & $10 \mathrm{~Hz}$ & $1 \mathrm{~Hz}$ & $0.1 \mathrm{~Hz}$ \\
\hline Dynamic modulus (MPa) & 14857 & 10845 & 7336 \\
\hline Phase angle (Degrees) & 11.21 & 15.02 & 19.92 \\
\hline Average temperature $\left({ }^{\circ} \mathrm{C}\right)$ & 4.4 & 4.3 & 4.1 \\
\hline Average confining pressure $(\mathrm{kPa})$ & 0.7 & 0.7 & 0.7 \\
\hline Average micro strain & 100 & 99 & 100 \\
\hline Load drift (\%) & 0.1 & 0.1 & 0 \\
\hline Load standard error (\%) & 0.9 & 0.4 & 0.4 \\
\hline Average deformation drift (\%) & -53.9 & -91.5 & -154.1 \\
\hline Average deformation standard error $(\%)$ & 1.8 & 1.8 & 2.4 \\
\hline Deformation uniformity $(\%)$ & 9.4 & 11.6 & 13.8 \\
\hline Phase uniformity (Degrees) & 0.3 & 0.4 & 0.4 \\
\hline
\end{tabular}


Table 43 - PG 70-22 15\% RAP Replicate $1-20^{\circ} \mathrm{C}$ DM Test Data

\begin{tabular}{|c|c|c|c|}
\hline PG 70-22 15\% RAP Replicate $1-20^{\circ} \mathrm{C}$ & $10 \mathrm{~Hz}$ & $1 \mathrm{~Hz}$ & $0.1 \mathrm{~Hz}$ \\
\hline Dynamic modulus (MPa) & 8470 & 5079 & 2723 \\
\hline Phase angle (Degrees) & 19.39 & 24.91 & 29.84 \\
\hline Average temperature $\left({ }^{\circ} \mathrm{C}\right)$ & 20 & 20 & 20 \\
\hline Average confining pressure $(\mathrm{kPa})$ & 0.5 & 0.4 & 0.4 \\
\hline Average micro strain & 100 & 97 & 96 \\
\hline Load drift (\%) & 0.2 & 0.1 & 0 \\
\hline Load standard error $(\%)$ & 1 & 0.4 & 0.5 \\
\hline Average deformation drift $(\%)$ & -163 & -229.3 & -291.1 \\
\hline Average deformation standard error $(\%)$ & 3.4 & 3.4 & 3.9 \\
\hline Deformation uniformity $(\%)$ & 17.7 & 15.5 & 14.2 \\
\hline Phase uniformity (Degrees) & 0.2 & 0.3 & 0.4 \\
\hline
\end{tabular}

Table 44 - PG 70-22 15\% RAP Replicate $1-40^{\circ} \mathrm{C}$ DM Test Data

\begin{tabular}{|c|c|c|c|c|}
\hline PG 70-22 15\% RAP Replicate $1-40^{\circ} \mathrm{C}$ & $10 \mathrm{~Hz}$ & $1 \mathrm{~Hz}$ & $0.1 \mathrm{~Hz}$ & $0.01 \mathrm{~Hz}$ \\
\hline Dynamic modulus (MPa) & 2019 & 865.9 & 368.2 & 182 \\
\hline Phase angle (Degrees) & 35.09 & 34.74 & 30.97 & 25.75 \\
\hline Average temperature $\left({ }^{\circ} \mathrm{C}\right)$ & 40.3 & 40.3 & 40.4 & 40.3 \\
\hline Average confining pressure $(\mathrm{kPa})$ & 0 & 0 & 0 & 0 \\
\hline Average micro strain & 91 & 91 & 96 & 107 \\
\hline Load drift (\%) & 0.3 & -0.1 & 0.1 & -0.2 \\
\hline Load standard error (\%) & 2.6 & 0.5 & 0.4 & 1.2 \\
\hline Average deformation drift $(\%)$ & -492.3 & -325.4 & -164.9 & -35.1 \\
\hline Average deformation standard error $(\%)$ & 10.2 & 5.2 & 5 & 6.5 \\
\hline Deformation uniformity $(\%)$ & 8.9 & 10 & 10.7 & 8.2 \\
\hline Phase uniformity (Degrees) & 0.4 & 0.2 & 1.1 & 1.7 \\
\hline
\end{tabular}


Table 45 - PG 70-22 15\% RAP Replicate $2-4^{\circ} \mathrm{C}$ DM Test Data

\begin{tabular}{|c|c|c|c|}
\hline PG 70-22 15\% RAP Replicate $2-4^{\circ} \mathrm{C}$ & $10 \mathrm{~Hz}$ & $1 \mathrm{~Hz}$ & $0.1 \mathrm{~Hz}$ \\
\hline Dynamic modulus (MPa) & 15626 & 12241 & 8878 \\
\hline Phase angle (Degrees) & 8.91 & 11.86 & 16.04 \\
\hline Average temperature $\left({ }^{\circ} \mathrm{C}\right)$ & 4.1 & 4.1 & 4 \\
\hline Average confining pressure $(\mathrm{kPa})$ & 0.7 & 0.7 & 0.7 \\
\hline Average micro strain & 97 & 98 & 101 \\
\hline Load drift (\%) & -0.1 & 0 & 0 \\
\hline Load standard error (\%) & 0.9 & 0.4 & 0.4 \\
\hline Average deformation drift (\%) & -33.3 & -54.7 & -96.3 \\
\hline Average deformation standard error $(\%)$ & 1.7 & 1.4 & 1.8 \\
\hline Deformation uniformity (\%) & 14.8 & 12.5 & 11 \\
\hline Phase uniformity (Degrees) & 0.5 & 0.3 & 0.4 \\
\hline
\end{tabular}

Table 46 - PG 70-22 15\% RAP Replicate $2-20^{\circ} \mathrm{C}$ DM Test Data

\begin{tabular}{|c|c|c|c|}
\hline PG 70-22 15\% RAP Replicate $2-20^{\circ} \mathrm{C}$ & $10 \mathrm{~Hz}$ & $1 \mathrm{~Hz}$ & $0.1 \mathrm{~Hz}$ \\
\hline Dynamic modulus (MPa) & 7944 & 4830 & 2610 \\
\hline Phase angle (Degrees) & 19.11 & 24.74 & 29.56 \\
\hline Average temperature $\left({ }^{\circ} \mathrm{C}\right)$ & 19.8 & 19.7 & 20 \\
\hline Average confining pressure (kPa) & 0.4 & 0.4 & 0.4 \\
\hline Average micro strain & 97 & 96 & 96 \\
\hline Load drift (\%) & 0.1 & 0 & 0 \\
\hline Load standard error (\%) & 1 & 0.4 & 0.5 \\
\hline Average deformation drift (\%) & -155.6 & -213.9 & -262 \\
\hline Average deformation standard error $(\%)$ & 3.5 & 3.3 & 4.1 \\
\hline Deformation uniformity $(\%)$ & 17.7 & 15.6 & 14.3 \\
\hline Phase uniformity (Degrees) & 0.3 & 0.4 & 0.6 \\
\hline
\end{tabular}


Table 47 - PG 70-22 15\% RAP Replicate $2-40^{\circ} \mathrm{C}$ DM Test Data

\begin{tabular}{|c|c|c|c|c|}
\hline PG 70-22 15\% RAP Replicate $2-40^{\circ} \mathrm{C}$ & $10 \mathrm{~Hz}$ & $1 \mathrm{~Hz}$ & $0.1 \mathrm{~Hz}$ & $0.01 \mathrm{~Hz}$ \\
\hline Dynamic modulus (MPa) & 2099 & 933.9 & 409 & 206.7 \\
\hline Phase angle (Degrees) & 33.24 & 33.58 & 30.82 & 26.45 \\
\hline Average temperature $\left({ }^{\circ} \mathrm{C}\right)$ & 40.4 & 40.4 & 40.4 & 40.2 \\
\hline Average confining pressure $(\mathrm{kPa})$ & 0 & 0 & 0 & 0 \\
\hline Average micro strain & 90 & 91 & 95 & 104 \\
\hline Load drift (\%) & 0.3 & 0 & -0.1 & 0.1 \\
\hline Load standard error (\%) & 2.9 & 0.4 & 0.4 & 1.4 \\
\hline Average deformation drift (\%) & -404.3 & -275.5 & -157 & -41.3 \\
\hline Average deformation standard error $(\%)$ & 9.3 & 4.7 & 4.4 & 5.7 \\
\hline Deformation uniformity (\%) & 10.2 & 9.7 & 9.9 & 8.5 \\
\hline Phase uniformity (Degrees) & 0.7 & 0.7 & 1.5 & 1.4 \\
\hline
\end{tabular}

Table 48 - PG 70-22 15\% RAP Replicate $3-4^{\circ} \mathrm{C}$ DM Test Data

\begin{tabular}{|c|c|c|c|}
\hline PG 70-22 15\% RAP Replicate $3-4^{\circ} \mathrm{C}$ & $10 \mathrm{~Hz}$ & $1 \mathrm{~Hz}$ & $0.1 \mathrm{~Hz}$ \\
\hline Dynamic modulus (MPa) & 18992 & 14610 & 10403 \\
\hline Phase angle (Degrees) & 9.15 & 12.44 & 16.85 \\
\hline Average temperature $\left({ }^{\circ} \mathrm{C}\right)$ & 3.9 & 3.9 & 3.8 \\
\hline Average confining pressure $(\mathrm{kPa})$ & 0.8 & 0.8 & 0.8 \\
\hline Average micro strain & 98 & 101 & 104 \\
\hline Load drift (\%) & 8.3 & 0 & 0 \\
\hline Load standard error (\%) & 7.7 & 0.4 & 0.4 \\
\hline Average deformation drift (\%) & -54.7 & -60.9 & -103.4 \\
\hline Average deformation standard error $(\%)$ & 7 & 1.5 & 1.9 \\
\hline Deformation uniformity $(\%)$ & 3.8 & 3.3 & 2.5 \\
\hline Phase uniformity (Degrees) & 0.1 & 0.1 & 0.3 \\
\hline
\end{tabular}


Table 49 - PG 70-22 15\% RAP Replicate $3-20^{\circ} \mathrm{C}$ DM Test Data

\begin{tabular}{|c|c|c|c|}
\hline PG 70-22 $15 \%$ RAP Replicate $3-20^{\circ} \mathrm{C}$ & $10 \mathrm{~Hz}$ & $1 \mathrm{~Hz}$ & $0.1 \mathrm{~Hz}$ \\
\hline Dynamic modulus (MPa) & 10068 & 6113 & 3344 \\
\hline Phase angle (Degrees) & 18.62 & 24.19 & 29.22 \\
\hline Average temperature $\left({ }^{\circ} \mathrm{C}\right)$ & 20 & 20 & 20 \\
\hline Average confining pressure $(\mathrm{kPa})$ & 0.5 & 0.5 & 0.5 \\
\hline Average micro strain & 104 & 99 & 99 \\
\hline Load drift (\%) & 0.2 & 0.1 & 0 \\
\hline Load standard error $(\%)$ & 1 & 0.4 & 0.5 \\
\hline Average deformation drift $(\%)$ & -155.4 & -212.9 & -257.6 \\
\hline Average deformation standard error $(\%)$ & 3.4 & 3.3 & 3.7 \\
\hline Deformation uniformity $(\%)$ & 5.2 & 3.6 & 2.1 \\
\hline Phase uniformity (Degrees) & 0.1 & 0.2 & 0.4 \\
\hline
\end{tabular}

Table 50 - PG 70-22 15\% RAP Replicate $3-40^{\circ} \mathrm{C}$ DM Test Data

\begin{tabular}{|c|c|c|c|c|}
\hline PG 70-22 $15 \%$ RAP Replicate $3-40^{\circ} \mathrm{C}$ & $10 \mathrm{~Hz}$ & $1 \mathrm{~Hz}$ & $0.1 \mathrm{~Hz}$ & $0.01 \mathrm{~Hz}$ \\
\hline Dynamic modulus (MPa) & 2622 & 1162 & 509.5 & 253.2 \\
\hline Phase angle (Degrees) & 32.95 & 33.19 & 30.11 & 25.41 \\
\hline Average temperature $\left({ }^{\circ} \mathrm{C}\right)$ & 40.1 & 40.1 & 40.2 & 40.2 \\
\hline Average confining pressure $(\mathrm{kPa})$ & 0 & 0 & 0 & 0 \\
\hline Average micro strain & 96 & 92 & 96 & 107 \\
\hline Load drift (\%) & 0.3 & 0 & 0.2 & -0.2 \\
\hline Load standard error $(\%)$ & 2.5 & 0.5 & 1.3 & 1.1 \\
\hline Average deformation drift $(\%)$ & -418.5 & -267.5 & -144.7 & -33.8 \\
\hline Average deformation standard error $(\%)$ & 9.8 & 4.9 & 4.8 & 6.5 \\
\hline Deformation uniformity $(\%)$ & 13.1 & 12.9 & 12.3 & 12.5 \\
\hline Phase uniformity (Degrees) & 0.5 & 1.1 & 1.4 & 1.9 \\
\hline
\end{tabular}


Table 51 - PG 70-22 25\% RAP Replicate $1-4^{\circ} \mathrm{C}$ DM Test Data

\begin{tabular}{|c|c|c|c|}
\hline PG 70-22 25\% RAP Replicate $1-4^{\circ} \mathrm{C}$ & $10 \mathrm{~Hz}$ & $1 \mathrm{~Hz}$ & $0.1 \mathrm{~Hz}$ \\
\hline Dynamic modulus (MPa) & 16180 & 12846 & 9592 \\
\hline Phase angle (Degrees) & 8.41 & 10.71 & 14.07 \\
\hline Average temperature $\left({ }^{\circ} \mathrm{C}\right)$ & 4 & 3.9 & 3.8 \\
\hline Average confining pressure $(\mathrm{kPa})$ & 0.9 & 0.9 & 0.8 \\
\hline Average micro strain & 102 & 101 & 104 \\
\hline Load drift (\%) & 0.1 & 0.1 & 0 \\
\hline Load standard error (\%) & 0.9 & 0.4 & 0.4 \\
\hline Average deformation drift (\%) & -30.8 & -42 & -72.7 \\
\hline Average deformation standard error $(\%)$ & 2.2 & 1.8 & 1.7 \\
\hline Deformation uniformity (\%) & 14.9 & 13.2 & 11 \\
\hline Phase uniformity (Degrees) & 0.3 & 0.2 & 0.2 \\
\hline
\end{tabular}

Table 52 - PG 70-22 25\% RAP Replicate 1-20 ${ }^{\circ}$ C DM Test Data

\begin{tabular}{|c|c|c|c|}
\hline PG 70-22 25\% RAP Replicate $1-20^{\circ} \mathrm{C}$ & $10 \mathrm{~Hz}$ & $1 \mathrm{~Hz}$ & $0.1 \mathrm{~Hz}$ \\
\hline Dynamic modulus (MPa) & 8839 & 5773 & 3422 \\
\hline Phase angle (Degrees) & 16.85 & 21.24 & 26.04 \\
\hline Average temperature $\left({ }^{\circ} \mathrm{C}\right)$ & 20 & 20 & 20 \\
\hline Average confining pressure (kPa) & 0.4 & 0.4 & 0.4 \\
\hline Average micro strain & 101 & 99 & 99 \\
\hline Load drift (\%) & 0 & 0.1 & 0 \\
\hline Load standard error (\%) & 1 & 0.4 & 0.5 \\
\hline Average deformation drift (\%) & -115.3 & -149.4 & -204 \\
\hline Average deformation standard error $(\%)$ & 3.8 & 2.7 & 3.1 \\
\hline Deformation uniformity $(\%)$ & 5.6 & 7.5 & 10 \\
\hline Phase uniformity (Degrees) & 0.6 & 0.2 & 0.2 \\
\hline
\end{tabular}


Table 53 - PG 70-22 25\% RAP Replicate 1-40 ${ }^{\circ} \mathrm{C}$ DM Test Data

\begin{tabular}{|c|c|c|c|c|}
\hline PG 70-22 25\% RAP Replicate $1-40^{\circ} \mathrm{C}$ & $10 \mathrm{~Hz}$ & $1 \mathrm{~Hz}$ & $0.1 \mathrm{~Hz}$ & $0.01 \mathrm{~Hz}$ \\
\hline Dynamic modulus (MPa) & 2551 & 1252 & 608.6 & 326.5 \\
\hline Phase angle (Degrees) & 30.03 & 30.91 & 28.97 & 24.88 \\
\hline Average temperature $\left({ }^{\circ} \mathrm{C}\right)$ & 40.2 & 40.2 & 40.2 & 40.1 \\
\hline Average confining pressure $(\mathrm{kPa})$ & 0 & 0 & 0 & 0 \\
\hline Average micro strain & 93 & 91 & 93 & 103 \\
\hline Load drift (\%) & 0.4 & 0 & 0 & -0.2 \\
\hline Load standard error $(\%)$ & 2.2 & 0.6 & 1.5 & 1 \\
\hline Average deformation drift (\%) & -335.5 & -247.9 & -168.7 & -77.6 \\
\hline Average deformation standard error $(\%)$ & 8 & 4.4 & 4.4 & 5.7 \\
\hline Deformation uniformity (\%) & 7.1 & 7.8 & 8.6 & 9.7 \\
\hline Phase uniformity (Degrees) & 0.1 & 0.5 & 0.1 & 0.3 \\
\hline
\end{tabular}

Table 54 - PG 70-22 25\% RAP Replicate 2- $4^{\circ} \mathrm{C}$ DM Test Data

\begin{tabular}{|c|c|c|c|}
\hline PG 70-22 25\% RAP Replicate $2-4^{\circ} \mathrm{C}$ & $10 \mathrm{~Hz}$ & $1 \mathrm{~Hz}$ & $0.1 \mathrm{~Hz}$ \\
\hline Dynamic modulus (MPa) & 17033 & 13621 & 10046 \\
\hline Phase angle (Degrees) & 8.28 & 10.83 & 14.56 \\
\hline Average temperature $\left({ }^{\circ} \mathrm{C}\right)$ & 4 & 4 & 3.9 \\
\hline Average confining pressure $(\mathrm{kPa})$ & 0.7 & 0.7 & 0.7 \\
\hline Average micro strain & 96 & 97 & 102 \\
\hline Load drift $(\%)$ & 0.1 & 0 & 0 \\
\hline Load standard error $(\%)$ & 1 & 0.4 & 0.4 \\
\hline Average deformation drift $(\%)$ & -28.4 & -45 & -78.5 \\
\hline Average deformation standard error $(\%)$ & 4.1 & 3.4 & 2.8 \\
\hline Deformation uniformity $(\%)$ & 27.8 & 20.5 & 14.1 \\
\hline Phase uniformity (Degrees) & 0.2 & 0.3 & 0.2 \\
\hline
\end{tabular}


Table 55 - PG 70-22 25\% RAP Replicate 2-20 ${ }^{\circ} \mathrm{C}$ DM Test Data

\begin{tabular}{|c|c|c|c|}
\hline PG 70-22 25\% RAP Replicate $2-20^{\circ} \mathrm{C}$ & $10 \mathrm{~Hz}$ & $1 \mathrm{~Hz}$ & $0.1 \mathrm{~Hz}$ \\
\hline Dynamic modulus (MPa) & 8965 & 5605 & 3148 \\
\hline Phase angle (Degrees) & 17.34 & 22.61 & 27.6 \\
\hline Average temperature $\left({ }^{\circ} \mathrm{C}\right)$ & 19.9 & 19.9 & 20 \\
\hline Average confining pressure $(\mathrm{kPa})$ & 0.5 & 0.5 & 0.4 \\
\hline Average micro strain & 97 & 98 & 99 \\
\hline Load drift (\%) & 0.1 & 0.1 & 0 \\
\hline Load standard error $(\%)$ & 1.1 & 0.4 & 0.5 \\
\hline Average deformation drift $(\%)$ & -133.1 & -185.4 & -243.3 \\
\hline Average deformation standard error $(\%)$ & 4.6 & 3.6 & 3.8 \\
\hline Deformation uniformity $(\%)$ & 24.4 & 18.7 & 15.7 \\
\hline Phase uniformity (Degrees) & 0.4 & 0.4 & 0.4 \\
\hline
\end{tabular}

Table 56 - PG 70-22 25\% RAP Replicate 2- $40^{\circ} \mathrm{C}$ DM Test Data

\begin{tabular}{|c|c|c|c|c|}
\hline PG 70-22 25\% RAP Replicate $2-40^{\circ} \mathrm{C}$ & $10 \mathrm{~Hz}$ & $1 \mathrm{~Hz}$ & $0.1 \mathrm{~Hz}$ & $0.01 \mathrm{~Hz}$ \\
\hline Dynamic modulus (MPa) & 2448 & 1145 & 529 & 272 \\
\hline Phase angle (Degrees) & 31.49 & 32.22 & 29.71 & 25.21 \\
\hline Average temperature $\left({ }^{\circ} \mathrm{C}\right)$ & 40.4 & 40.4 & 40.4 & 40.2 \\
\hline Average confining pressure $(\mathrm{kPa})$ & 0 & 0 & 0 & 0 \\
\hline Average micro strain & 93 & 92 & 94 & 105 \\
\hline Load drift (\%) & 0.4 & 0 & 0 & -0.2 \\
\hline Load standard error (\%) & 2.4 & 0.5 & 0.6 & 1.4 \\
\hline Average deformation drift $(\%)$ & -391.7 & -287.4 & -180.7 & -76.9 \\
\hline Average deformation standard error $(\%)$ & 8.7 & 5 & 4.8 & 6.1 \\
\hline Deformation uniformity $(\%)$ & 2.4 & 1.2 & 1.3 & 3.8 \\
\hline Phase uniformity (Degrees) & 0.2 & 0.4 & 0.6 & 0.8 \\
\hline
\end{tabular}


Table 57 - PG 70-22 25\% RAP Replicate $3-4^{\circ} \mathrm{C}$ DM Test Data

\begin{tabular}{|c|c|c|c|}
\hline PG 70-22 25\% RAP Replicate $3-4^{\circ} \mathrm{C}$ & $10 \mathrm{~Hz}$ & $1 \mathrm{~Hz}$ & $0.1 \mathrm{~Hz}$ \\
\hline Dynamic modulus (MPa) & 15941 & 12770 & 9434 \\
\hline Phase angle (Degrees) & 8.13 & 11.01 & 14.67 \\
\hline Average temperature $\left({ }^{\circ} \mathrm{C}\right)$ & 4.1 & 4.1 & 4 \\
\hline Average confining pressure (kPa) & 0.7 & 0.7 & 0.7 \\
\hline Average micro strain & 104 & 98 & 101 \\
\hline Load drift (\%) & 0 & 0.1 & 0 \\
\hline Load standard error (\%) & 0.9 & 0.4 & 0.4 \\
\hline Average deformation drift (\%) & 21.8 & -44.1 & -76.5 \\
\hline Average deformation standard error $(\%)$ & 3.6 & 2.1 & 2.1 \\
\hline Deformation uniformity (\%) & 19.2 & 19.9 & 19.7 \\
\hline Phase uniformity (Degrees) & 0.5 & 0.5 & 0.4 \\
\hline
\end{tabular}

Table 58 - PG 70-22 25\% RAP Replicate 3-20 ${ }^{\circ}$ C DM Test Data

\begin{tabular}{|c|c|c|c|}
\hline PG 70-22 25\% RAP Replicate $3-20^{\circ} \mathrm{C}$ & $10 \mathrm{~Hz}$ & $1 \mathrm{~Hz}$ & $0.1 \mathrm{~Hz}$ \\
\hline Dynamic modulus (MPa) & 8170 & 5078 & 2864 \\
\hline Phase angle (Degrees) & 17.8 & 22.68 & 27.42 \\
\hline Average temperature $\left({ }^{\circ} \mathrm{C}\right)$ & 19.9 & 20 & 20.1 \\
\hline Average confining pressure (kPa) & 0.4 & 0.5 & 0.3 \\
\hline Average micro strain & 99 & 98 & 97 \\
\hline Load drift (\%) & 0.1 & 0.1 & 0 \\
\hline Load standard error (\%) & 1.1 & 0.4 & 0.6 \\
\hline Average deformation drift (\%) & -126.5 & -176.2 & -231.8 \\
\hline Average deformation standard error $(\%)$ & 3.3 & 3 & 3.5 \\
\hline Deformation uniformity $(\%)$ & 6.1 & 6.1 & 6.6 \\
\hline Phase uniformity (Degrees) & 0.3 & 0.3 & 0.3 \\
\hline
\end{tabular}


Table 59 - PG 70-22 25\% RAP Replicate $3-40^{\circ} \mathrm{C}$ DM Test Data

\begin{tabular}{|c|c|c|c|c|}
\hline PG 70-22 25\% RAP Replicate $3-40^{\circ} \mathrm{C}$ & $10 \mathrm{~Hz}$ & $1 \mathrm{~Hz}$ & $0.1 \mathrm{~Hz}$ & $0.01 \mathrm{~Hz}$ \\
\hline Dynamic modulus (MPa) & 2615 & 1257 & 589.7 & 297.6 \\
\hline Phase angle (Degrees) & 30.29 & 31.79 & 30.2 & 26.02 \\
\hline Average temperature $\left({ }^{\circ} \mathrm{C}\right)$ & 40.2 & 40.2 & 40.3 & 40.2 \\
\hline Average confining pressure $(\mathrm{kPa})$ & 0 & 0 & 0 & 0 \\
\hline Average micro strain & 96 & 92 & 94 & 105 \\
\hline Load drift (\%) & 0.4 & 0.1 & 0 & 0.2 \\
\hline Load standard error (\%) & 2.1 & 0.4 & 0.5 & 1.1 \\
\hline Average deformation drift (\%) & -350.8 & -280.3 & -210.2 & -112.4 \\
\hline Average deformation standard error $(\%)$ & 7.7 & 4.3 & 4.3 & 5.3 \\
\hline Deformation uniformity (\%) & 13.6 & 13.1 & 12.4 & 11.5 \\
\hline Phase uniformity (Degrees) & 0.8 & 1 & 1.2 & 1.3 \\
\hline
\end{tabular}

Table 60 - PG 64-22 25\% RAP Replicate $1-4{ }^{\circ} \mathrm{C}$ DM Test Data

\begin{tabular}{|c|c|c|c|}
\hline PG 64-22 25\% RAP Replicate $1-4^{\circ} \mathrm{C}$ & $10 \mathrm{~Hz}$ & $1 \mathrm{~Hz}$ & $0.1 \mathrm{~Hz}$ \\
\hline Dynamic modulus (MPa) & 16145 & 12422 & 8845 \\
\hline Phase angle (Degrees) & 9.19 & 12.21 & 16.55 \\
\hline Average temperature $\left({ }^{\circ} \mathrm{C}\right)$ & 4.3 & 4.2 & 4 \\
\hline Average confining pressure $(\mathrm{kPa})$ & 0.7 & 0.7 & 0.7 \\
\hline Average micro strain & 101 & 100 & 103 \\
\hline Load drift (\%) & 0 & 0.1 & 0 \\
\hline Load standard error $(\%)$ & 1 & 0.4 & 0.4 \\
\hline Average deformation drift $(\%)$ & -35.5 & -58.4 & -104.4 \\
\hline Average deformation standard error $(\%)$ & 1.5 & 1.3 & 1.7 \\
\hline Deformation uniformity (\%) & 13.3 & 13.3 & 12.9 \\
\hline Phase uniformity (Degrees) & 0.1 & 0.1 & 0.2 \\
\hline
\end{tabular}


Table 61 - PG 64-22 25\% RAP Replicate 1-20 ${ }^{\circ} \mathrm{C}$ DM Test Data

\begin{tabular}{|c|c|c|c|}
\hline PG 64-22 25\% RAP Replicate $1-20^{\circ} \mathrm{C}$ & $10 \mathrm{~Hz}$ & $1 \mathrm{~Hz}$ & $0.1 \mathrm{~Hz}$ \\
\hline Dynamic modulus (MPa) & 8334 & 5105 & 2793 \\
\hline Phase angle (Degrees) & 18.39 & 23.82 & 28.79 \\
\hline Average temperature $\left({ }^{\circ} \mathrm{C}\right)$ & 20 & 20 & 20 \\
\hline Average confining pressure (kPa) & 0.4 & 0.4 & 0.4 \\
\hline Average micro strain & 101 & 98 & 97 \\
\hline Load drift (\%) & 0.2 & 0 & 0 \\
\hline Load standard error $(\%)$ & 1.1 & 0.4 & 0.5 \\
\hline Average deformation drift $(\%)$ & -148.2 & -212.1 & -270.5 \\
\hline Average deformation standard error $(\%)$ & 3.1 & 3.2 & 3.8 \\
\hline Deformation uniformity $(\%)$ & 7.6 & 8.7 & 8.7 \\
\hline Phase uniformity (Degrees) & 0.2 & 0.1 & 0.1 \\
\hline
\end{tabular}

Table 62 - PG 64-22 25\% RAP Replicate 1-40 ${ }^{\circ} \mathrm{C}$ DM Test Data

\begin{tabular}{|c|c|c|c|c|}
\hline PG 64-22 25\% RAP Replicate $1-40^{\circ} \mathrm{C}$ & $10 \mathrm{~Hz}$ & $1 \mathrm{~Hz}$ & $0.1 \mathrm{~Hz}$ & $0.01 \mathrm{~Hz}$ \\
\hline Dynamic modulus (MPa) & 2070 & 909.5 & 395 & 194.7 \\
\hline Phase angle (Degrees) & 33.8 & 33.52 & 30.05 & 25.46 \\
\hline Average temperature $\left({ }^{\circ} \mathrm{C}\right)$ & 40.3 & 40.3 & 40.3 & 40.1 \\
\hline Average confining pressure $(\mathrm{kPa})$ & 0 & 0 & 0 & 0 \\
\hline Average micro strain & 91 & 91 & 95 & 108 \\
\hline Load drift (\%) & 0.3 & 0 & 0 & 0 \\
\hline Load standard error (\%) & 2.6 & 0.4 & 0.7 & 1.1 \\
\hline Average deformation drift $(\%)$ & -437.5 & -275.8 & -117.9 & -3.8 \\
\hline Average deformation standard error $(\%)$ & 9.8 & 5.1 & 5 & 6.7 \\
\hline Deformation uniformity $(\%)$ & 2.8 & 2.8 & 0.7 & 4.5 \\
\hline Phase uniformity (Degrees) & 0.5 & 0.9 & 1.9 & 1.8 \\
\hline
\end{tabular}


Table 63 - PG 64-22 25\% RAP Replicate $2-4^{\circ} \mathrm{C}$ DM Test Data

\begin{tabular}{|c|c|c|c|}
\hline PG 64-22 25\% RAP Replicate $2-4^{\circ} \mathrm{C}$ & $10 \mathrm{~Hz}$ & $1 \mathrm{~Hz}$ & $0.1 \mathrm{~Hz}$ \\
\hline Dynamic modulus (MPa) & 16745 & 13282 & 9804 \\
\hline Phase angle (Degrees) & 8.36 & 10.72 & 14.28 \\
\hline Average temperature $\left({ }^{\circ} \mathrm{C}\right)$ & 4.1 & 4.1 & 3.9 \\
\hline Average confining pressure (kPa) & 0.7 & 0.7 & 0.7 \\
\hline Average micro strain & 102 & 100 & 104 \\
\hline Load drift (\%) & 0.2 & 0.1 & 0 \\
\hline Load standard error (\%) & 1 & 0.4 & 0.4 \\
\hline Average deformation drift (\%) & -27.6 & -41.5 & -68.7 \\
\hline Average deformation standard error $(\%)$ & 1.3 & 1.2 & 1.2 \\
\hline Deformation uniformity (\%) & 17.8 & 17.4 & 17 \\
\hline Phase uniformity (Degrees) & 0.3 & 0.4 & 0.5 \\
\hline
\end{tabular}

Table 64 - PG 64-22 25\% RAP Replicate $2-20^{\circ} \mathrm{C}$ DM Test Data

\begin{tabular}{|c|c|c|c|}
\hline PG 64-22 25\% RAP Replicate $2-20^{\circ} \mathrm{C}$ & $10 \mathrm{~Hz}$ & $1 \mathrm{~Hz}$ & $0.1 \mathrm{~Hz}$ \\
\hline Dynamic modulus (MPa) & 7979 & 4974 & 2803 \\
\hline Phase angle (Degrees) & 18.24 & 23.3 & 28 \\
\hline Average temperature $\left({ }^{\circ} \mathrm{C}\right)$ & 20 & 20 & 20 \\
\hline Average confining pressure (kPa) & 0.6 & 0.6 & 0.6 \\
\hline Average micro strain & 100 & 97 & 97 \\
\hline Load drift (\%) & 0.2 & 0 & 0 \\
\hline Load standard error (\%) & 1.1 & 0.4 & 0.6 \\
\hline Average deformation drift (\%) & -136.7 & -186.4 & -231.8 \\
\hline Average deformation standard error $(\%)$ & 3.1 & 3.1 & 3.5 \\
\hline Deformation uniformity $(\%)$ & 1.5 & 3.3 & 5.4 \\
\hline Phase uniformity (Degrees) & 0.4 & 0.9 & 1 \\
\hline
\end{tabular}


Table 65 - PG 64-22 25\% RAP Replicate $2-40^{\circ} \mathrm{C}$ DM Test Data

\begin{tabular}{|c|c|c|c|c|}
\hline PG 64-22 25\% RAP Replicate $2-40^{\circ} \mathrm{C}$ & $10 \mathrm{~Hz}$ & $1 \mathrm{~Hz}$ & $0.1 \mathrm{~Hz}$ & $0.01 \mathrm{~Hz}$ \\
\hline Dynamic modulus (MPa) & 2253 & 1059 & 491.2 & 252 \\
\hline Phase angle (Degrees) & 31.7 & 32.25 & 29.75 & 25.33 \\
\hline Average temperature $\left({ }^{\circ} \mathrm{C}\right)$ & 40.4 & 40.4 & 40.4 & 40.4 \\
\hline Average confining pressure $(\mathrm{kPa})$ & 0 & 0 & 0 & 0 \\
\hline Average micro strain & 95 & 91 & 95 & 105 \\
\hline Load drift (\%) & 0.5 & 0.1 & 0.4 & -0.2 \\
\hline Load standard error (\%) & 3.3 & 0.5 & 1.5 & 1.2 \\
\hline Average deformation drift (\%) & -363.8 & -248.5 & -149.2 & -51.4 \\
\hline Average deformation standard error $(\%)$ & 8.8 & 4.7 & 4.4 & 5.5 \\
\hline Deformation uniformity (\%) & 11.3 & 10.5 & 11.9 & 13.7 \\
\hline Phase uniformity (Degrees) & 0.7 & 0.9 & 0.9 & 0.1 \\
\hline
\end{tabular}

Table 66 - PG 64-22 25\% RAP Replicate $3-4^{\circ} \mathrm{C}$ DM Test Data

\begin{tabular}{|c|c|c|c|}
\hline PG 64-22 25\% RAP Replicate $3-4^{\circ} \mathrm{C}$ & $10 \mathrm{~Hz}$ & $1 \mathrm{~Hz}$ & $0.1 \mathrm{~Hz}$ \\
\hline Dynamic modulus (MPa) & 17517 & 13893 & 10138 \\
\hline Phase angle (Degrees) & 8.54 & 11.19 & 14.83 \\
\hline Average temperature $\left({ }^{\circ} \mathrm{C}\right)$ & 4.2 & 4.2 & 4.1 \\
\hline Average confining pressure $(\mathrm{kPa})$ & 0.8 & 0.8 & 0.8 \\
\hline Average micro strain & 99 & 99 & 104 \\
\hline Load drift (\%) & 0 & 0.1 & 0 \\
\hline Load standard error (\%) & 0.9 & 0.4 & 0.4 \\
\hline Average deformation drift (\%) & -31.8 & -48.4 & -81.7 \\
\hline Average deformation standard error $(\%)$ & 1.7 & 1.4 & 2.2 \\
\hline Deformation uniformity (\%) & 3.6 & 2 & 8.6 \\
\hline Phase uniformity (Degrees) & 0.8 & 1 & 1.4 \\
\hline
\end{tabular}


Table 67 - PG 64-22 25\% RAP Replicate $3-20^{\circ} \mathrm{C}$ DM Test Data

\begin{tabular}{|c|c|c|c|}
\hline PG 64-22 25\% RAP Replicate $3-20^{\circ} \mathrm{C}$ & $10 \mathrm{~Hz}$ & $1 \mathrm{~Hz}$ & $0.1 \mathrm{~Hz}$ \\
\hline Dynamic modulus (MPa) & 9674 & 6162 & 3549 \\
\hline Phase angle (Degrees) & 16.18 & 20.81 & 25.68 \\
\hline Average temperature $\left({ }^{\circ} \mathrm{C}\right)$ & 20 & 20 & 20 \\
\hline Average confining pressure $(\mathrm{kPa})$ & 0.4 & 0.4 & 0.3 \\
\hline Average micro strain & 103 & 101 & 102 \\
\hline Load drift (\%) & 0 & 0 & 0 \\
\hline Load standard error (\%) & 1 & 0.4 & 0.4 \\
\hline Average deformation drift (\%) & -107.2 & -152.9 & -189.6 \\
\hline Average deformation standard error $(\%)$ & 3.2 & 2.8 & 3.1 \\
\hline Deformation uniformity (\%) & 18.1 & 22.5 & 24.3 \\
\hline Phase uniformity (Degrees) & 1.4 & 1.1 & 1 \\
\hline
\end{tabular}

Table 68 - PG 64-22 25\% RAP Replicate $3-40^{\circ} \mathrm{C}$ DM Test Data

\begin{tabular}{|c|c|c|c|c|}
\hline PG 64-22 25\% RAP Replicate $3-40^{\circ} \mathrm{C}$ & $10 \mathrm{~Hz}$ & $1 \mathrm{~Hz}$ & $0.1 \mathrm{~Hz}$ & $0.01 \mathrm{~Hz}$ \\
\hline Dynamic modulus (MPa) & 2615 & 1230 & 568.6 & 289.9 \\
\hline Phase angle (Degrees) & 30.76 & 31.84 & 29.77 & 25.91 \\
\hline Average temperature $\left({ }^{\circ} \mathrm{C}\right)$ & 40.4 & 40.4 & 40.4 & 40.2 \\
\hline Average confining pressure $(\mathrm{kPa})$ & 0 & 0 & 0 & 0 \\
\hline Average micro strain & 100 & 92 & 95 & 105 \\
\hline Load drift (\%) & 0.2 & 0 & 0.1 & 0.2 \\
\hline Load standard error (\%) & 2.6 & 0.4 & 0.3 & 1.3 \\
\hline Average deformation drift $(\%)$ & -353.2 & -221.9 & -126.1 & -36.1 \\
\hline Average deformation standard error $(\%)$ & 8.7 & 4.5 & 4.3 & 5.6 \\
\hline Deformation uniformity (\%) & 20.7 & 18.9 & 17.9 & 17.4 \\
\hline Phase uniformity (Degrees) & 1.6 & 1 & 1.1 & 0.9 \\
\hline
\end{tabular}




\section{Appendix C}

Fatigue Sample Properties (Summer 2014)

Table 69 - FT Specimen Volumetrics

\begin{tabular}{|c|c|c|c|c|c|c|c|c|c|}
\hline Binder & $\%$ RAP & Replicate & $\mathbf{P b}$ & Gmm & Gmb & Gsb & VTM & VMA & VFA \\
\hline \multirow{27}{*}{ PG 70-22 } & \multirow{9}{*}{0} & $1 \mathrm{a}$ & $4.9 \%$ & 2.527 & 2.357 & 2.679 & $6.7 \%$ & $16.3 \%$ & $58.8 \%$ \\
\hline & & $1 b$ & $4.9 \%$ & 2.527 & 2.358 & 2.679 & $6.7 \%$ & $16.3 \%$ & $59.0 \%$ \\
\hline & & $1 \mathrm{c}$ & $4.9 \%$ & 2.527 & 2.349 & 2.679 & $7.0 \%$ & $16.6 \%$ & $57.6 \%$ \\
\hline & & $2 a$ & $4.9 \%$ & 2.527 & 2.348 & 2.679 & $7.1 \%$ & $16.6 \%$ & $57.5 \%$ \\
\hline & & $2 b$ & $4.9 \%$ & 2.527 & 2.35 & 2.679 & $7.0 \%$ & $16.6 \%$ & $57.8 \%$ \\
\hline & & $2 c$ & $4.9 \%$ & 2.527 & 2.357 & 2.679 & $6.7 \%$ & $16.3 \%$ & $58.8 \%$ \\
\hline & & $3 a$ & $4.9 \%$ & 2.527 & 2.342 & 2.679 & $7.3 \%$ & $16.9 \%$ & $56.6 \%$ \\
\hline & & $3 b$ & $4.9 \%$ & 2.527 & 2.342 & 2.679 & $7.3 \%$ & $16.9 \%$ & $56.6 \%$ \\
\hline & & $3 c$ & $4.9 \%$ & 2.527 & 2.342 & 2.679 & $7.3 \%$ & $16.9 \%$ & $56.6 \%$ \\
\hline & \multirow{9}{*}{15} & $1 \mathrm{a}$ & $4.6 \%$ & 2.535 & 2.37 & 2.676 & $6.5 \%$ & $15.5 \%$ & $58.0 \%$ \\
\hline & & $1 b$ & $4.6 \%$ & 2.535 & 2.371 & 2.676 & $6.5 \%$ & $15.5 \%$ & $58.2 \%$ \\
\hline & & $1 \mathrm{c}$ & $4.6 \%$ & 2.535 & 2.365 & 2.676 & $6.7 \%$ & $15.7 \%$ & $57.3 \%$ \\
\hline & & $2 a$ & $4.6 \%$ & 2.535 & 2.362 & 2.676 & $6.8 \%$ & $15.8 \%$ & $56.8 \%$ \\
\hline & & $2 b$ & $4.6 \%$ & 2.535 & 2.358 & 2.676 & $7.0 \%$ & $15.9 \%$ & $56.2 \%$ \\
\hline & & $2 c$ & $4.6 \%$ & 2.535 & 2.361 & 2.676 & $6.9 \%$ & $15.8 \%$ & $56.6 \%$ \\
\hline & & $3 a$ & $4.6 \%$ & 2.535 & 2.36 & 2.676 & $6.9 \%$ & $15.9 \%$ & $56.5 \%$ \\
\hline & & $3 b$ & $4.6 \%$ & 2.535 & 2.362 & 2.676 & $6.8 \%$ & $15.8 \%$ & $56.8 \%$ \\
\hline & & $3 c$ & $4.6 \%$ & 2.535 & 2.36 & 2.676 & $6.9 \%$ & $15.9 \%$ & $56.5 \%$ \\
\hline & \multirow{9}{*}{25} & $1 \mathrm{a}$ & $4.9 \%$ & 2.526 & 2.358 & 2.695 & $6.7 \%$ & $16.8 \%$ & $60.4 \%$ \\
\hline & & $1 b$ & $4.9 \%$ & 2.526 & 2.351 & 2.695 & $6.9 \%$ & $17.0 \%$ & $59.3 \%$ \\
\hline & & $1 \mathrm{c}$ & $4.9 \%$ & 2.526 & 2.363 & 2.695 & $6.5 \%$ & $16.6 \%$ & $61.2 \%$ \\
\hline & & $2 a$ & $4.9 \%$ & 2.526 & 2.361 & 2.695 & $6.5 \%$ & $16.7 \%$ & $60.9 \%$ \\
\hline & & $2 b$ & $4.9 \%$ & 2.526 & 2.362 & 2.695 & $6.5 \%$ & $16.7 \%$ & $61.0 \%$ \\
\hline & & $2 c$ & $4.9 \%$ & 2.526 & 2.357 & 2.695 & $6.7 \%$ & $16.8 \%$ & $60.2 \%$ \\
\hline & & $3 \mathrm{a}$ & $4.9 \%$ & 2.526 & 2.362 & 2.695 & $6.5 \%$ & $16.7 \%$ & $61.0 \%$ \\
\hline & & $3 b$ & $4.9 \%$ & 2.526 & 2.362 & 2.695 & $6.5 \%$ & $16.7 \%$ & $61.0 \%$ \\
\hline & & $3 c$ & $4.9 \%$ & 2.526 & 2.359 & 2.695 & $6.6 \%$ & $16.8 \%$ & $60.5 \%$ \\
\hline \multirow{9}{*}{ PG 64-22 } & \multirow{9}{*}{25} & $1 \mathrm{a}$ & $4.9 \%$ & 2.522 & 2.345 & 2.695 & $7.0 \%$ & $17.3 \%$ & $59.3 \%$ \\
\hline & & $1 b$ & $4.9 \%$ & 2.522 & 2.35 & 2.695 & $6.8 \%$ & $17.1 \%$ & $60.1 \%$ \\
\hline & & $1 \mathrm{c}$ & $4.9 \%$ & 2.522 & 2.332 & 2.695 & $7.5 \%$ & $17.7 \%$ & $57.5 \%$ \\
\hline & & $2 a$ & $4.9 \%$ & 2.522 & 2.356 & 2.695 & $6.6 \%$ & $16.9 \%$ & $61.0 \%$ \\
\hline & & $2 b$ & $4.9 \%$ & 2.522 & 2.353 & 2.695 & $6.7 \%$ & $17.0 \%$ & $60.5 \%$ \\
\hline & & $2 c$ & $4.9 \%$ & 2.522 & 2.355 & 2.695 & $6.6 \%$ & $16.9 \%$ & $60.8 \%$ \\
\hline & & $3 a$ & $4.9 \%$ & 2.522 & 2.356 & 2.695 & $6.6 \%$ & $16.9 \%$ & $61.0 \%$ \\
\hline & & $3 b$ & $4.9 \%$ & 2.522 & 2.353 & 2.695 & $6.7 \%$ & $17.0 \%$ & $60.5 \%$ \\
\hline & & $3 c$ & $4.9 \%$ & 2.522 & 2.349 & 2.695 & $6.9 \%$ & $17.1 \%$ & $59.9 \%$ \\
\hline
\end{tabular}


Table 70 - FT Specimen Height and Diameter

\begin{tabular}{|c|c|c|c|c|}
\hline Binder & $\%$ RAP & Replicate & Average Height (mm) & Average Diameter (mm) \\
\hline \multirow{27}{*}{ PG 70-22 } & \multirow{9}{*}{0} & $1 \mathrm{a}$ & 130.95 & 100.39 \\
\hline & & $1 b$ & 129.97 & 100.45 \\
\hline & & $1 \mathrm{c}$ & 131.47 & 100.42 \\
\hline & & $2 \mathrm{a}$ & 130.56 & 100.46 \\
\hline & & $2 b$ & 130.88 & 100.42 \\
\hline & & $2 \mathrm{c}$ & 131.05 & 100.44 \\
\hline & & $3 a$ & 132.14 & 100.40 \\
\hline & & $3 b$ & 130.81 & 100.45 \\
\hline & & $3 c$ & 130.11 & 100.42 \\
\hline & \multirow{9}{*}{15} & $1 \mathrm{a}$ & 130.10 & 70.40 \\
\hline & & $1 b$ & 130.81 & 100.43 \\
\hline & & $1 \mathrm{c}$ & 130.18 & 100.44 \\
\hline & & $2 \mathrm{a}$ & 130.50 & 100.42 \\
\hline & & $2 b$ & 130.40 & 100.48 \\
\hline & & $2 \mathrm{c}$ & 130.12 & 100.43 \\
\hline & & $3 a$ & 130.61 & 100.41 \\
\hline & & $3 b$ & 130.53 & 100.41 \\
\hline & & $3 c$ & 130.72 & 100.40 \\
\hline & \multirow{9}{*}{25} & $1 \mathrm{a}$ & 129.43 & 100.43 \\
\hline & & $1 \mathrm{~b}$ & 130.65 & 100.45 \\
\hline & & $1 \mathrm{c}$ & 131.32 & 100.38 \\
\hline & & $2 a$ & 130.20 & 100.41 \\
\hline & & $2 b$ & 130.49 & 100.39 \\
\hline & & $2 c$ & 130.15 & 100.41 \\
\hline & & $3 a$ & 130.08 & 100.44 \\
\hline & & $3 b$ & 130.53 & 100.39 \\
\hline & & $3 c$ & 130.48 & 100.42 \\
\hline \multirow{9}{*}{ PG 64-22 } & \multirow{9}{*}{25} & $1 \mathrm{a}$ & 130.29 & 100.50 \\
\hline & & $1 b$ & 130.01 & 100.40 \\
\hline & & $1 \mathrm{c}$ & 130.17 & 100.46 \\
\hline & & $2 a$ & 130.79 & 100.43 \\
\hline & & $2 b$ & 129.67 & 100.44 \\
\hline & & $2 c$ & 130.46 & 100.44 \\
\hline & & $3 a$ & 130.00 & 100.41 \\
\hline & & $3 b$ & 130.88 & 100.41 \\
\hline & & $3 c$ & 130.81 & 100.47 \\
\hline
\end{tabular}


ALPHA-Fatigue Analysis Reports (Summer 2015)

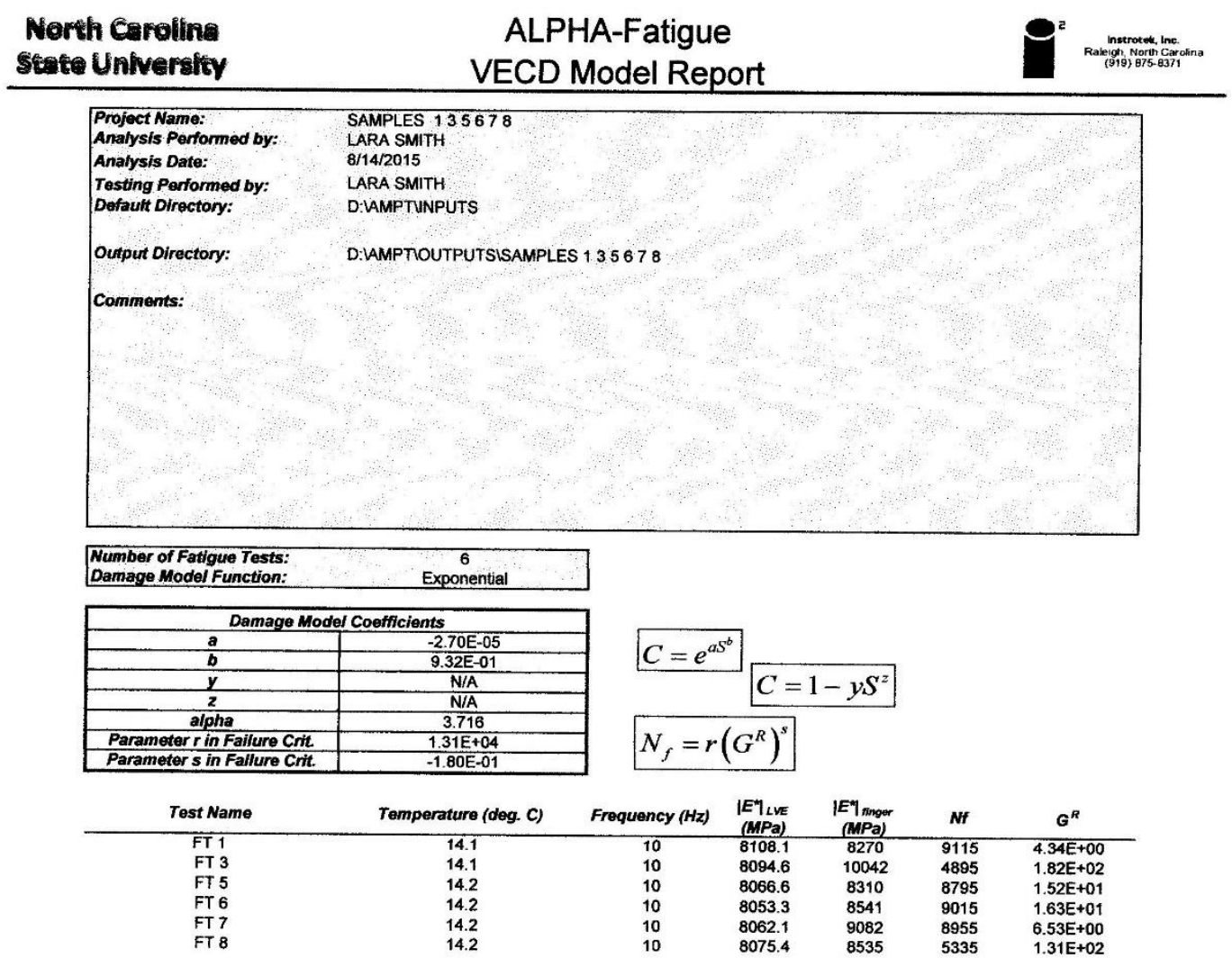

Figure 61 - PG 70-22 With 0\% RAP Fatigue Report Page 1 


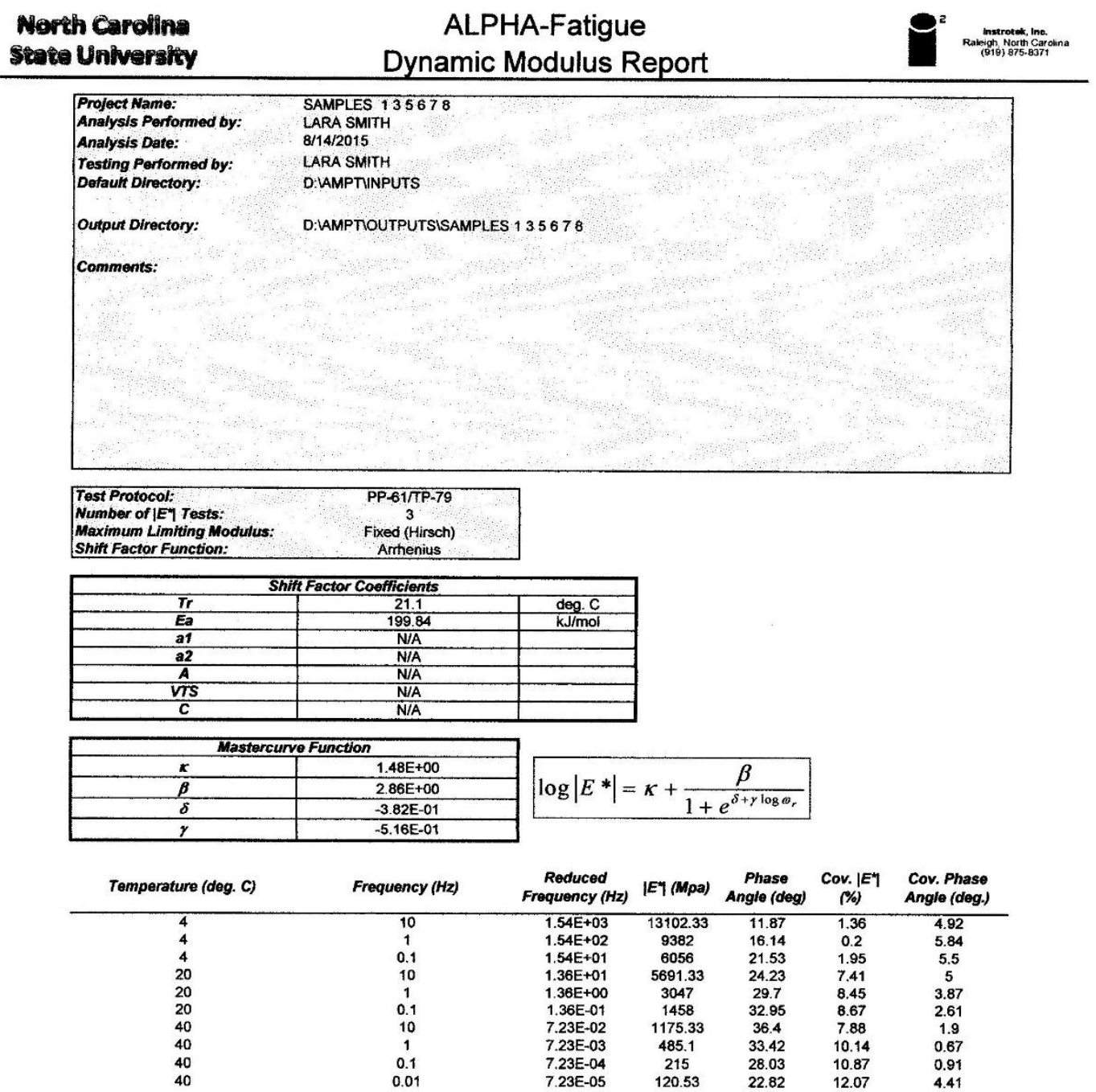

Figure 62 - PG 70-22 With 0\% RAP Fatigue Report Page 2 


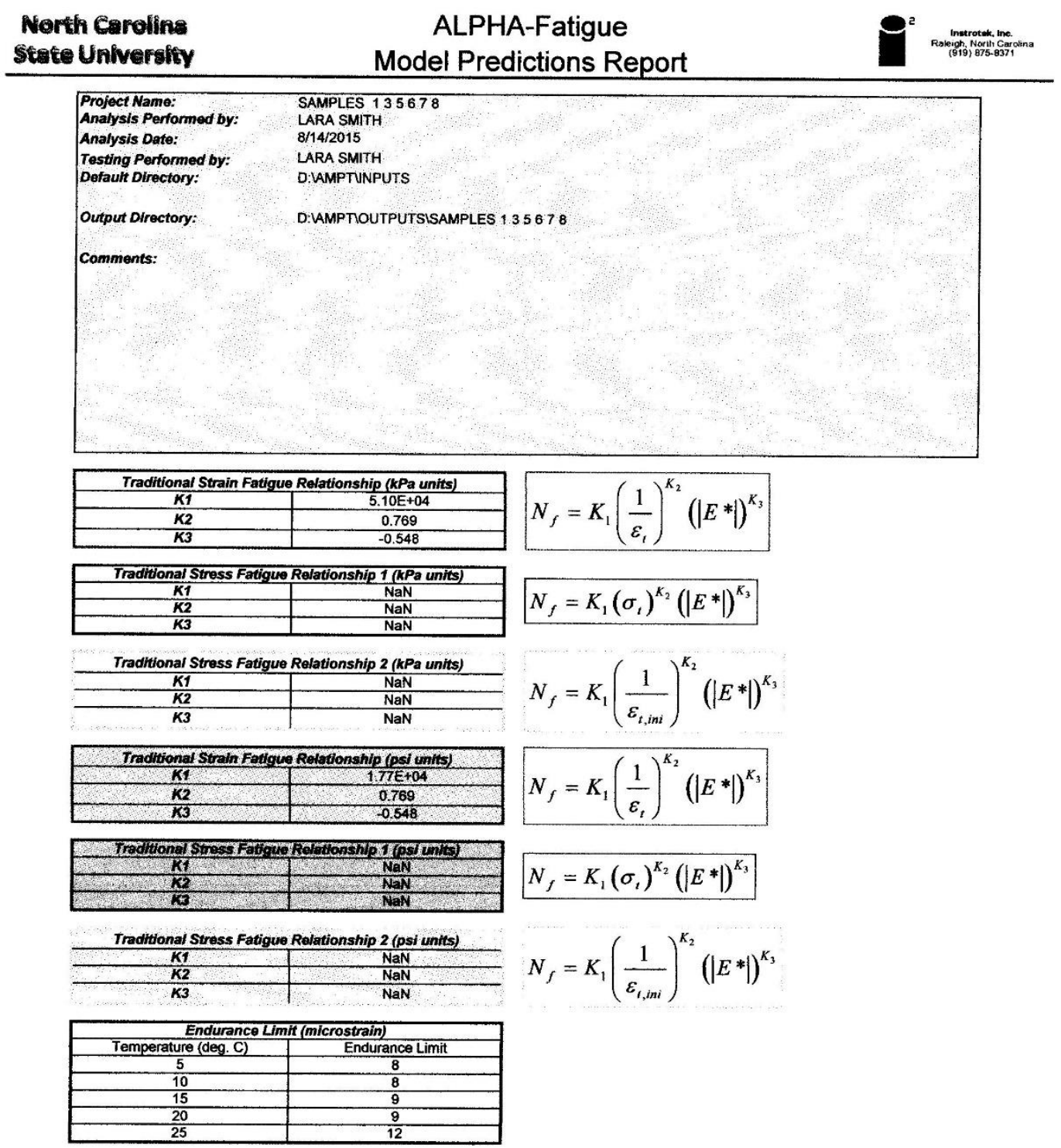




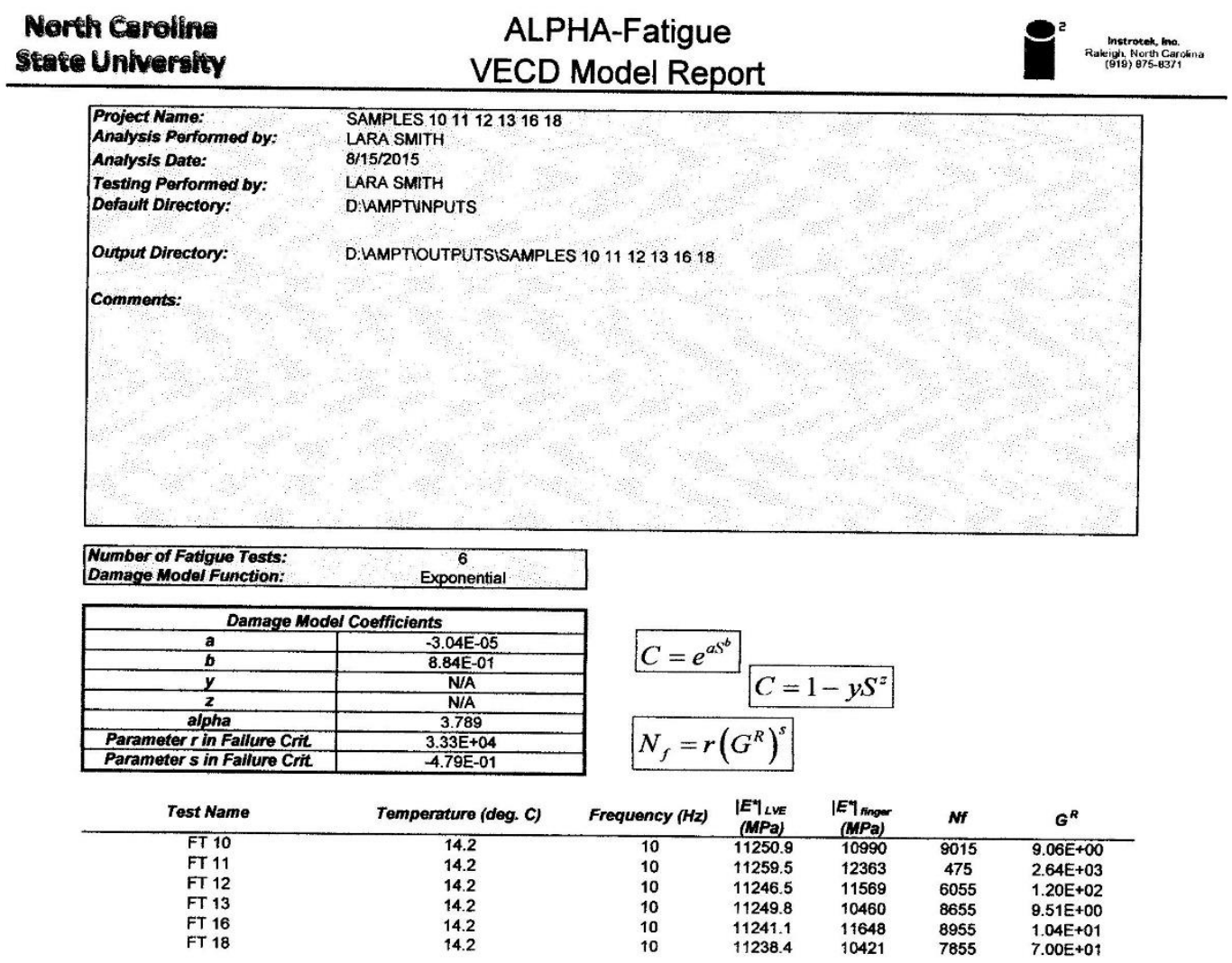

Figure 64 - PG 70-22 With 15\% RAP Fatigue Report Page 1 


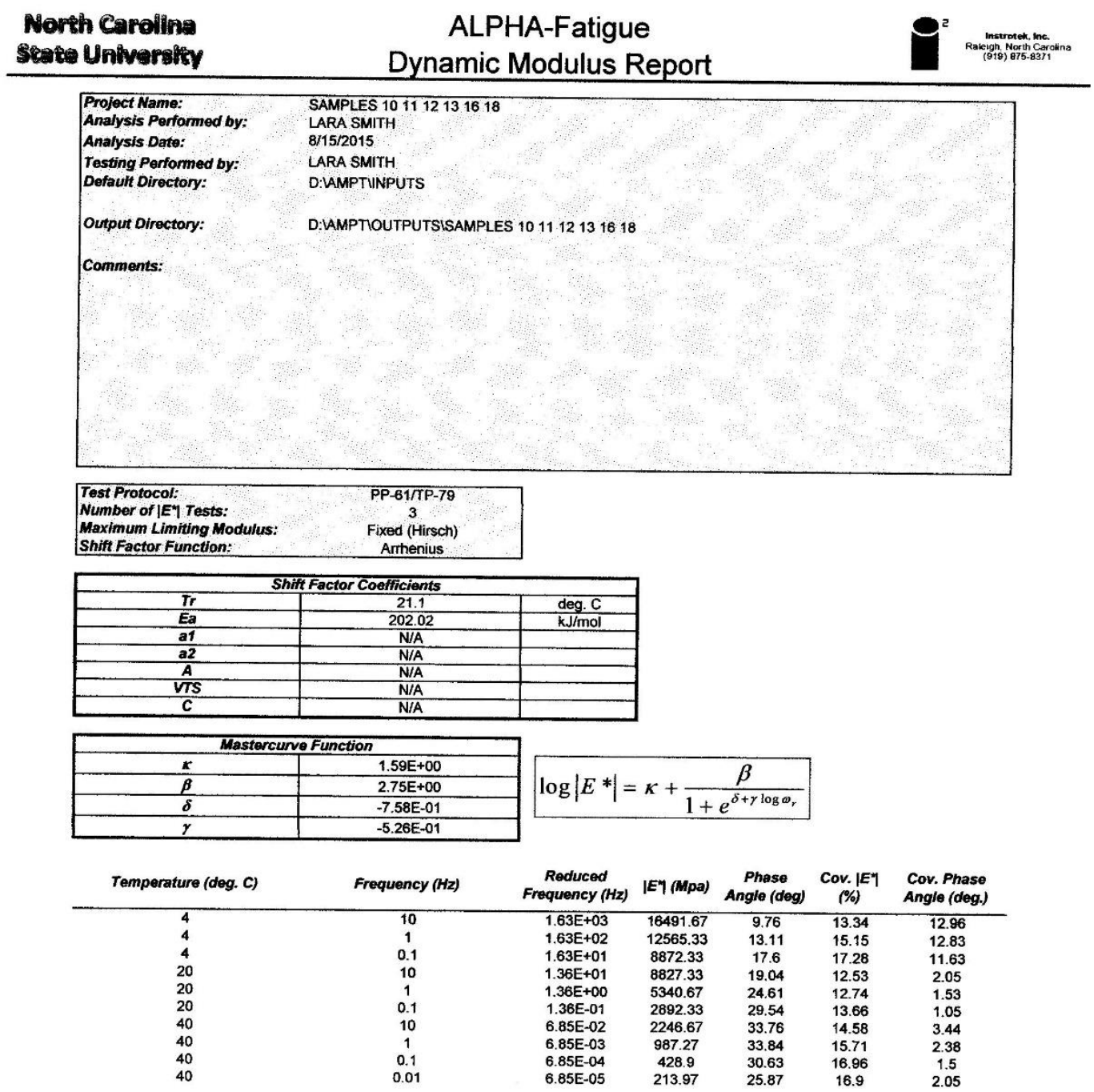

Figure 65 - PG 70-22 With 15\% RAP Fatigue Report Page 2 


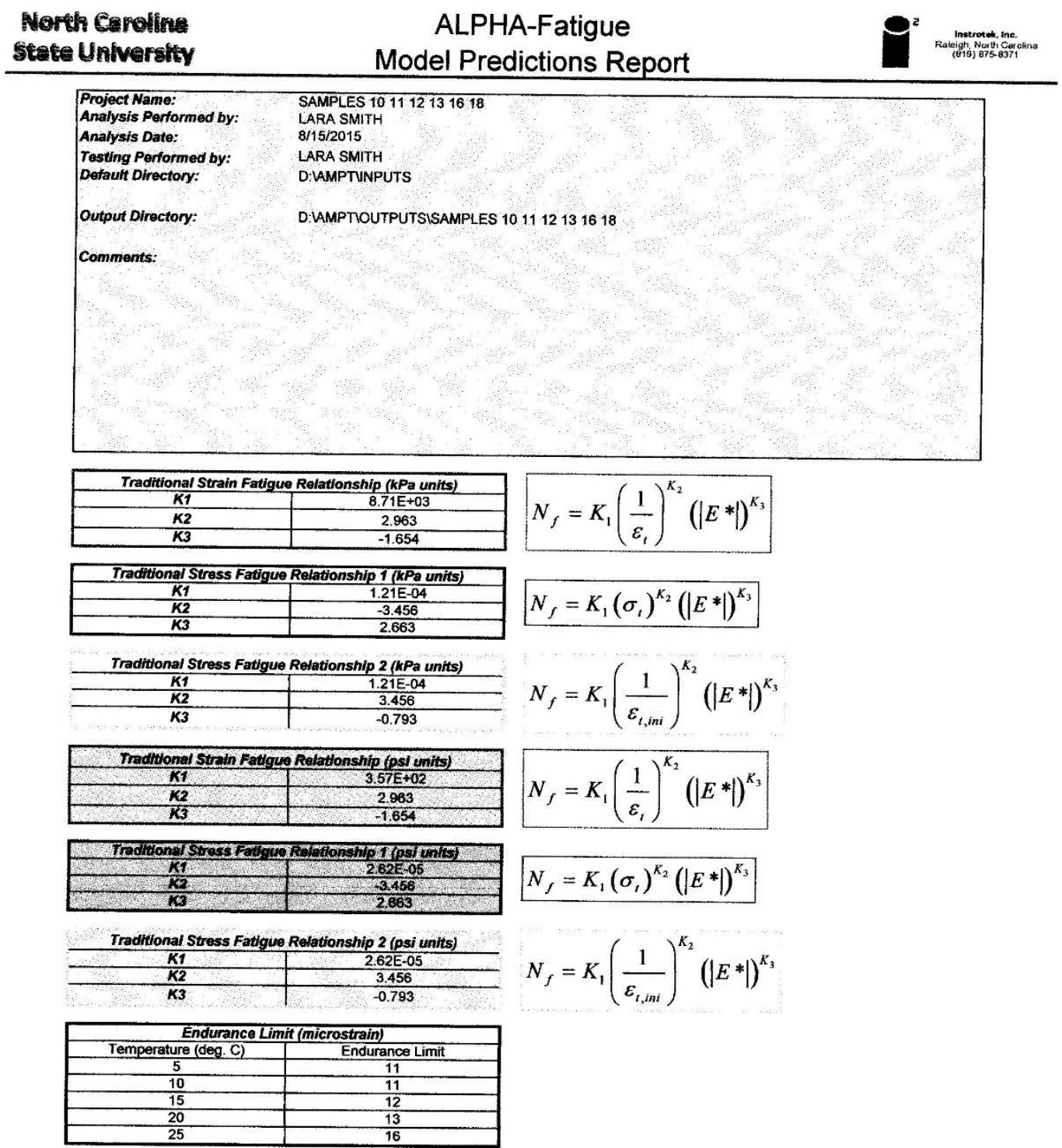

Figure 66 - PG 70-22 With 15\% RAP Fatigue Report Page 3 


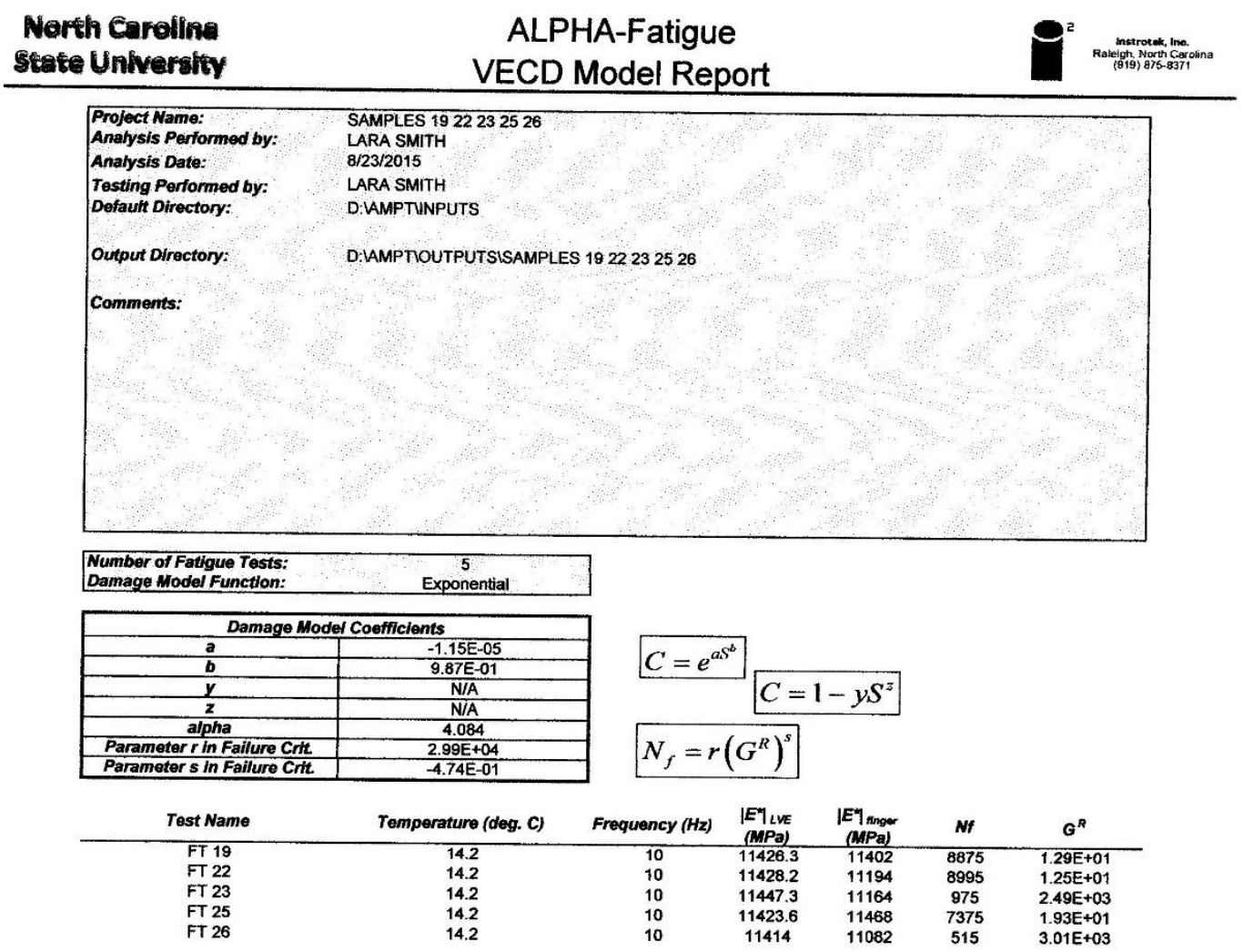

Figure 67 - PG 70-22 With 25\% RAP Fatigue Report Page 1 


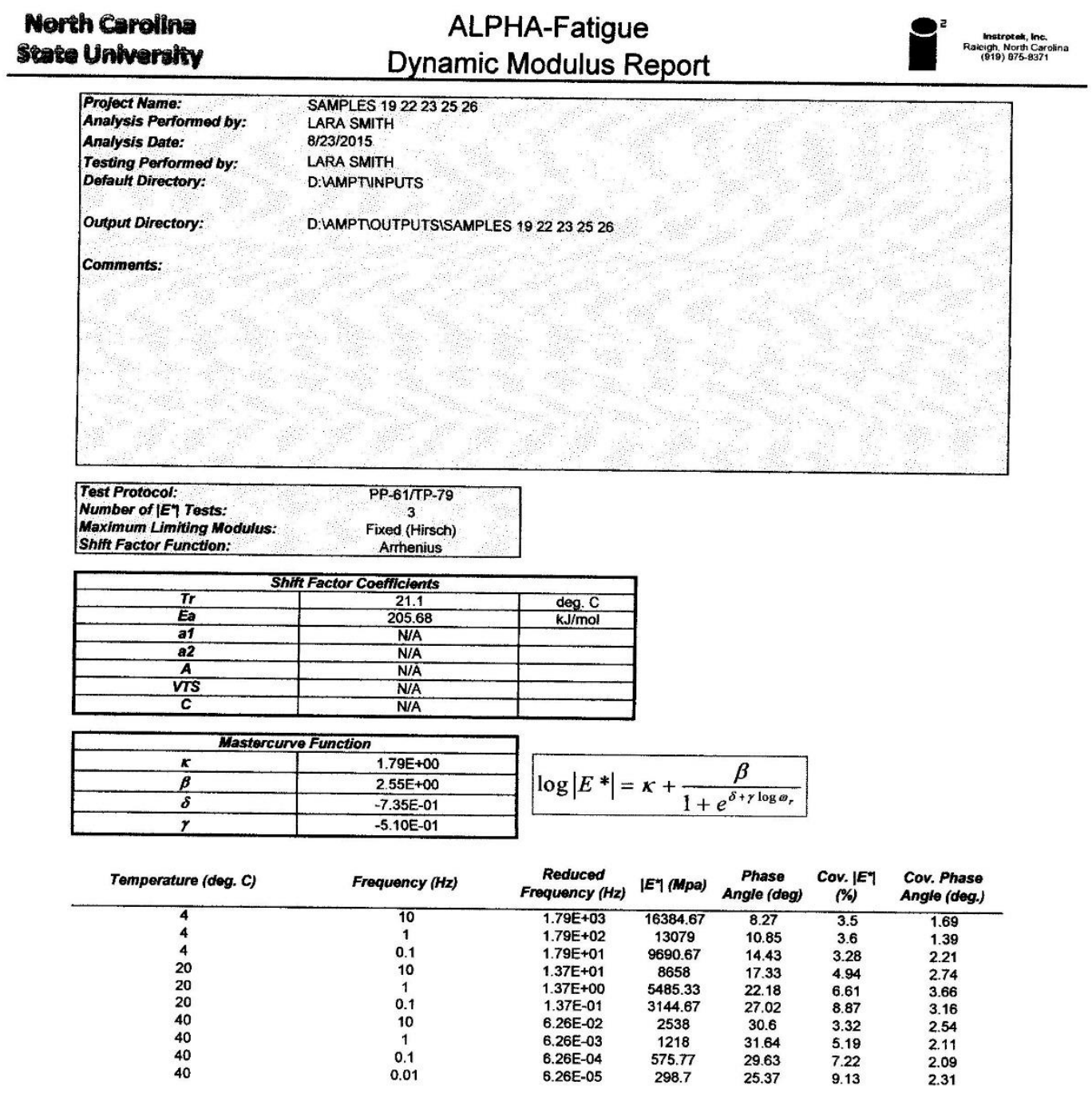

Figure 68 - PG 70-22 With 25\% RAP Fatigue Report Page 2 


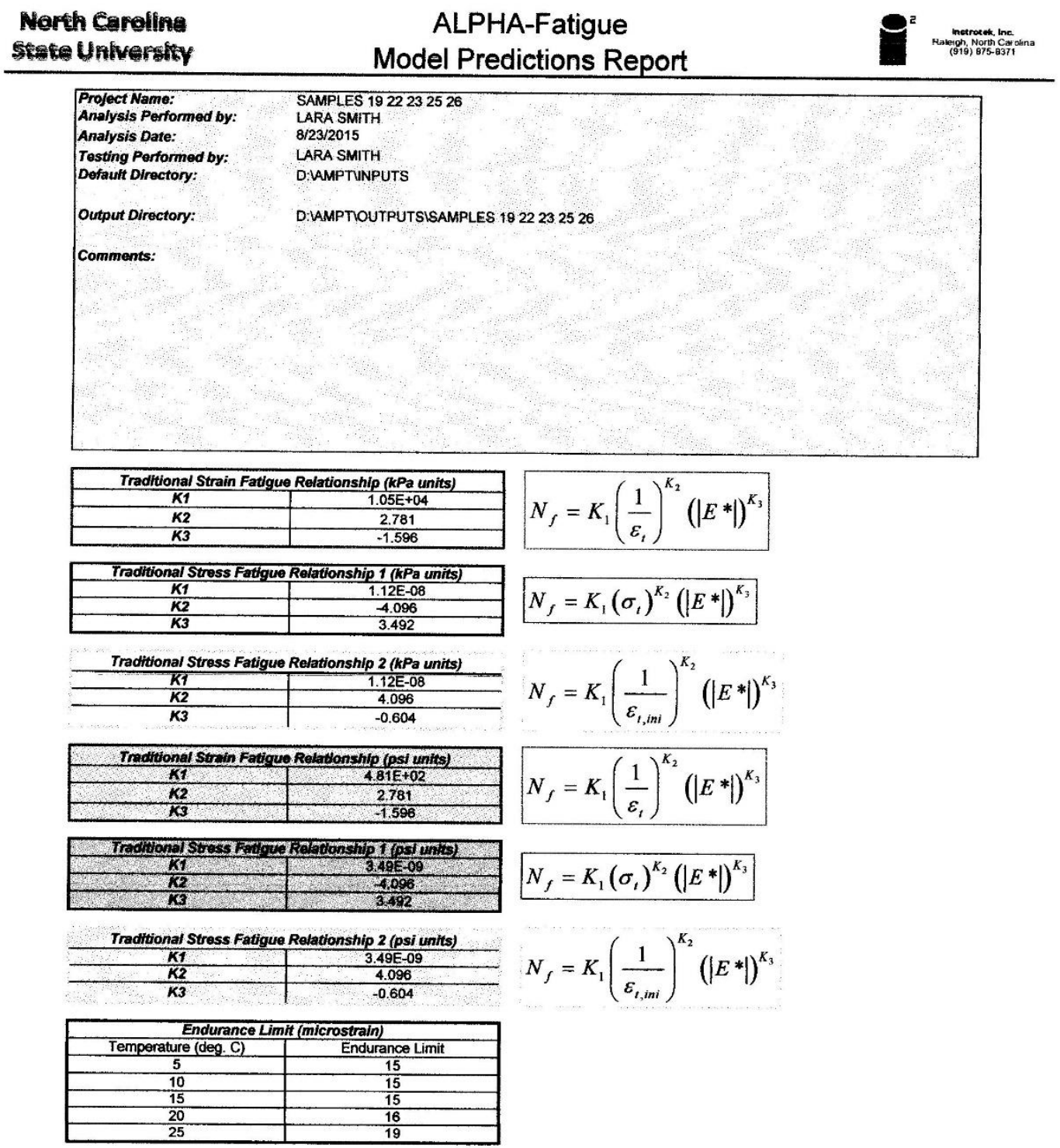

Figure 69 - PG 70-22 With 25\% RAP Fatigue Report Page 3 


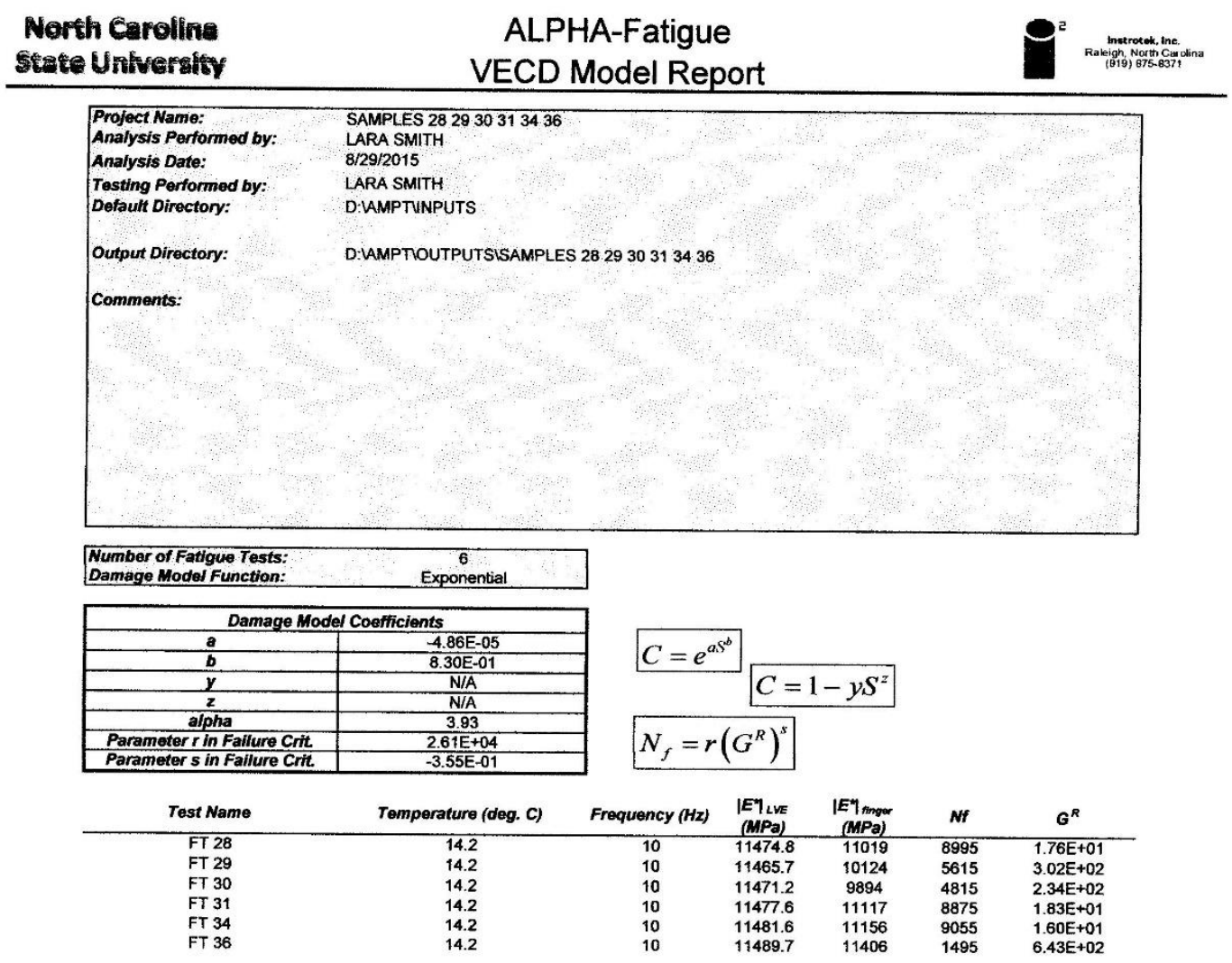

Figure 70 - PG 64-22 With 25\% RAP Fatigue Report Page 1 
North Carolins
State University

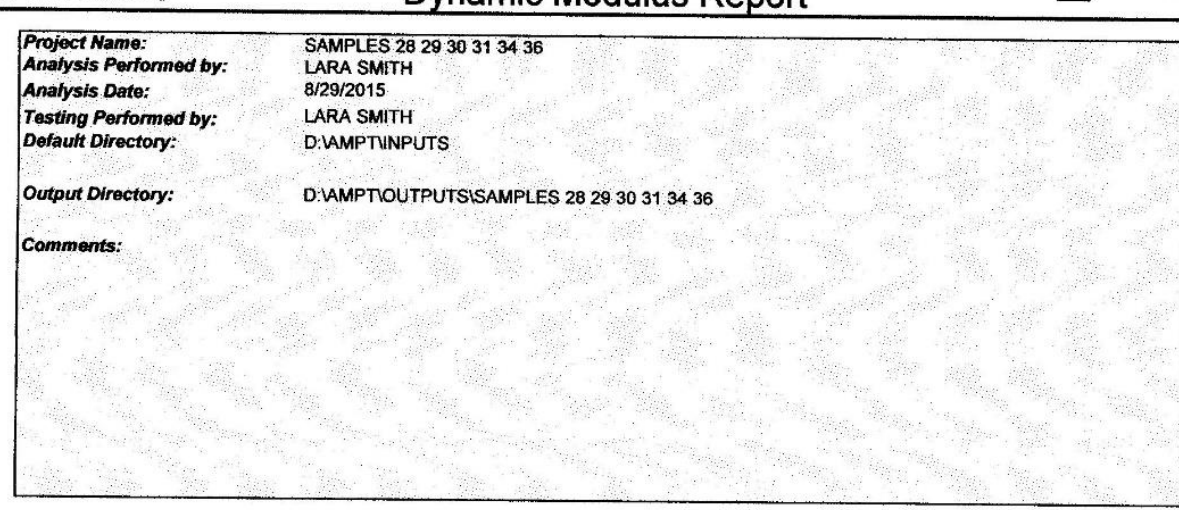

Test Protocol:

Number of |E丩 Tests:

Maximum Limiting Modulus:

Shift Factor Function
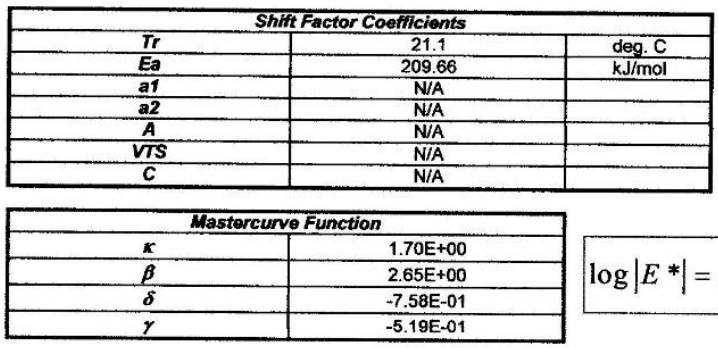

$\log \left|E^{*}\right|=\kappa+\frac{\beta}{1+e^{\delta+\gamma \log \omega_{r}}}$

\begin{tabular}{ccccccc} 
Temperature (deg. C) & Frequency (Hz) & $\begin{array}{c}\text { Reduced } \\
\text { Frequency (Hz) }\end{array}$ & IEY (Mpa) & $\begin{array}{c}\text { Phase } \\
\text { Angle (deg) }\end{array}$ & $\begin{array}{c}\text { Cov. |E'1 } \\
\text { (\%) }\end{array}$ & $\begin{array}{c}\text { Cov. Phase } \\
\text { Angle (deg.) }\end{array}$ \\
\hline 4 & 10 & $1.98 \mathrm{E}+03$ & 16802.33 & 8.7 & 4.09 & 5.02 \\
4 & 1 & $1.98 \mathrm{E}+02$ & 13199 & 11.37 & 5.6 & 6.7 \\
4 & 0.1 & $1.98 \mathrm{E}+01$ & 9595.67 & 15.22 & 6.99 & 7.78 \\
20 & 10 & $1.38 \mathrm{E}+01$ & 8662.33 & 17.6 & 10.32 & 7.02 \\
20 & 1 & $1.38 \mathrm{E}+00$ & 5413.67 & 22.64 & 12.03 & 7.11 \\
20 & 0.1 & $1.38 \mathrm{E}-01$ & 3048.33 & 27.49 & 14.22 & 5.88 \\
40 & 10 & $5.68 \mathrm{E}-02$ & 2312.67 & 32.09 & 11.99 & 4.85 \\
40 & 1 & $5.68 \mathrm{E}-03$ & 1068.17 & 32.54 & 15.04 & 2.69 \\
40 & 0.1 & $5.68 \mathrm{E}-04$ & 484.93 & 29.86 & 17.93 & 0.56 \\
40 & 0.01 & $5.68 \mathrm{E}-05$ & 245.53 & 25.57 & 19.52 & 1.19
\end{tabular}

Figure 71 - PG 64-22 With 25\% RAP Fatigue Report Page 2 
North Carofine State Universtity

\section{ALPHA-Fatigue Model Predictions Report}
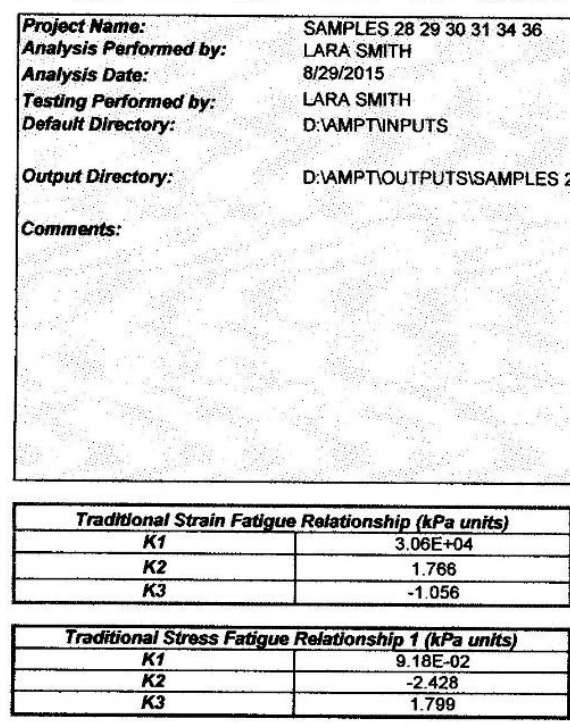

Traditional Stress Fatigue Relationship 2 (KPa units)

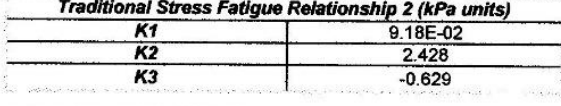

\begin{tabular}{|c|c|}
\hline \multicolumn{2}{|c|}{ Traditional Strain fatigue Relationship (psi units) } \\
\hline $\mathrm{KI}$ & $\frac{3.89 \mathrm{E}+03}{\mathrm{~K} 2}$ \\
\hline $\mathrm{K} 3$ & $\frac{1.786}{}$ \\
\hline
\end{tabular}

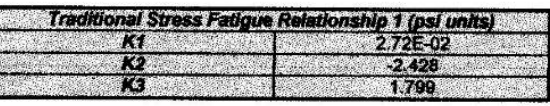

Traditional Stress Fatigue Relationship 2 (psi units)
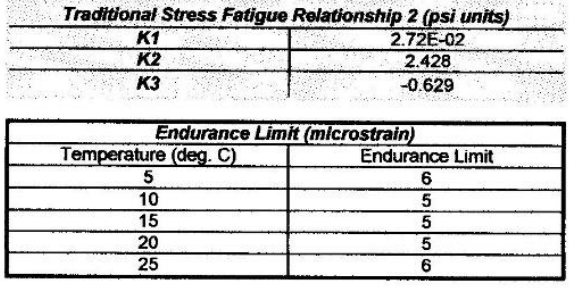

$N_{f}=K_{1}\left(\frac{1}{\varepsilon_{t}}\right)^{K_{2}}(|E *|)^{K_{3}}$

$N_{f}=K_{1}\left(\sigma_{t}\right)^{K_{2}}(|E *|)^{K_{3}}$

$N_{f}=K_{1}\left(\frac{1}{\varepsilon_{t, i n i}}\right)^{K_{2}}\left(\left|E^{*}\right|\right)^{K_{3}}$

$N_{f}=K_{1}\left(\frac{1}{\varepsilon_{t}}\right)^{K_{2}}(|E *|)^{K_{3}}$

$N_{f}=K_{1}\left(\sigma_{t}\right)^{K_{2}}(|E *|)^{K_{3}}$

$N_{f}=K_{1}\left(\frac{1}{\varepsilon_{t, i n i}}\right)^{K_{2}}\left(\left|E^{*}\right|\right)^{K_{3}}$

Figure 72 - PG 64-22 With 25\% RAP Fatigue Report Page 3 